\title{
THE IMPACT OF ANTHROPOGENIC LAND-USE CHANGE ON SOIL ORGANIC CARBON, OPORAE VALLEY, LAKE TUTIRA, NEW ZEALAND
}

by

Roderick Charles James Boys

A Research Paper Submitted in Partial Fulfilment of the Requirements for the Master of Science Degree in

Physical Geography

Victoria University of Wellington

November 2008 


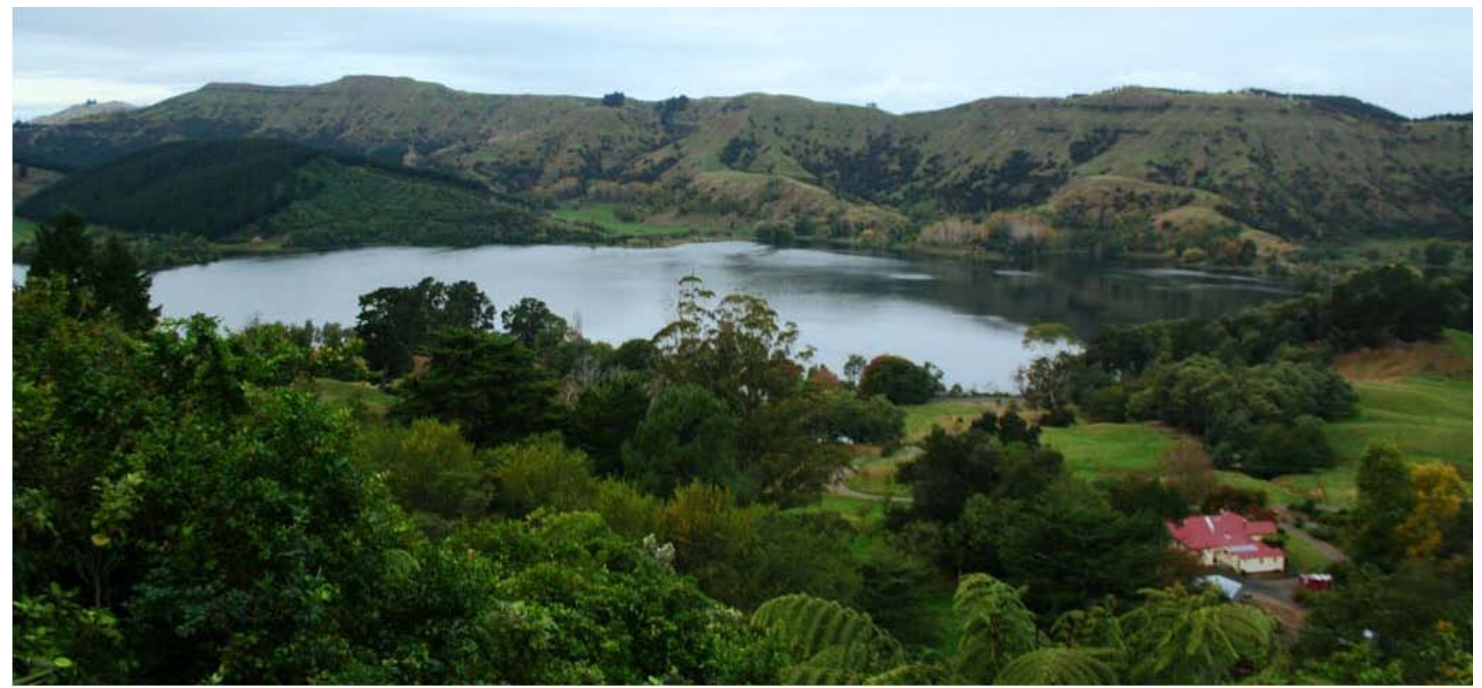

Lake Tutira looking east from The Hangar above the Guthrie Smith Homestead in the foreground. The Oporae Valley is left of centre on the eastern (far) side of the lake. 


\section{Acknowledgements}

I am immensely grateful to my thesis supervisor Dr. Nicholas Preston of Victoria University of Wellington (VUW) for his patience, encouragement and interest in this study. It would not have been possible without his guidance and support throughout.

The scope of this thesis was greatly enhanced by the gracious assistance of Dr. Troy Baisden and Dr. Karyne Rogers of Geological and Nuclear Science (GNS) who carried out the stable isotope analysis at the GNS stable isotope laboratory and provided valuable advice on the interpretation of the results. The stable isotope analyses were funded through GNS FRST funding - The Global Change Through Time Programme.

This work was supported by Edward and Isabel Kidson Scholarship administered by the New Zealand Vice Chancellors Committee. Further support was provided by Victoria University of Wellington through a Post Graduate Award. This funding was used to fund radio carbon ages and sedimentation analysis at GNS and VUW.

I would also like to express my thanks to Mike Page for permission to draw on the GNS photographic archive.

Thanks also to Dr. Bill McLea of Victoria University of Wellington for offering his expertise and advice in carrying out the pollen analyses and subsequent result interpretation.

I would also like to extend thanks to all the students of the GEOG 323 field trip who assisted with the coring.

Heartfelt thanks to my office buddy Helen Tribe for all of the laughs, distractions and shared geomorphological ponderings.

Finally, I would like to thank my family, Rodger and Thelma Boys, and Charlotte Sterck for their unwavering support throughout all of life's challenges. 
Table of Contents

Abstract $x$ xiii

CHAPTER 1: INTRODUCTION

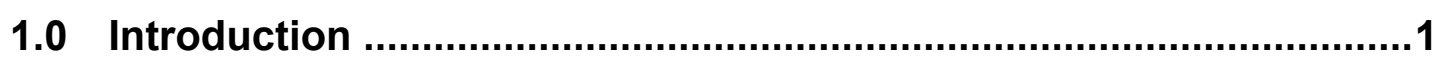

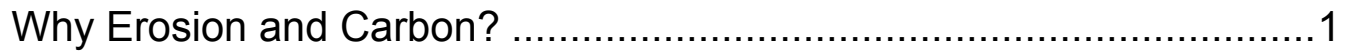

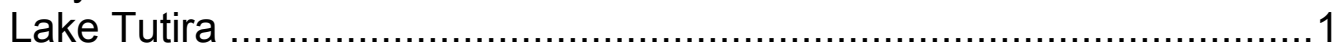

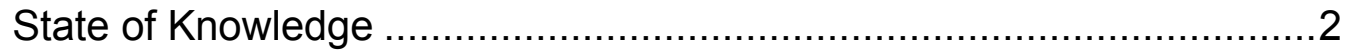

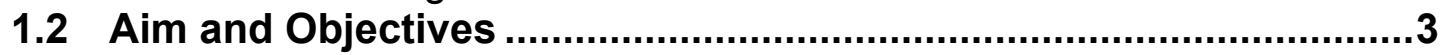

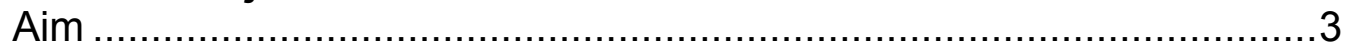

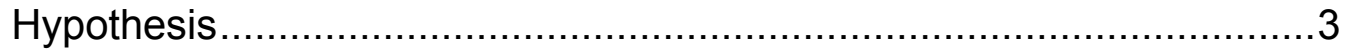

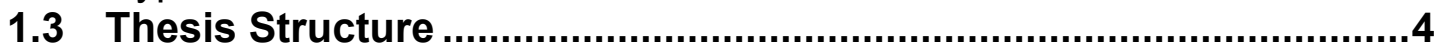

CHAPTER 2: BACKGROUND THEORY - CARBON AND

GEOMORPHOLOGY .................................................................

2.0 Introduction ...........................................................................

2.1 Climate Change and the Carbon Cycle...........................................

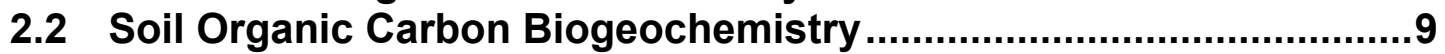

Stabilising Soil Organic Matter ……............................................10

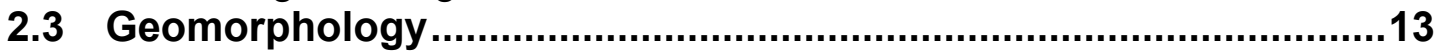

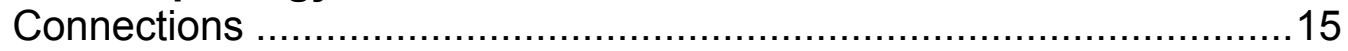

CHAPTER 3: PRACTICAL BACKGROUND - TUTIRA …….................17

3.0 Lake Tutira .............................................................................

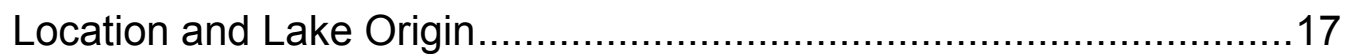

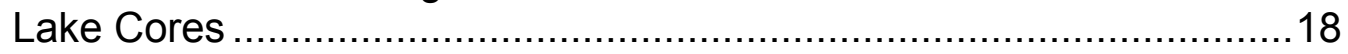

Lake Level Change................................................................. 19

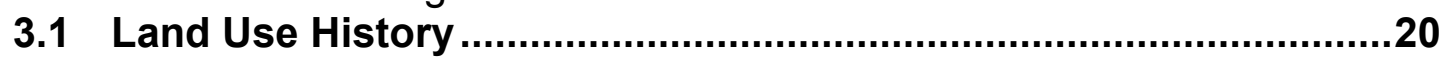

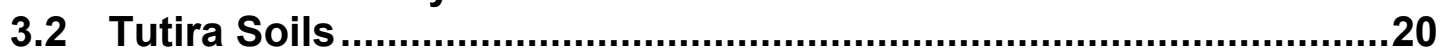

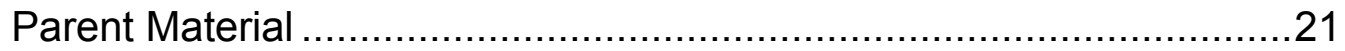

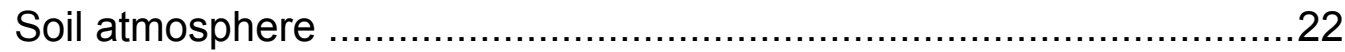

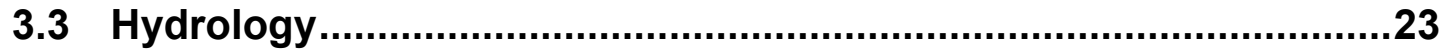

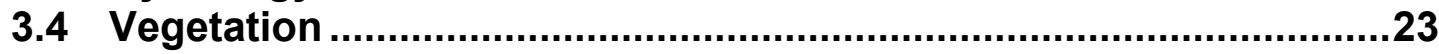

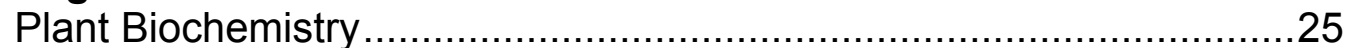

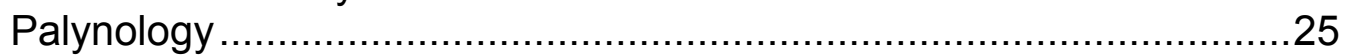

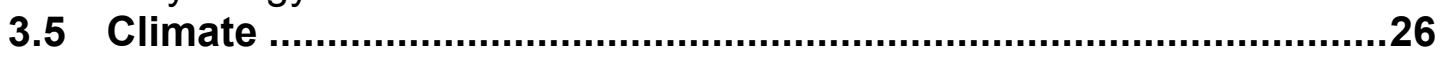

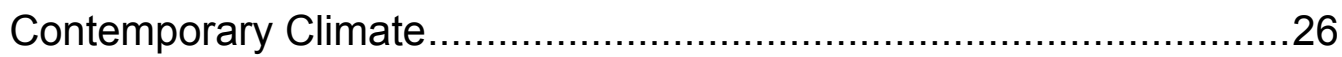

Climate Change and Cyclonic Storms ..........................................27

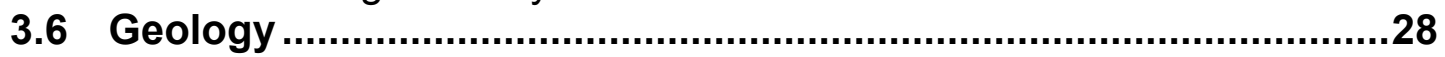

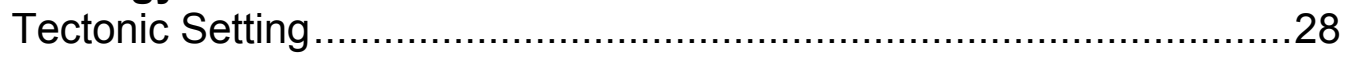

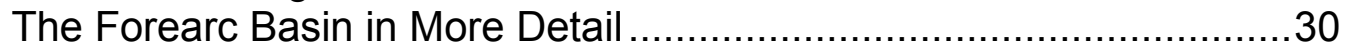

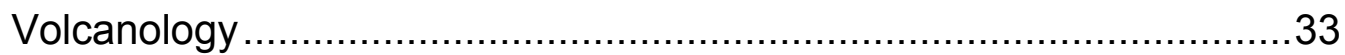

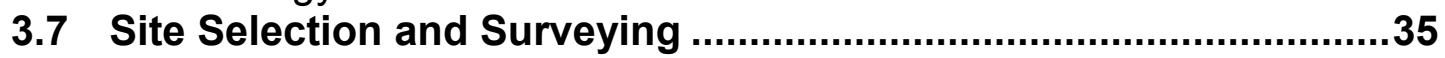

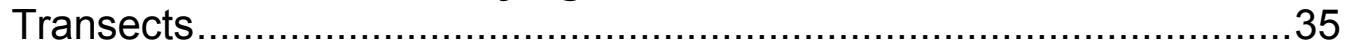

CHAPTER 4: METHODS

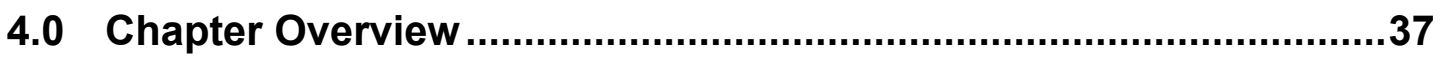

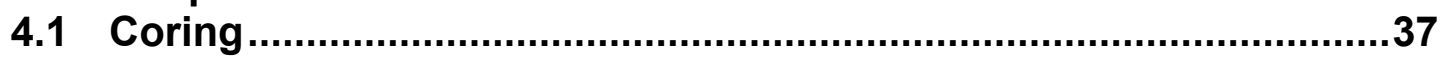

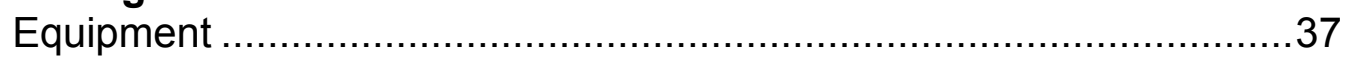




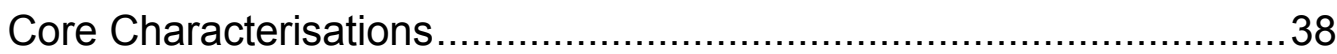

Core Sampling ....................................................................... 38

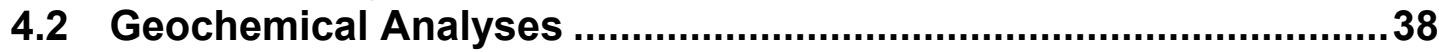

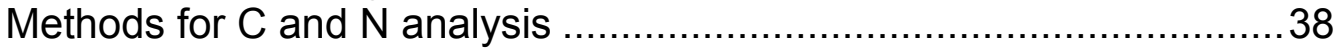

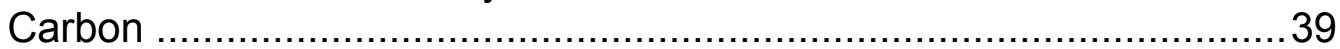

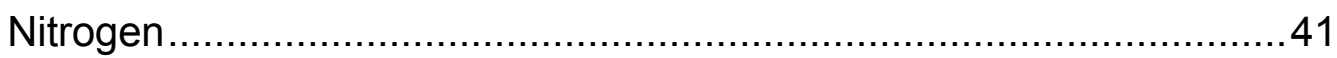

Carbon and Nitrogen Stable Isotopes ...................................... 41

Procedure .......................................................................... 42

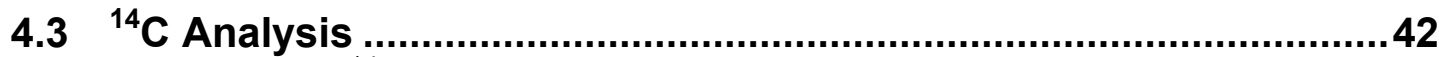

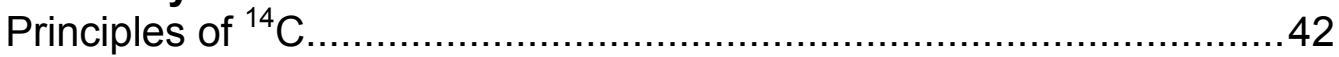

Procedure ............................................................................. 42

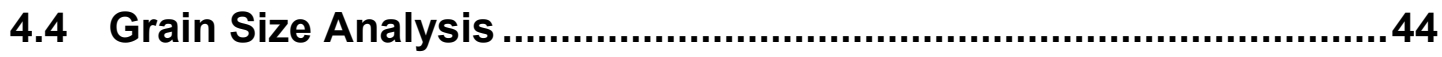

Methods ............................................................................. 45

Sieving - Advantages and Disadvantages ................................. 45

Wet Sieving Procedure................................................................... 46

Mechanical Sieving Procedure .....................................................4 46

Pipette and Settling Tube Methods ............................................46

Laser Diffractometry ................................................................ 47

4.5 Result Calculations ..................................................................52

Volume to Mass Conversion.......................................................52

Laser Diffractometry to Wet Sieve Fraction Conversion .....................53

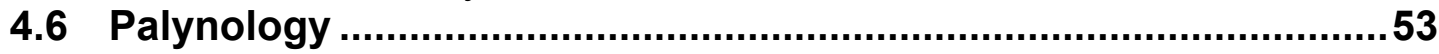

CHAPTER 5: RESULTS $\quad 55$

5.0 Results Chapter Overview ...........................................................55

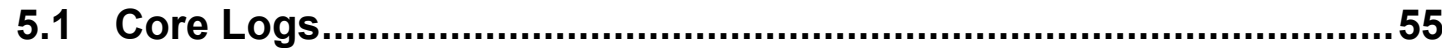

General Observations from Transect 1 ....................................... 56

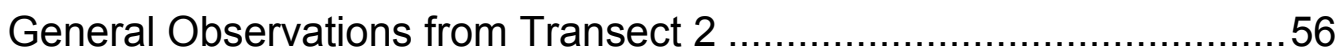

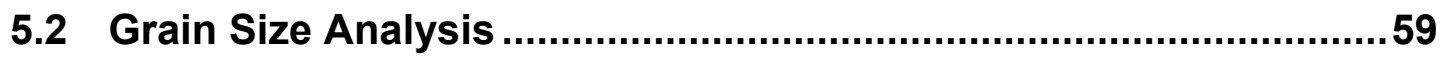

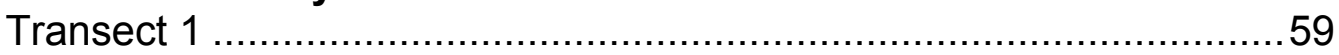

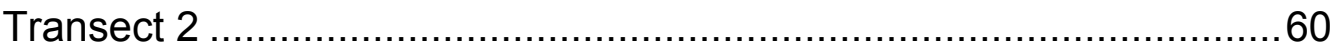

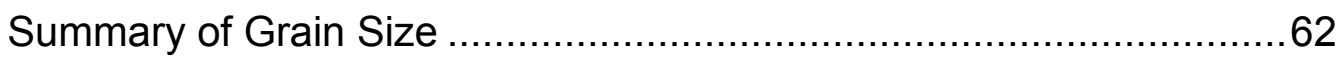

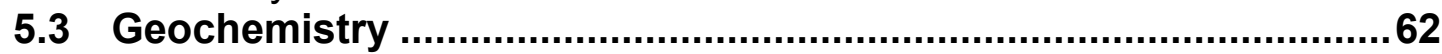

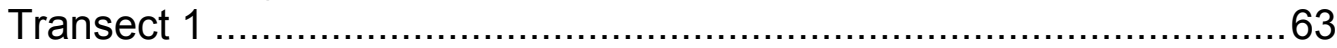

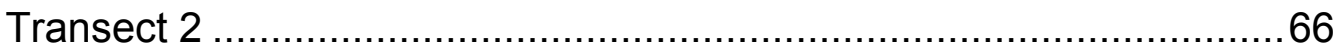

Bivariate Plots ...................................................................... 69

Mixing Models ........................................................................... 71

Carbon Loss through Land-use Change ...................................... 72

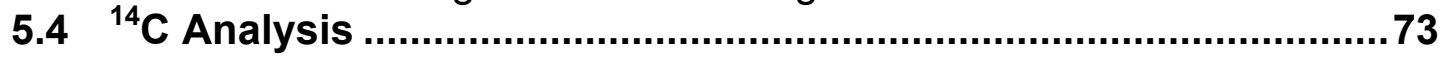

5.5 Palynology ............................................................................ 74

5.6 Organic Matter Species Identification ...........................................75

CHAPTER 6: DISCUSSION $\quad 79$

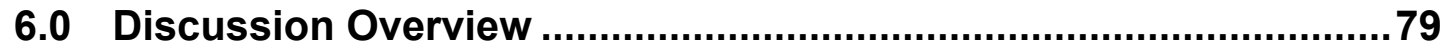

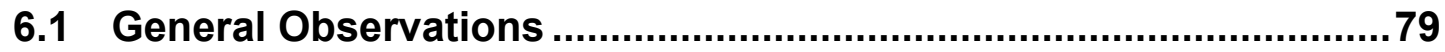

Water Table Fluctuation ........................................................ 79

Pumice Inclusions .................................................................. 80

6.2 Contemporary Pasture and Forest Soils .....................................80

Geochemical Analyses ......................................................... 81

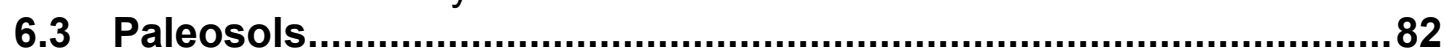

6.4 Geomorphology of Paleosols.................................................. 84 


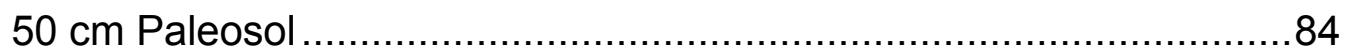

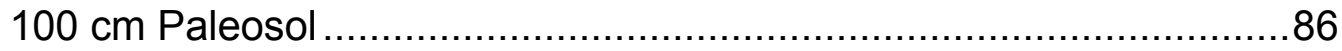

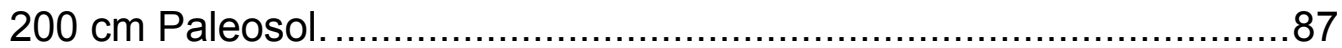

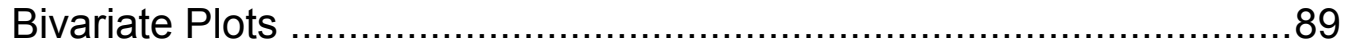

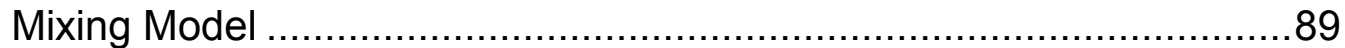

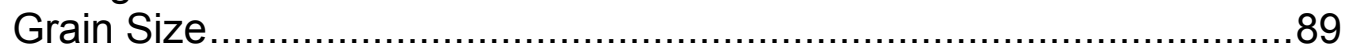

The Colluvial Footslope ...........................................................90

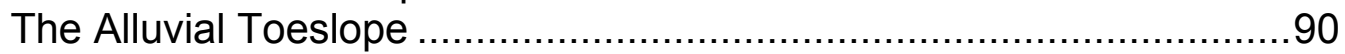

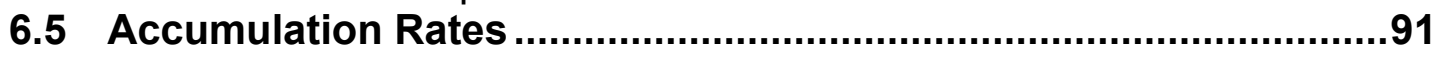

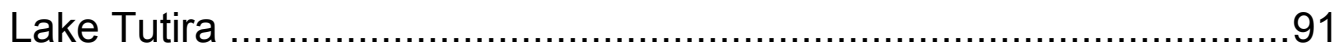

Oporae Valley ................................................................. 91

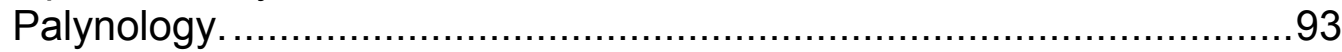

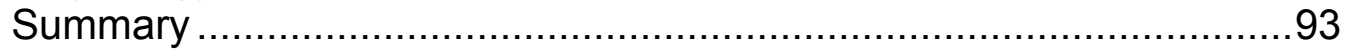

CHAPTER 7: CONCLUSION

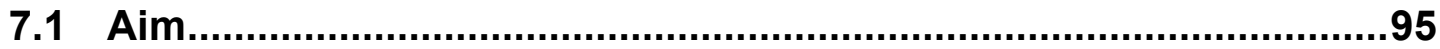

7.2 Land Use Change and Soil Organic Carbon .................................95

7.3 Paleosols and Soil Organic Carbon ................................................95

7.4 Geomorphology of Paleosols.......................................................96

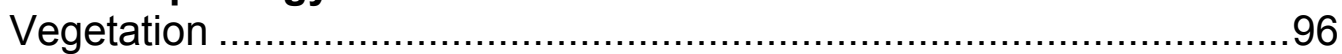

Geomorphic Activity ........................................................ 97

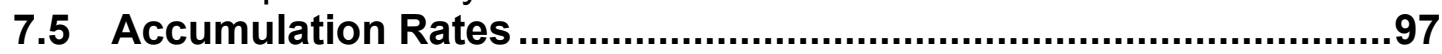

7.6 Hypothesis Evaluation ................................................................98

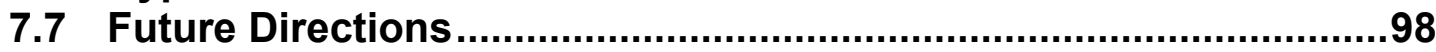

Carbon Accumulation Rates ................................................... 98

Linking C Pools .................................................................... 98

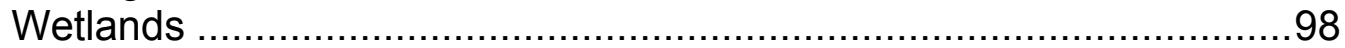

List of References ................................................................................101

APPENDIX I Isotope Geochemistry Definitions, Terminology

APPENDIX II $\quad \begin{aligned} & \text { and Notation ...........................................................107 } \\ & \text { Isotope Geochemistry Sample Preparation .............111 }\end{aligned}$

APPENDIX III Transect 1 and 2 Core Log Descriptions....................117

APPENDIX IV Mechanical Sieving Results ....................................121

APPENDIX V EA-IRMS Result Tables ............................................123 


\section{Figures}

Figure 1.1 Changes in SOC through pedospheric processes ..................

Figure 2.1 The global carbon cycle .................................................. 8

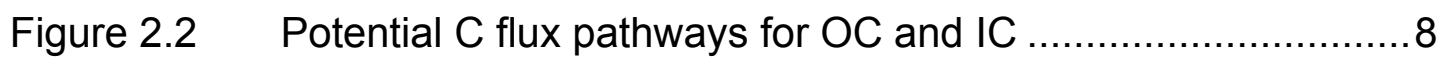

Figure 2.3 Composition of $\mathrm{C}$ compounds in plants ..............................11

Figure 2.4 Soil aggregate size impact on SOC turnover time .................12

Figure 2.5 The nine unit land surface model..................................... 14

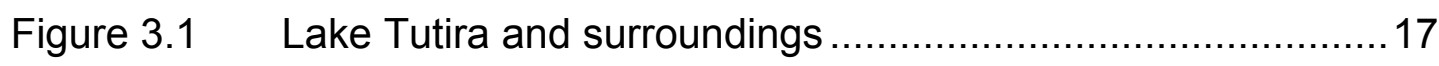

Figure $3.2 \quad$ Lake Tutira sediments ..................................................18

Figure 3.3 The Oporae Valley after Cyclone Bola ................................19

Figure 3.4 Buried SOM in the Oporae Valley.....................................21

Figure 3.5 Lake Tutira catchment with the Oporae Valley

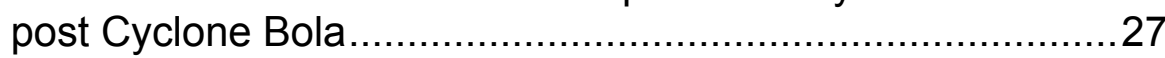

Figure 3.6 The Taupo-Hikurangi subduction system ...........................29

Figure 3.7 Hawke's Bay Tectonic Model........................................29

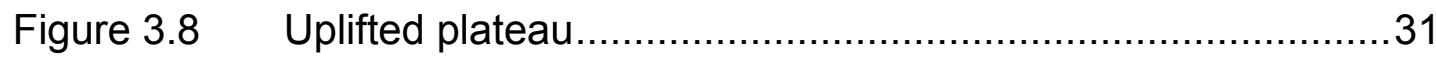

Figure 3.9 Cuesta dominated landscape showing cyclothems ...............32

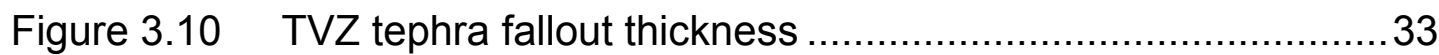

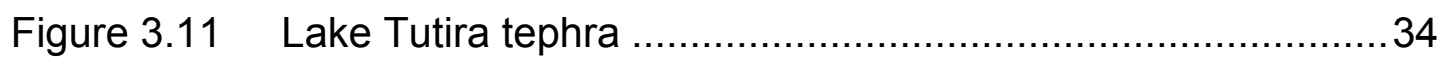

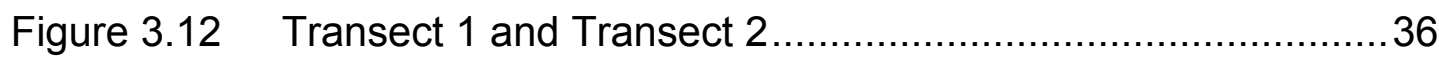

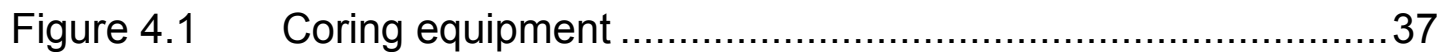

Figure 4.2 Preserved wood fragment for ${ }^{14} \mathrm{C}$ analysis ...........................44

Figure 4.3 Laser diffractometry schematic........................................47

Figure 4.4 A SEM photograph of "plate like" clay particles ....................50

Figure 4.5 The Malvern Mastersizer and Hydro MU dispersion unit .......49

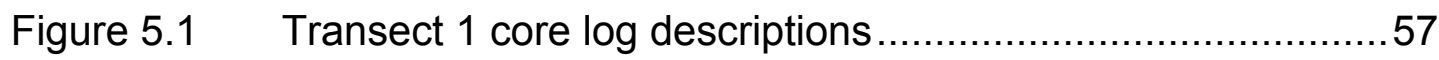

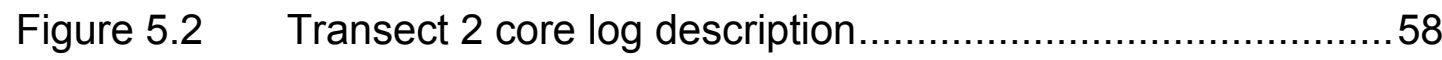

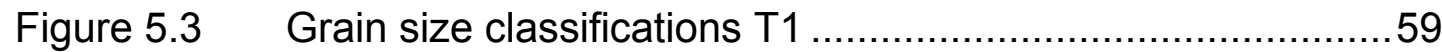

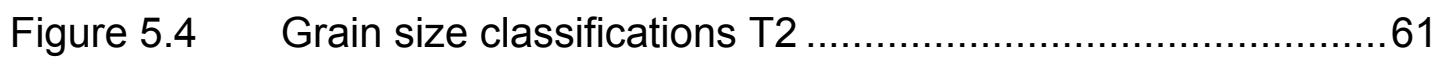

Figure 5.5 C and N EA-IRMS summary graphs for Transect $1 \ldots \ldots \ldots \ldots \ldots . .64$

Figure 5.6 C and N EA-IRMS summary graphs for Transect 2 ...............65

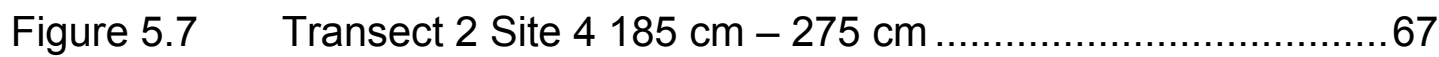

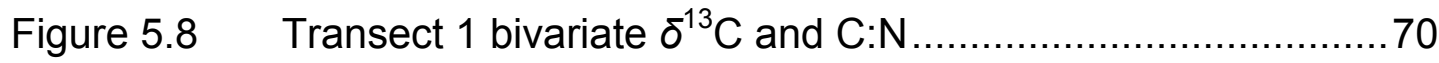

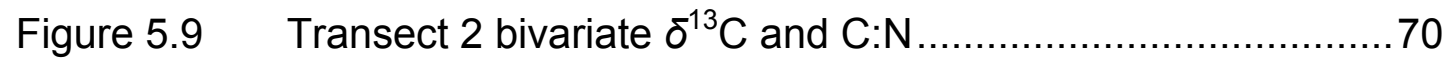

Figure 5.10 Transect 1 bivariate $\delta^{13} \mathrm{C}$ and $\delta^{15} \mathrm{~N}$ and mixing triangle ..........71

Figure 5.11 Transect 2 bivariate $\delta^{13} \mathrm{C}$ and $\delta^{15} \mathrm{~N}$ and mixing triangle .........72

Figure $5.12 \%$ TOC from forest soils and pasture soils to $35 \mathrm{~cm}$ depth $\ldots . . . .73$

Figure $5.13 \quad{ }^{14} \mathrm{C}$ ages from the Oporae Valley........................................

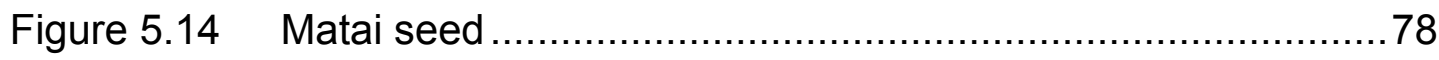




\section{Tables}

Table 4.1 Comparison of total $\mathrm{C}$ determination methods in soils ...............39

Table 4.2 Comparison of OC determination methods in soils ....................40

Table 4.3 Summary of Literature on $\mathrm{C}$ and $\mathrm{N}$ environmental variation ......43

Table 4.4 Lake Tutira soil mineral composition .......................................49

Table 5.1 New Zealand boundary classifications ......................................55

Table 5.2 Depths, textures, \%TOC and \%TN of Transect $1 \ldots \ldots \ldots \ldots \ldots \ldots \ldots . . . .60$

Table 5.3 Depths, textures, \%TOC and \%TN of Transect 2 .....................61

Table 5.4 Distribution and depth range of known ${ }^{14} \mathrm{C}$ ages from the Oporae Valley .................................................................

Table 5.5 Pollen Grain Count for the Oporae Valley Terrestrial Cores ......77

Table 6.1 Actual SOC for Pasture/Proxy Forest Soils and $200 \mathrm{~cm}$ Paleosol

Table 6.2 Relative SOC content of Surface soils, paleosols and background sediments

\section{Appendices}

Table 1 Characteristics of some common isotopes ............................107

Table 2 Carbon and Nitrogen isotopologues......................................107

Table 3 Sand fraction distributions for Transect 1 .............................121

Table 4 Sand fraction distributions for Transect 2 ...............................122

Table 5 Transect 1 EA-IRMS Result Table ......................................123

Table 6 Transect 2 EA-IRMS Result Table .......................................124

C Carbon

\section{List of Abbreviations}

IPCC Intergovernmental Panel on Climate Change

$\mathrm{N} \quad$ Nitrogen

OC Organic Carbon

IC Inorganic Carbon

OM Organic Matter

$\mathrm{P}$ Phosphorous

SOC Soil Organic Carbon

SOM Soil Organic Matter

TN Total Nitrogen

TOC Total Organic Carbon

DW Drying and Wetting (cycles) 


\begin{abstract}
During the anthropocene land use change has exacerbated erosion of the Soil Organic Carbon (SOC) rich topsoil in the Oporae Valley. As well as reducing the SOC content of the contemporary topsoil, the large scale redistribution of sediment has created a quantifiable long-term SOC sink in paleosols. Using contemporary native forest soils as a proxy, pasture covered topsoils contain $\sim 40 \%$ less SOC (a loss of 5,338 $\mathrm{T} / \mathrm{km}^{2}$ SOC). The pre-human paleosol at $\sim 200$ $\mathrm{cm}$, an average $32 \mathrm{~cm}$ thickness, contains $9180 \mathrm{~T} / \mathrm{km}^{2}$. Significantly more SOC buried at depth than what currently exists in the contemporary topsoil indicates the relative importance of paleosols as $C$ stores and the role of land use change on SOC. The preservation characteristics of a paleosol in the Oporae Valley are determined by slope angle and the relative position they hold in relation to the inter-fingering of the alluvial toeslope with the colluvial footslope. Groupings of ${ }^{14} \mathrm{C}$ ages in and above the pre-human paleosol allow for calculation of terrestrial sedimentation rates. At $\sim 0.9 \mathrm{~mm} \mathrm{yr}^{-1}$ the terrestrial pre-human sedimentation rate averaged over the valley floor is approximately half (0.53) of the corresponding pre-human lake rate of $\sim 1.7 \mathrm{~mm}^{-1} r^{-1}$. As a proportion of the lake's anthropogenic sedimentation rate at $\sim 4.8 \mathrm{~mm} y r^{-1}$, the terrestrial anthropogenic sedimentation rate has slightly increased to $\sim 2.8 \mathrm{~mm} \mathrm{yr}^{-1}$ (0.58 of the lake sedimentation rate). These initial findings demonstrate the potential for further research in this area, so that ongoing land-use change can be accurately incorporated into terrestrial carbon accounting.
\end{abstract}





\section{Chapter 1: Introduction}

\subsection{Introduction}

Since the pre-industrial era approximately $25 \%$ of global anthropogenic $\mathrm{CO}_{2}$ emissions ${ }^{1}$ have come from land-use change through deforestation - primarily burning and changing agricultural practices (Denman et al. 2007). Land-use change creates land surfaces that are vulnerable to erosion generated by wind, water, gravity and further land use change. These erosional processes cause many problems globally, but landslides and soil nutrient loss are common problems faced by most areas that have undergone deforestation. Surface erosion preferentially removes the uppermost topsoil first. This mobilises Soil Organic Matter (SOM). In terms of climate change this is highly significant, as carbon represents around half of the SOM in typical soils (by weight), but the fate of this Soil Organic Carbon (SOC) is still only partially understood in terms of its contributions to the global carbon cycle (Roose et al. 2006). Terrestrial carbon pools have the capacity to act as both a sink and source for atmospheric carbon. Based on what is currently known from studies across a range of environments, the SOC pool after forest clearance for pasture can increase or decrease dependant upon a range of factors, some known, some unknown (Cerri et al. 1998). What has happened and what is currently happening to New Zealand's SOC pool? How should we plan for the future management of this very significant component of the global carbon cycle? These are the sorts of questions that remain open to research and interpretation both in New Zealand and globally.

\section{Why Erosion and Carbon?}

The role of erosion as a physical process that can influence the flux of terrestrial carbon sources and sinks remains unclear. This is because the quantification SOC mobilised by erosion is often monitored in the fluvial system, where sampling is at its most cost effective but only representative of a catchment's riverine transport and storage. Quantifying the impacts of land-use change on terrestrial SOC storage is an important additional component to the complete source (terrestrial) to sink (ocean) system. It is the intention of this research to look at the impacts of land-use change in the contemporary topsoil SOC pool and in paleosols formed as a result of anthropogenically enhanced geomorphic processes. This research is to be carried out in the Oporae Valley, a subcatchment valley of the Lake Tutira catchment, with a view to expanding the current knowledge of this issue.

\section{Lake Tutira}

The Lake Tutira catchment lies within the Hawke's Bay - Wairarapa dry east coast hill country of New Zealand's North Island. This area covers over 10,000

\footnotetext{
${ }^{1}$ This estimate is based on anthropogenic $\mathrm{CO}_{2}$ emissions only; the other $75 \%$ is from fossil fuel burning and cement production. Natural sinks have offset the impact of anthropogenic $\mathrm{CO}_{2}$ emissions by approximately half over the last 15 years slowing the rate of atmospheric $\mathrm{CO}_{2}$ concentration increase despite the dramatic increase in emissions from 3.2 to $4.1 \mathrm{PgC} \mathrm{yr}^{-1}$ over the last 25 years (as of 2005).
} 
$\mathrm{km}^{2}$ and is representative of about $19 \%$ of New Zealand soft rock hill country (Page et al. 2004). This study focuses on two representative transects of four 1$4 \mathrm{~m}$ cores taken from either side of the Oporae Valley Stream at Lake Tutira. The site is typical of an alluvial/colluvial deposit in-filled valley from an eroded catchment in the soft-rock hill country of the Hawke's Bay and wider East Coast region.

\section{State of Knowledge}

Studies from across the world have shown that for a deforested catchment converted to pasture, the SOC pool can either decrease or increase depending upon a variety of factors (Neill et al. 1998). For example, processes that increase (sequester) SOC are biomass production, humification, aggregation (union of mineral and organic matter to form stable aggregates), and sediment deposition. Processes that decrease SOC are erosion, leaching and SOM decomposition. The net increase or decrease of SOC is influenced by land use change and other anthropogenic factors which determine the pool of SOC in the pedosphere (Lal et al. 1998). Figure 1.1 shows the pedospheric processes that increase and decrease SOC.

Changes in SOC through Pedospheric Processes

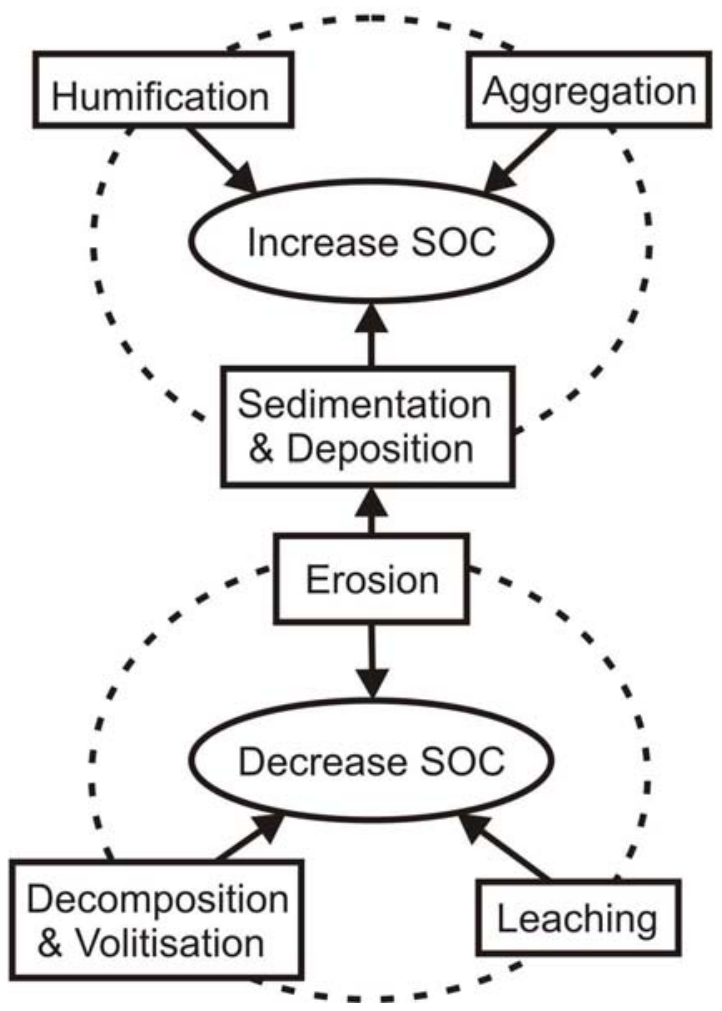

Figure 1.1: boxes represent pedospheric processes that can increase or decrease the SOC pool, ellipses are changes in SOC and dashed connecters represent interconnection of the pedospheric processes. Note how if erosion occurs it both decreases and increases (via sedimentation and deposition) the SOC pool. Modified from: (Lal et al. 1998).

The biogeochemical cycling of carbon is inherently complicated as there are many overlapping spheres of influence in the exchange processes. Although 
the common factor of erosion (Figure 1.1) is of primary interest here, the impacts on SOC of all of the processes from Figure 1.1 and their relations to each other need to be clearly understood if we are to accurately predict the consequences of anthropogenic modification on the global terrestrial $\mathrm{C}$ cycle (Lal et al. 1998). To this end, $\mathrm{C}$ and $\mathrm{N}$ are often used as the key indicators for the analysis of any given SOM pool, the reason for this is grounded in the basic necessity for $\mathrm{C}, \mathrm{N}$ and Phosphorous $(\mathrm{P})$ as the elements that are required in largest quantities for the growth and reproduction of living organisms (Ågren et al. 2003). The aims of this research stem from the gaps in knowledge identified from the various studies on carbon and erosion that have already taken place in the Lake Tutira catchment. Page et al. (2004) calculated that $1.17 \pm 0.23 \mathrm{Mg} \mathrm{C}$ $\mathrm{ha}^{-1}$ per year was eroded over a 114 year period $(1887-2001)$. Of that eroded material $0.94 \pm 0.23 \mathrm{MgC}^{-1}$ per year entered the lake, of which, $0.50 \pm 0.15$ $\mathrm{Mg} \mathrm{C} \mathrm{ha-1} \mathrm{per} \mathrm{year} \mathrm{is} \mathrm{from} \mathrm{landslide} \mathrm{erosion} \mathrm{and} 0.44 \pm 0.17 \mathrm{Mg} \mathrm{C} \mathrm{ha}^{-1}$ per year is from sheetwash erosion. Page et al. (2004) also calculated that the sediment delivery ratio from 1887 - 2001 was 0.43 (13.8 Tg eroded, to $8.5 \mathrm{Tg}$ delivered, based on an assumed $95 \%$ lake sediment trap efficiency). But what happened to the $5.3 \mathrm{Tg}$ of sediment and its associated SOC retained as deposited material on the landscape? In the lake cores used by Page et al. (2004), over $75 \%$ of the sediment volume from the European period (1887-2001) was deposited by storm generated erosion pulses attributed to landsliding (see Page et al. 1994). The evidence for the relative importance of landsliding as a geomorphic agent for sediment transportation has equal importance for the storage and retention of SOC on the landscape. Owing to the rapid accumulation and relative density of depositional material sourced during a mass movement event, SOM could be quickly buried and effectively removed from a position in the soil profile where it is readily available for decomposition. To establish what has happened in the Oporae Valley, samples were gathered for $\mathrm{C}$ and $\mathrm{N}$ analyses as indicators of SOM. Sediment characterisations and grain size analysis have also been used to provide an interpretation of the geomorphic impact on the SOC pool. Pollen grain analysis and ${ }^{14} \mathrm{C}$ ages augment these analyses by adding temporal constraints to the sediments which

allow for the calculation of terrestrial accumulation rates that can be compared with the sediment accumulation of the lake.

\subsection{Aim and Objectives}

\section{Aim}

Qualitatively and quantitatively describe the impact that land-use change has had on carbon in contemporary soils and paleosols from the late Holocene in the Oporae Valley, Lake Tutira, New Zealand.

\section{Hypothesis}

During the anthropocene land use change has exacerbated erosion of the SOC rich topsoil in the Oporae Valley. As well as reducing the SOC content of the contemporary topsoil, the large scale redistribution of sediment has created a long term SOC sink at depth in buried soils or paleosols. 


\section{Land Use Change and Soil Organic Carbon}

Objective 1: Quantify the SOC content of topsoil that has undergone anthropogenic land-use change. Compare these values with topsoil values of local proxy native forest soils to establish whether the net balance of SOC has increased or decreased post land use change.

\section{Paleosols and Soil Organic Carbon}

Objective 2: To identify and quantify the SOC content of paleosols, thereby determining the significance of paleosols as a $C$ sink.

\section{Geomorphology of Paleosols}

Objective 3: To correlate the physical sediment characteristics and the geochemical signatures across the core sites, using the relationships and stratigraphy to ascertain the impact of slope and fluvial process dominance on SOC preservation.

\section{Accumulation Rates}

Objective 4: Define the residence time and sedimentation rate of carbon in the soil profile, based on the stratigraphy established using elemental analysis and sediment characterisation, corroborated with pollen analysis and ${ }^{14} \mathrm{C}$ dating.

\subsection{Thesis Structure}

This thesis is structured with seven principle chapters. Chapter 1 introduces the reader to the topic, study area and state of knowledge. This introduces the knowledge gap identified from within the recent literature on the understanding of terrestrial carbon flux. Once identified the knowledge gap sets up the aim, hypothesis and objectives.

The background is split into two chapters. Chapter 2 contains the relevant background theory for carbon cycles and geomorphology that is relevant to interpreting and understanding the results. Chapter 3 contains the practical background covering the characteristics of Tutira and all physical variables that impact or interact with the soils in the Oporae Valley. Finally, Chapter 3 describes the transect and site locations that the cores were taken from.

Chapter 4 covers all of the methods utilised in compiling the physical and geochemical data sets necessary for answering the target information objectives stated in Chapter 1. The methods are described either in full or summarised where it is not practical to do so. Where this is the case the complete method description is given in the appendices.

Chapter 5 presents the summary results for the physical and geochemical analyses. As with the methods, for the purposes of practicality, large result data sets have been moved to the appendices.

Chapter 6, the discussion, begins with some general observations that are generic to the interpretation of the results. The various elements of the results 
chapter then feed into discussions on land use change and SOC, paleosols and SOC, the geomorphology of paleosols and the calculated accumulation rates.

Chapter 7 is the conclusion which resolves the main points made in the discussion into summary statements which answer the target information objectives and ultimately confirm the hypothesis.

Appendices: As stated above the appendices contain further detailed information pertaining to both the methods and the results. 


\section{Chapter 2: Background Theory - Carbon and Geomorphology}

\subsection{Introduction}

Understanding and quantifying the earth system processes requires a multidisciplinary approach (Flanagan 2005). Chapter 2 explains the background theory to aspects of carbon cycling and geomorphology that are relevant to this study. Understanding this theory puts the physical background (Chapter 3) into perspective when considering how land use change has impacted on the terrestrial carbon pool in the Oporae Valley.

\subsection{Climate Change and the Carbon Cycle}

The global $\mathrm{C}$ cycle is the natural continuous flow of large volumes of carbon between the atmosphere, hydrosphere, cryosphere, biosphere and lithosphere. These spheres are the reservoirs (or pools) of global carbon which are constantly in exchange with each other. The rate of exchange varies through space and time and this is known as carbon flux between reservoirs. The $C$ flux between reservoirs has been quantified using annual flux between conceptually compartmentalised source and sink pools. Figure 2.1 shows the global carbon cycle during the 1990s with the natural annual fluxes in black (based on those prior to 1750 , the beginning of the industrial revolution) and the anthropogenic fluxes in red. The world's soils contain $1500-2000$ Petagrams of Carbon (PgC) and vegetation contains $600-700 \mathrm{PgC}$. In contrast the world's deep oceans are estimated to contain some 38,100 PgC (Roose et al. 2006; Stevenson et al. 1999).

Anthropogenic changes in carbon flux have introduced measurable changes in the natural rate of flux and global reservoir volumes (IPCC 2007). Due to the rapid pace of land-use change introducing increased complexity to the terrestrial carbon cycle, it is difficult to accurately calculate the annual terrestrial flux i.e. a forest cut down may or may not be allowed to re-grow several years later. Figure 2.1 shows vegetation, soil and detritus together as one pool, with fluxes of respiration, gross annual terrestrial primary production (GPP) and weathering as the natural background fluxes, and (residual) land sink (formerly 'missing sink') and land use change as the anthropogenic fluxes. Despite flux

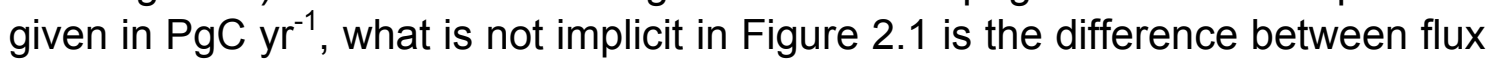
that is operating in the long term and short term $\mathrm{C}$ cycles. The long term is important in terms of the anthropogenic release of hydrocarbons, but this cycle happens over a temporal scale that is not significant in terms of rapid climate change mitigation e.g. the storage of $\mathrm{C}$ on the ocean floor surface sediments only occurs at a rate of $0.2 \mathrm{PgC}_{\mathrm{yr}^{-1}}$. The short term $\mathrm{C}$ cycle has greater potential as either a $C$ sink or source that can be influenced to either enhance or mitigate the impacts of the industrial revolution e.g. it has been estimated that an increase in global temperature of just $0.03^{\circ} \mathrm{C} \mathrm{yr}^{-1}$ will increase $\mathrm{CO}_{2}$ release

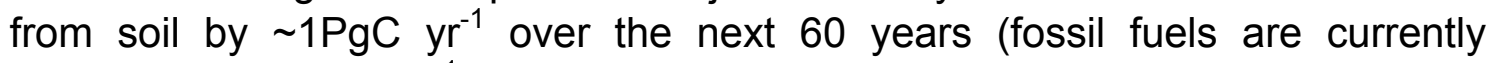
contributing 6.4 PgC yr ${ }^{-1}$ - Figure 2.1) (Sollins et al. 1999). 


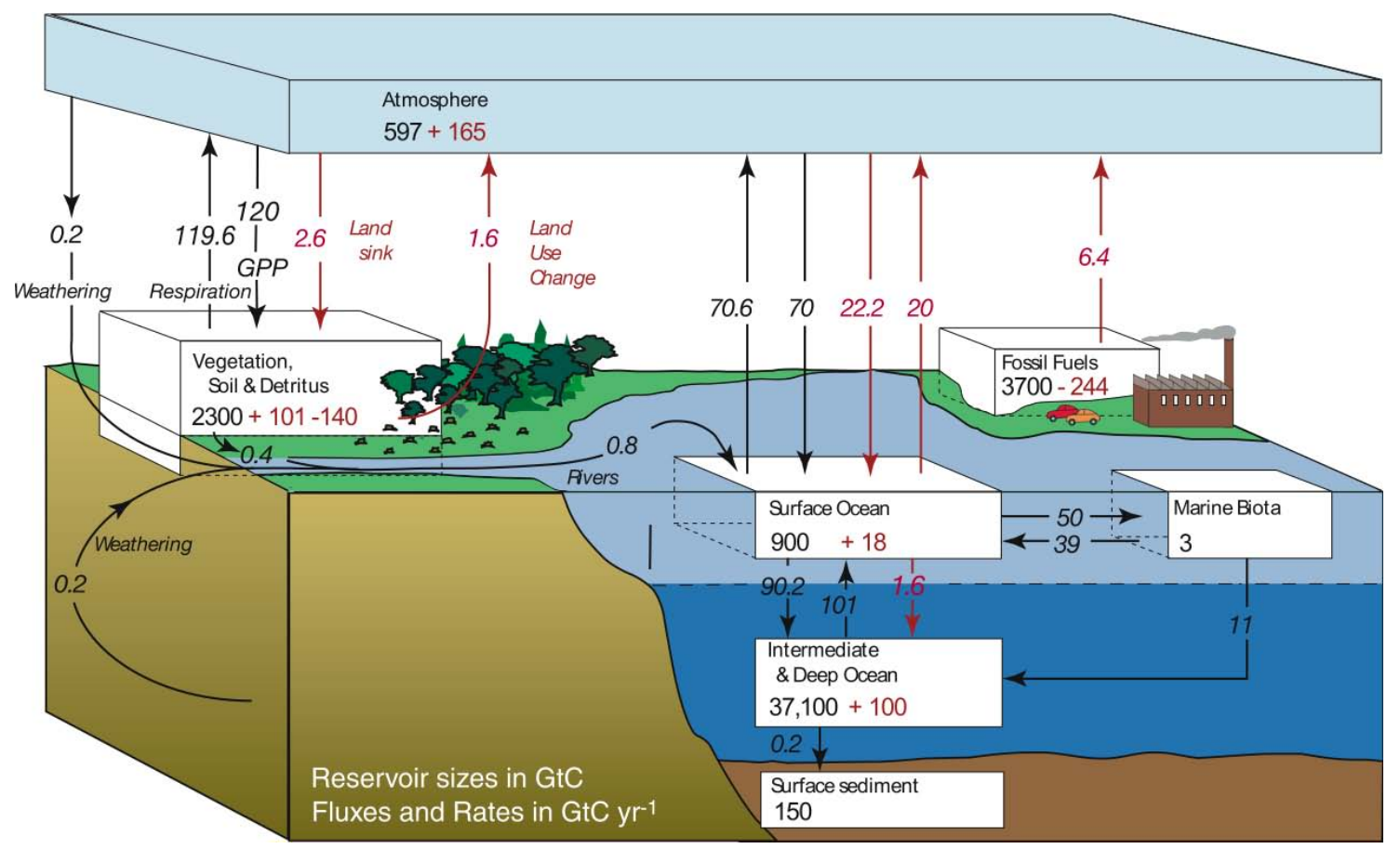

Figure 2.1: The global carbon cycle showing the annual fluxes in $\mathrm{PgC}^{-1}$; pre 1750 in black and anthropogenic fluxes in red. Source: IPCC (2007).

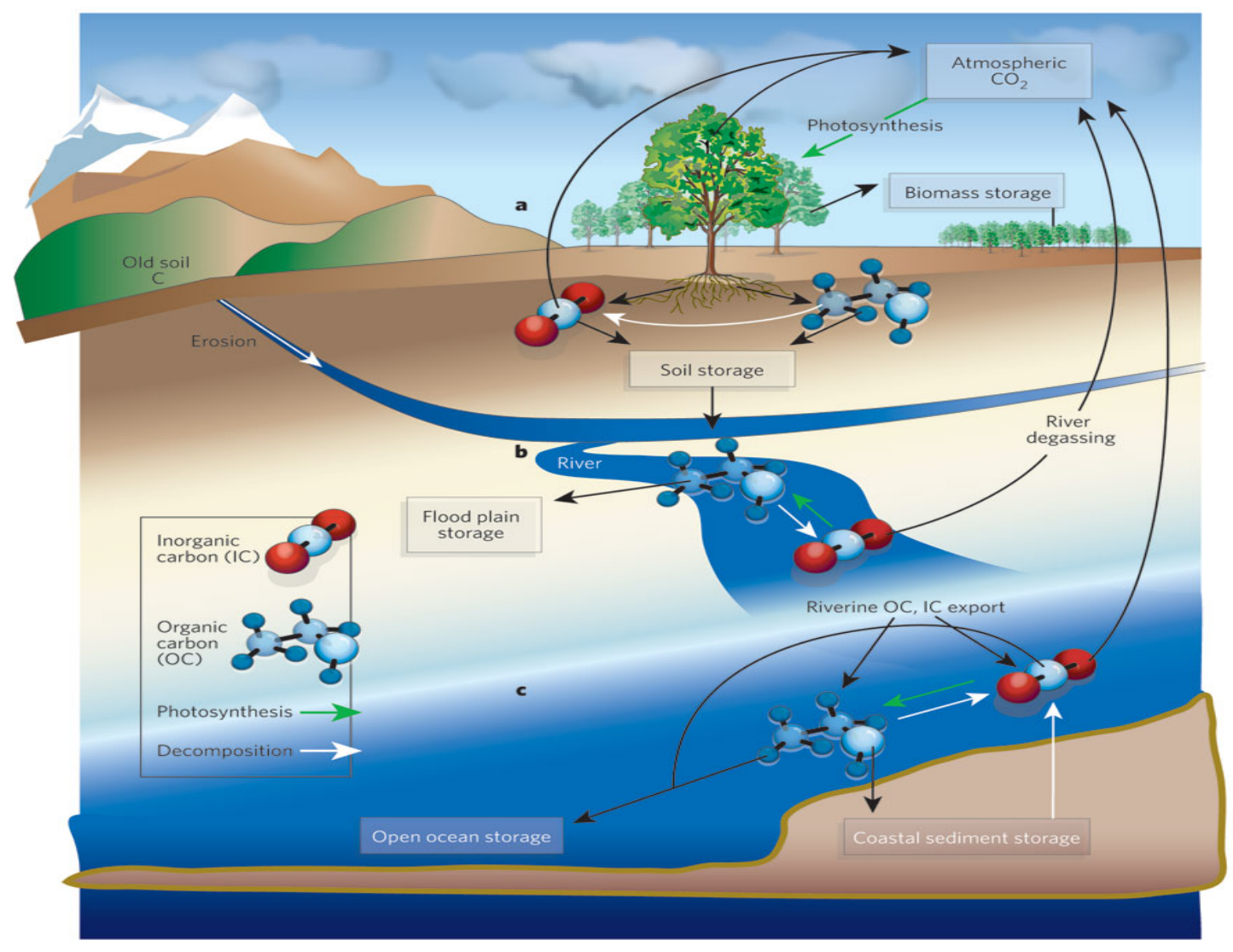

Figure 2.2: Photosynthesis and Respiration (Decomposition) and the potential C flux pathways for OC and IC transitions from the atmosphere (a), biosphere/pedosphere (b) and hydrosphere (c). Source: Raymond (2005).

Figure 2.1 shows the gross figures for global fluxes of $\mathrm{C}$ between reservoirs, but while terrestrial carbon flux is a part of the global $\mathrm{C}$ cycle it is necessary to more 
closely examine the processes specific to the earth surface so that we may gain an understanding of how this significant source/sink impacts on the global cycle. There are two main forms of carbon: Organic Carbon (OC) e.g. the biomass in vegetation, and Inorganic Carbon (IC) e.g. $\mathrm{CO}_{2}$ in the atmosphere or lithified in carbon contained within rocks (Raymond 2005). In the pedosphere the two main forms of carbon are Soil Organic Carbon (SOC) and Soil Inorganic Carbon (SIC). It is estimated that the SIC pool is $\sim 12 \%$ larger than SOC pool, although the degree of uncertainty surrounding the SIC pool is high and little is known about the impacts of land-use change on SIC (Lal et al. 1998). Carbon molecules move between the atmosphere, biosphere, pedosphere and hydrosphere pools. Figure 2.2 shows the photosynthesis and respiration pathways and how they impact on the transition and transformation of OC to IC and vice versa.

Using the transition and transformation pathways of $\mathrm{OC}$ and IC demonstrated in Figure 2.2, shows that when analysing the SOC pool stored or accumulated within the Oporae Valley cores, there are three primary factors that could alter the amount of $\mathrm{OC}$ within the soil:

1) the pool transition and $C$ state transformation from IC to OC through photosynthesis,

2) the transition and transformation of $\mathrm{OC}$ to IC through plant or soil respiration and decomposition,

3) and the removal of IC and OC from the pedospheric pool by the hydrological cycle.

The impact of leaching and dissolution of carbonate during soil formation can remove IC altogether, leaving $\mathrm{OC}$ to form the significant proportion of $\mathrm{C}$ within the soil. This is particularly common in humid regions (Nelson et al. 1996; Robertson et al. 2000).

The transition from IC to $O C$ and back again is a natural process that will operate in relative equilibrium without external interference or major perturbation. However, this cycle is vulnerable to anthropogenic influence; in the case of the Oporae Valley the loss of forest-cover through fires will have significantly changed the input pathway of $\mathrm{OC}$ to the terrestrial system. The redistribution of SOC stored on the landscape post land clearance occurs through erosion and deposition: as the physical environment seeks a new equilibrium within the new system boundaries, so too does the biogeochemical C cycle operating within the physical system.

\subsection{Soil Organic Carbon Biogeochemistry}

Soil organic matter (SOM) in the broadest sense refers to both the organic compounds and associated carbon that has been derived from alive and recently living organisms that are capable of decay (e.g. nutrients from humus, roots, branches, leaves, macro fauna, mesofauna, and micro-organisms) (McLaren et al. 1990). SOC is the primary element present in SOM ranging from $48-58 \%$ of the total weight (Nelson et al. 1996). The study of SOC is therefore intimately linked with SOM and nutrient flux. In this study SOC is 
quantified through empirical determination. Often such determinations are used for the calculation of SOM content through multiplication using a factor (Nelson et al. 1996). However the factor can range from 1.9 to 2.5 (surface and subsoils respectively) and vary widely even within soil horizons. Therefore, while SOM is useful as an index of SOC, it is preferable to quantitatively determine SOC and other nutrients independently (Nelson et al. 1996).

While living organisms constitute organic matter in soils, SOM here refers to only the dead organic material found in the soil structure that is forming or constituted as humus or humic horizons. Dead material can be added to soils from either above, or in the soils as organisms die. Organism death initiates decomposition which in turn impacts on the recycling of nutrients and soil fertility. Andreux et al. (1990) identified three main categories of SOM decomposed through biological or chemical means:

1. Humic macromolecules which precipitate onto the surfaces of minerals.

2. Transient organic compounds which are often water soluble and thus become dissolved e.g. dissolved organic carbon (DOC).

3. Gaseous products which are returned to the atmosphere e.g. $\mathrm{N}_{2}$ or $\mathrm{CO}_{2}$ (often referred to as mineralisation of the organic compound).

Only a small fraction of the OM added to the soil through these means is directly incorporated into stable compounds. As a result the inputs and outputs of SOM are often in equilibrium within natural ecosystems (assuming constant boundary conditions).

The organic compounds derived from a dead organism provide food to increasingly smaller organisms via consumption (respiration) and excretion of wastes. This aerobic process breaks down the organic compounds and releases carbon in the form of carbon dioxide $\left(\mathrm{CO}_{2}\right)$ to the atmosphere, thus the $\mathrm{C}$ within the organic compounds is recycled. In water logged anaerobic conditions, less oxidised versions of $\mathrm{C}$ compounds are typically produced e.g. methane $\left(\mathrm{CH}_{4}\right)$ or ethylene $\left(\mathrm{C}_{2} \mathrm{H}_{4}\right)$ (McLaren et al. 1990).

\section{Stabilising Soil Organic Matter}

Complex $\mathrm{C}$ compounds that are resistant to the oxidative process form the basis of humic material e.g. cellulose and lignins. Therefore, the composition of C compounds within the original OM will impact on the biogeochemical breakdown of that compound, and consequently its retention in the soil complex (McLaren et al. 1990). Figure 2.3 shows the organic compound composition of three different plant materials: young lucerne tops (a), mature wheat straw (b), and old pine needles (c).

In temperate grasslands (the predominant contemporary vegetation at Tutira), SOM is primarily derived from roots, leaves, stems of grasses and stock excreta, and depending on the residence time can form an integral part of the soil structure both in buried horizons and topsoils as a humic layer. 
Depending on the fraction of interest (pools) the amount of OC stored is derived from the net balance between the rate of SOC input and the rate of SOC mineralisation (Post et al. 2000). SOM residence time (and therefore OC residence time) can range from short (hours-days), intermediate (10-15 years), to long (thousands of years) (Post et al. 2000). The residence time (reflected in

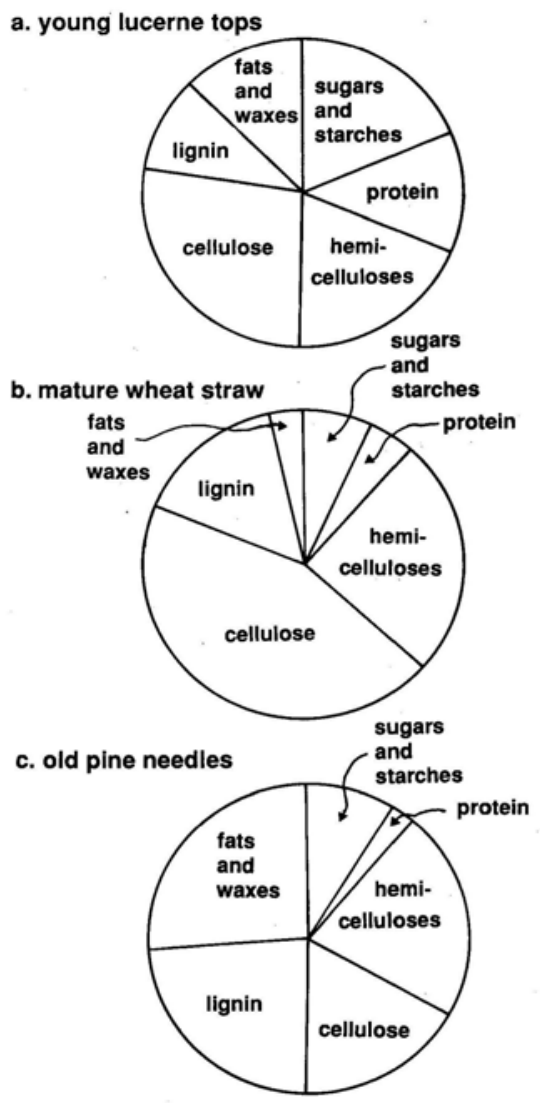

Figure 2.3: Fats, waxes, lignins and cellulose form more complex compounds. Therefore, where they are present in small proportions the organism breaks down faster. This is due to the higher proportion of readily oxidised compounds (simple carbohydrates and proteins) e.g. in young lucerne tops only $\sim 50 \%$ of the total is comprised of fats, waxes, lignins and cellulose; whereas in old pine needles the same compounds account for $\sim \mathbf{8 0} \%$ of the total, slowing the rate of decomposition. Source: McLaren et al. (1990).

the rate of transfer of $\mathrm{C}$, otherwise known as the turnover time) varies depending on a number of variables and their complex interactions of biological, physical and chemical processes. All of these processes interact with each other to determine which temporal category (residence time) any given pool of $\mathrm{OC}$ will fall. The following list contains some of the most important factors causing variation in the residence time of SOM (SOC):

1. SOM source (roots leaf, stem, macro fauna, meso fauna, or microorganisms)

2. Moisture

3. Temperature

4. Soil acidity

5. State of decomposition (see "humus stages" below)

6. Exudation, mucilage production and sloughing from living roots 
7. Microbial activity (difficult to distinguish from plant fraction of $\mathrm{C}$ )

8. Disturbance regime (disturbance tends to reduce the residence time of SOC e.g. tillage or landslides)

9. Encapsulation within soil aggregates

(McLaren et al. 1990; Jones et al. 2004)

The above list of possible variables generates a number of different classifications for SOM depending on the research perspective e.g. the study of discrete pools of SOM has been used widely in the literature, but a precise definition of what a pool constitutes also varies extensively (Jones et al. 2004). The most relevant pool characterisation for this process based study is the impact of OM incorporation into soil aggregates of different grain sizes (No.9 above). Figure 2.4 shows how grain size impacts on the incorporation of $\mathrm{OM}$ into the soil matrix.

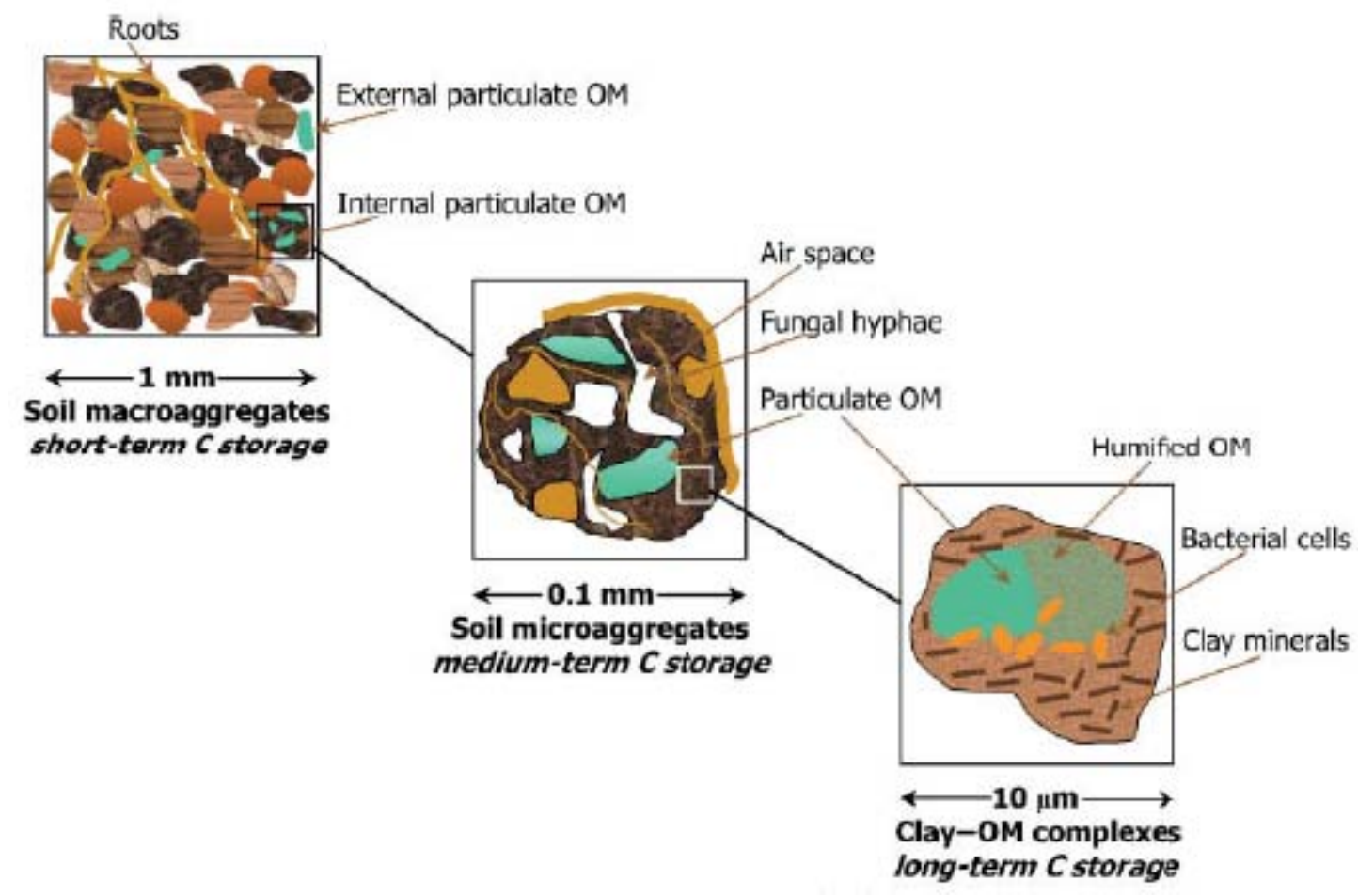

Figure 2.4 shows how soil aggregate size impacts on SOC turnover time. Where macro aggregates dominate the soil structure, $O M$ is readily available for decomposition through biogeochemical processes and thus, in short term storage. Contrastingly in clay aggregates $\mathrm{OM}$ is physically protected from decomposition and as a result is entered into long term storage. Source: Jones and Donnelly (2004).

Of the other variables listed above disturbance regime (8) and climate (2 and 3 ) are also likely to be significant factors for the Lake Tutira SOM pool. As previously stated over $80 \%$ of the catchment regolith has at some point been disturbed by landsliding (Hawke and McConchie 2003), and the impact of changing soil temperatures associated with either land-use change and/or climate change will have affected soil biogeochemical processes. This very aspect of SOM dynamics has become a focus area for the ongoing investigations of the IPCC (2007). In particular, the impact on nutrient flux (C 
and N) associated with global land-surface changes requires greater understanding of processes at local scales for incorporation into global models (Smith et al. 2007).

The relative importance of soil aggregates on the retention of SOM is reflected in the varying terminology used within the literature when referring to humus. Humus therefore is an encompassing word that requires some additional clarification. 'Stable humus' refers to that organic material which will cease to break down further unless there is a change in boundary conditions. It consists of insoluble humic acids, or humins, which are often tightly bound to clay microaggregates that microbes cannot penetrate, and therefore are in long term OC storage (Jones and Donnelly 2004). Stable humus is usually derived from woody plant materials such as cellulose and lignins (e.g. Broadleaf/Podocarp woodland forest pre-human settlement at Lake Tutira). These compounds contribute few nutrients to the soil, but form a critical component in soil structure and form a recalcitrant SOC pool lasting for thousands of years (Ponge 2003). Humus can also be referred to as the OC component that has reached a state of equilibrium with input equalling output, the soil is then known as a having 'steady state organic matter turnover' (McLaren et al. 1990). Finally humus with the capacity to further decompose is known as "effective or active" - it is composed of simple organic (fulvic) acids, sugars, starches, and proteins (the labile OC pool). It forms the basis of soil nutrients, but does not form a significant long-term structural component of the soil (Ponge 2003).

\subsection{Geomorphology}

The following discussion on geomorphology will primarily focus on the colluvial and alluvial depositional environment of the hill-slope geomorphic system and the associated characteristics of those deposits. The definition of a slope unit is where a portion of the slope profile has an angle that remains roughly the same, and an element is a portion of a slope profile where the curvature remains roughly the same (Huggett 2007). A catena is formed from three basic sections that describe an idealised hill-slope (convex hill-top, straight hill-slope and concave toe-slope). From the idealised catena various authors have devised characterisation schemes to describe the sub units that encompass the changing erosional, transportational and depositional surfaces that occur within the catena. Figure 2.5 shows one of the most comprehensive, the Dalrymple et al. (1968) nine-unit land-surface model. The Dalrymple et al. (1968) model is a very useful descriptor of the typical catena morphology in the Oporae Valley, as the soft rock hill country of the North Island was used as an example in subsequent supporting literature written by Conacher and Dalrymple (1977).

Deforestation and conversion to pasture in New Zealand soft rock hill country has caused the intensification of geomorphic processes acting on unit 5, which in turn will change the morphologies of Units 6, 7, 8, and 9 (Conacher et al. 1977). Unit 5 will often exhibit slumping, soil flows, landsliding and gully erosion in soils that have incorporated tephra or formed on sedimentary lithology (Conacher et al. 1977). This type of mass movement will produce a colluvial toe-slope (Unit 6) characterised by deposits of heterogeneous material 
overlying paleosols formed in similarly derived deposits. Due to the spatial and temporal variation in erosion type (Unit 5) and deposit extent (Units 6 and 7), the burial of paleosols on lower slopes can form a sequence of discontinuous paleosol horizons. Alternatively, the alluvial toe-slope (Unit 7) may exhibit relatively continuous paleosol horizons. This is due to the intermittent alluvial deposition covering either the whole or large parts of the valley floor. This alluvial material is sourced from colluvial deposits both up-slope and upstream resulting in relatively shallow but wide ranging burial of the contemporary Ahorizon.

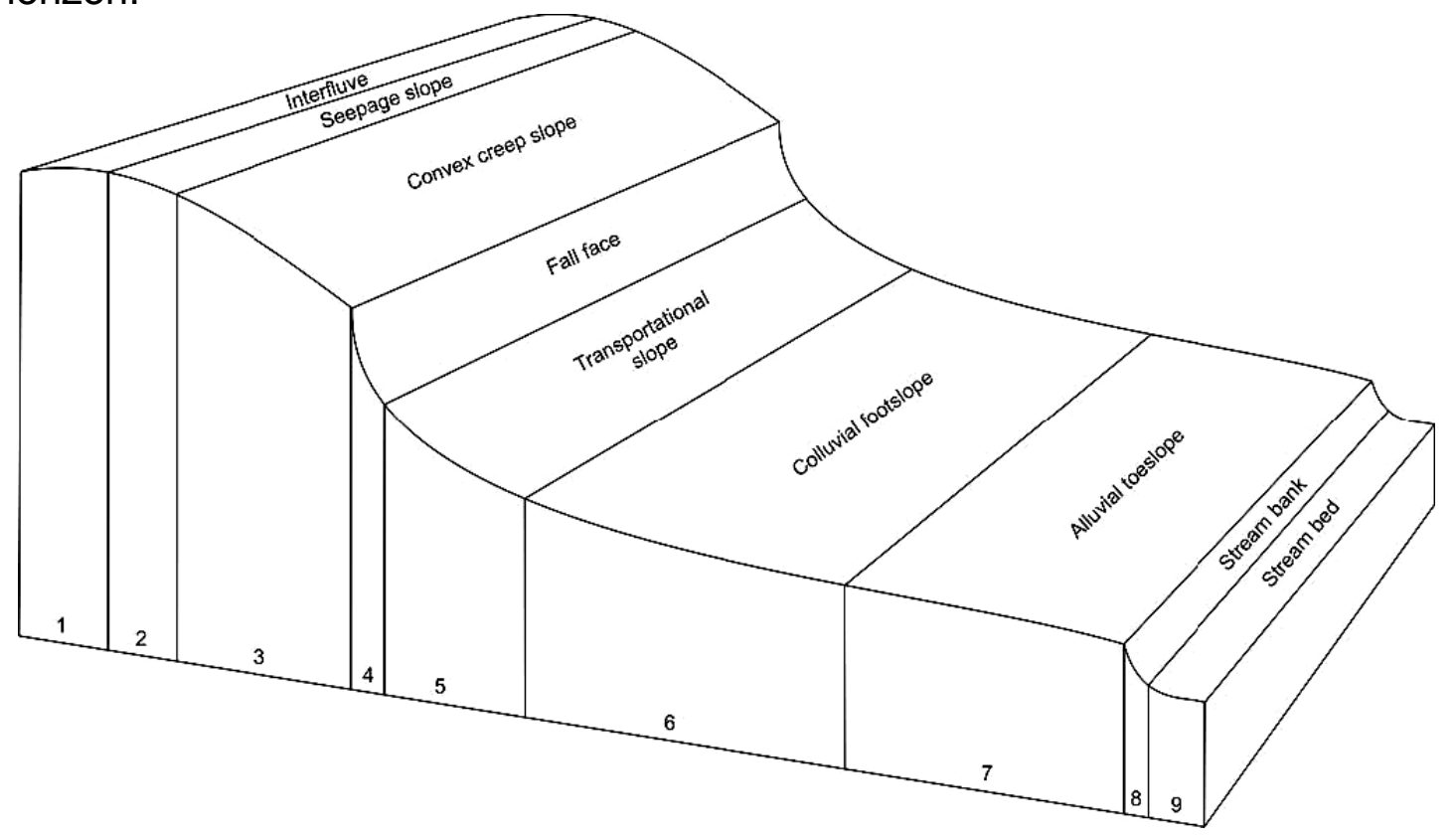

Figure 2.5: The Dalrymple et al. (1968) nine unit land surface model. Figure adapted from (Huggett 2007), unit characteristics taken from Conacher and Dalrymple (1977). Unit 1) the interfluve is characterised by a low slope angle (0$1^{\circ}$ ) with shallow uniform soils that retain water when covering a large area, or increasingly lose water when the unit narrows. Unit 2) the seepage slope transmits gathered water from the edge of unit 1 to those down-slope causing leaching of soil nutrients. Unit 3 ) is a convex unit dominated by soil creep causing lateral movement. Unit 4$)$ the fall face is a steep $\left(>45^{\circ}\right)$ irregular cliff line where bedrock is often exposed. Unit 5) the transportational slope is characterised by large volumes of soil moving down slope relative to the other units. The dominant processes include flows, slumps, slides, raindrop impact and surface wash. Soils typically have thin A horizons and are often disrupted due to the variety of transportation processes operating. Unit 6) the colluvial foot-slope is a zone of redeposition from material sourced from up-slope. The nature of the dominant process dictates the unit surface topography and angle, sometimes forming a low angle fan. This unit may contain significantly more $\mathrm{OM}$, clays and illuvial horizons as a result of deposition, translocation and leaching. Unit 7) the alluvial toe-slope is characterised by a low slope angle $\left(0-4^{\circ}\right)$ impacting on surface runoff. Subsurface drainage is also limited by the water table causing mottling. Alluvial deposition results in frequent and repetitive laminations of well sorted sand and silts over-lying the surface of contemporary A-horizons which may vary in depth from millimetres to meters. Unit 8) the channel wall is characterised by saturation and slumping and in some cases can be difficult to distinguish from unit 7 and 9. Unit 9) the channel bed is dominated by fluvial processes and can undergo periods of aggradation and erosion (Conacher et al. 1977). 
In practice, the separation of depositional Units 6 and 7 into discrete zones along a dividing line is somewhat subjective and only reflects the contemporary dominant mode of deposition either side of that line. The dominant mode may have changed through time for any given point either side of the dividing line, instead forming a deposition mode transition zone between Unit 6 and 7 . Therefore, this zone of overlap will have an inter-fingering of Unit 6 and 7 resulting in discontinuous, laterally bifurcating or composite paleosol horizon sequences (Conacher et al. 1977). Due to the spatial-temporal discontinuity of deposition, the contemporary top-soil will have underlying paleosols that have undergone different stages of pedogenic development leading to variations in the quantity of accumulated $\mathrm{OM}$ in the buried soil horizons. Furthermore, while the 2-dimensional 9 unit land surface model is suitable for the geomorphic interpretation of the Oporae Valley transects (estimated as $\sim 70 \%$ representative of the valley floor), a more complex 3-dimensional model and further sampling and analysis would be more appropriate for further extrapolation.

\section{Connections}

This study seeks to determine the impact land-use change has had on the SOC pool in the Oporae Valley. A brief background to the carbon cycle, SOC, SOM and characteristics of the physical environment in which the SOC resides has been given here to aid the interpretation of the more complicated aspects of the geochemical analyses. 


\section{Chapter 3: Practical Background - Tutira}

\subsection{Lake Tutira}

\section{Location and Lake Origin}

The Lake Tutira catchment covers an area of $32.08 \mathrm{~km}^{2}$. Lake Tutira itself was formed 7,400 years ago (Carter et al. 2004), when a landslide or a series of landslides, possibly triggered by a large earthquake, or a series of smaller earthquakes, blocked off the Papakiri Stream draining to the south (Eden et al. 1993; Lowe 1987). By blocking off the stream valley to create a lake the landslide has created a system that is almost hydrologically closed. Only a small amount of circulation occurs via a re-routed stream network to the north. As a result the lake has a $\sim 97 \%$ trap efficiency for sediment, and any physical changes in the catchment are recorded in the lake's sediments (Eden et al. 1993; Page et al. 1997). The implication of this is that any significant change in sedimentation source materials and/or rate will be preserved in the lake sediments. Figure 3.1 shows the $1.8 \mathrm{~km}^{2}, 42 \mathrm{~m}$ deep Lake Tutira; it is located at $155 \mathrm{~m}$ above sea level, $30 \mathrm{~km}$ north of Napier on State Highway 2.

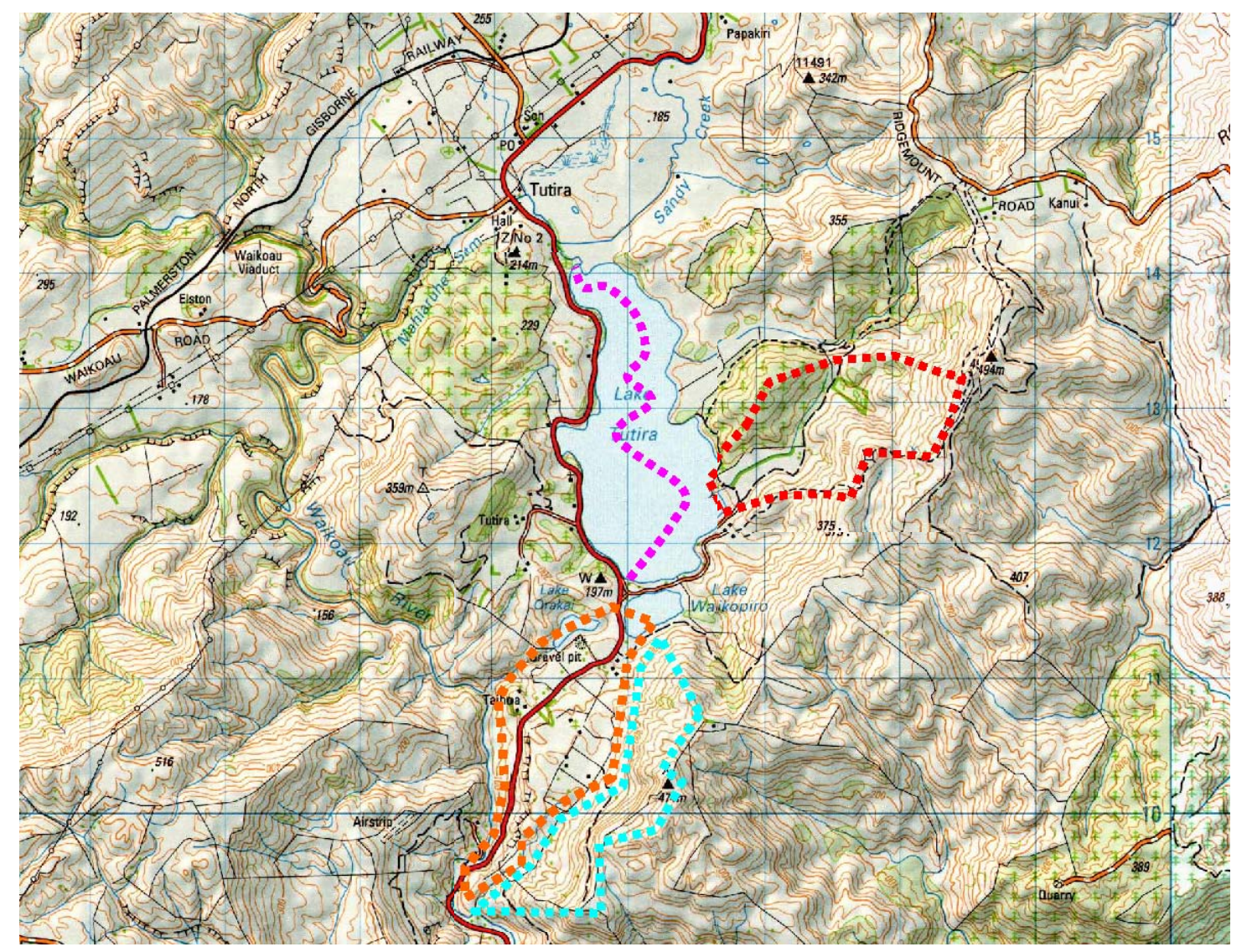

Figure 3.1: Lake Tutira and surroundings showing the Oporae catchment (red), the Taihoa landslide 'block' (orange), likely source area (light blue), and the sinuous line of deepest bathymetry across the lake indicating a drowned river valley (pink). Sources: modified from G.M. Turner (1997); D.A. Lowe (1987); NZ TopoMap Series: 1:50,000 [260], Sheet: V20 1997. 
The significantly shallower Lakes Waikopiro $(16 \mathrm{~m})$ and Orakai $(<10 \mathrm{~m})$ are thought to be sitting on top of the landslide block, while the bathymetry of the Lake Tutira floor is a sinuous line between spurs deepest at the southern 'dammed' end, indicative of a drowned river valley (Lowe 1987; Turner 1997).

\section{Lake Cores}

The impact of ongoing geomorphic activity has been compounded by land use change removing the evidence of earlier erosion events and/or soil development. This is common in high energy environments such as hill-slopes, rivers and beaches. However, the lake core sediments have provided a record that has remained relatively undisturbed (Page et al. 1997), and some of the background for this report is derived from the literature based on the lake cores. Many cores have been taken from Lake Tutira for a variety of analyses: isotopes, magnetism, mineralogy, sedimentary and pollen stratigraphies have all been used to infer the impacts of land-use change, paleoclimate and event frequency/magnitude; tephras, and ash have been used to identify eruption events, thus temporally constraining the time frame for the intervening deposition rates.

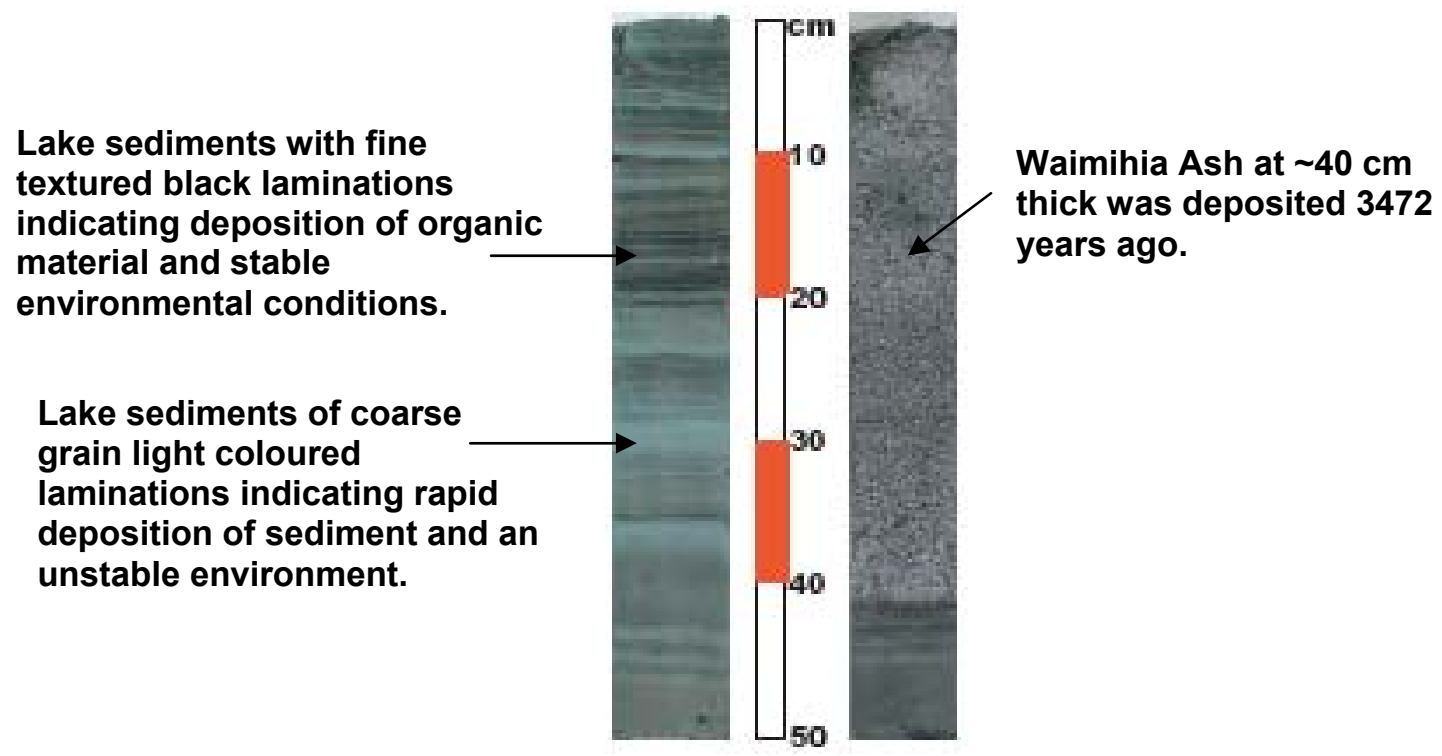

Figure 3.2: Lake Tutira sediments showing laminations representing contrasting environmental stability and the Waimihia Ash, adapted from Carter et al. 2004; Page et al. 1994.

For example; Eden et al. (1993) took a $16.57 \mathrm{~m}$ core from sediments in the lake's northern end, it contained two visually distinct zones represented by different particle sizes. The upper core material $(0 \mathrm{~m}-5.77 \mathrm{~m})$ was often coarse in texture indicating phases of rapid sediment deposition, whereas the lower core $(5.77 \mathrm{~m}-16.57 \mathrm{~m})$ was fine in texture, with organic material, sand, silts and laminated clays, indicating slow accumulation (Eden et al. 1993). The initial observation by Guthrie-Smith has been confirmed. 'Problems' began at the time of the removal of the last remaining scrub in the conversion to pasture is when the problems really began. Deforestation had led to extensive erosion, and over the last 600 years the sedimentation rate has increased by seven times that of its pre-existing forest covered rate (Eden et al. 1998). Figure 3.2 shows how 
environmental conditions such as land-use, storm events and eruptions can impact on the sedimentation on the lake bed.

High resolution records from multiple lake cores have provided valuable insight into the impact of fire, climate, extreme weather events and land- use change on the predominant erosion regime and lake bed sedimentation. These records show the result of sedimentation associated with land-use change, further investigation into the terrestrial accumulation rates using ${ }^{14} \mathrm{C}$ ages (Table 5.4) highlight the differences in terrestrial and lake sediment accumulation rates.

\section{Lake Level Change}

If the high rate of deposition observed in the period $1963-1988$ is maintained, the $42 \mathrm{~m}$ deep Lake Tutira will be infilled within the next 600 years, shrinking as it does so (Page et al. 1997). Previous lake levels remain speculative. Evidence of one lacustrine deposit located $3 \mathrm{~m}$ above the current day lake level has been found, however, lake levels rose by $3.5 \mathrm{~m}$ during Cyclone Bola in 1988. Fluctuations in lake level have also been confirmed using diatom assemblages from the surrounding valley floor sediments (Page et al. 1997). Prior to European settlement the valley floors were arms of the lake; Herbert GuthrieSmith (1953) described them as 'swampy' with unconfined stream networks.

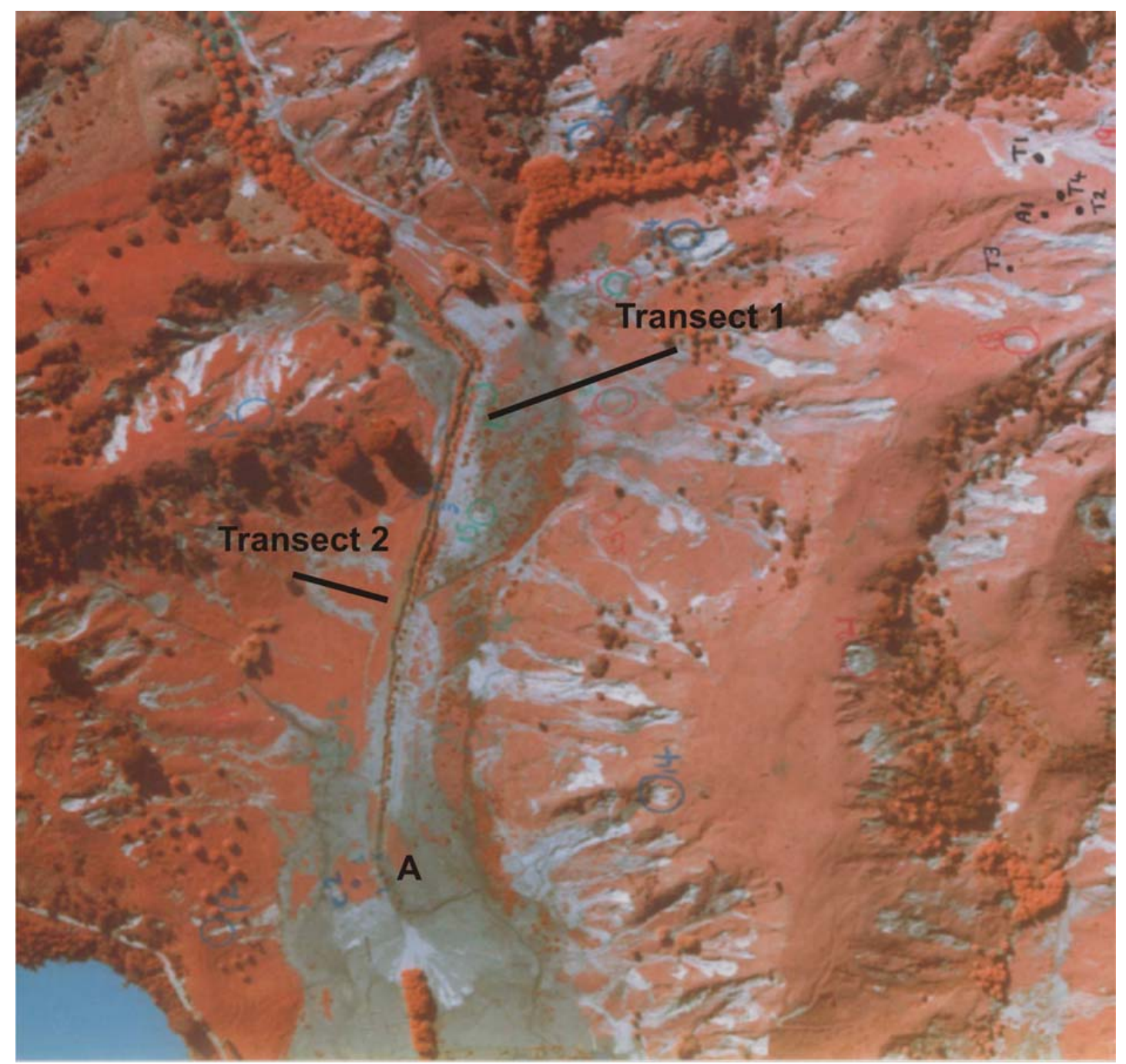

Figure 3.3: The Oporae Valley after Cyclone Bola. Photo courtesy of Mike Page (GNS). 
These natural wetlands would have acted as natural sediment traps, accumulating both sediment and SOM washed in from the surrounding hills. Between 1890 and 1920 a drainage ditch was cut in the Oporae Valley, which has since down cut through a number of buried soil horizons (Page et al. 1997). The pre-human soil on the Oporae flat was situated $\sim 1.75 \mathrm{~m}$ below the contemporary valley topsoil in the drainage channel located in the lower valley (Figure 3.4 located as ' $\mathrm{A}$ ' in Figure 3.3) The drainage channel can clearly be seen in infrared image of the Oporae Valley after Cyclone Bola in Figure 3.3.

Infrared images of the Cyclone Bola erosion scars and deposits (light blue/grey on Figure 3.3 above) shows the extent of damage caused to the landscape by a single large rainfall event spanning three days in 1988. This photo also shows the widespread colluvial runout covering all of T1 and some of T2.

\subsection{Land Use History}

Herbert Guthrie-Smith was among the original European settlers of this catchment. As a self-described naturalist he documented in detail the geomorphic and ecological change he witnessed upon his sheep station in the now internationally recognised 'Tutira - The Story of a New Zealand Sheep Station' (1953). Because of his accounts, descriptions and records, there exists a detailed historical chronology of the impact of high magnitude low frequency events and land-use change on the catchment. Fire was the principal method used by both European and Maori settlers for clearing land and hunting, by the late 1930s much of the Tutira catchment was in pasture. The pasture has been used for sheep and cattle farming contributing stock dung and urine to the nutrient content of the water and soils. Additionally top dressing of the catchment began in the 1950s, this triggered weed infestations and algal blooms in the lake itself (Page et al. 1997). Since 1980 improved management has led to nutrient controlling measures for the lake, such as small blocks of scrub and forest regenerating on strategic areas of the landscape, and drainage ditches to alleviate nutrient laden runoff during storm events (Page et al. 1997). Land use management in the Lake Tutira region has impacted upon the biogeophysical processes operating in the catchment. Nutrient content (specifically nitrogen) will have been increased for periods of time immediately following the application of fertiliser or animal wastes. While the increase $\mathrm{N}$ content may also increase plant growth and photosynthesis ( $C$ sequestration), it will also increase the decomposition rate and subsequent conversion of stored $\mathrm{C}$ to $\mathrm{CO}_{2}$ via respiration.

\subsection{Tutira Soils}

The contemporary topsoil has been defined here as the uppermost depositional unit (or units) from each core containing recognisable features of pedological development, and that its contemporary SOC content is in a predominantly aerobic environment and readily able to interact with the atmosphere (controlled by the water table height). 


\section{Parent Material}

The principal lithology of this area includes marine derived mud, silt, sand and limestone. Soils are formed in regolith derived from the underlying sedimentary rock but also contain remnants of comparatively high OM forest soils, volcanic tephra and loess depositional units (allochthonous soils) (Eden et al. 1993). Compounding the natural variability found in the basement lithology, over $80 \%$ of the catchment regolith has at some point been disturbed by landsliding, resulting in highly variable soil profiles (Hawke and McConchie 2003). Figure 3.4 shows a buried soil horizon from the stream channel in the lower Oporae Valley (location 'A' in Figure 3.3).

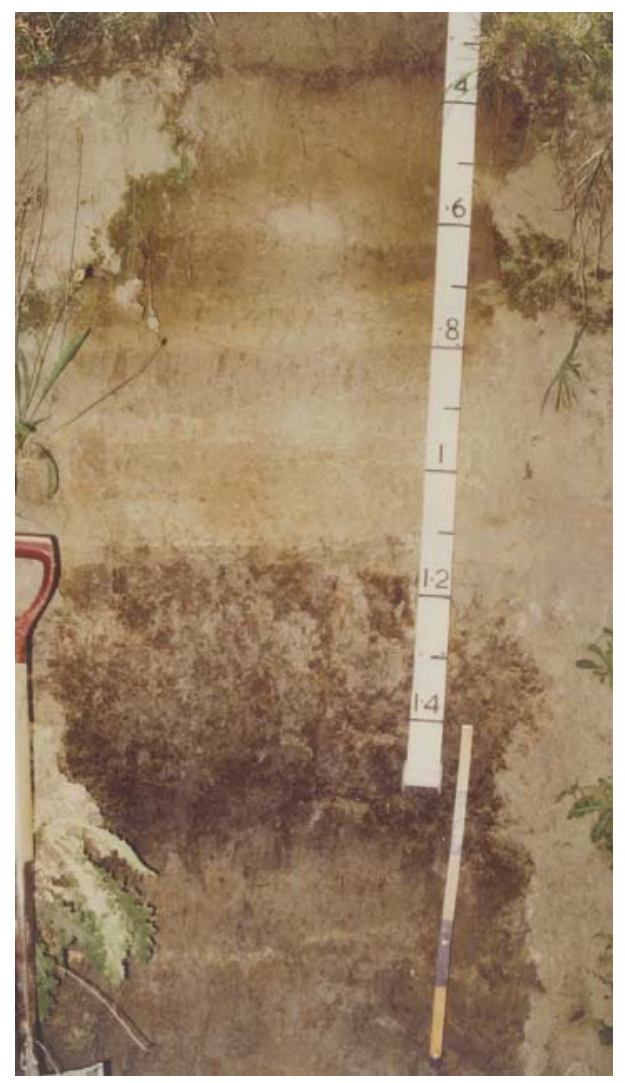

Figure 3.4: buried SOM horizon in the Oporae Valley. Photo courtesy of Mike Page (GNS).

The buried OM in Figure 3.4 is typical of paleosols that were formed under Podocarp forest present in the Oporae Valley before human intervention. These paleosols represent a sink of OC effectively removed from gaseous atmospheric exchange and the short term carbon cycle. Quantification of this stored carbon is important for predicting the impact of land-use change on SOC e.g. a hectare of soil $(100 \mathrm{~m} \times 100 \mathrm{~m}), 12$ inches or $30.48 \mathrm{~cm}$ deep, has a volume of $3,048 \mathrm{~m}^{3}$. At a soil density of 1.2 , this foot-deep hectare of soil weighs 3,658 metric tons. One percent of this weighs 36.58 metric tons, and if this one percent is organic matter ( $58 \%$ carbon by weight), it contains 21.21 tons of carbon.

In the Lake Tutira catchment it is possible that base-level changes as a result of regional tectonic activity caused relative lake level change. Large earthquakes such as that in 1931 may have naturally drained wet-land valleys and initiated a 
change in ecosystem dominance from forested swamp/marsh to Podocarp forest (pre-human) or bracken/pasture (historic). A change in drainage conditions of this nature would have significantly impacted on the OM preservation characteristics of the valley floor, shifting the predominant soil OM decomposition type from anaerobic to aerobic respiration. Additionally soil development would have been influenced by climate, vegetation and local topography and time. All of these variables and their impacts on the local soil formation factors are described in the relevant sections below.

The Oporae Valley soils used in this study are a composite of minerals, tephra and $\mathrm{OM}$ from pasture. These topsoils are formed principally in event related colluvial/alluvial deposits containing either in-situ or reworked airfall material. The Oporae Valley soils are poorly weathered due to their relatively short residence times and make easily erodible allochthonous soils that are vulnerable to changing boundary conditions. To compare the $\mathrm{OM}$ of these pasture covered soils with that of the pre-human forest soils it is necessary to use proxy data from a similar environment either in undisturbed or regenerating native forest. Unpublished data were obtained from Landcare Research. These represent White Pine Bush, to the southwest of Lake Tutira under undisturbed native forest (aspect unknown), and the Hangar, to the West of Lake Tutira under regenerating forest ( 100 years).

\section{Soil atmosphere}

When the water table recedes the soil pore spaces are filled with air. Due to decomposition of $\mathrm{OM}$ by micro-organisms, $\mathrm{OC}$ is gradually oxidised into $\mathrm{CO}_{2}$ through respiration. Below ground this $\mathrm{CO} 2$ is not then immediately available for photosynthesis by plants, and so the $\mathrm{CO}_{2}$ concentration in soil can build up e.g. the atmosphere contains $20.9 \% \mathrm{O}_{2}$ and $0.03 \% \mathrm{CO}_{2}$, while soil contains $15-20 \%$ $\mathrm{O}_{2}$ and $0.25-4.5 \% \mathrm{CO}_{2}$, a concentration up to 300 times higher (Courtney et al. 1984). In wet or dense soils with a lower capacity for gaseous diffusion the $\mathrm{CO}_{2}$ concentration can build up to even higher levels thereby inhibiting soil organisms from reproducing and carrying out the decomposition of OM (Courtney et al. 1984). When analysing the cores, $\mathrm{CO}_{2}$ concentrations and organism activity where not measured. However, mineral oxidation leaves a distinct visual indication of past soil atmosphere and soil water table height, which can be used to make inferences about microbial activity. The reddish brown colours of many soils are due to the Ferric Iron compounds (Fe III, $+E_{h}$ ). When there is no air available, as with waterlogged soils, they have a blue or green appearance, which is due to the colour of the Ferrous Iron compounds (Fe II, $-E_{h}$ ) which remain unoxidised. These reactions are termed REDOX reactions. Where red mottles appear in blue or green matrices, this is usually interpreted as air penetrating down old root channels or worm holes (Courtney et al. 1984). Furthermore, this visual indication of soil atmosphere can be correlated to the grain size characteristics of the sediment, allowing for inferences about the potential (or lack of) gaseous diffusion and the build up of $\mathrm{CO}_{2}$ to be made. 


\subsection{Hydrology}

Hydrology plays in important role in determining the frequency and magnitude of erosion events (pore water pressure) and the state under which minerals and SOM are stored or transformed (water table fluctuation leading to reducing or oxidising conditions). The dominant form of erosion in the Tutira catchment is landsliding, which is often triggered by a change in porewater pressure in the soils on gradients sufficient for mass movement to occur (McConchie 1992). The exact mechanism for pore water pressure triggering mass movements is complicated by the antecedent moisture conditions, variability within soils and the type of flow dictated by rainfall intensity (Hawke and McConchie. 2003). An increase in pore water also leads to boggy or saturated soils on the valley floor, creating an environment that is conducive to the storage of $\mathrm{OM}$ and the associated SOC.

Due to the changing slope gradient of each transect, the impact of hydrology on SOM translocation and preservation will vary through space and time. A lack of SOM at depth up-slope (Units 4 and 5) would primarily be attributed to removal by erosion. Additionally, a steeper gradient also increases the rate of hydrological throughput thereby increasing the potential for particle and solute (DOC) translocation e.g. Andersson and Nyberg (2008) found that catchment mean slope has the strongest correlation to the increase in DOC output from soils in wetlands (Andersson and Nyberg 2008). Slope gradient also reduces the duration of soil water storage causing the water table height to fluctuate at a faster rate and with greater frequency, exposing more SOM to oxidising conditions. Another study has shown that where increased temperatures and droughts have lowered the water table height in areas of England, the reduction can be correlated to an increase in DOC in rivers (Worrall and Burt 2007). In this case the majority of DOC was accounted for by an increase in hydrological throughput after draining the peaty topsoil. Based on the impact of slope and climate on water table height and fluctuation at Tutira, it is expected that there will be a larger transition zone between reducing and oxidising conditions upslope (Unit 6 the colluvial foot slope) contributing to less SOM preservation and increased translocation of SOM particles and DOC down-slope through the soil profile.

Unit 7, the alluvial toeslope, significantly changes gradient thereby slowing the hydrological throughput, stabilising the water table height and increasing the storage time and volume. This leads to the potential for increased preservation of SOM at depth. Therefore it is speculated that the shallow slope of Unit 7 will help preserve SOM as did the pre-human forested and/or swamp conditions that were dominant in the Oporae Valley before its clearing.

\subsection{Vegetation}

Lake Tutira catchment was forested with podocarp broadleaf forest typical of the North Island prior to Polynesian colonization. Subsequent fire caused by Maori and naturally occurring forest fires had removed the taller trees, which were replaced with bracken and scrub before European settlers arrived in 1873. 
European settlers later cleared the catchment also using fire, to replant in pasture and other exotic species (Trustrum and Page 1992). Janet M. Wilmshurst (1997) carried out a detailed pollen and charcoal analysis of Lake Tutira core $\mathrm{LT} 16 \sim 6 \mathrm{~m}$ in length. Four distinct pollen zones were recognized by Wilmshurst (1997) and are summarised below:

Zone 1 - Pre human settlement

Tall conifer broadleaf forest - a wide range of podocarp trees, shrubs, climbers and ferns

\section{Zone 2 - Early Maori settlement}

Fern Scrubland - Rapid decline in tall podocarp pollen, increase in Pteridium esculentum (Bracken) and other sub-canopy broadleaf species are dominant. This zone was also characterised by the presence of charcoal from forest fires during the Maori occupation of the region.

Zone 3 - Early European settlement

$\sim 1870$ new flora pollen introduced include - Pinus spp., Plantago lanceolata, Rumex spp., Salix spp. (Willow), Trifolium spp. (Clover) and Juglans spp. (Walnut), while Pteridium esculentum remain high, all dominating the upper part of the core. Broadleaf shrubs cease to be as dominant as they were in Zone 2. Charcoal fragments become common in Zone 3.

Zone 4 - Post 1940s

Pinus and Poaceae (Grasses) steadily increase as agriculture and exotic plantations intensify.

Based on abundance of taxa, deforestation by fire is estimated to have taken only 53 calendar years (Wilmshurst 1997). The rapid burning and clearing of the catchment has led to erosion problems, and the distinct pollen zones identified by Wilmshurst were used as means to further constrain the sedimentation rate associated with each period of land-use and vegetation change. The rates for each zone are:

- Zone 1: Forest

- Zone 2: Bracken

- Zones 3 and 4 combined:
$1.7 \mathrm{~mm} \mathrm{yr}^{-1}$

$2.7 \mathrm{~mm} \mathrm{yr}^{-1}$

$13.8 \mathrm{~mm} \mathrm{yr}^{-1}$

Erosion rates associated with European settlement and land-use change (Zones 3 and 4 ) are $\sim 8$ times higher than pre human settlement (Zone 1) and $\sim 5$ times higher than Maori settlement (Wilmshurst 1997). The sedimentation rates were found to be much higher immediately post fire clearance event, and the catchment stabilised to an equivalent pre-human forested sedimentation rate with bracken establishment. However, once the bracken and scrubland was burnt and replaced with grasslands the sedimentation rate increased again. During the period of Maori and European settlement ( 490 cal. yr BP) there was no evidence for a dramatic increase in the frequency of high intensity storms, and thus the changes in sedimentation rates can be directly attributed to the vegetation species type and abundance in the Lake Tutira catchment (Wilmshurst 1997; Eden et al. 1998; Page et al. 1997). 


\section{Plant Biochemistry}

Note: for an explanation of delta $(\delta)$ values please see Appendix I.

Mineral soils typically have $\delta^{13} \mathrm{C}$ values that progressively increase with depth (Andreux et al. 1990). The mean $\delta^{13} \mathrm{C}$ value for SOM is most likely reflecting the vegetation or change in vegetation from which the SOM was originally derived (Andreux et al. 1990). In contemporary topsoils the $\delta$ signature can be used to trace shifts in the dominant vegetation species where the change is from C3 to C4 photosynthetic pathways and visa-versa. Where buried SOM is concerned there is a multitude of processes that can potentially shift the $\delta$ value away from the original value reflecting the vegetation input. Individual plants can have a range of $\delta^{13} \mathrm{C}$ values in different functional pant materials e.g. differences of 1 $2 \%$ are commonly observed between the leaves and roots of the same plant (Andreux et al. 1990). More recent studies have shown that the change in $\delta^{13} \mathrm{C}$ values within different biogeochemical fractions of SOM have been shown to impact on the residence time of SOM.

Through the successions of vegetation types at Lake Tutira, it is highly likely that all of the New Zealand plants used the C3 photosynthesis pathway. This has significance for the isotopic analysis discussed further in Chapter 4 and Appendix 1. There are only two known native plants in New Zealand that have the C4 pathway; Atriplex buchananii distribution favours arid sites with salt laden winds and saline soils, found south of Wellington, and Theleophyton billiardierei is a coastal herb that prefers sandy soils that is now an endangered species whose presence is largely confined to the Chatham Islands (Wardle 1991). Guthrie Smith and other European settlers introduced species to the area, Rye Grass (Lolium) and Clover (Trifolium), this mix was commonly used to sew pasture in the Lake Tutira catchment (Guthrie-Smith 1953). Introduced crop species such as maize have the C4 photosynthetic pathway (Eleki et al. 2005). Both Rye Grass (Lolium) and Clover (Trifolium) have the C3 photosynthetic pathway (Eleki et al. 2005; Lawton 1988) meaning that the often used approach of tracing land-use change through the different isotope ratio signatures of native forest SOM (C3) and introduced crop species SOM (often C4) can not be used in the Oporae Valley soil samples. However, $\delta^{13} \mathrm{C}$ values that progressively increase with depth can still be used to interpret buried soils.

\section{Palynology}

Pollen analysis has provided a useful chronology for applying temporal constraints to the sediment deposition regime in Lake Tutira (Section 3.4). Pollen analysis is usually confined to areas where accumulation and preservation are considered to be likely. The ideal conditions for preservation of pollen grains are peats, lake beds, acid soils and in the accumulation zone of a podsol (Moore and Webb 1978). Pollen grains themselves are resistant to biogeochemical breakdown, but only in certain conditions. Typically in aerobic soils of any kind with a neutral $\mathrm{pH}$, pollen will be broken down by small invertebrates (corroded in the gut) and micro-organisms. Temperature, texture or soil type appear to have little impact on pollen grain preservation (Moore and Webb 1978). A pH of 5 or less is sufficient to have some preservation; however, pollen grains have differential rates of decomposition, thus impacting on the pollen 
count. In anaerobic conditions pollen will degrade if the $\mathrm{pH}$ is high (Moore and Webb 1978). Based on the rapid accumulation rates associated with anthropogenic burning of the catchments vegetation, and the apparent anoxic conditions at depth within the Oporae Valley cores, a pollen analysis was carried out on eight samples as a test for the presence of a useable pollen archive that would correspond to the lake record.

\subsection{Climate}

\section{Contemporary Climate}

The climate of Hawke's Bay varies as a function of its topographic characteristics. The Lowland has a sporadic and highly variable rainfall, with large and often sudden variation in temperature. Light winds and the orographic

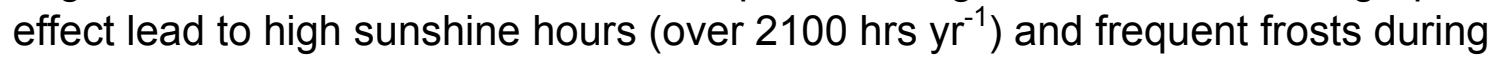
the winter months. Often during summer the rainfall is so sporadic in nature that the soil moisture is completely depleted, often halting plant growth altogether (Thompson 1987).

Lake Tutira situated in the uplifted plateau between the high country and lowland plains has a climate different to both, yet the local climate is heavily influenced by the surrounding topography. The high country area often has gale force winds and rain for approximately 150 days a year, delivering 2,400 $\mathrm{mm}$ to the mountain ranges. Snow is also frequent during the winter months (Thompson 1987). The high altitude western ranges shelter the Hawke's Bay from the predominantly westerly flowing winds over New Zealand. These ranges effectively squeeze the moisture from the air as it forces it to rise in altitude; this orographic effect also creates dry foehn winds that flow down onto the plains and uplifted plateau below, further reducing the soil moisture levels (Thompson 1987). With predominant westerly flow, and the protection offered by the orographic effect, the Hawke's Bay lowlands rainfall comes from other directions. Over $60 \%$ of rainfall occurring in Napier comes when the wind is from the south or south east. The variability of easterly flow rainfall is high but it produces the most intense rainfall from the north east to east airstreams (Thompson 1987).

These contrasts within the climate variables of the Hawke's Bay region serve to make it more vulnerable to less frequent weather extremes. A high degree of temperature and precipitation variation leads to drying and wetting (DW) cycles and freeze-thaw processes (Kamp 1992). The climate control on enhancing erosion processes is then compounded by the removal of vegetation causing micro-climate changes at local scales, and increased vulnerability of surface materials through alluvial erosion and deposition at regional scales.

The Lake Tutira rainfall is considerably less than the highlands to the west at $\sim 1,400 \mathrm{~mm} \mathrm{a}^{-1}$, however the rainfall is highly variable at $>25 \%$ during summer, rainfall frequency is greatest during winter (Thompson 1987). The high degree of variability in rainfall often accompanied by drought conditions ( $>15$ days of no rain) makes the region vulnerable to both fire and large rainstorm events. Low frequency high magnitude rainfall events have had well documented impacts on 
the Lake Tutira catchment. Herbert Guthrie-Smith kept detailed records of rainfall; describing instances where over 'three or four days' duration, not infrequently one foot and over, on one occasion nearly two feet" fell, while in Napier $30 \mathrm{~km}$ to the south, little or no rainfall was recorded (Guthrie-Smith 1953). When approaching from the east or south east the uplifted plateau in which the lake Tutira catchment is situated creates its own orographic effect, thus causing precipitation from the oceanic moisture laden atmosphere that did not fall on the plains to the south. This combination of westerly dry foehn winds and the localised orographic effect from the less frequent east to south east weather patterns exacerbates DW cycle in Tutira soils, increasing erosion vulnerability.

\section{Climate Change and Cyclonic Storms}

In March 1988 Cyclone Bola delivered $753 \mathrm{~mm}$ of rainfall over the Lake Tutira catchment in just four days ( $54 \%$ of average annual rainfall). As a result 1.35 million $\mathrm{m}^{3}( \pm 0.13)$ of sediment was transported off and redistributed around the landscape, that is equivalent to $42 \mathrm{~mm}$ of topsoil mobilised across the total watershed $(3,208 \mathrm{ha})$, or $83 \mathrm{~mm}$ for those severely affected landforms $(1,427$ ha or $\sim 44 \%$ ) (Page et al. 1994). Figure 3.5 shows Lake Tutira after Cyclone Bola in 1988.

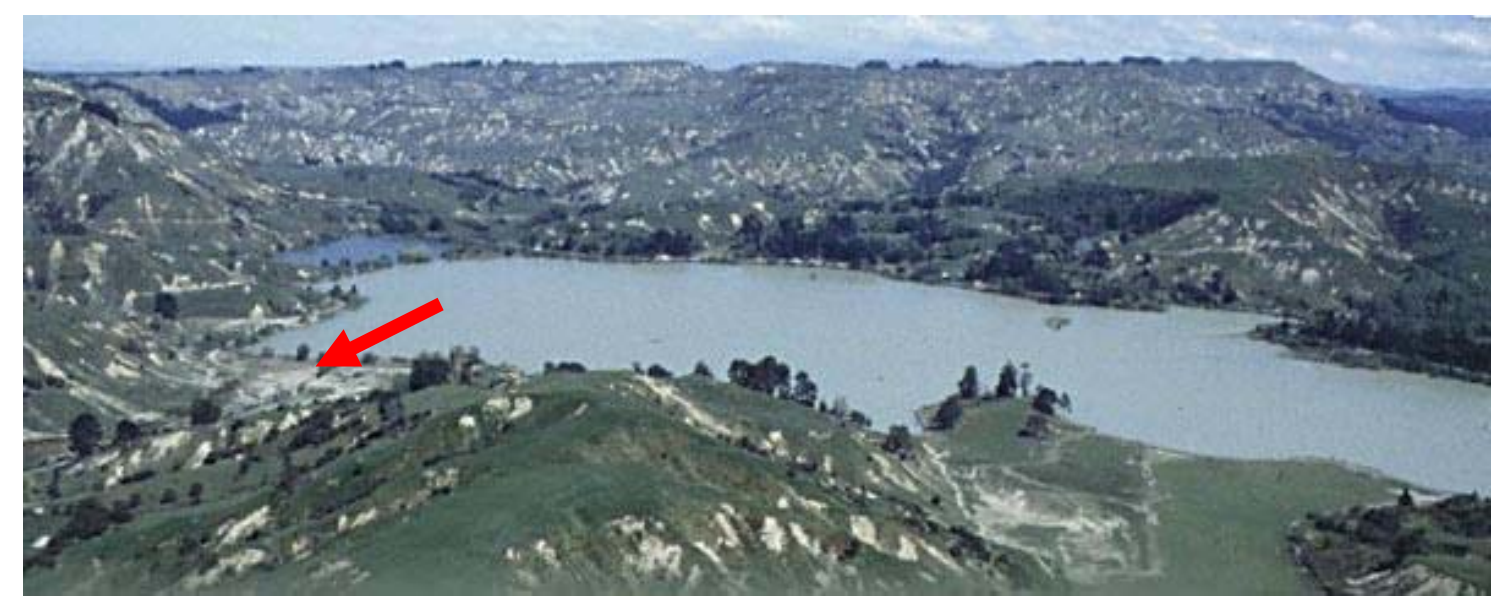

Figure 3.5: shows the Lake Tutira catchment with the Oporae Valley to the left of the ridgeline in the foreground and the lower Oporae Valley floodplain indicated by the red arrow. Source: www.niwa.co.nz, Photo: Landcare Research

The National Institute of Water and Atmosphere (NIWA) has monitored the changes in climate for the Hawke's Bay region since the 1980s and has concluded that winters are becoming gradually warmer, with fewer frosts and lower rainfall, while summers are becoming wetter, with more cyclones. Despite the potential for an increase in sediment mobilisation due to these changes in climate, the impact has potentially been offset by sediment exhaustion.

The observed trends in the Hawke's Bay region can be linked not only to the increase in atmospheric $\mathrm{CO}_{2}$, but also to the vegetation change at a local scale. Once vegetation has been removed, the impact of soil moisture input on the exchange of energy between sensible and latent heat is altered. This can have 
impacts on local and regional temperatures, and possibly precipitation (Denman et al. 2007). It has been shown that change in vegetation accentuated the erosion regime on the northern slopes where wetting and drying cycles have proven to be the most critical factor in slope stability (Lowe 1987). These two interconnected factors (vegetation impact on soil moisture and soil moisture impact on climate) form a feedback loop which could dictate future potential land-use within the region. Warmer climates can lead to a longer water deficit, which leads to a reduction in photosynthetic activity at the surface (less carbon sequestration), and increases the vulnerability of soils to erosion during the wet season, which in turn reduces the vegetation present on slopes, and the slopes capacity to retain water, therefore accentuating the frequency of wetting and drying cycles which leads to increased erosion, etc. Alternatively, in areas that are wet (anaerobic conditions), an increase in temperature can cause an increase in microbial action, enhancing the decomposition of organic materials, causing an increase in the dissolved organic carbon concentration in rivers (Worrall and Burt 2007). Longer dry periods during the summer season will also result in water table draw down to levels below normal depth, thereby increasing the zone of oxidation and the aerobic respiration environment for biological activity (Worrall and Burt 2007).

\subsection{Geology}

\section{Tectonic Setting}

The Hawke's Bay geologic setting is dominated by the active tectonic convergence zone of the Australian and Pacific plates shown in Figure 3.6 The Pacific oceanic plate is subducting beneath the over riding Australian continental plate at an oblique angle at a rate of $\sim 50 \mathrm{~mm} \mathrm{a}^{-1}$ (Berryman 1988). This oblique angle can be separated into its two vectors with a compressional

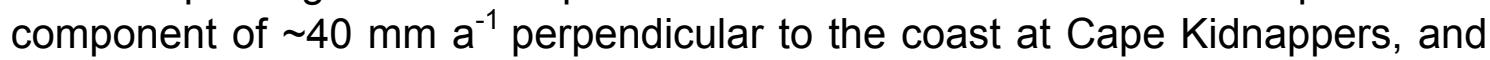
$\sim 30 \mathrm{~mm} \mathrm{a}^{-1}$ strike slip parallel to the Hawke's Bay coastline (Lowe 1987).

Cole and Lewis (1981) developed the four unit model of the Taupo-Hikurangi subduction system exemplified in the rectangle from Figure 3.6. From the Hikurangi Trough inland there are four tectonically controlled domains. The principal differences between these domains stem from the differential rates of uplift, glacio-eustatic oscillation, erosion and deposition, faulting and folding (Kamp, 1992). Unit 1, an accretionary slope; Unit 2, a forearc basin; Unit 3, a frontal ridge; and Unit 4, a backarc basin, determine the type of landforms associated with them (Berryman, 1988). Figure 3.7 shows this four unit model as it was modified by Pettinga (2001) (different terminology for Units 2 and 4).

The surface expression of initial subduction (the Hikurangi Trough) is located $\sim 80 \mathrm{~km}$ east of the Hawke's Bay coastline. Westward of this structural trench is Unit 1, the accretionary slope. This unit extends landward, and reaches the coastal cliffs and hills; the majority, however, remains submerged offshore. 


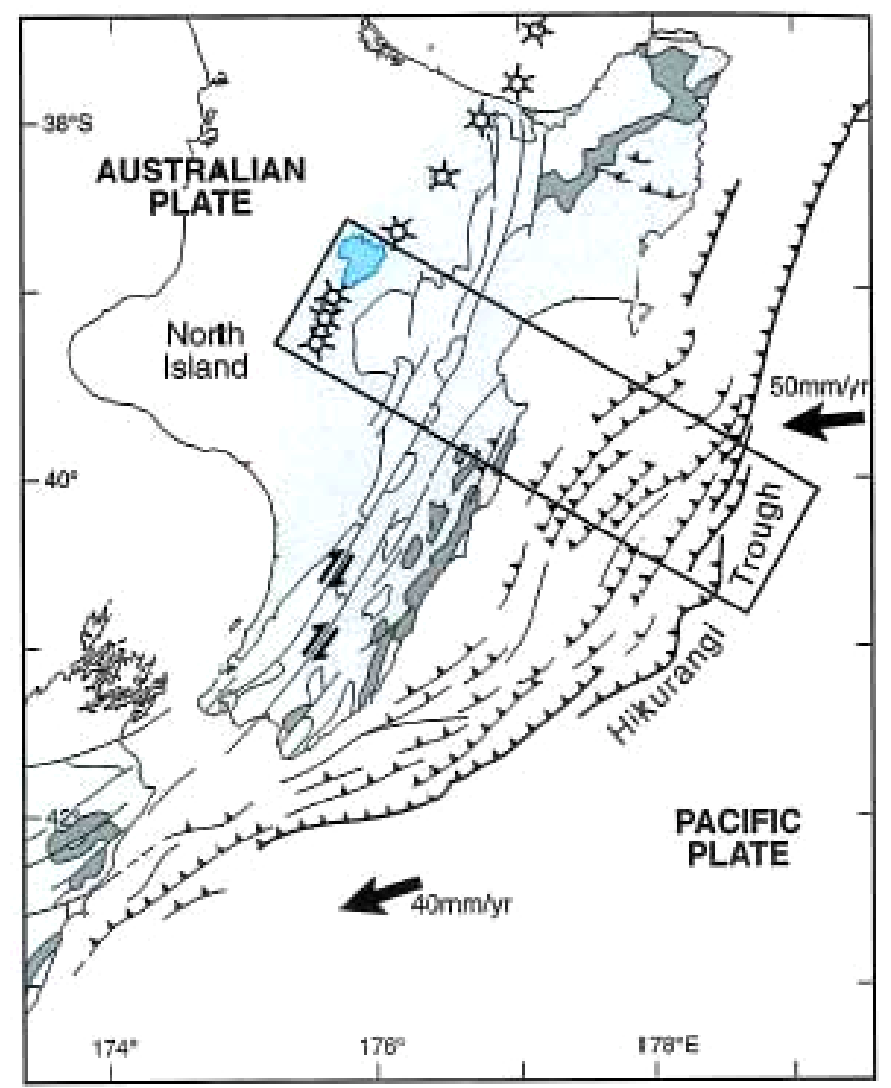

Figure 3.6: The Taupo-Hikurangi subduction system showing the compressional vectors and the outline for the cross section of Figure 3.7. Source: Pettinga (2001) adapted from Cole et al. (1981).

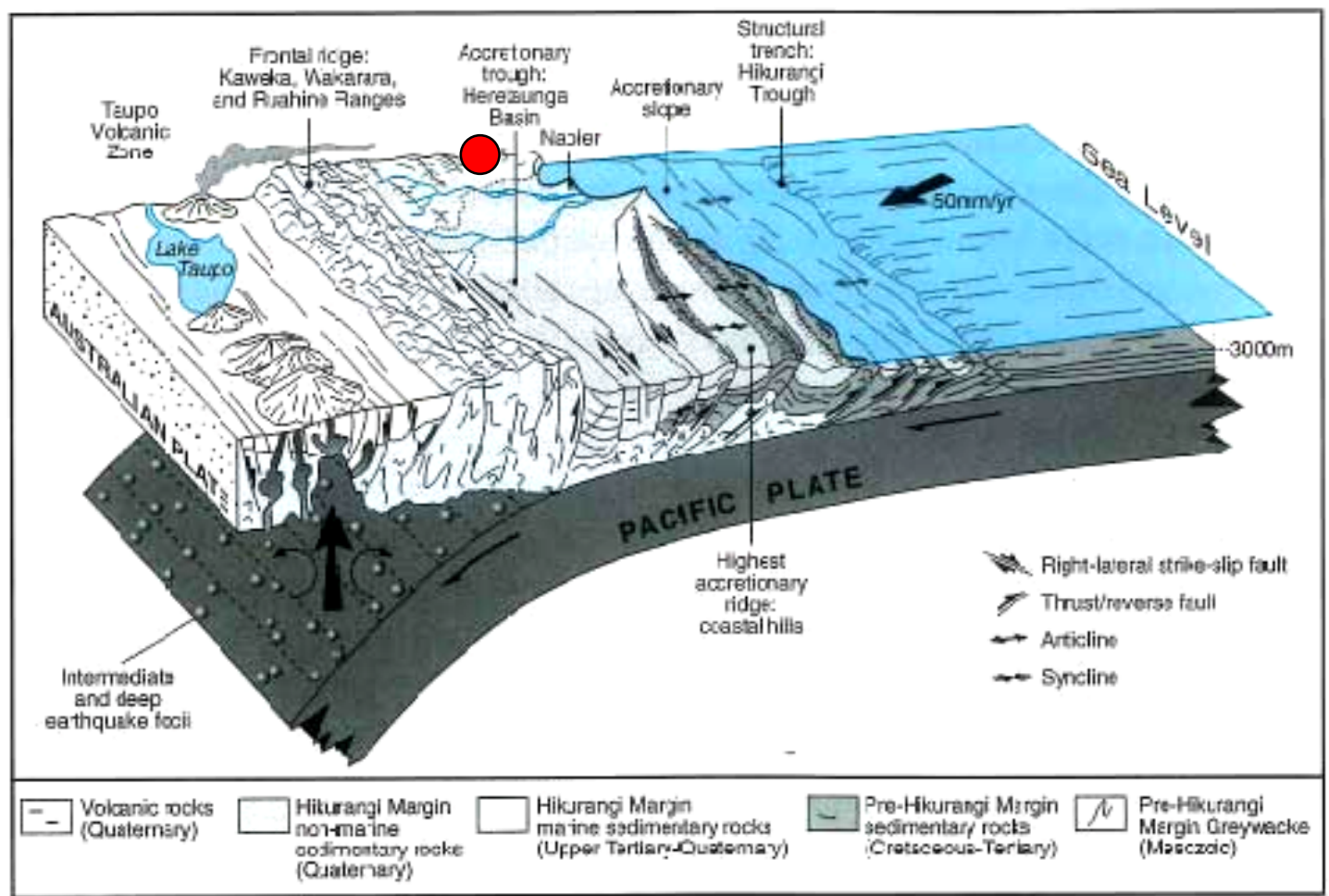

Figure 3.7: Hawke's Bay Tectonic Model and the position of Lake Tutira within the model indicated with a red marker dot. Source: Pettinga (2001) adapted from Cole et al. (1981). 
Further west of the accretionary slope is Unit 2, the forearc basin. This unit contains several distinct terrain topographies identified and described by Kamp (1992) that are of relevance to this report as the Lake Tutira catchment contains all of them. The aforementioned topographies of the forearc basin are intimately linked to the synclinal formation of the regional basin, the rate of uplift, and the lithology of the basins sedimentary units. The regional basin is approximately 35 $\mathrm{km}$ across at Wairoa and has been filled with sediments up to $5 \mathrm{~km}$ thick comprised of siltstone, sandstone and limestone of late Cretaceous to early mid- Pleistocene age (Berryman 1988). Since the cessation of subsidence in the Pliocene and the onset of uplift since the mid Pleistocene, compression and faulting combined with fluvial dissection has created an area of low lying hill country, ranging from flat to steep terrain (predominantly steep $10-55^{\circ}$ in the Lake Tutira district) (Hawke and McConchie 2003; Lowe 1987). Unit 2 is discussed in more detail in the following section. Further westward of the forearc basin and separated by major faults lines lies Unit 3, the frontal ridge. This unit is primarily composed of Mesozoic greywacke, forming the axial ranges of the North Island with strong NNE-SSW structural control over the topography and drainage network (Berryman 1988). Rapid uplift (estimated at $2000 \mathrm{~m}$ since the early Pleistocene) has provided large amounts of source material for fluvial gravels, now found in the secondary basins or river valleys of the forearc basin (Berryman 1988). Finally, Unit 4 is the backarc basin, a 2 - 4 $\mathrm{km}$ deep graben overlaying a Mesozoic greywacke base, also known as the Taupo Volcanic Zone. The TVZ stretches $\sim 300 \mathrm{~km}$ from Mt Ruapehu in the south to White Island in the north and contains many active volcanoes. The four major volcanic centres within this unit are Tongariro, Taupo, Maroa and Okataina (Berryman 1988). Due to the prevailing westerly winds this unit also is of significance for the Lake Tutira catchment, as it provided the source material for the ubiquitous tephra and ash found within the soils of Tutira today.

\section{The Forearc Basin in More Detail}

Unit 2, the forearc basin, is composed of two distinct zones: the Heretaunga plains to the south and an uplifted plateau to the north (Figure 3.8). The Heretaunga Plains are derived from both alluvial deposition and sedimentation from glacio-eustatic oscillations which have in filled the Heretaunga Basin. To the north the forearc basin is dominated by an uplifted, gently dipping plateau of Pliocene and early Pleistocene sediments that are heavily dissected from a combination of faulting through uplift and fluvial erosion of sediments. The maximum height of this plateau is $1000 \mathrm{~m}$ asl at the Mangaharuru Range, gently dipping at $5-10^{\circ}$ toward Hawke Bay, where it drops to $300 \mathrm{~m}$ asl at the coast (Kamp 1992; Berryman 1988). Figure 3.8 shows the heavily dissected uplifted plateau of limestone and mudstone.

The $5-10^{\circ}$ dip has had feedback on the fluvial system, and thus forms a significant controlling factor on the fluvial erosion regime. Due to differential uplift rates the strike of bedding changes from due east at Wairoa to northeast west of Napier, the resultant stream channel network for this region has a radial pattern draining toward the semi-circular Hawke Bay (Kamp 1992). This convergent pattern delivers eroded materials from a large source area to the 


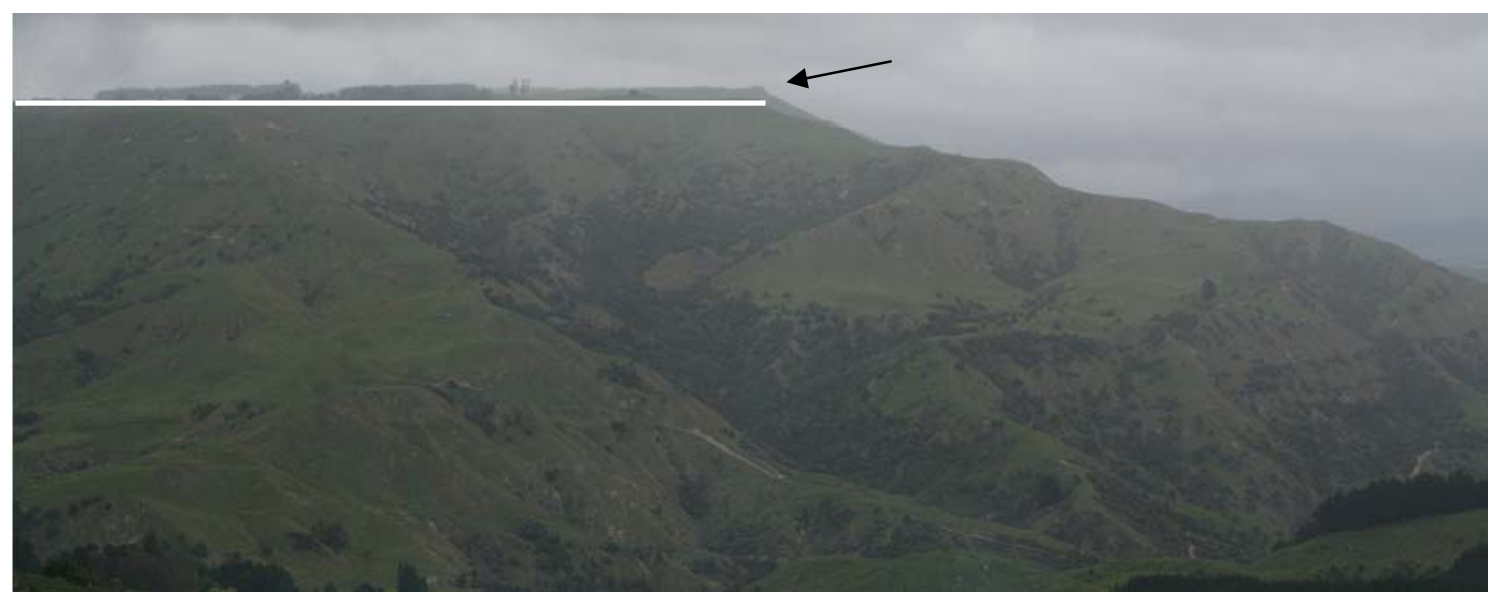

Figure 3.8: looking SWW from the uplifted plateau above and to the east of Lake Waikopiro ( $\sim 400 \mathrm{~m}$ asl). The $5-10^{\circ}$ dip can be seen in consecutive outcropping limestone bluffs (indicated by the black arrow), the first is $\sim 5.5 \mathrm{~km}$ distant at $\sim 520$ $\mathrm{m}$ asl, the second (Darky's Spur) at $\sim 7.3 \mathrm{~km}$ distant at $\sim 630 \mathrm{~m}$ asl. The white line is horizontal and the gentle dip can be seen in the land surface beneath as it drops away to the NE.

Hawke Bay near shore environment.

The area northeast of Lake Tutira is comprised of early Pleistocene mudstone which is easily weathered and much of the mudstone has already been mobilised. However despite this rotational and translational landslides are still common during high rainfall events (Kamp 1992; Trustrum and Page 1992; Eden et al. 1998). The redistribution of mudstone has left behind late Pliocene coquina limestone forming a series of cuestas (asymmetrical ridgelines) where the back slope is approximately equal to the dip slope due to the differential erosion of mudstone and limestone (Kamp 1992; Whittow 1984). To the south, south west and east of Lake Tutira early Pleistocene limestones are found horizontally outcropping as prominent bluffs (Figures 3.8 and 3.9). This is known as the Pentane Limestone Group and is also found at Tangoio Bluff, Napier Hill (remnant) and Maraekakaho, and is thus referred to as the NapierPentane-Tangoio area (Kamp 1992; Lowe 1987). These large promontories are composed of repetitive sedimentary sequences (cyclothems) which grade from fine grain mudstone and sandy silts upwards into coarse-grained formations of sand and gravel or coquina limestone that is characteristic of the Tangoio block of the Pentane Group covering $\sim 450 \mathrm{~km}^{2}$ (Haywick et al. 1992).

Five cyclothems forming a $560 \mathrm{~m}$ thick block have been identified in the Tangoio district (the 'Tangoio block'), relative sea level fluctuations in the order of $75 \mathrm{~m}-150 \mathrm{~m}$ are required to generate cyclothems of this magnitude (Haywick et al. 1992). Haywick et al. (1992) attribute the Tangoio block cyclothems to strong 40,000 year Milankovitch tilt-controlled glacio-eustasy. The fine grained marine mudstone section of each cyclothem was deposited during high stand system tracts (some non-marine in cyclothems 1 and 2, but not considered to be likely source materials for the Oporae Valley) (Haywick et al. 1992). And coarse grained sedimentation is attributed to low stand system tracts. Transgressive system tracts are represented by a $1 \mathrm{~m}-5 \mathrm{~m}$ thick layer of silt at 
the upper contact of each carbonate dominated cyclothem (3, 4 and 5) (Haywick et al. 1992). In the upper cyclothems there is some lateral discontinuity between siliciclastic sedimentation $\left(\mathrm{CaCO}_{3} \leq 50 \%\right)$ and carbonate sedimentation $\left(\mathrm{CaCO}_{3} \geq 50 \%\right)$, most likely controlled by the near shore bathymetry and coastal estuarine environments, however despite these unconformities coquina limestone and carbonate sand dominate the coarse grain formations in cyclothems $3-5$ which are often exposed as bluffs and cuestas due to differential weathering rates (Haywick et al. 1992). Figure 3.9 shows the distinct depositional units associated with cyclothems.

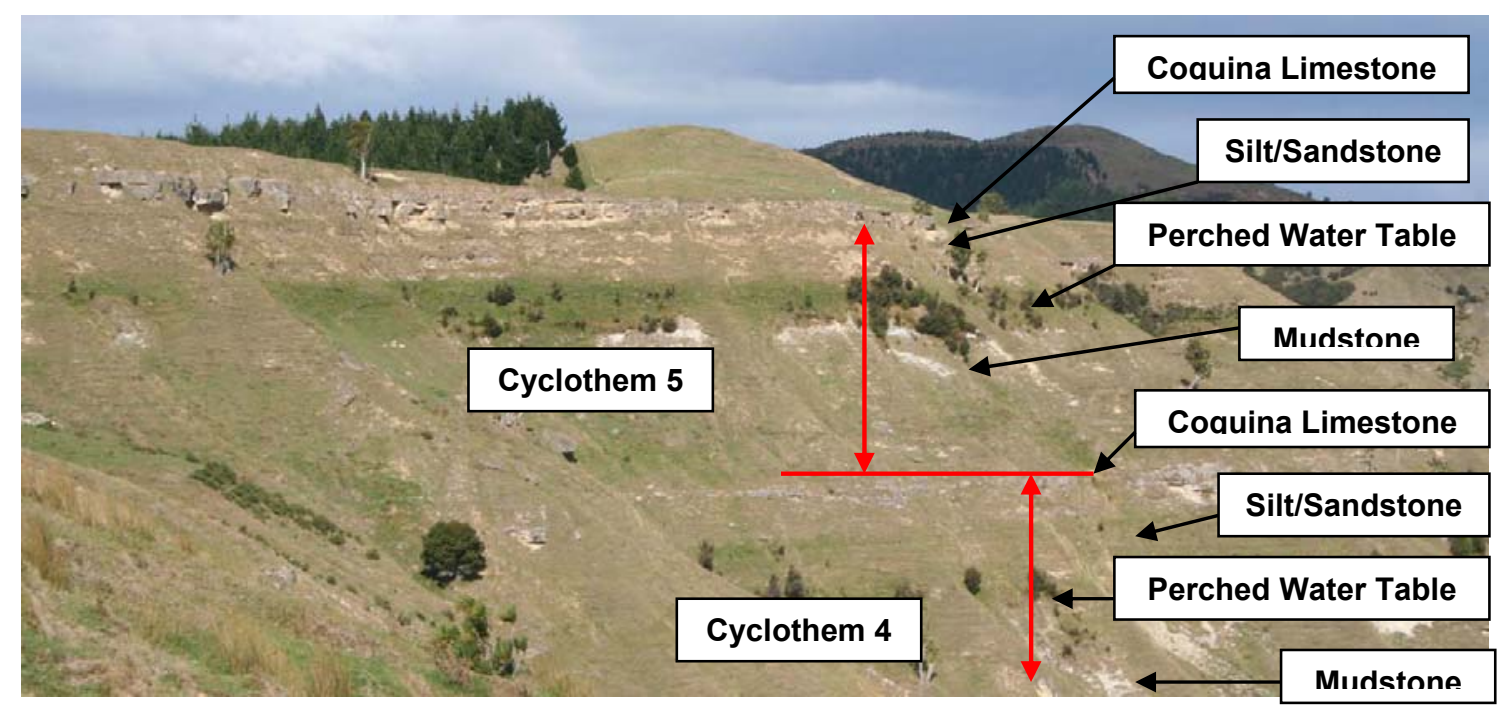

Figure 3.9 is east of Lake Tutira and looking south. It shows the cuesta dominated landscape with its gently dipping coquina limestone of the uplifted plateau grading down into fine grain impermeable mudstones. The increasing density within the units of each cyclothem can clearly be seen in the control over the hydrological flow paths, and the resultant 'bands' of greener vegetation and higher species abundance. The instability in the soils created by the impermeable mudstone creating increased flow during rain storm events can also clearly be seen. Photo: R. Boys (2007).

These sedimentary units are significant for this study as they provide the source material for the colluvial and alluvial deposits found on the Oporae valley floors. Both the in-situ sediments and depositional units associated with erosion processes become the substrate in which soils develop. In particular the amount of carbonate associated with the different source materials and their transport mechanisms may influence the inorganic carbon content isotopic analysis of the Oporae Valley cores. Figure 3.9 shows two fully exposed cyclothems on the scarp face which is the source area for the valley floor adjacent and to the south of the Oporae Valley. The ridgeline continues north (to the left of Figure 3.9) where it becomes part of the source area for the upper Oporae Valley. Due to the Oporae Valley spur ridgeline adjoining the main ridgeline and an overall shallower hill-slope only the uppermost cyclothem is currently fully exposed as source material, whereas the lower cyclothems are mantled in debris from up-slope. Despite this, the constituent lithologies found in the cyclothems form part of the primary source materials for mass movement debris down-slope through both initial mass movements and reworking of sediments deposited on the hill-slope. 


\section{Volcanology}

The North Island TVZ (Unit 4 above) has delivered large quantities of allochthonous material to the Lake Tutira catchment. So significant is the quantity of sediment that the accumulated depth of tephra from the Taupo volcano alone across the Lake Tutira catchment is estimated to be on the order of $1 \mathrm{~m}-2 \mathrm{~m}$ from the last 22,000 years of eruptions (Froggatt 2007). Figure 3.10 shows the accumulated air-fall deposits from the Taupo rhyolitic volcano over the last 22,000 years.

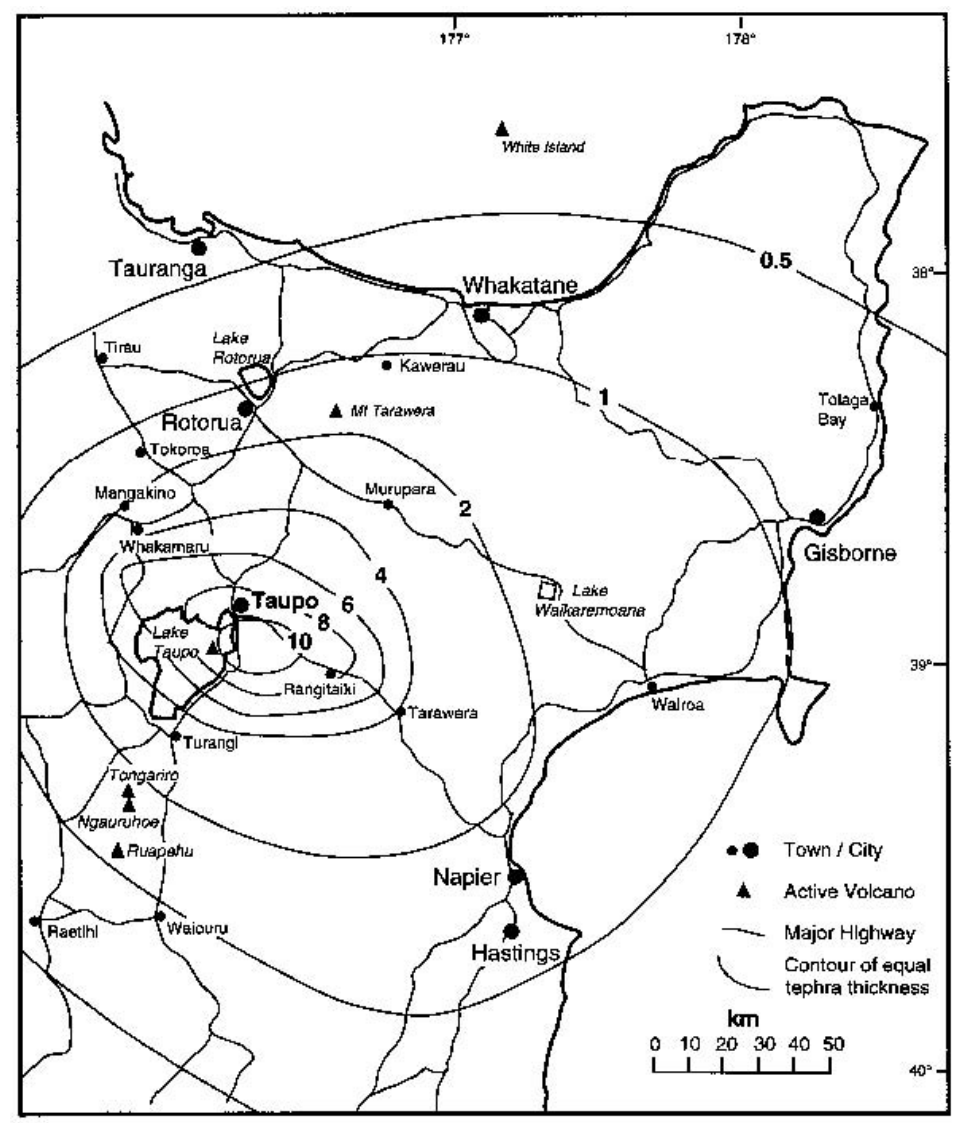

Figure 3.10 shows the contour lines of tephra thickness $(m)$ from the last 22,000 years of eruptions radiating out from Lake Taupo the Taupo Volcano Caldera. These contour lines also highlight the probable distribution of air-fall for the next medium sized event. Source GNS (2007).

Lake Tutira forms the ideal repository for tephra due to its minimal circulation characteristics, and high sediment input, which rapidly buries and preserves the tephra layers. Eden and Froggatt (1996) identified a sequence of 23 tephra layers (16 macroscopic) from a series of lake cores dating back 6,500 $\mathrm{yr}$ BP, taken $\sim 500 \mathrm{~m}$ off the current Oporae Valley shoreline. Within the last 1,000 years 8 tephra layers were identified, all of which, with one exception (Egmont), originated from Tongariro. Layer 8 lies stratigraphically below the pollen spectra changes indicating the arrival of both European ( 110 yr BP) and Polynesian (700 - 900 yr BP) settlers ${ }^{2}$ (McGlone et al. 1994; Anderson 1991; Eden et al. 1996). Layer 2 (uppermost contact identified) has an age of ca. $295 \mathrm{yr}$ BP.

\footnotetext{
${ }^{2}$ There are differing opinions on the arrival time of Polynesian settlers to the Lake Tutira district, the 700-900yr BP time frame encapsulates both estimates put forward by Anderson (1991) and McGlone et al. (1994).
} 
Lapilli, ash and pumiceous silicic glass, black glassy pyroclasts and mafic minerals all appear within the lake cores as either discrete tephra layers, or as reworked catchment sediments (Eden et al. 1996). While volcanic glass is predominantly both rhyolitic and andesitic for the full depth of the cores $(6,500$ $\mathrm{yr} \mathrm{BP})$, the composition for the upper core $(1,000 \mathrm{yr} \mathrm{BP})$ is relatively uniform.

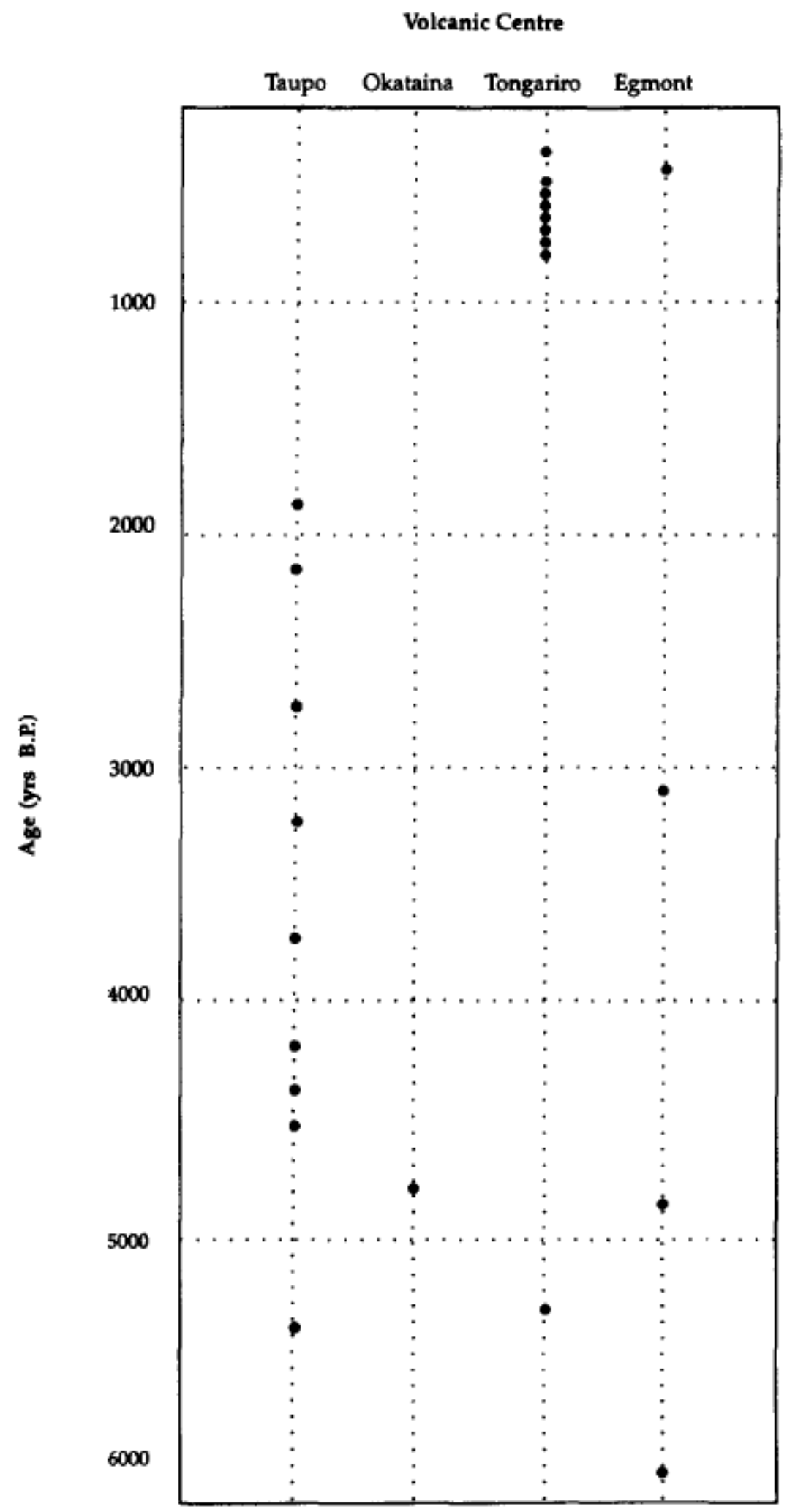

Figure 3.11 shows the strong bias of Tongariro for the last 1000 years of tephric deposition in Lake Tutira. Source: Eden et al. (1996). 
Layers 3 - 9 are all andesitic (Tongariro), and layer 2 is dacitic (Egmont). Figure 3.11 shows the source volcano and chronology of tephra found within the Lake Tutira cores.

Both andesitic and rhyolitic tephra occur ubiquitously within the soils of Lake Tutira and when in situ as with the lake cores they are an excellent chronological marker. However, due to the high degree of disturbance associated the colluvial foot-slope and alluvial toe-slope in the Oporae Valley in situ tephra may be difficult to distinguish from the surrounding sediments.

\subsection{Site Selection and Surveying}

The Oporae Valley was chosen for the following advantageous characteristics: accessibility, photographic records, land-use spectrum, and previous research conducted in the valley. The transects were chosen to cover areas representative of deposition on both colluvial foot-slope and alluvial flood-plain within the main branch of the Oporae Valley. The transect surveys were carried out using a SOKKIA laser range finder linked into the NZTM co-ordinate system.

\section{Transects}

Two transects were selected to represent the dominant depositional environments within the lower section of the Oporae Valley. While Transect 1 (T1) was originally sampled in a position opposite to that of Transect 2 (T2), the inclusion of recent anthropogenic landscapes such as road and track cuts, fencing and unstable terrain, rendered the transect unsuitable for detailed analyses. T1 was taken further up the valley; the source area for the colluvial depositional zone has a north-westerly facing aspect. T1 has predominantly grass (pasture) cover with areas of Willow planted on the toe-slope and source area gully system as an erosion mitigation measure. T2 is lower in the valley and has a south-easterly facing aspect. While T2 is covered in pasture the same as T1, the source area for T2 has regenerating mixed introduced and native forest vegetation. Figure 3.12 shows the $\mathrm{T} 1$ and $\mathrm{T} 2$ transect surveys and the core site locations on each transect. Each transect has four drill sites labelled Site $1-4$ as they occur descending slope. Henceforth transects will be referred to as $\mathrm{T} 1$ or $\mathrm{T} 2$ and Sites as $\mathrm{S} 1, \mathrm{~S} 2, \mathrm{~S} 3$ and $\mathrm{S} 4$, the combination of which will read T1 S1, T1 S2, T1 S3,...T2 S4.

Both transects have been historically used as grazing areas for sheep and cattle livestock. Significantly both transects lie in colluvial runout zones from the 1988 Cyclone Bola event. The continued regeneration of forest cover since this event has significantly reduced the vulnerability of the up-slope source area of $\mathrm{T} 2$ to erosion, resulting in a relatively stable down-slope depositional zone. T1 has some planting in the gullies immediately up-slope, but active erosion processes and fresh scarps are still evident within the source area. 

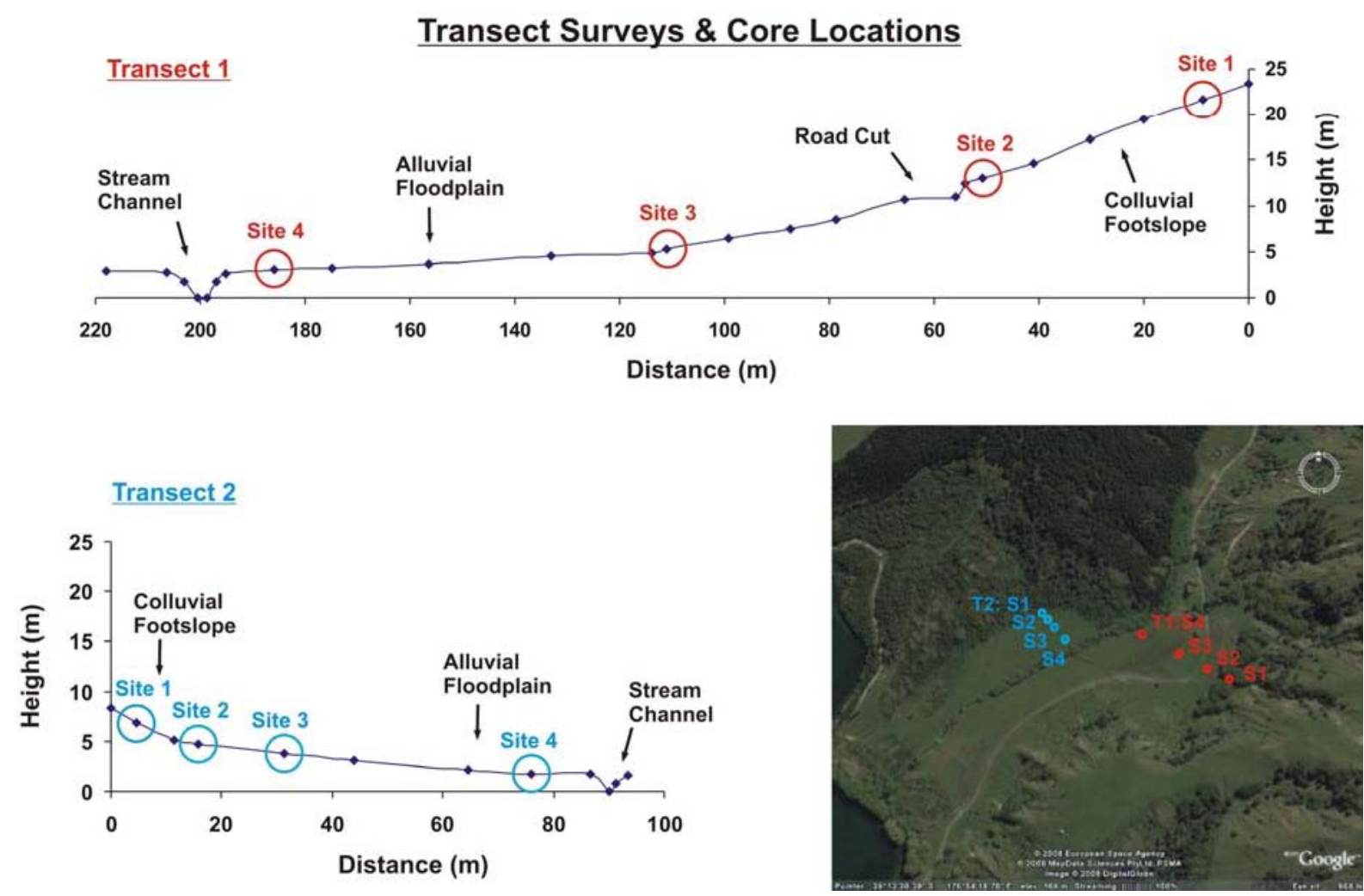

Figure 3.12: $\mathrm{T} 1$ and $\mathrm{T} 2$ both cover the inter-fingering of colluvial and alluvial depositional environments. The stream channel occurring in both transect profiles can be seen in the map locator key as a straight line of vegetation running down the lower valley centre. As shown by the profiles, T1 is longer and higher in elevation than T2, and T1 S3 and T1 S4 lie in the depositional zone of other source areas i.e. the upper valley catchment. 


\section{Chapter 4: Methods}

\subsection{Chapter Overview}

After a brief description of the methodologies associated with the coring equipment, field characterisations and sampling strategy the methodologies for the geochemical and sedimentological laboratory analyses are arranged using the following structure:

1. Factors governing method selection

2. Methods types

3. Advantages and disadvantages

4. Method utilised and brief explanation of principles and procedure

Where applicable reference to the full method employed for each laboratory analysis can be found in the appendices.

\subsection{Coring}

\section{Equipment}

The hydraulic soft sediment drill rig used a percussion hammer to drive either an open barrel or closed barrel with $63 \mathrm{~mm} \varnothing$ plastic sleeve insert, both being 1 $m$ in length. The extraction unit was then used to retrieve each metre before drilling the next. Figure $4.1 \mathrm{a}$ and $\mathrm{b}$ show the components and usage of the hydraulic drill rig assembly.
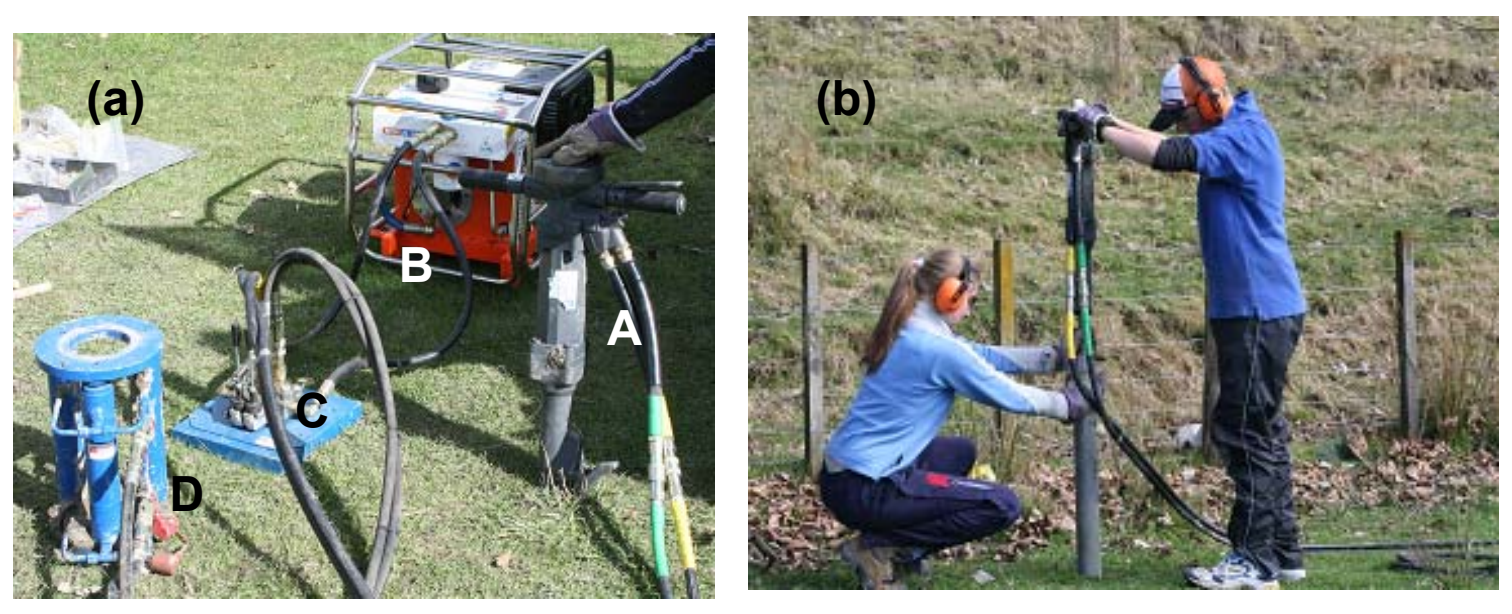

Figure 4.1 (a) shows the Percussion Hammer (A), Hydraulic Pump (B), Switch Unit (C) and Extraction Unit (D). Figure 4.1 (b) shows the closed barrel being used on a colluvial footslope at Lake Tutira.

Moisture content of the soil was found to greatly impact on both the achievable depth and contamination of the core sediments. Cores taken from an adjacent valley during winter months (August 2006) were deeper, but due to high water tables and soil moisture content, the drill hole often suffered some collapse and consequent contamination of the next core with material of the same depth as the previous cores. Cores used in this analysis were taken in April 2007 at the end of summer, and suffered from considerably lower levels of contamination 
due to hole collapse as a result of lower soil moisture content, but were also shallower due to the increased relative 'hardness' of the sediments.

\section{Core Characterisations}

Of the original three transects (four drill sites per transect) only two were utilised for further analysis, as the third was found to consist largely of material displaced during road construction. Basic descriptions of the core characteristics such as texture, colour (Munsell colour chart), horizons, inclusions and stratigraphic units were noted in the field. Half of each core was given to this purpose and for providing source material for isotope and grain size analysis. The other half was sealed in shrink wrap (airtight) and cool stored for further detailed characterisation and pollen analysis.

\section{Core Sampling}

Either a discrete or continuous sampling strategy for the core sediments can be used. Continuous sampling allows for a fuller representation of the sediments; although, the averaging effect could potentially subdue peaks in the isotopic analysis associated with events. As the cores exhibit 'event' type stratigraphy, a discrete sampling method was employed to capture the nature of the events. Sufficient sample material and no more was sampled and prepared for drying the day the core was taken. In most cases $10 \mathrm{~cm}$ intervals separated sampling depths, except where event stratigraphy, pedogenic development or other features indicated either a more or less frequent sample rate should be employed.

\subsection{Geochemical Analyses}

To trace the history of terrestrial carbon and the impacts upon it of anthropogenic land-use change, it is necessary to understand more about the nature of the element than simply where it is and in what abundance. By utilising different types of geochemical analyses a cross-reference can be made to determine the influence of biogeochemical and physical processes on carbon. Target information requirements for the geochemical analyses include, $\mathrm{C}$ and $\mathrm{N}$ content (\%), $\mathrm{C}$ and $\mathrm{N}$ stable isotope ratios (\%), and radiocarbon ages of the down core profiles.

\section{Methods for $\mathbf{C}$ and $\mathbf{N}$ Analysis}

The typical modern technique for $\mathrm{C}$ and $\mathrm{N}$ analyses of mineral soils is whole soil combustion (wet or dry) to produce oxides $\left(\mathrm{CO}_{2}\right.$ and $\left.\mathrm{N}_{2}\right)$, and subsequent quantification through gravimetric, titrimetric, volumetric, spectrophotometric (infrared gas analysis on $\mathrm{CO}_{2}$ only), or gas chromatographic techniques (Nelson and Sommers 1996). The following section focuses on $C$ analysis methods; whereas $\mathrm{N}$ is a useful elemental analysis, it will be discussed in less detail and is supplementary to the primary methodology selection for determining the impacts of land-use change on carbon. 


\section{Carbon}

Carbon quantification within soils can be determined through either wet or dry combustion techniques. The apparatus available and the end-use of the data will normally determine the best approach for determining $C$ content within soils.

For dry combustion methods $\left(>1000^{\circ} \mathrm{C}\right)$, the soil sample and catalyst are converted to evolved $\mathrm{CO}_{2}$ in an induction or resistance furnace. The resultant gases are mobilised in a gas stream (typically $\mathrm{O}_{2}$ or another $\mathrm{CO}_{2}$ free medium) that is then measured by gas chromatography for percent volume and subsequent mass spectrometry for detailed isotopic studies (Nelson and Sommers 1996).

Wet combustion involves boiling the sample in a mixture of potassium dichromate, sulphuric acid and phosphoric acid where evolved $\mathrm{CO}_{2}$ is once again mobilised in a $\mathrm{CO}_{2}$-free gas stream and collected in a tared weighting bulb containing ascarite (Nelson and Sommers 1996). Carbon analysis by rapid dichromate, oxidation-titration techniques can suffer from incomplete recovery of elemental C (charcoal) and organic C (humus) (Nelson and Sommers 1996). There also exists an older technique using a wet combustion manometric quantification procedure (pressure measurement) in the Van Slyke-Neil apparatus (Nelson and Sommers 1996). Table 4.1 summarises the advantages and disadvantages for different methodologies for total carbon (TC) in soils.

Table 4.1. Comparison of total $C$ determination methods in soils, summarised from Nelson and Sommers (1996).

\begin{tabular}{|l|l|l|l|}
\hline \multicolumn{1}{|c|}{ Method } & CO $_{2}$ Determination & \multicolumn{1}{c|}{ Advantages } & \multicolumn{1}{c|}{ Disadvantages } \\
\hline $\begin{array}{l}\text { Dry combustion } \\
\sim 1000^{\circ} \mathrm{C} \\
\text { (resistance } \\
\text { furnace) }\end{array}$ & $\begin{array}{l}\text { Gravimetric, } \\
\text { titrimetric }\end{array}$ & $\begin{array}{l}\text { Reference method } \\
\text { for other disciplines, } \\
\text { variable sample } \\
\text { sizes, and sampling } \\
\text { sizes. }\end{array}$ & $\begin{array}{l}\text { Time consuming, } \\
\text { leak free, slow } \\
\text { release of } \mathrm{CO}_{2} \\
\text { from alkaline earth } \\
\text { carbonates. }\end{array}$ \\
\hline $\begin{array}{l}\text { Dry combustion } \\
>1650^{\circ} \mathrm{C} \\
\text { (induction furnace) }\end{array}$ & $\begin{array}{l}\text { Gravimetric, } \\
\text { titrimetric }\end{array}$ & $\begin{array}{l}\text { Rapid combustion } \\
\text { at high temp } \\
\text { ensures conversion } \\
\text { of all C to CO }\end{array}$ & $\begin{array}{l}\text { Leak free } \mathrm{O}_{2} \\
\text { sweep train, and } \\
\text { induction furnace } \\
\text { is expensive. }\end{array}$ \\
\hline $\begin{array}{l}\text { Dry combustion } \\
\text { (automated } \\
\text { methods) }\end{array}$ & $\begin{array}{l}\text { Thermal } \\
\text { conductivity, } \\
\text { conductimetric, } \\
\text { infrared detector, } \\
\text { gravimetric }\end{array}$ & $\begin{array}{l}\text { Rapid and simple, } \\
\text { good accuracy and } \\
\text { precision. }\end{array}$ & $\begin{array}{l}\text { Expensive, slow } \\
\text { release of CO } \\
\text { from alkaline earth } \\
\text { carbonates with a } \\
\text { resistance furnace. }\end{array}$ \\
\hline $\begin{array}{l}\text { Wet combustion } \\
\text { (combustion train) }\end{array}$ & $\begin{array}{l}\text { Titrimetric, } \\
\text { gravimetric }\end{array}$ & $\begin{array}{l}\text { Equipment usually } \\
\text { readily available, } \\
\text { adaptable, } \\
\text { titrimetric analysis } \\
\text { less subject to } \\
\text { error. }\end{array}$ & $\begin{array}{l}\text { Time consuming, } \\
\text { gravimetric } \\
\text { requires analytical } \\
\text { techniques, } \\
\text { titrimetric is less } \\
\text { precise. }\end{array}$ \\
\hline
\end{tabular}

As shown in Table 4.1, dry combustion techniques generally have a higher degree of accuracy and precision over that of wet combustion, but also require 
specialist and expensive equipment. The advantages and availability of equipment dictated a dry combustion (resistance furnace) method. A Europa Geo 20-20 isotope ratio mass spectrometer, interfaced to an ANCA-SL elemental analyser in continuous flow mode (EA-IRMS) was utilised to run the $\mathrm{C}$ and $\mathrm{N}$ analysis.

While TC is a useful measurement, it is often necessary to separate organic carbon (OC) from inorganic carbon (IC) when running analysis on terrestrial samples. In this instance the soil organic carbon (SOC) is the component of most interest. For SOC analysis the sample either:

a) has the IC content removed prior to combustion, or

b) the IC component is analysed separately, and then subtracted from the results after the combustion process has taken place (Robertson and Eldor 2000).

The differentiation of the $\mathrm{IC}$ and $\mathrm{OC}$ components from the TC measurement is particularly important when taking into account the climate conditions under which the soil formed. In arid or semi-arid regions carbonate minerals such as calcite, dolomite, and soluble carbonate salts dominate soils delivering very low SOC yields. Low SOC content is also often seen in soils that have been limed for agricultural purposes, and in young soils formed on carbonate parent materials. In humid regions leaching and dissolution of carbonate during soil formation can remove IC altogether leaving $\mathrm{OC}$ to form the significant proportion of $\mathrm{C}$ within the soil (Nelson and Sommers 1996; Robertson and Eldor 2000). Table 4.2 summarises the methodologies for OC determination in soils.

Table 4.2. Comparison of OC determination methods in soils Summarised from: Nelson and Sommers (1996).

\begin{tabular}{|c|c|c|}
\hline Method & Advantages & Disadvantages \\
\hline $\mathrm{OC}=\mathrm{TC}-\mathrm{IC}$ & $\begin{array}{c}\text { Useful for routine } \\
\text { determination of } \mathrm{TC} \text { and IC }\end{array}$ & $\begin{array}{l}\text { Requires two separate } \\
\text { analyses, thus some } \\
\text { inherent error. TC } \\
\text { requires special } \\
\text { equipment. }\end{array}$ \\
\hline $\begin{array}{c}\text { TC is determined after IC } \\
\text { is removed by acid pre- } \\
\text { treatment }\end{array}$ & $\begin{array}{l}\text { Accurate if dolomite is } \\
\text { absent }\end{array}$ & $\begin{array}{l}\text { Not all dolomite may be } \\
\text { removed by acid pre } \\
\text { treatment, specialised } \\
\text { equipment needed }\end{array}$ \\
\hline Dichromate oxidation & $\begin{array}{c}\text { Rapid and simple, no } \\
\text { special equipment needed }\end{array}$ & $\begin{array}{l}\text { Not all OC in samples is } \\
\text { oxidised when external } \\
\text { heat is omitted, therefore } \\
\text { a correction factor is } \\
\text { required and error is } \\
\text { introduced }\end{array}$ \\
\hline $\begin{array}{c}\text { Dichromate oxidation with } \\
\text { external heat }\end{array}$ & $\begin{array}{l}\text { Rapid and simple, with } \\
\text { complete oxidation of OC }\end{array}$ & $\begin{array}{l}\text { Chloride, } \mathrm{Fe}^{2+} \text {, and } \mathrm{MnO}_{2} \\
\text { interfere with the method; } \\
\text { some specialised } \\
\text { equipment required, } \\
\text { variable recovery of } \mathrm{C} \text { in } \\
\text { carbonised materials }\end{array}$ \\
\hline
\end{tabular}


As shown in Table 4.2 acid pre-treatment for the removal of IC allows for the direct measurement of $\mathrm{OC}$. Due to the total sample combustion technique employed (EA-IRMS), the quantification of IC and OC from TC can only be determined with two sets of analyses. Based on the high precision of dry combustion gravimetric techniques, and the assumption that IC content of the samples would be low, measurements of TC and OC using EA-IRMS were made with the difference calculated as IC content removed by acid pretreatment. This method is subject to error, based on separate sub-sample analyses being used to calculate the difference, but duplicates were made within each run to establish error. The primary reasons for a dry combustion gravimetric technique were; the availability of equipment, the high degree of precision and accuracy, and the assumption that IC content of the samples would be low, minimising the amount of error from running separate analyses for the different components of $\mathrm{C}$ within the sample.

\section{Nitrogen}

The target elemental analysis for this study is carbon, but due to the sophistication of modern isotopic elemental analysers, the elemental components can be separated using gas chromatography into two temporally separate gas streams from one unit of sample combustion. This allows for the measurement of carbon and nitrogen sequentially in the same gas stream i.e. from one run. The nitrogen component of the geochemical analyses supplements the $\mathrm{C}$ data by providing extra information on the duration of aerobic respiration $\mathrm{OM}$ has undergone. Stable isotopes provide the only practical way to study the dynamics of $\mathrm{N}$, as the radioactive isotope of ${ }^{13} \mathrm{~N}$ has a half life of only ten minutes (Andreux et al. 1990). An alternative method is emission spectroscopy, but this method suffers from precision and reproducibility error when compared to mass spectrometry (Andreux et al. 1990)

\section{Carbon and Nitrogen Stable Isotopes}

Tracing the impacts of land-use change is possible by analysing the stable isotope composition of the soil in question. Isotopic analysis offers a powerful tool for determining biogeochemical cycles; however the terrestrial system must be approached cautiously from the interpretation standpoint. A large array of variables exist that can impact upon the isotopic value of any given element, often requiring the application of more than one technique to support the isotopic interpretation. This type of analysis provides quantifiable $C$ turnover rates when the input $\mathrm{C}$ and $\mathrm{N}$ delta value signatures change suddenly. $\mathrm{A}$ common example is that of the change from C3 to C4 photosynthetic pathway plants following land-use change and the introduction of new crop species by humans. The plants input OM into the soil which in turn registers the different isotope ratio held within the plants cells. This signature change can be used to trace the movement of carbon through different pools and thus quantify the $C$ turnover rate.

Studies in soils have shown that the small quantifiable variations in $\mathrm{C}$ and $\mathrm{N}$ isotopes make spectrometry one of the most accurate and precise methods available (Andreux et al. 1990). However, due to the specialist nature of this 
method it is necessary to give an explanation of the definitions, terminology, notation and the key factors that can impact upon the interpretation of the results. This information is given in Appendix I. For those familiar with the method a summary of the delta values for $\delta^{13} \mathrm{C}$ and $\delta^{15} \mathrm{~N}$ that are relevant to this study are summarised in Table 4.3. Also summarised in Table 4.3 are the range of typical values for the $\mathrm{C}: \mathrm{N}$ ratio, $\% \mathrm{C}$ and $\% \mathrm{~N}$ for the relevant variables.

\section{Procedure}

The carbon and nitrogen isotopes and total organic carbon (\%TOC) and total nitrogen (\%TN) content were measured using a Europa Geo 20-20 isotope ratio mass spectrometer, interfaced to an ANCA-SL elemental analyser in continuous flow mode (EA-IRMS). To measure the $\mathrm{C}$ and $\mathrm{N}$ using EA-IRMS, careful sampling, preparation and pre-treatment of the sample is required as only small amounts of material are processed for the analysis (further detailed explanation of the sample preparation procedure see Appendix II). After demineralisation between 20-100 mg of powdered sediment was weighed in duplicate into tin capsules for automated combustion. The carbon dioxide and nitrogen gases were resolved using gas chromatographic separation on a column at $60{ }^{\circ} \mathrm{C}$, and analysed simultaneously for isotopic abundance as well as total organic carbon and total nitrogen. The analytical precision of the EA-IRMS analyser is high. It is established by running duplicate samples, blanks and standards for internal calibration. The international standards were VPDB (for $\mathrm{C}$ ) and Air $\mathrm{N}_{2}$ (for $\mathrm{N}$ ). The errors for the EA-IRMS analyses are; $N$ and $\mathrm{C} \pm 5 \%$ e.g. a TOC value of $4 \%$ has an error of $\pm 0.2 \%, \delta^{13} \mathrm{C} \pm 0.1 \%$, and $\delta^{15} \mathrm{~N} \pm 0.3 \%$ (pers. comm. Rogers 2007).

\section{$4.3{ }^{14} \mathrm{C}$ Analysis}

For the dating of the buried wood fragments found within the Oporae Valley cores only ${ }^{14} \mathrm{C}$ was available within the budget and time frame. Furthermore, other ${ }^{14} \mathrm{C}$ analyses have also been carried out in the Oporae Valley. Using the same method for comparative purposes reduces the risk of error between two different methods and makes correlation of ages easier to achieve.

\section{Principles of ${ }^{14} \mathrm{C}$}

${ }^{14} \mathrm{C}$ is formed and naturally occurs in the atmosphere; through photosynthesis plants obtain ${ }^{14} \mathrm{C}$ which will remain in equilibrium with the atmospheric ${ }^{14} \mathrm{C}$ content. Once the organism dies the renewal of ${ }^{14} \mathrm{C}$ through photosynthesis stops and the decay of the ${ }^{14} \mathrm{C}$ to the stable isotopes of ${ }^{12} \mathrm{C}$ and ${ }^{13} \mathrm{C}$ begins. ${ }^{14} \mathrm{C}$ has a half life of 5730 years, after which one half of the original atmospheric ${ }^{14} \mathrm{C}$ will remain (Stevenson and Cole 1999). Using mass spectrometry the proportion of the original ${ }^{14} \mathrm{C}$ left can be measured and used to calculate a radiocarbon age for the sample in years before present (yr BP) to within an established error for that sample.

\section{Procedure}

Three large pieces of wood within the cores were identified as being suitable for ${ }^{14} \mathrm{C}$ age analysis. Pre-treatment was carried out at Geological and Nuclear 
Table 4.3. Summary of Literature on $\mathrm{C}$ and $\mathrm{N}$ environmental variation.

\begin{tabular}{|c|c|c|c|c|c|c|}
\hline & $\delta^{13} \mathrm{C}(\%)$ & OC\% & $\delta^{15} \mathrm{~N}(\%)$ & N\% & C:N (at.) & Source: \\
\hline SOM C3 & $\begin{array}{c}-27^{*},-26^{\dagger} \\
(-32 \text { to }-22)\end{array}$ & $48-58^{\Delta}$ & +2 to $+5^{*}$ & & $\begin{array}{c}8 \text { to } 15^{*} \\
(5 \text { to }>80)\end{array}$ & \\
\hline SOM C4 & $\begin{array}{l}-13^{*},-12^{\dagger} \\
(-17 \text { to }-9)\end{array}$ & $48-58^{\Delta}$ & +2 to $+5^{*}$ & & $\begin{array}{c}8 \text { to } 15^{*} \\
(5 \text { to }>80)\end{array}$ & \\
\hline $\begin{array}{l}\text { Terrestrial plants } \\
\text { C3 }\end{array}$ & $\begin{array}{l}-27^{*} \text { to }-26 \\
(-32 \text { to }-22)^{*} \\
(-40 \text { to }-22)^{\dagger}\end{array}$ & & $\begin{array}{c}+3 \text { to }+7^{*} \\
(-10 \text { to }+10)\end{array}$ & & $\begin{array}{c}>15^{*} \\
(15 \text { to }>50)\end{array}$ & \\
\hline $\begin{array}{l}\text { Terrestrial plants } \\
\text { C4 }\end{array}$ & $\begin{array}{l}-14 \text { to }-13^{*} \\
(-17 \text { to }-9)^{*} \\
(-20 \text { to }-9)^{\dagger}\end{array}$ & & $\begin{array}{c}+3 \text { to }+7^{*} \\
(-10 \text { to }+10)\end{array}$ & & $\begin{array}{c}>15^{\star} \\
(15 \text { to }>50)\end{array}$ & \\
\hline $\begin{array}{l}\text { Increasing Depth } \\
\text { of Soil (temperate } \\
\text { semi arid) }\end{array}$ & $\begin{array}{l}\text { Enrichment } \\
1-4 \% \text {, up to } 6 \% \text {, }\end{array}$ & & & & $\begin{array}{l}8-15 \text { from } 0-15 \mathrm{~cm} \text {, } \\
\text { median } 10-12 .\end{array}$ & Krull et al. (2003) \\
\hline $\begin{array}{l}\text { Increasing age of } \\
\text { Soil (biogenic } \\
\text { decomposition) }\end{array}$ & $\begin{array}{l}\text { Values increase } \\
\text { (relatively small } \\
\text { shift for C) }\end{array}$ & $\begin{array}{l}\text { Decrease in \%C } \\
\text { non-proportional to } \\
\% \mathrm{~N} \text { (slower) }\end{array}$ & $\begin{array}{l}\text { Values increase (- } \\
9 \text { to }+8 \text { increase } \\
\text { to }+10 \text { or more } \\
\text { rapidly) }{ }^{\dagger}\end{array}$ & $\begin{array}{l}\text { Decrease in } \% \mathrm{~N} \\
\text { non-proportional to } \\
\% \mathrm{C} \text { (faster) }\end{array}$ & $\begin{array}{l}\text { Decrease in C:N } \\
\text { ratio }\end{array}$ & $\begin{array}{l}\text { Kendall et al. } \\
(2001)\end{array}$ \\
\hline $\begin{array}{l}\text { SOM } \\
\text { decomposition }\end{array}$ & $\begin{array}{l}\delta^{13} \mathrm{C} \text { enriched } \\
\text { cellulose } \\
\text { degradation } \\
\text { causes a } 1-4 \% \text { o } \\
\text { decrease }\end{array}$ & & & & & \\
\hline $\begin{array}{l}\text { Climate and } \\
\text { Atmosphere }\end{array}$ & -7 to -8 & & & $0.366^{\dagger}$ & $\begin{array}{l}\text { Higher humidity or } \\
\text { colder areas have } \\
\text { higher C: } \mathrm{N} \text { ratios }\end{array}$ & $\begin{array}{l}\text { Kendall et al. } \\
\text { (2001) }\end{array}$ \\
\hline Weathered Rock & $-26.0 \pm 1.2$ & $\%$ C $0.4 \pm 0.2$ & $3.4 \pm 1.0$ & $0.04 \pm 0.01$ & $9.6 \pm 4.8$ & Gomez et al. 2004 \\
\hline
\end{tabular}

* Kendall et al. (2001)

${ }^{\dagger}$ Andreux et al. (1990)

${ }^{\Delta}$ Nelson and Sommers (1996)

Average values and normal range (Parentheses) 
Sciences National Isotope Centre, Wellington. Initially the sample was examined under a microscope, and all detritus and foreign matter were removed with a scalpel, the sample was then sliced and dried at $40^{\circ} \mathrm{C}$ in a vacuum oven. Once dry, the samples were ground using a ball mill and weighed. The samples were all well preserved, containing distinct and recognisable light coloured wood grain at the centre; this portion was targeted for the analysis.

Due to the volume (Figure 4.2) and high degree of sample preservation, the most aggressive chemical pre-treatment option was employed. A cellulose extraction was undertaken in accordance with standard laboratory practices at the Rafter Radiocarbon Laboratory within the National Isotope Centre, Wellington.

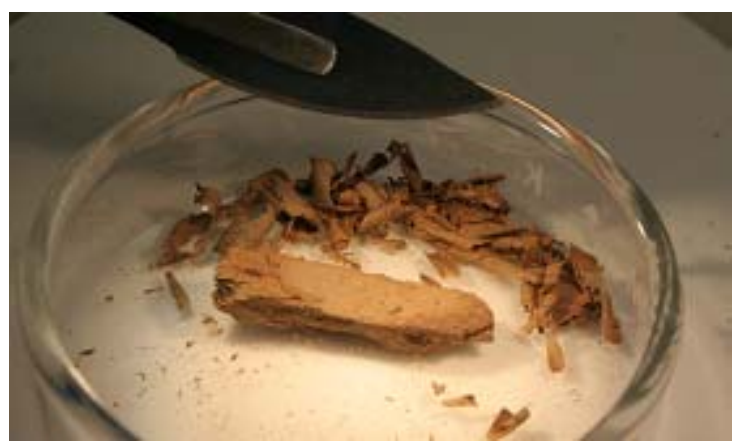

Figure 4.2 shows the well preserved wood fragment and shavings taken from $\sim 2$ $m$ depth T1 S4 before grinding and cellulose extraction.

The pre-treatment procedure is essential for ensuring that the target component of the sample is that which is run during final combustion. Contamination can arise in a sample post organism death. If contaminated samples are combusted, then the ${ }^{14} \mathrm{C}$ age can be relatively precise, but highly inaccurate e.g. Eden et al. (1993) found that radio carbon ages from organic rich clays in Lake Tutira sediments when calibrated against well known tephra chronologies were $\sim 500$ years too old in one instance and 600-800 years too old in another. They inferred that this was likely due to the incorporation of old reworked carbon and/or 'dead carbon' from eroding Tertiary limestone present within the catchment. The effect of dead carbon where calcareous lithologies exist is well known (Eden et al. 1993). Therefore the use of clean and uncontaminated wood samples over that of soils was the preferred option for the ${ }^{14} \mathrm{C}$ analyses in this study.

\subsection{Grain Size Analysis}

Supplementary to field textural characterisation, detailed grain size analysis was carried out over discrete areas of interest from the cores. This was dictated by the presence of what was shown through the isotopic analyses to be buried organic rich layers. Grain size analysis has been used to aid the interpretation of sedimentation processes responsible for burying the organic layers (Sperazza et al. 2004). The primary factors governing the methods utilised for 
grain size analysis were the equipment available and the range over which the grain size distribution fell as indicated by the field textural characterisations.

\section{Methods}

The available methods for grain size analysis included: dry mechanical sieving, wet sieving, settling tube or pipette method (Stokes Law), and the more recently developed laser diffractometry method (Mie Theory). Other grain size analysis methods for which the necessary equipment was unavailable include: X-ray attenuation (sedigraph), electro resistance particle counting (Coulter Counter), SEM (Scanning Electron Microscope), photometrical techniques (hydrophotometer) and other image analyses (IA) techniques (Beuselinck et al. 1998).

\section{Sieving - Advantages and Disadvantages}

Mechanical sieving is best suited for $0.063-16 \mathrm{~mm}$ particles, i.e. very fine sand to medium gravel (Barrett et al. 2000). For sediments with a field textural classification of predominantly fine sands down to clay size particles, mechanical sieving does not offer the appropriate range of measurement. It does however offer a suitable form of analysis for the fraction of sample $>63 \mu \mathrm{m}$ if the fractions are separated via wet sieving first. While splitting fractions of the same sample for analysis via two different methods is not normally recommended (Konert and Vandenberghe 1997), it was undertaken here due to the lack of an accurate alternative for analysing the fine grain fraction in accordance with procedure in Barrett et al. (2000).

There are a number of considerations to take into account when sieving. For example, factors that affect the probability that a particle will present itself to the aperture within any given sieve are:

1. Surface properties (shape and dimension) of the particle mean that it is seldom spherical; therefore, the length of the b-axis, or intermediate axis, becomes the defining characteristic for particle selection during the sieve process

2. The load on the sieve (number of particles), relative to available surface area of the sieve, thus impacting on the time necessary to expose all grains to an aperture within any given sieve

3. How the particle is presented to the sieve (orientation), i.e. without mechanical vibration or agitation with a spatula during wet sieving, particles may not align with their b-axis perpendicular to the sieve aperture

4. The particle size distribution exceeds the limit of what can be accurately measured during mechanical sieving

5. The method of shaking the sieve

6. When wet sieving the particle may be bendy or softened in a solution and therefore pass where dry particles would not

7. Adhesion of particles fine particles (typically clays) to larger particles through electrostatic or chemical bonding (flocculation), requiring some deflocculating procedures

8. Wear on the sieves increasing the aperture size and skewing the data 
9. Variation in the sieve aperture

10. Human Error in observation, experiment and sampling

11. Effect of different equipment

(Goudie et al. 1998; Allen 1975)

Historically sieving is one of the most widely used and cheapest methods for grain size analysis (Allen 1975; Barrett et al. 2000), and provided due consideration for the possible variables affecting the analysis is given, a combination of dry and wet sieving will provide the coarse fraction data and fine fraction sample that can be used for textural classification, and subsequent fine fraction analyses via other methods e.g. pipette method or laser diffractometry.

\section{Wet Sieving Procedure}

In preparation for separation of the coarse and fine fractions via wet sieving for separate analyses the organic content was first removed using hydrogen peroxide $\left(\mathrm{H}_{2} \mathrm{O}_{2}\right)$ in accordance with Barrett et al. (2000), and re-weighed to obtain a mass value for the organic component. Afterward the samples were ultrasonically disaggregated in $250 \mathrm{ml}$ of $\mathrm{dH}_{2} \mathrm{O}$ using a VirSonic digital 600 microprobe for 5 mins on level 7. Excessive sonication has been shown to reflocculate clay particles and/or fracture grains (Sperazza et al. 2004), although these authors have shown there is a possible range of sonication time-strength ratios that will achieve optimal dispersal. Immediately following the ultrasonic disaggregation the samples were wet sieved with $\mathrm{dH}_{2} \mathrm{O}$ through a $63 \mu \mathrm{m}$ sieve. The sand fraction was then dried in the oven at $105^{\circ} \mathrm{C}$ to remove all moisture; as little as $1 \%$ of surface moisture will impact on adhesion forces for grains below $1 \mathrm{~mm}$ (Müller 1967). The fine fraction was kept in $\mathrm{dH}_{2} \mathrm{O}$ as a slurry for laser diffractometry. Deflocculant was omitted from the wet sieving procedure in favour of ultrasonic disaggregation alone, the low sodium content of the samples and prior removal of carbonate and organic content meant that flocculation was expected to be minimal. However, this may have resulted in incomplete segregation of some of the fines during the wet sieving procedure (Ingram 1971). Nevertheless, this faction will have been subsequently picked up during the dry sieving procedure and accounted for in the sum result.

\section{Mechanical Sieving Procedure}

Mechanical sieving of the sand fraction was carried out on a Fritsch Laborgerätebau 6580 sieve agitator for $18 \mathrm{~min}$ at amplitude $6-6 \mathrm{~min}$ on interval, $6 \mathrm{~min}$ on microsieving, $6 \mathrm{~min}$ on interval, in accordance with Barrett et al. (2000). Capturing each phi fraction in the appropriate sieve allows for the calculation of the grain size distribution, and subsequent graphical representation on a grain size tri plot. Here the mean loss of coarse silt or finer $(<4 \Phi, \geq 4.5 \Phi)$ from the silt/clay fine fraction was re-captured and included in the final distribution calculation. The mean coarse silt fraction weight was $4.1 \%$ of the original sample.

\section{Pipette and Settling Tube Methods}

The pipette or settling tube methods, based on Stokes Law, can suffer from precision error in the order of $\sim 25-40 \%$ affecting reproducibility, and is limited 
to a certain number of grain size classes (Sperazza et al. 2002). Despite the relative cheapness of these methods, they are also very time consuming and therefore limiting on data set size. Laser diffractometry has become more affordable, is faster, more precise and provides greater resolution of analysis than sieving and other sedimentation techniques based on Stokes Law (Sperazza et al. 2002).

\section{Laser Diffractometry}

Laser diffractometry has rapidly advanced as a replicable and precise $( \pm 1 \%)$ high resolution alternative for measuring grain size distributions of synthetic compositionally homogeneous materials over a wide range of class sizes $(0.002$ - $2 \mathrm{~mm}$ ) (Malvern Instruments Ltd. 2007; Sperazza et al. 2002). However the potential for loss of accuracy (not precision) with laser diffractometry is high due to the assumption of correct user defined variables (index of refraction and absorption). Because the grain size calculation is based on a formula (Mie Theory), errors of this nature can be reduced through calibration and recalculation of the original data without re-running the sample.

\section{Principles of Operation}

Laser diffractometry is a grain size analysis technique that is based on the forward scattering of monochromatic coherent light (Konert et al. 1997). Put more simply, as a particle passes through a laser beam, the angle and intensity at which the light scatters is directly related to the particle size. As the particle size decreases (cross sectional area), the intensity of diffraction decreases, and the angle at which the light scatters increases logarithmically (Malvern Instruments Ltd. 2007). The principal components of a laser diffractometer (Figure 4.3) consist of: a laser focused at fixed wavelength of $0.632 \mu \mathrm{m}$, a range of detectors/collectors positioned in clusters to pick up the logarithmically increasing scatter angle, (ranging from $0.01^{\circ}-130^{\circ}$ ), and the sample presentation system (Sperazza et al. 2004; Malvern Instruments Ltd. 2007).

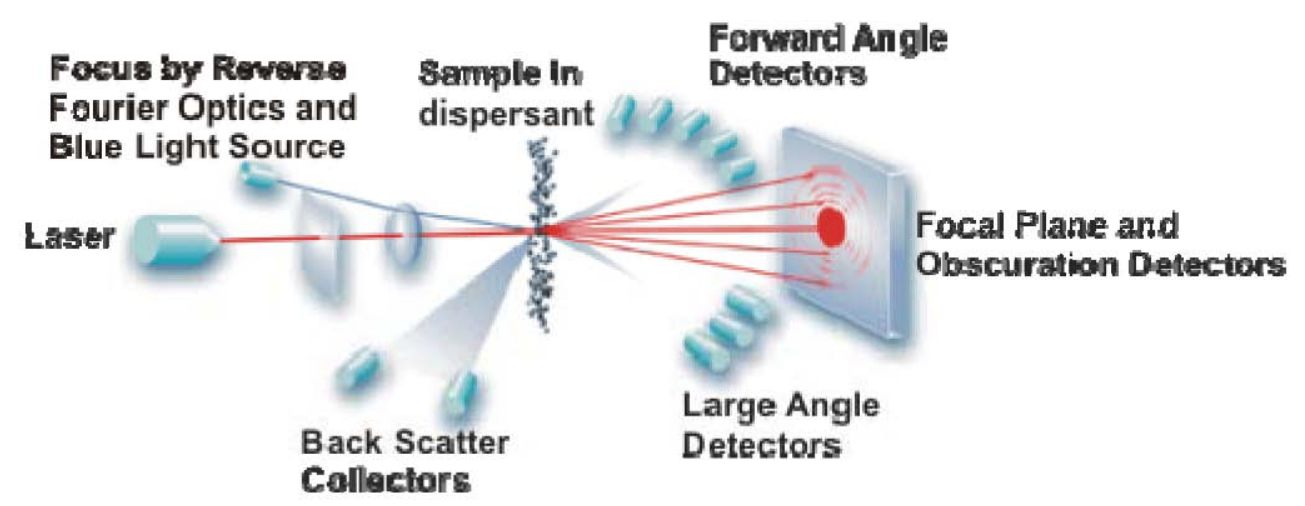

Figure 4.3 shows the schematic displaying principle of operation for laser diffractometry: the detectors are grouped according to the logarithmic scattering angle associated with decreasing particle size, small angles (large particles) have large clusters of closely spaced detectors, whereas large angles (small particles) have fewer detectors spaced further apart. With this kind of array the range of particle size analyses encompasses five orders of magnitude. Source: Malvern Instruments Ltd. (2007), adapted from: www.malvern.co.uk and Sperazza et al. (2004). 
The sample in dispersant is constantly mixed and pumped through the diffractometer at constant velocity. For a 20 second run the detector array will take a measurement of the particle scattering pattern every $1 \mathrm{~ms}$, equalling a total of 20,000 measurements (or 'snaps'). A 20 second run actually takes 40 seconds as there is a 20 second exposure to red light (helium neon laser captures forward scattering, side scattering and back scattering), and 20 second blue light exposure (solid state light source captures wide angle forward and back scattering). Using two different light spectrums enables the Malvern to capture and analyse a wider range of particle characteristics.

The particle size is calculated from the laser diffraction measurement using Mie Theory; this theory predicts both the surface scattering and secondary scattering from within the internal surfaces of the particle (Malvern Instruments Ltd. 2007). When particle size calculations are based on both the external and internal surface refraction angles, the transparency of the particle becomes a critical measure in determining the outcome of that calculation (especially for particles $<50 \mu \mathrm{m})$. Furthermore the scattering intensity is calculated by the difference between the refractive index of the dispersion medium and the sample (Malvern Instruments Ltd. 2007). This necessitates that the equipment be calibrated to the dispersion medium prior to the addition of sample slurry for every run. Combining these two variables allows for the calculation of particle grain size using Mie Theory.

Mie Theory operates with four assumptions:

1. The particle is spherical in shape

2. The dispersion medium is sufficiently dilute (ideal obscuration 5-10\%), such that light scattered from one particle is not interfered with by the passing of another particle before it can be measured

3. The optical properties of the particles and the dispersion medium are known (so that these operator defined characteristics may be input correctly).

4. The sample is representative of the original source material

5. The orientation of the particles is random (particles may undergo some alignment in a piped, pump driven continuous flow situation)

The first assumption of particle sphericity places the analysis of 'plate like' clay particles in question. The problem of particle size and shape has been addressed widely in the literature through comparative technique analyses. Both the instrument manufacturer (Malvern Instruments Ltd 2007) and independent peer reviewed research Blott and Pye 2006; Konert and Vandenberghe 1997) have shown that for spherical, non-porous, larger sand particles $(>63 \mu \mathrm{m})$, laser diffractometry has a high degree of correlation to sieving and pipette techniques. For sand particles with non-spherical shape when compared with spherical glass beads of the same sieve fraction, the sand appears coarser than the glass spheres by a mean of $\sim 15 \%$. Despite this variation, the mean diameters of the glass spheres stay within the boundaries of the sieve fractions, i.e. $+0.125 \Phi$ (Konert and Vandenberghe 1997; Blott and 
Pye 2006). Blott and Pye (2006) have also shown that laser diffractometer instrument sensitivity to coarse particles in a fine matrix was high $(1-2 \%$ detection threshold), but poor for fine particles in a coarse matrix $(12-17 \%$ detection threshold). For coarse grain skewed or bimodal distributions the presence of 'hidden' fine grain particles needs to be calibrated for. This in part can be used as justification for separation of the sand fraction from the silt/clay where sand forms a significant component of the sample. For the silt/clay fraction $(\leq 63 \mu \mathrm{m})$ Konert and Vandenberghe (1997) have shown that the pipette clay fraction of $<2 \mu \mathrm{m}$ corresponds to the laser analysis at $8 \mu \mathrm{m}$ (very fine silt), and the pipette fine silt fraction at $<16 \mu \mathrm{m}$ corresponds to the $<22 \mu \mathrm{m}$ medium silt fraction, which is a shift of $2 \Phi$ and $0.5 \Phi$ respectively. Calibration of laser diffractometry data from sedimentological samples of differing grain size distributions but of the same or similar lithology have been carried out (Konert et al. 1997; Sperazza et al. 2004; Beuselinck et al. 1998; Blott and Pye 2006), where lithology or other user defined parameters differ significantly between samples, this would necessitate calibration of every sample.

Grainmount examination of the marine derived sedimentary soil substrate within the Lake Tutira region has been undertaken by D. A. Lowe (1987). Lowe carried out 300 point counts of the $3-3.5 \Phi$ fraction across four replicates for each unit analysed.

Table 4.4. Lake Tutira soil mineral composition.

\begin{tabular}{|c|c|c|c|c|c|}
\hline Origin & $\begin{array}{c}\text { Grain size } \\
\text { classification } \\
\text { (Folk et al. } \\
1970)\end{array}$ & Quartz (\%) & $\begin{array}{c}\text { Feldspar } \\
(\%)\end{array}$ & $\begin{array}{c}\text { K-Feldspar } \\
(\%)\end{array}$ & Others \\
\hline $\begin{array}{c}\text { Darky's } \\
\text { Spur } \\
\text { Sandstone }\end{array}$ & $\begin{array}{c}\text { Silty } \\
\text { sandstone, } \\
\text { with Pumice } \\
\text { laminae }\end{array}$ & 39 & $\begin{array}{c}15.5(6 \% \\
\text { Plagioclase) }\end{array}$ & 6 & $\begin{array}{c}\text { Glass } \\
\text { shards } \\
(41 \%)\end{array}$ \\
\hline $\begin{array}{c}\text { Esk } \\
\text { Mudstone }\end{array}$ & $\begin{array}{c}\text { Clay siltstone, } \\
\text { silty } \\
\text { sandstone, } \\
\text { siltstone and } \\
\text { sandy } \\
\text { siltstone }\end{array}$ & Unknown & Unknown & Unknown & Unknown \\
\hline $\begin{array}{c}\text { Wandy } \\
\text { Siltstone }\end{array}$ & 55.5 & 26.5 & 10.5 & $\begin{array}{c}\text { Lithic } \\
\text { fragments, } \\
\text { zeolite and } \\
\text { muscovite } \\
\text { are minor } \\
\text { components }\end{array}$ \\
\hline $\begin{array}{c}\text { Kotemaori } \\
\text { Sandstone }\end{array}$ & $\begin{array}{c}\text { Silty sand } \\
\text { Rare lithic } \\
\text { fragments, } \\
\text { hornblende, } \\
\text { hypersthene, } \\
\text { glauconite, } \\
\text { muscovite, } \\
\text { calcite, and } \\
\text { unidentified } \\
\text { grains }\end{array}$ \\
\hline
\end{tabular}


This high degree of variability shown in Table 4.4 highlights the problematic issue of measuring grain size when soils are composed from different materials. Laser diffractometry assumes the optical properties of the grains being measured are known and are homogenous across samples. The wide variety of compounds and minerals present at Lake Tutira suggest that this assumption would be false.

Despite the assumptions and possible sources of error associated with quantifying plate like clay particles with laser diffractometry, this technique is preferable to the alternative pipette method. Scanning Electron Microscopy (SEM) Photography of clay particles provides a useful tool for calibration of samples with other methods. SEM photography is not practical for many samples however, but rather as a calibration tool for a set of samples. A SEM photograph of the 1-2 $\mu \mathrm{m}$ fraction sampled via pipette method governed by Stokes Law is shown in Figure 4.4. The large particle at $\sim 10 \times 6 \mu \mathrm{m}$ is not representative of the 1-2 $\mu \mathrm{m}$ fraction that should be present in the settling tube at time interval determined by Stokes Law. Despite correction factors as previously stated, the pipette method has an error of $25 \%-40 \%$ (Konert and Vandenberghe 1997; Sperazza et al. 2002).

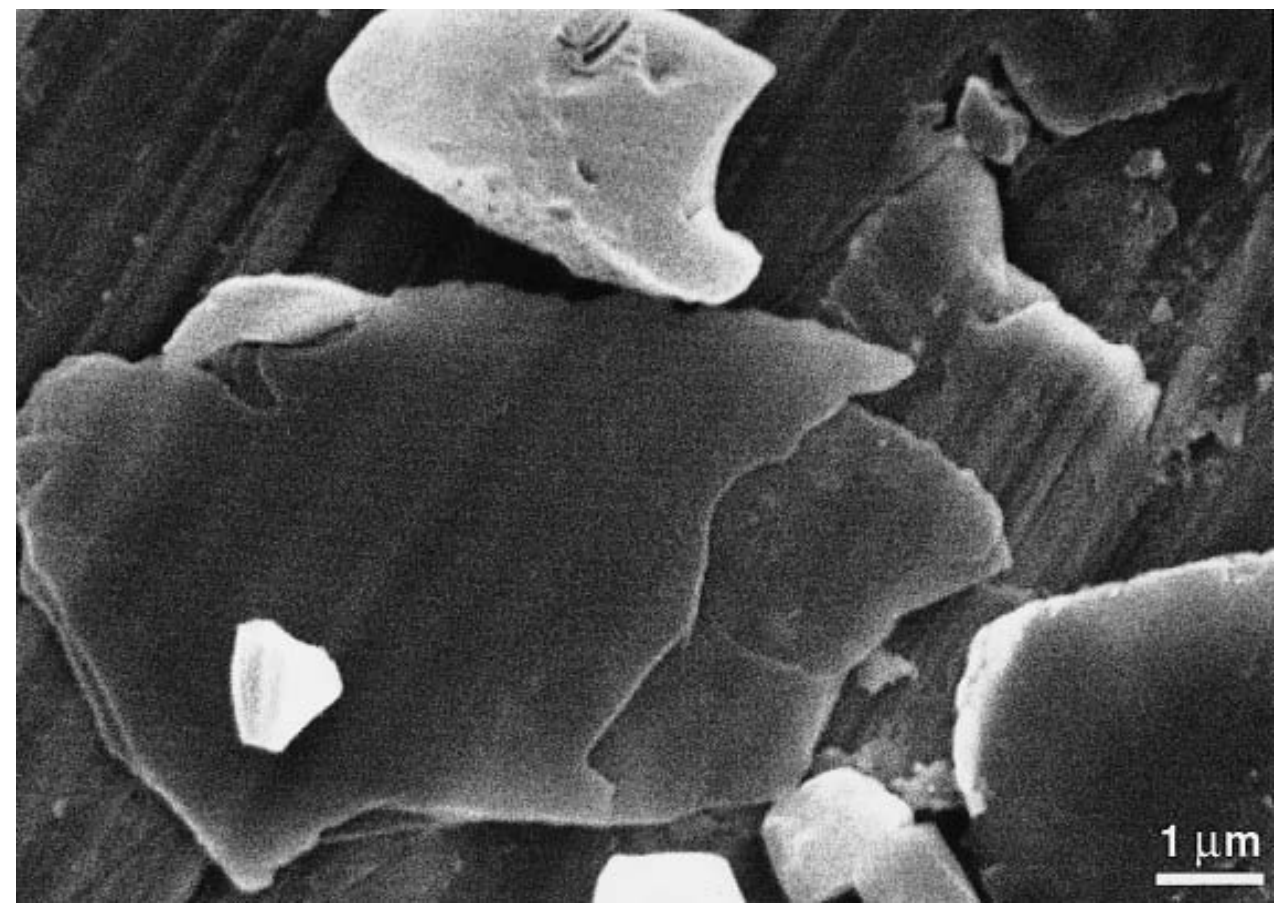

Figure 4.4: A SEM photograph shows the "plate like" clay particles that are the cause of analytical error across all common methods of analysis. Source: Konert and Vandenberghe (1997).

Provided the instrument operator has carefully considered and accounted for the assumptions associated with laser diffractometry, there is general consensus within the literature that this method is precise, rapid and reliable, and is an excellent diagnostic tool for sedimentological samples where the main objective is to establish trends associated with temporal or spatial characteristics of particles size distribution (qualitative analysis). However, if 
defining the class size proportions accurately is necessary, then as with the other methods, due consideration to the sources of error must be given in the interpretation (quantitative analysis) (Blott and Pye 2006). In the grain size analysis of the Oporae Valley cores, the primary interest is on the relative change in grain size indicating geomorphic process dominance (qualitative), and of secondary interest possible source areas from which the sediment was derived (quantitative).

\section{Equipment}

The Malvern Mastersizer 2000 laser diffractometer ('Malvern') with the Hydro MU dispersion unit attached was used for the Oporae Valley grain size analysis. This apparatus has a stated range of $0.02-2000 \mu \mathrm{m}^{3}$ and dispersant/sample capacity of 600-1000 ml. Figure 4.5a shows the Malvern Mastersizer 2000 laser diffractometer, and 4.5b shows the Hydro MU dispersion unit.

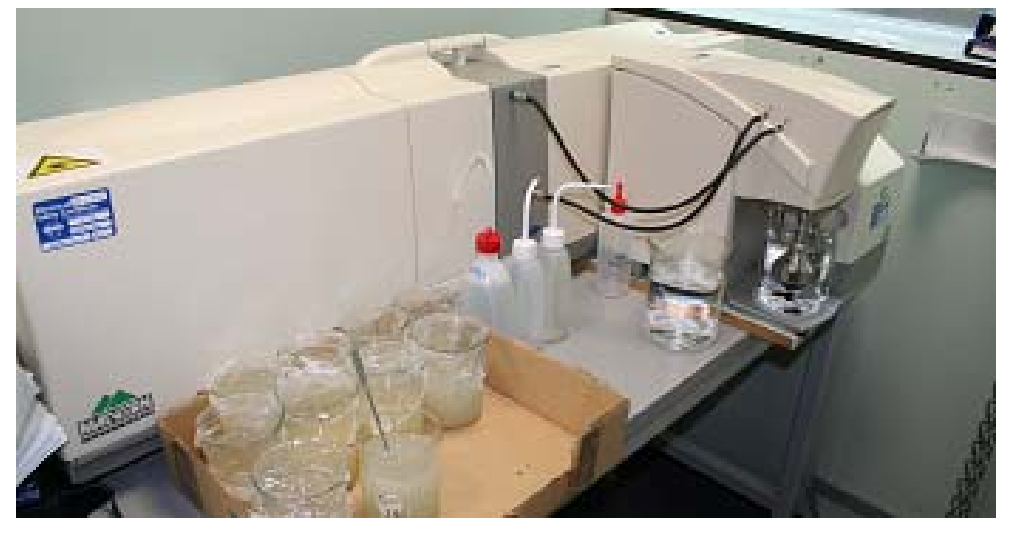

Figure 4.5a: the Malvern with samples in slurry (foreground).

Figure 4.5b: the Hydro MU dispersion unit containing sample slurry with an obscuration value of $\sim 6 \%$. Note: the actual volume of sample in slurry needed to achieve the optimal obscuration is small $(\sim 20-50 \mathrm{ml})$, and varies from

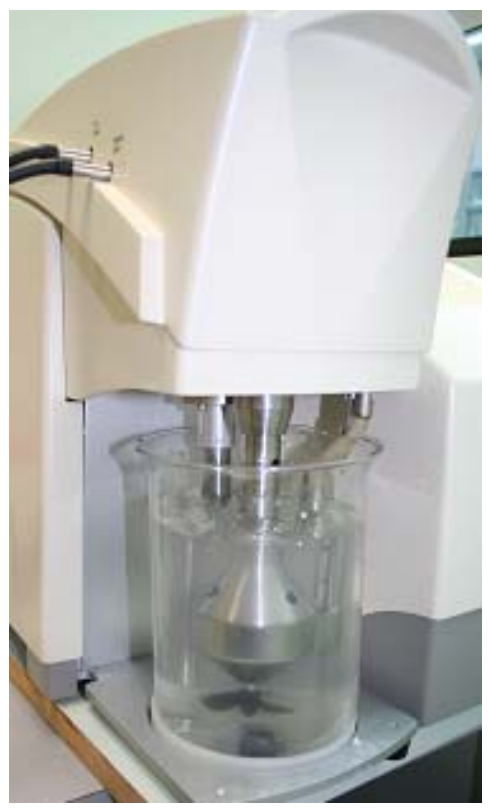
sample to sample.

The Malvern Mastersizer 2000 is the same apparatus used by Sperazza et al. (2004) in their experiments associated with sources of error associated with laser diffractometry. As the sediments used in these experiments were fine grained (1-50 $\mu \mathrm{m})$, and based on generic volcanic, fluvial, lake and soil origins, they provide a useful reference for definition of the user defined settings without repetition of the full experimental set on the Oporae Valley samples.

\section{Sample Preparation}

The sample was prepared in a slurry for wet analysis in accordance with the method laid out in Sperazza et al. (2004) and the Malvern wet method application notes based on ISO 13320 (1999) and ISO 14887 (2000) (Malvern

\footnotetext{
3 Victoria University's School of Chemical and Physical Sciences Malvern Mastersizer has been restricted to sedimentological samples $\leq 200 \mu \mathrm{m}$, as fouling of the pump has necessitated expensive repairs (pers. comm (Johnstone 2007). This was the basis for splitting the analysis across two techniques even though the samples would have fallen within the operating range of the laser diffractometer.
} 
Instruments Ltd 2007). Duplicate samples were run both with and without the addition of the dispersing agent sodium hexametaphosphate (Calgon) 10\%, and with and without 60 seconds of sonication. The Calgon slurries were left for 24 hours in accordance with the most effective dispersing time defined by (Sperazza et al. 2004).

\section{Procedure}

The procedure requires that the unit be cleaned prior to each sample run using a wash bottle, and several system flushes with tap water $(800 \mathrm{ml})$. The ultrasonic feature was used to remove bubbles caused by flushing the system. Once the system is decontaminated and purged, dispersant calibration is carried out so that it may later calculate the difference in refraction index of the dispersant and the sample. Once complete the sample slurry was dispersed evenly ( $3 \mathrm{~min}$ ) and introduced to the dispersant ( $800 \mathrm{ml}$ of tap water) using a pipette. Due to the potential ions tap water may carry and their capacity to flocculate small particles $\mathrm{dH}_{2} \mathrm{O}$ is the ideal dispersant; although, with a minimum of three system flushes at $800 \mathrm{ml}$ each, this was seen as impractical. The sample slurry was then introduced to the dispersant until an obscuration of 5$10 \%$ was achieved. During this stage if flocculation was occurring, a change in obscuration would be observed. Alternatively if the particles were already flocculated then sonication would either disperse or in the case of oversonication, fracture small particles once again causing a potential change in obscuration. Once stabilised, there was no significant observable changes in obscuration during the experimental runs for any of the sample duplicates that had undergone differing pre-treatment. At this point the physical analysis is complete, although user defined variables such as material properties can still be manipulated using the accompanying software.

The variables and values used were:

1. Particle refractive index (1.544)

2. Absorption (0.1)

3. Dispersant refractive index (1.330)

4. Model type (general purpose)

5. Particle shape (irregular)

6. Result calculation transformations (volume)

\subsection{Result Calculations}

\section{Volume to Mass Conversion}

The sieve and laser diffractometry analyses yielded different result units i.e. weight or volume. It was necessary to covert the \%volume result obtained with laser diffractometry to \%mass of the original sample for the summary classifications. This calculation was simplified by the use of $1 \mathrm{~g}$ for the initial sample size e.g.

$$
\begin{array}{rll}
1 \mathrm{~g} \text { sample }( \pm 0.01 \mathrm{~g}) & =\quad \begin{array}{l}
(0.52 \mathrm{~g} \text { sand }+0.48 \mathrm{~g} \text { silt/clay }) \\
=
\end{array} \quad(52 \% \text { sand mass }+48 \% \text { silt/clay mass }) .
\end{array}
$$




\section{Laser Diffractometry to Wet Sieve Fraction Conversion}

The grains recognised as fine sand fraction $>63 \mu \mathrm{m}$ by laser diffractometry were likely done so as a function of the difference in grain axis orientation in the sample slurry to that of the b-axis orientation which allowed them to pass the through the wet sieving procedure, which serves to highlight the possible sources of error between techniques. Although conversion factors are available (Shillabeer et al. 1992), the conversion for the fraction $\leq 63 \mu \mathrm{m}$ is best carried out with a sample specific calibrating image analysis (IA) e.g. SEM photography, and is not practical when conducting many analyses on sedimentological samples of varying composition. The fine fraction of sand from the laser diffractometry was added to the total sand fraction (as a percent of the $>63 \mu \mathrm{m}$ fraction mass), and the remainder converted to percent of $\leq 63 \mu \mathrm{m}$ fraction mass under the categories of silt or clay e.g. from the original $0.52 \mathrm{~g}$ sand, $0.48 \mathrm{~g}$ silt/clay; of the $\leq 63 \mu \mathrm{m}$ silt/clay fraction, $3.01 \%$ is $>63 \mu \mathrm{m}$ and must be added back to the sand fraction, i.e. $(3.01 \times 0.48)+52=53.45 \%$ of the total sample is sand. The remaining silt and clay fraction volumes are then converted i.e. $72.92 \%$ of the $\leq 63 \mu \mathrm{m}$ silt/clay fraction volume is silt multiplied by 0.48 (fraction of the total mass) $=35 \%$ of the total sample mass is silt, and the same for clay; $24.07 \%$ (vol) $\times 0.48$ (mass) $=11.55 \%$ (total mass). The above calculated category ratios were used for the Tri-plot grain size summary graphs (Figures 5.3 and 5.4) in Chapter 5.

\subsection{Palynology}

Pollen analyses were carried out using the standard method from Moore and Webb (1978). This extraction method is aimed at disintegrating, dissolving and removing the matrix materials that surround the pollen spores (Moore and Webb 1978). Pollen grains are extremely resistant to treatment from many chemicals, and so a series of steps targeting different aspects of the pollen grain supporting matrix material are carried out. These include:

1. $\mathrm{HCl}$ treatment for removal of calcium carbonates,

2. $\mathrm{KOH}$ digestion deflocculates and removes humic colloids,

3. HF treatment removes siliceous material,

4. Acetolysis removes cellulose,

5. Oxidation removes lignin and clears the sample,

6. Staining and mounting,

7. Pollen count and interpretation

(Moore and Webb 1978).

The preparation techniques and analysis requires specialist training (use of HF is restricted to authorised persons only) and expertise in pollen identification. Palynology expert Dr. William McLea of Victoria University's School of Geography, Environment and Earth Sciences undertook the sample preparation and analysis on eight samples taken from the Oporae Valley core sediments. 


\section{Chapter 5: Results}

\subsection{Results Chapter Overview}

The results chapter is structured as follows: core logs, grain size analyses, geochemical analyses (C\%, N\%, C:N, ${ }^{13} \mathrm{C},{ }^{15} \mathrm{~N}$ and $\left.{ }^{14} \mathrm{C}\right)$ and palynology. Only summary data is presented here due to the large quantity of that which was obtained. Full data are included in the appendices.

\subsection{Core Logs}

All sites were cored to the greatest depth achievable given the nature of the soft sediments and the percussion coring equipment. All field textural characterisation and observations have been cross-referenced with the detailed laboratory grain size analyses results and compiled into core logs for T1 and T2 in Figures 5.1 and 5.2 respectively. There is good correlation between the two methods except for a tendency (less than or equal to one class difference) for field textural classification to over estimate the clay fraction, and underestimate the fine sand fraction. This deviation in agreement is greater where organic matter (OM; removed prior to laboratory grain size analysis) is present and has been misinterpreted in the field as silt/clay particles. All grain size classification boundaries are described using the New Zealand boundary classifications found in Milne et al. (1991; Table 5.1). Here it is important to note that the boundary transitions described below are based on observations from the cores alone.

Table 5.1. New Zealand boundary classifications. Source: Milne et al. (1991)

\begin{tabular}{|l|l|}
\hline \multicolumn{1}{|c|}{ Distinctness $\mathbf{( c m )}$} & \multicolumn{1}{c|}{ Topography } \\
\hline 1. Sharp 0 - 0.5 & S Smooth - Nearly plane surface \\
\hline 2. Abrupt 0.5 - 2 & W Wavy - Pockets less deep than wide \\
\hline 3. Distinct 2 - 5 & I Irregular - Pockets more deep than wide \\
\hline 4. Indistinct 5 - 10 & C Convolute - Pockets deeper than wide but not recurved \\
\hline 5. Diffuse $>10$ & O Occluded - Pockets deeper than wide and in parts recurved \\
\hline
\end{tabular}

A brief summary and explanation of Figures 5.1 and 5.2 are given below. For the full core descriptions please see Appendix III. The core photographs are situated next to the core log and were taken within 1-2 minutes of opening the casings. The photographs depict the vivid hues associated with oxidation and reduction and the dark browns of $\mathrm{OM}$ in the contemporary topsoil and paleosols. What the photographs do not depict well in all instances are the abrupt and gradual changes in grain size classification associated with deposition. The core log itself shows different grain size classifications as either blocks that transition abruptly from one grain size to another e.g. T1 S4 $50 \mathrm{~cm}$ $150 \mathrm{~cm}$, or as units that grade (sloped transition) from one grain size classification to another e.g. T2 S2 $40 \mathrm{~cm}-140 \mathrm{~cm}$. 


\section{General Observations from Transect 1}

Transect 1's contemporary topsoils all exhibit similar characteristics, and there is some similarity between S2 and S3 at greater depth $(>1 \mathrm{~m})$. All sites show some evidence of paleosols through local concentrations of $\mathrm{OM}$. The increase in paleosol frequency down slope is correlated with increasing complexity within the cores. Site $1, S 2$ and the upper half of $S 3$ all exhibit relatively indistinct or diffuse transitions and large thicknesses of one grain size classification. Site 4 and the lower half of S3 exhibit sharp or abrupt transitions and relatively thin units of one grain size classification. The effect of oxidation and reduction processes can be seen quite clearly at each site as rust coloured mottling (oxidation) and a distinctly blue hue which increases in brightness with increasing depth (reduction). The range of overlap (indicated by the arrows in Figure 5.1) can be used as a proxy for the fluctuation in height of the water table. The effect of slope on water table height fluctuation is shown as a decreasing range of overlap between oxidation and reduction zones progressing down slope.

\section{General Observations from Transect 2}

Site 1's shallow contemporary topsoil sits on a solid unit of compacted silty clay with no evidence of buried OM, pumice or lapilli below the contemporary soil profile. These characteristics make $\mathrm{S} 1$ distinctly different from all other sites on T2 (and T1). Sites 2, 3 and 4 all contain OM at or above $50 \mathrm{~cm}$ depth which has the appearance of being overlain by an OM deficient depositional unit (or units) of sediment. Due to the complexity of each core below the initial $50 \mathrm{~cm}$, direct linkages or common units from each site are difficult to discern. Despite this, there appears to be a correlation between the middle sections of S3 and S4 above the inclusion of a pumice lamination at 245 and $202 \mathrm{~cm}$ respectively. In addition there is a distinctly different depositional environment evident in the lower section of S4 with two sets of laminations, the first exhibiting high resolution alternation in grain size characteristics and the second in OM content. As with $\mathrm{T} 1$, the effects of oxidation and reduction processes can be seen quite clearly at each site as rust coloured mottling (oxidation) and a distinctly blue hue which increases in brightness with increasing depth (reduction). As with $\mathrm{T} 1$, the range of overlap (as indicated by the arrows in Figure 5.2) can be used as a proxy for the fluctuation in height of the water table.

The complexity of the stratigraphy in both $\mathrm{T} 1$ and $\mathrm{T} 2$ progressively increases down-slope with sharp to abrupt transitions between silts and sands occurring more frequently. Paleosols containing OM are evident in both T1 and T2 and also appear to increase in frequency down-slope. Pumice clasts are ubiquitous throughout most of the cores irrespective of the grain size, OM content or apparent mode of deposition. Quantifying the OC content of the contemporary top soils and the paleosols will allow for the further interpretation of land-use change and geomorphic processes on the terrestrial carbon pool. 


\section{Figure 5.1: Transect 1 Core Logs}
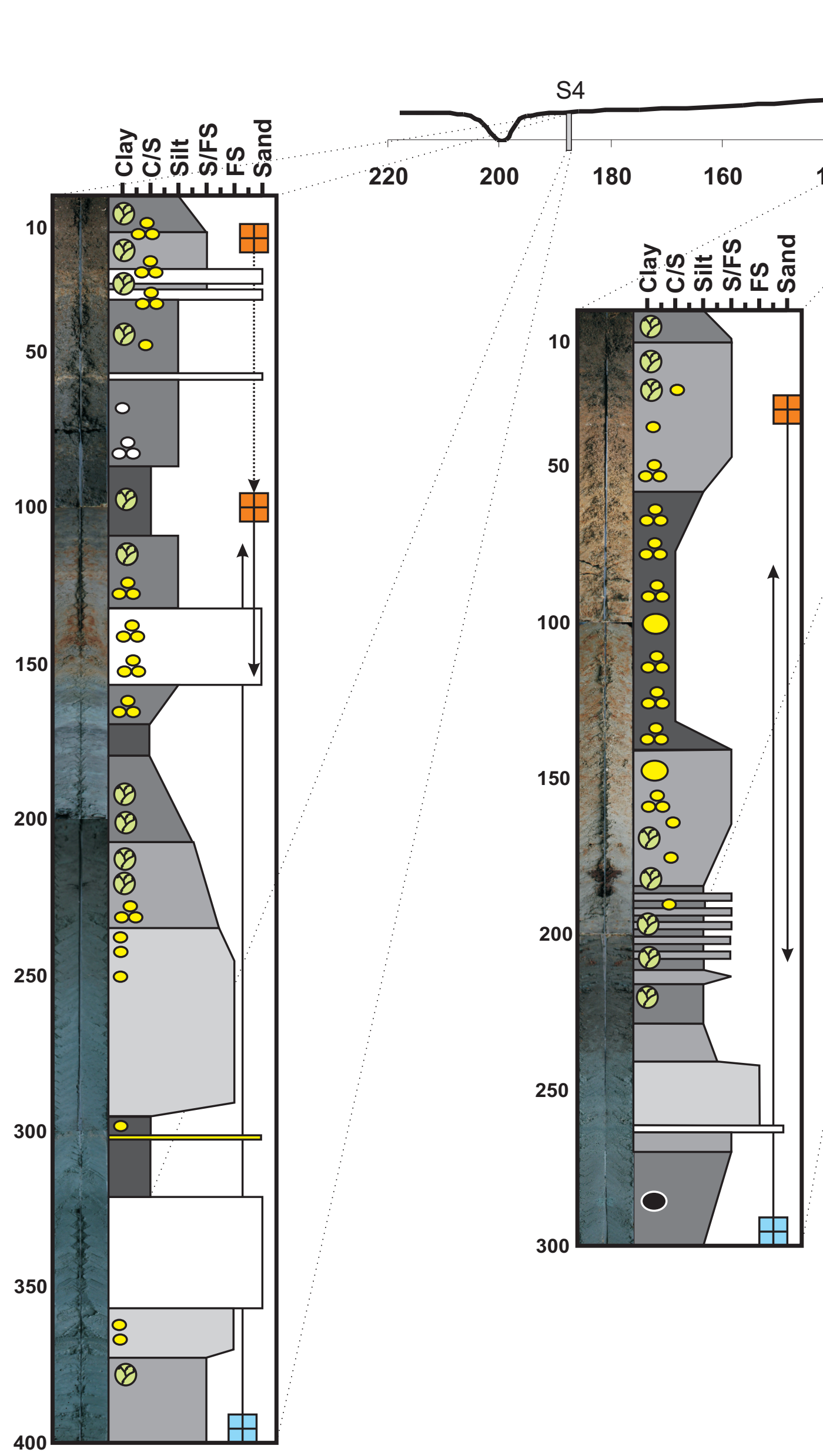


\subsection{Grain Size Analysis}

Field textural characterisations revealed wide ranging grain size classifications (see Figures 5.1 and 5.2). Where OC rich layers were identified, supplementary detailed grain size analyses were undertaken to aid the \%TOC, \% TN and stable isotope interpretations.

\section{Transect 1}

Covering a larger source and depositional area than T2, T1's grain size analysis data reflect the differences in colluvial and alluvial fan depositional environments. Figure 5.3 shows the different ranges in grain size classification for T1.

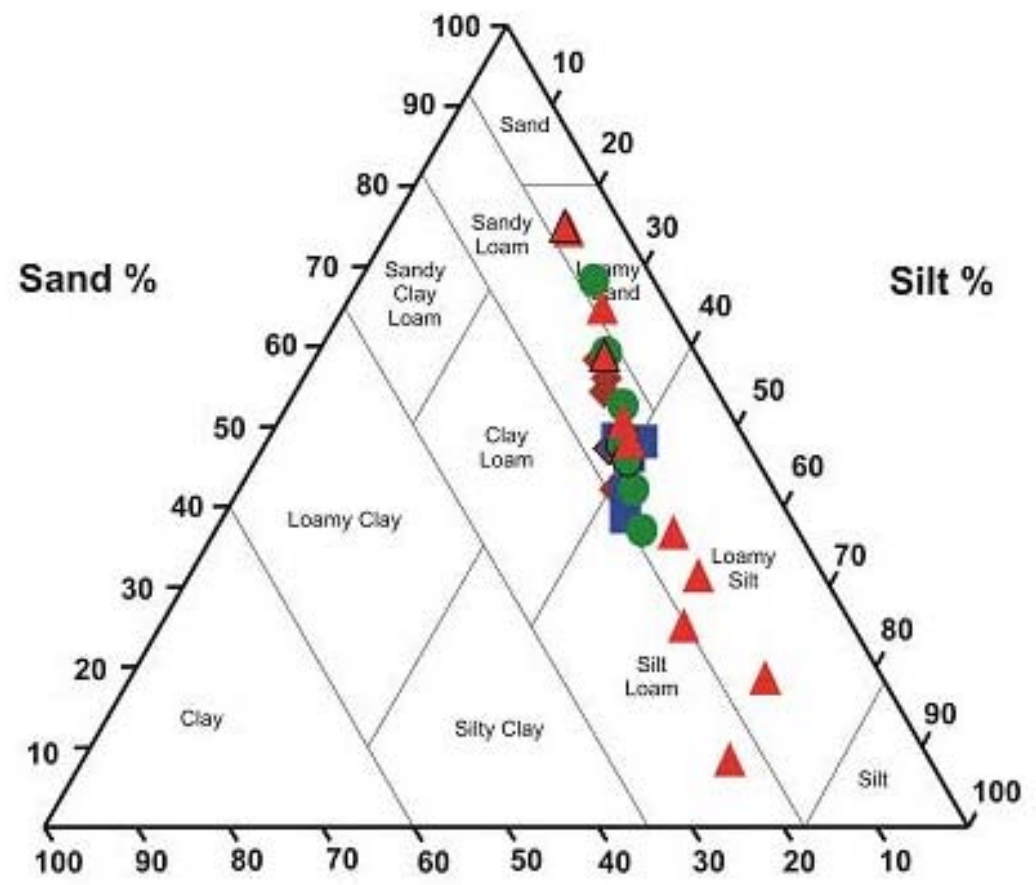

\section{Clay \%}

Figure 5.3: The distribution of grain size classifications through buried $C$ rich sections of $\mathrm{T} 1$; $\mathrm{S} 1$ (brown diamonds), $\mathrm{S} 2$ (blue squares), S3 (green circles), and S4 (red triangles).

Figure 5.3 shows that the range of grain size classifications across the four sites in T1 varies significantly. S1 and S2 have little variation in clay content, and some variation in the sand and silt percentages ranging across 2-3 adjacent Silt and Loam classifications. Site 3 and S4 are more wide spread in clay, silt and sand percentages, ranging across 3-4 adjacent Silt, Loam and Sand categories. The grain size classification distribution differs according to a range of factors affecting the depositional mode and origin of the sediments, but depending on the depth of the $\mathrm{C}$ rich section in the core and the position of the site on the transect slope there are some general observable trends. Table 5.2 shows the depths, proportion of each grain size classification, and the corresponding $\%$ TOC and \%TN values. 
As shown in table 5.2 (indicated in bold) there is a correlation between paleosols and grain size classification. Site 1 and S2 show the shallow more recent paleosols on the colluvial foot slope present in loamy silts and sandy loams with a relatively narrow classification distribution. Site 3 and S4 have deeper paleosols (SOC) in the alluvial toeslope characterised by loamy silts, silt loams and sandy loams, they are surrounded by sediments with a significantly greater proportion of sand.

\section{Transect 2}

Covering a smaller source and depositional area than T1, T2's grain size analysis data reflect the differences in mass movement runout and the spatial connection of colluvial and alluvial fan depositional environment. Figure 5.4 shows the distributions in grain size classification for $\mathrm{T} 2$.

Table 5.2. Depths, textures, \%TOC and \%TN of Transect 1.

$\begin{array}{ccccccc}\begin{array}{c}\text { Depth (cm) } \\ \text { Site } 1\end{array} & \text { Sand (\%) } & \text { Silt (\%) } & \text { Clay (\%) } & \text { Soil Class } & \text { \%TOC } & \text { \%TN } \\ 60 & 56.3 & 32.4 & 11.3 & \text { Sandy Loam } & - & - \\ 70 & 58.4 & 30.6 & 11 & \text { Sandy Loam } & 0.25 & 0.06 \\ 80 & 54.6 & 33.1 & 12.3 & \text { Sandy Loam } & - & - \\ \mathbf{9 0} & \mathbf{4 7 . 3} & \mathbf{3 7 . 9} & \mathbf{1 4 . 8} & \text { Sandy Loam } & \mathbf{1 . 1 3} & \mathbf{0 . 0 9} \\ \mathbf{1 1 0} & \mathbf{4 2 . 3} & \mathbf{4 0 . 5} & \mathbf{1 7 . 2} & \text { Loamy silt } & \mathbf{0 . 7 3} & \mathbf{0 . 0 7} \\ 120 & 47.6 & 37 & 15.4 & \text { Sandy Loam } & - & - \\ \text { Site 2 } & & & & & & \\ 5 & 42.2 & 41.6 & 16.2 & \text { Loamy silt } & 3.52 & 0.41 \\ 15 & 48.5 & 40.2 & 11.3 & \text { Loamy silt } & 1.61 & 0.18 \\ 35 & 39.1 & 43.2 & 17.7 & \text { Loamy silt } & 1.31 & 0.12 \\ 45 & 46.7 & 39.8 & 13.5 & \text { Loamy silt } & - & - \\ 55 & 48.6 & 37.4 & 14 & \text { Sandy Loam } & 0.13 & 0.02 \\ \text { Site 3 } & & & & & & \\ 165 & 53 & 35.9 & 11.1 & \text { Sandy Loam } & 0.25 & 0.03 \\ 185 & 49 & 38 & 13 & \text { Sandy Loam } & 0.30 & 0.04 \\ \mathbf{2 0 5} & \mathbf{3 7 . 4} & \mathbf{4 5 . 7} & \mathbf{1 6 . 9} & \text { Loamy silt } & \mathbf{1 . 1 9} & \mathbf{0 . 0 9} \\ \mathbf{2 1 5} & \mathbf{4 8} & \mathbf{3 8 . 3} & \mathbf{1 3 . 7} & \text { Sandy Loam } & \mathbf{1 . 7 9} & \mathbf{0 . 1 2} \\ \mathbf{2 2 5} & \mathbf{4 2 . 5} & \mathbf{4 2 . 4} & \mathbf{1 5 . 1} & \text { Loamy silt } & \mathbf{2 . 0 6} & \mathbf{0 . 1 6} \\ 235 & 46.1 & 39.8 & 14.1 & \text { Sandy Loam } & - & - \\ 245 & 59.3 & 31 & 9.7 & \text { Sandy Loam } & - & - \\ 255 & 68.3 & 25.1 & 6.6 & \text { Loamy Sand } & 0.22 & 0.03 \\ \text { Site 4 } & & & & & & \\ 125 & 25.4 & 56.3 & 18.3 & \text { Silt Loam } & 0.63 & 0.06 \\ 135 & 74.7 & 19.2 & 6.1 & \text { Loamy Sand } & - & - \\ 145 & 75.2 & 18.5 & 6.3 & \text { Loamy Sand } & 0.24 & 0.03 \\ 155 & 65 & 27.7 & 7.3 & \text { Loamy Sand } & - & - \\ \mathbf{1 6 5} & \mathbf{1 8 . 9} & \mathbf{6 8 . 5} & \mathbf{1 2 . 6} & \text { Loamy silt } & \mathbf{0 . 3 0} & \mathbf{0 . 0 3} \\ \mathbf{1 7 5} & \mathbf{8 . 9} & \mathbf{6 9 . 5} & \mathbf{2 1 . 6} & \text { Silt Loam } & \mathbf{1 . 6 0} & \mathbf{0 . 1 3} \\ \mathbf{1 8 5} & \mathbf{3 7} & \mathbf{4 9 . 4} & \mathbf{1 3 . 6} & \text { Loamy silt } & - & - \\ \mathbf{1 9 5} & \mathbf{3 1 . 7} & \mathbf{5 4 . 8} & \mathbf{1 3 . 5} & \text { Loamy silt } & - & - \\ \mathbf{2 0 7} & \mathbf{4 8 . 3} & \mathbf{3 9} & \mathbf{1 2 . 7} & \text { Sandy Loam } & \mathbf{1 . 2 9} & \mathbf{0 . 1 0} \\ 225 & 51 & 37 & 12 & \text { Sandy Loam } & - & - \\ 235 & 59.1 & 30.8 & 10.1 & \text { Sandy Loam } & 0.67 & 0.07\end{array}$

Figure 5.4 shows the range of grain size classifications across the four sites in T2. Site 1 and S2 have slightly greater variation in texture ranging across 3-4 


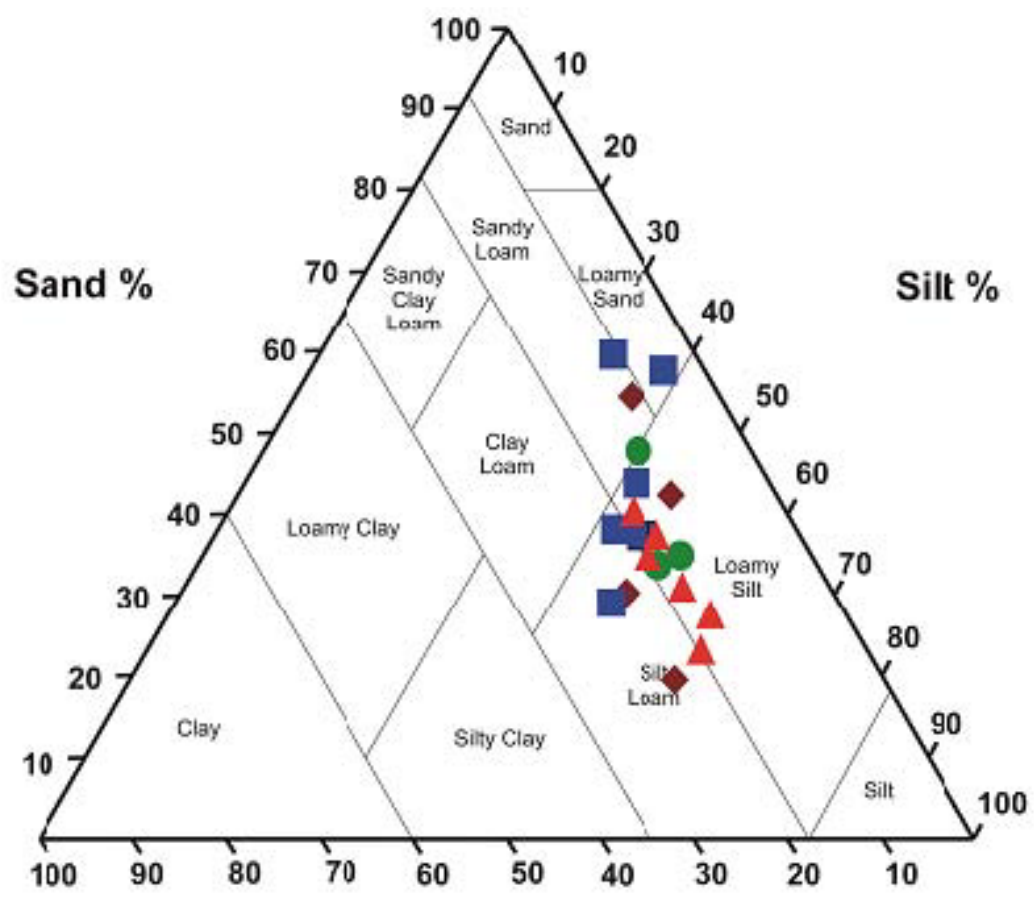

Clay $\%$

Figure 5.4: The distribution of grain size classifications through buried $\mathrm{C}$ rich sections of T2; S1 (brown diamonds), S2 (blue squares), S3 (green circles), and S4 (red triangles).

Table 5.3: Depths, textures, \%TOC and \%TN of Transect 2.

\begin{tabular}{|c|c|c|c|c|c|c|}
\hline $\begin{array}{l}\text { Depth }(\mathrm{cm}) \\
\text { Site } 1\end{array}$ & Sand (\%) & Silt (\%) & Clay (\%) & Soil Class & \% TOC & $\% \mathrm{TN}$ \\
\hline 5 & 42.4 & 46.4 & 11.2 & Loamy Silt & 6.23 & 0.65 \\
\hline 15 & 54.6 & 35.9 & 9.5 & Sandy Loam & 2.14 & 0.24 \\
\hline 25 & 30.3 & 47.5 & 22.2 & Silt Loam & 0.72 & 0.08 \\
\hline 35 & 19.2 & 58.3 & 22.5 & Silt Loam & 0.31 & 0.04 \\
\hline \multicolumn{7}{|l|}{ Site 2} \\
\hline 5 & 37.5 & 45.7 & 16.8 & Loamy Silt & 3.65 & 0.37 \\
\hline 25 & 43.8 & 41.9 & 14.3 & Loamy Silt & 1.75 & 0.13 \\
\hline 45 & 37.3 & 45.4 & 17.3 & Loamy Silt & 2.63 & 0.17 \\
\hline 55 & 38.2 & 42.5 & 19.3 & Silt Loam & 1.40 & 0.10 \\
\hline 95 & 57.7 & 38 & 4.3 & Loamy Sand & 1.34 & 0.11 \\
\hline 125 & 59.9 & 31.4 & 8.7 & Sandy Loam & 0.47 & 0.06 \\
\hline 135 & 28.9 & 46.7 & 24.4 & Silt Loam & 0.29 & 0.02 \\
\hline \multicolumn{7}{|l|}{ Site 3} \\
\hline 35 & 47.8 & 40.2 & 12 & $\begin{array}{l}\text { Sandy Loam } \\
\text {-Loamy Silt }\end{array}$ & 0.75 & 0.07 \\
\hline 45 & 33.6 & 49.4 & 17 & Loamy Silt & 1.57 & 0.13 \\
\hline 55 & 35 & 51 & 14 & Loamy Silt & 0.56 & 0.06 \\
\hline \multicolumn{7}{|l|}{ Site 4} \\
\hline 25 & 23.1 & 59.1 & 17.8 & $\begin{array}{l}\text { Silt Loam- } \\
\text { Loamy Silt }\end{array}$ & 1.14 & 0.12 \\
\hline 35 & 34.9 & 47.6 & 17.5 & $\begin{array}{l}\text { Loamy Silt - } \\
\text { Silt Loam }\end{array}$ & 1.61 & 0.13 \\
\hline 45 & 37.4 & 47.2 & 15.4 & Loamy Silt & 0.93 & 0.08 \\
\hline 55 & 27.5 & 57.8 & 14.7 & Loamy Silt & 0.54 & 0.06 \\
\hline 65 & 40.4 & 43.3 & 16.3 & Loamy Silt & - & - \\
\hline 75 & 31 & 53.2 & 15.8 & Loamy Silt & - & - \\
\hline
\end{tabular}


adjacent Silt, Loam and Sand classifications. Sites 3 and 4 have little variation in clay percentage and some variation in the silt and sand percentages, although less so than T1, ranging across 2-3 adjacent Silt and Loam categories. The grain size analyses profile from $\mathrm{T} 1$ differs with the depth of the $\mathrm{C}$ rich section in the core and the position of the site on the transect slope. The grain size classification of $\mathrm{T} 2$ is predominantly taken from the top $1 \mathrm{~m}$ of the cores as there was little evidence of paleosols below this depth (S4 is the exception). In T2 the range of silt and sand percentages is more tightly grouped than in T1. Table 5.3 shows the depths, proportion of each grain size classification, and the corresponding \%TOC and \% TN values in T2.

As shown in Table 5.3: $\mathrm{S} 1$ shows the expected decrease in \%TOC and \%TN with increasing depth on the colluvial fan toe. This shallow core contains no inflection in \%TOC or \%TN down the core, and is characterised by loamy silts, sandy loam and silty loam. Site 2, S3 and S4 are all deeper cores, all of which contain a shallow paleosol. This shallow common paleosol is reflected in the $\%$ TOC and \%TN inflections at $25-45 \mathrm{~cm}$ in a loamy silt matrix (bolded) surrounded by the same or very similar textural classifications.

\section{Summary of Grain Size}

Transect 1 has a steeper source area, predominantly grassland vegetation upslope and a significantly longer runout path to the contemporary drainage channel. T1 also has paleosols at greater depth identified through \%TOC and $\% \mathrm{TN}$ inflections in the alluvial toeslope. The type of depositional process responsible for paleosol formation is reflected in the grain size analysis as a tightly grouped range of classifications (or more homogenous) in the colluvially dominant footslope, and a wider range of classifications (distinct laminations) in the alluvially dominant toeslope (S4). Buried nutrient inflections (\%TOC and $\% \mathrm{TN}$ ) in S1, S2 and S4 are bracketed by sandier sediments as evidenced in bold in Tables 5.2 and 5.3 .

Transect 2 has a source area that is less steep with regenerating forest cover up-slope and a shorter runout path to the contemporary drainage channel. Before the stabilising forest cover was established, colluvial deposition would have dominated the environment all the way to the stream channel. This is reflected in fewer paleosols and one common paleosol in S2, S3 and S4 at approximately $50 \mathrm{~cm}$ depth shown by \%TOC and \%TN inflections. These inflections are all Loamy-Silt surrounded by the same or similar classifications.

\subsection{Geochemistry}

The isotope ratio, percent element and $\mathrm{C}$ to $\mathrm{N}$ ratios are presented as summary graphs for T1 and T2 (Figures 5.5 and 5.6), with brief descriptions of the observable trends and significant values. For the complete data set see Appendix III. 


\section{Transect 1}

TOC (\%) and TN (\%)

Transect 1 TOC and TN content display similar trends across all sites with topsoil $(5 \mathrm{~cm})$ peak values ranging from $2.95 \%-3.92 \%$ TOC and $0.31 \%-0.4 \%$ $\mathrm{TN}$, decreasing rapidly in the top $45 \mathrm{~cm}$ of the contemporary soil profile to $0.57 \%-1.22 \%$ TOC ( $74 \%$ reduction) and $0.08 \%-0.12 \%$ TN ( $72 \%$ reduction). Site $4 \%$ TOC and \%TN exhibit a small inflection against this trend at $45 \mathrm{~cm}$ which corresponds to an OM concentration overlain with coarser sand sediments (Figure 5.1). Sites 1, 2 and 4 exhibit another inflection at the 75-95 $\mathrm{cm}$ depth varying in magnitude within the cores. Sites 3 and 4 then exhibit major inflections in TOC and TN at $225 \mathrm{~cm}$ and $175 \mathrm{~cm}$ respectively. Site 3 has a TOC inflection of $2.06 \%$ at $225 \mathrm{~cm} \mathrm{(} \Delta 85.5 \%$ relative to TOC content of surrounding sediment) placing it at the equivalent TOC content of $10-15 \mathrm{~cm}$ depth from the contemporary surface. Site 4 has a TOC inflection of $1.6 \%$ at $175 \mathrm{~cm}(\Delta 81 \%$ relative to TOC content of surrounding sediment), which is similar to the TOC content at $15 \mathrm{~cm}$ depth. TN inflections are of a similar magnitude for both S3 and S4 at $0.14 \%$ TN $(\Delta 79 \%)$ which places them at the equivalent TN content of contemporary soil at $15-25 \mathrm{~cm}$ depth.

\section{C:N}

The C:N ratio (TOC:TN) for each site on $\mathrm{T} 1$ shows uniformity with increasing depth from $5 \mathrm{~cm}$ to $35-45 \mathrm{~cm}$ at a mean value of $11.1 \pm 0.7$. Variability from $35-$ $45 \mathrm{~cm}$ depth rapidly increases and as a ratio is directly correlated to the abundance of $\mathrm{C}$ and $\mathrm{N}$ at each sample. Large increases in $\mathrm{C}: \mathrm{N}$ occur in Site 1 $(17.8$ at $90 \mathrm{~cm})$, and Site $3(18.8 \mathrm{~mol}$ at $215 \mathrm{~cm})$. These increases correspond to increases in $\% \mathrm{C}$ and $\% \mathrm{~N}$ of different magnitude (disregarding orders of magnitude difference in scale). At $\mathrm{S} 190 \mathrm{~cm} \mathrm{C:N}$ is 17.8. At this depth TOC $(1.13 \%)$ is inflecting against the depletion trend, TN at $0.07 \%$. While $S 495 \mathrm{~cm}$ is also inflecting (TOC $1.34 \%$ and TN $0.11 \%$ ) the positive shift in C:N ratio is muted, as a proportion of TOC, TN is greater in S4 than S1. Site 2 mirrors S1's $\mathrm{C}: \mathrm{N}$ profile trends, but is significantly reduced in magnitude at similar depth (ratio of 11.7 at $85 \mathrm{~cm}$ ). The same observation can be made for S3 at $215 \mathrm{~cm}$ depth (ratio of 18.8) when compared to Site 4 at $207 \mathrm{~cm}$ depth (ratio of 14.7).

$\delta^{13} \mathrm{C}$

Across all sites at $5 \mathrm{~cm}$ the $\delta^{13} \mathrm{C}$ values are clustered around a mean $(\bar{x})$ of $28.3 \%$ \% \pm 0.3 . The $\delta^{13} \mathrm{C}$ values then rapidly enrich to $\bar{x}=-24.5 \%$ o \pm 0.8 at $25-45$ cm depth, where they stabilise with increasing depth at $\bar{x}=-24.9 \%$ o down to 85$95 \mathrm{~cm}$. This produces the characteristic enrichment curve expected with increasing depth across all sites; the only exception is the S4 outlier of $-23.2 \%$ o at $45 \mathrm{~cm}$. Initially thought to be the result of incomplete sample demineralisation, this sample was then re-processed producing the same result. Between 100-150 cm lies a transition zone, after which S1 and S2 then maintain the approximate value they have at $100 \mathrm{~cm}$ depth $(\bar{x}=-24.9 \%$ o to $25 \%$ ), whereas S3 and S4 show depletion trends. For S3 the depletion trend is equivalent to that of the contemporary $5 \mathrm{~cm}$ topsoil $\delta^{13} \mathrm{C}$ value over the depth range of $150-225 \mathrm{~cm}$ peaking twice at $-28.5 \%$ and $-27.8 \%$, at $165 \mathrm{~cm}$ and 205 


\section{$\underline{\text { Transect } 1}$}

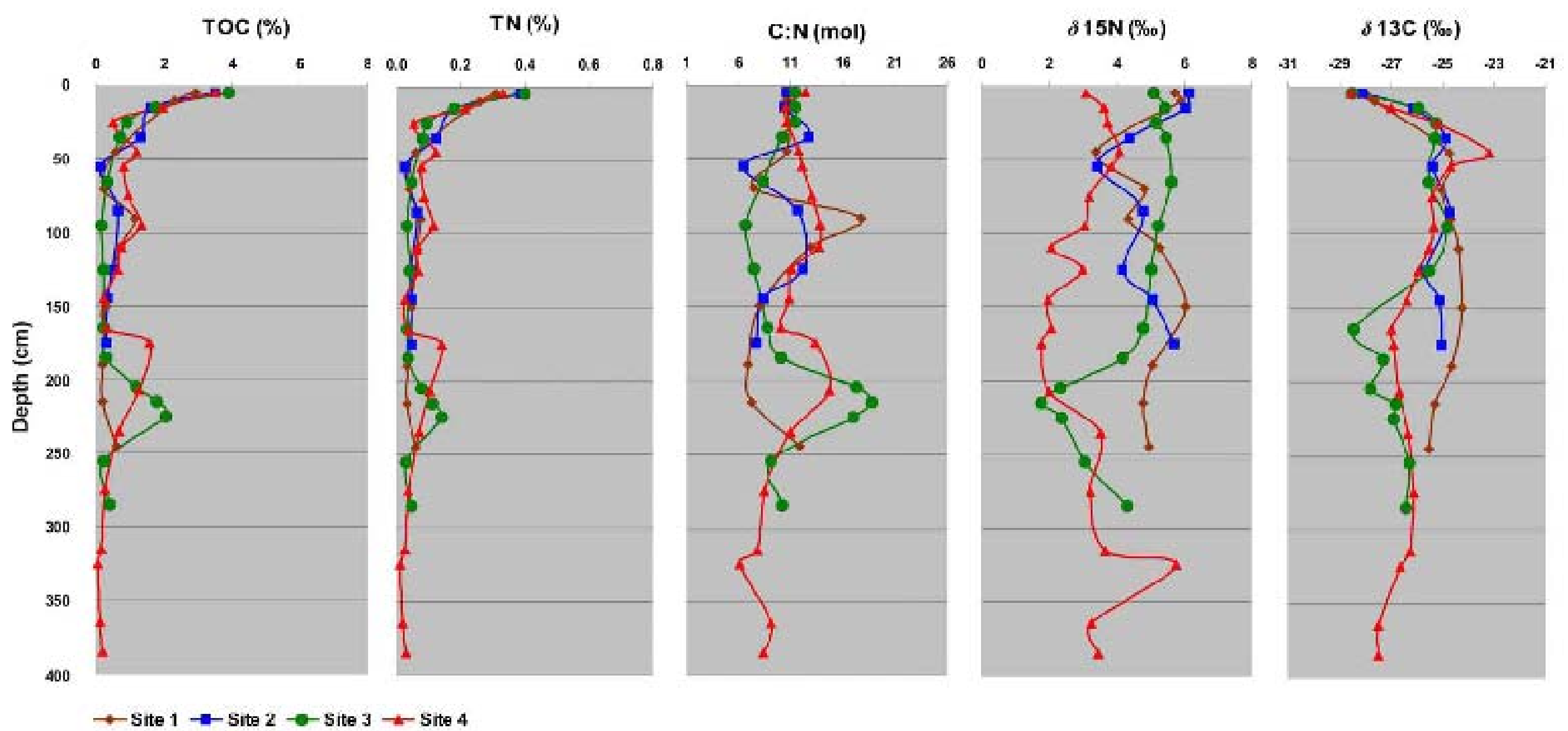

Figure 5.5: C and N EA-IRMS summary graphs for Transect 1. All of the ‘ \pm ' notations quoted in the results in the following section refer to the range of data values for any given parameter, not the pre-established sample processing errors. 


\section{Transect 2}

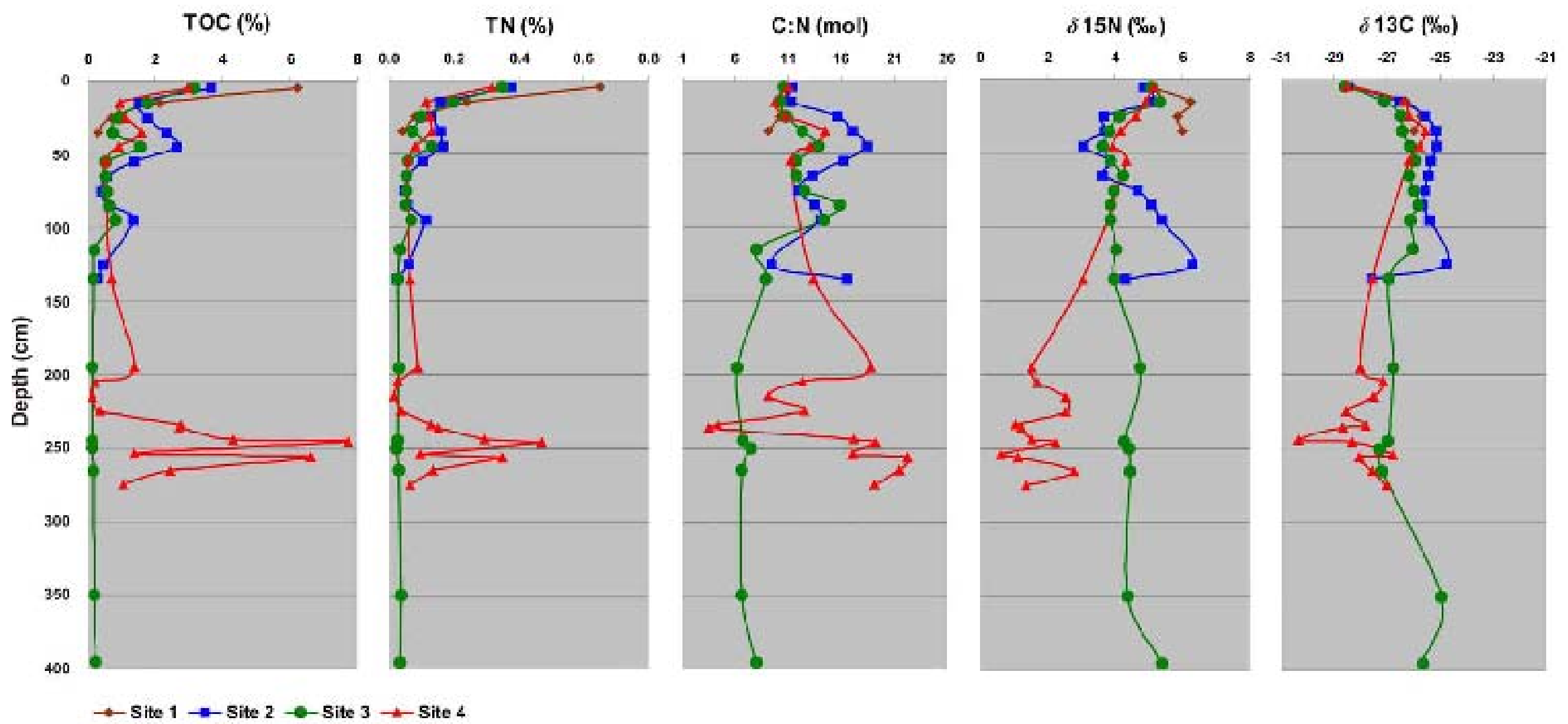

Figure 5.6: $\mathrm{C}$ and $\mathrm{N}$ EA-IRMS summary graphs for Transect 2. 
cm respectively. S4 below $150 \mathrm{~cm}$ depth and S3 below $225 \mathrm{~cm}$ both stabilise at a mean of $-26.8 \%$.

$\delta^{15} \mathrm{~N}$

For $\mathrm{T} 1$ the $\delta^{15} \mathrm{~N}$ values of the $5 \mathrm{~cm}$ topsoil show more variation (6.1\%o at $\mathrm{S} 2$ and $3.1 \%$ at S4), but still fall within the expected ranges for C3 terrestrial plants at +3 to $+7 \%$ and SOM of $+2-+5 \%$ (Kendall et al. 2001). Sites 1 and 2 initially display very similar trends of rapid depletion from a mean of $5.9 \%$ at $5-10 \mathrm{~cm}$ to a mean of $3.4 \%$ at $45-55 \mathrm{~cm}$ depth. This trend of rapidly decreasing values is opposite to that of $\delta^{13} \mathrm{C}$ values in the same sites to similar depths. From $\sim 50 \mathrm{~cm}$ both S1 and S2 have mean trends of gradual enrichment with increasing depth to 245 and $145 \mathrm{~cm}$ respectively. The trend line curves mirror that of the corresponding $\delta^{13} \mathrm{C}$ values below $\sim 50 \mathrm{~cm}$. Site 3 displays a very linear trend with a mean value of $5.2 \pm 0.5$ from $5-165 \mathrm{~cm}$ depth, before a large depletion spike from $185-285 \mathrm{~cm}$ of $1.8 \%$. Site 4 also has a relatively linear trend profile (excluding outlier of sand at $325 \mathrm{~cm}$ ) that shows slight inflections of enrichment from $5-45 \mathrm{~cm}$ of $1 \%$, then depletion from $45-175 \mathrm{~cm}$ of $2.3 \%$, then enrichment again to $1.7 \%$ at $385 \mathrm{~cm}$ depth. At $385 \mathrm{~cm}$ an outlier exists at $5.8 \%$. Prior to carbonate removal the same sand sample returned a value of $3.6 \%$ which is the largest significant $\delta^{15} \mathrm{~N}$ deviation due to demineralisation within the data set.

\section{Transect 1 Summary}

Sites 1 and 2 display very similar trends across all variables analysed. All sites across all variables hold similar values for the top $35-45 \mathrm{~cm}$ except for $\delta^{15} \mathrm{~N}$ which displays different profiles for S3 and S4 and similar for S1 and S2. $\delta^{13} \mathrm{C}$ profiles all show the characteristic enrichment curve with increasing depth in the contemporary topsoil; then either stabilisation (S1 and S2), or depletion (S3 and S4) shifts. All sites contain sections of core that have accumulated or buried OM as indicated by the \%TOC and $\% \mathrm{~N}$ increases at depth. There are some significant deviations from the mean topsoil value in $\mathrm{C}: \mathrm{N}$ profiles that correspond to peaks in \%TOC and \% TN.

\section{Transect 2}

TOC (\%) and TN (\%)

Transect 2 TOC and TN display trends of nutrient depletion with increasing depth similar to $\mathrm{T} 1$, but have wider ranging nutrient values in the contemporary topsoil across the sites $1-4$ at the same depth. Site 1 has high TOC $(6.2 \%)$ and TN $(0.65 \%)$ at $5 \mathrm{~cm}$ depth, declining rapidly to very low values at $35 \mathrm{~cm}$ of $0.31 \%(\Delta 95 \%)$ and $0.04 \%(\Delta 93.8 \%)$ respectively. This rapid reduction in nutrient content of $\mathrm{S} 1$ topsoil is the largest decline across all sites on both T1 and T2 to $35 \mathrm{~cm}$ depth. Below $40 \mathrm{~cm} \mathrm{S1}$ is devoid of organic content and consists of a uniform highly compacted lithology. Further isotope analyses beyond $35 \mathrm{~cm}$ depth on this site were not undertaken. Sites 2, 3 and 4 have values ranging from $3.65-2.98 \%$ TOC and $0.35-0.32 \% \mathrm{TN}$ at $5 \mathrm{~cm}$ depth, decreasing in value with increasing depth initially but then inflecting strongly at $35-45 \mathrm{~cm}$. As with T1, the inflections correspond to the appearance of OM concentrations overlain with a unit (or units) of a different grain size 
classification. The most pronounced TOC inflection of these is in S2 where TOC drops from $3.65 \%$ at $5 \mathrm{~cm}$ to $1.62 \%$ at $15 \mathrm{~cm}$, then returns to $2.63 \%$ at $45 \mathrm{~cm}$ ( $72 \%$ of the surface TOC). Site 2 and S3 undergo another inflection in TOC and $\mathrm{TN}$ at $95 \mathrm{~cm}$, corresponding to the presence of a visible OM horizon in S2 and a buried OM rich clayey silt unit overlain by a lamination of sand in S3.

Site 4 has a distinctly different depositional environment from $\sim 165-280 \mathrm{~cm}$. Figure 5.7 shows the section of core from $185 \mathrm{~cm}$ to $275 \mathrm{~cm}$ that displays the characteristics of alluvial deposition.

As shown in Figure 5.7 there is a set of thin laminations of alternating texture from $185-202 \mathrm{~cm}$, At $195 \mathrm{~cm}$ depth there is visible OM (roots and twigs) and SOM inflection in TOC (1.4\%) and TN (0.09\%). At $202 \mathrm{~cm}$ a distinct lamination sequence of pumice, sand and silt/fine sand is correlated with the sudden drop

Alluvial Inorganic Sediments

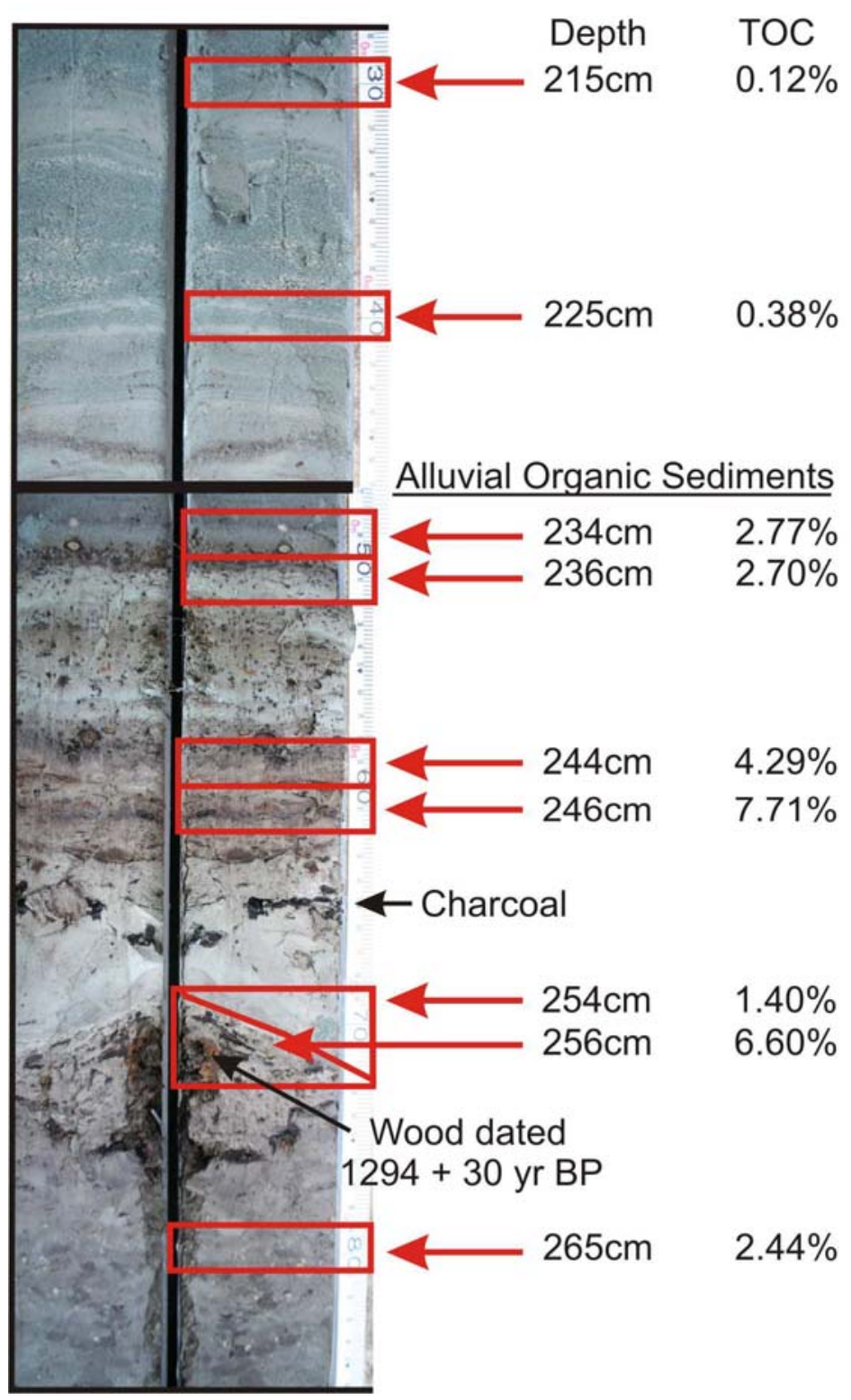

Figure 5.7: Transect 2 Site $4185 \mathrm{~cm}-275 \mathrm{~cm}$. 
in nutrient content for samples at $205 \mathrm{~cm}, 215 \mathrm{~cm}$ and $225 \mathrm{~cm}(\bar{x}=0.23 \% \pm$ $0.1 \%$ TOC, $\bar{x}=0.023 \% \pm 0.006 \% \mathrm{TN}$ ). From $230-260 \mathrm{~cm}$ paired samples at $234 \mathrm{~cm}$ and $236 \mathrm{~cm}, 244 \mathrm{~cm}$ and $246 \mathrm{~cm}$ and $254 \mathrm{~cm}$ and $256 \mathrm{~cm}$ were selected to highlight the differences in OM content of the laminations in the now more uniform silt or sandy silt matrix. These samples contained well preserved wood fragments (evidence of charring on some specimens), charcoal, root complexes, blades of grasses, Podocarp leaves and seeds which were all removed from the surrounding sediments prior to isotopic analyses. Samples from $234 \mathrm{~cm}$ and $236 \mathrm{~cm}$ yielded similar values despite the apparent visual difference in OM concentration ( $2.77 \%$ and $2.7 \%$ TOC, $0.13 \%$ and $0.15 \% \mathrm{TN})$. Samples from $244 \mathrm{~cm}$ and $246 \mathrm{~cm}$ showed an increase in TOC from $4.29 \%$ to $7.71 \%$ and an increase in TN from $0.29 \%$ to $0.47 \%$. The high level of TOC in S4 at $246 \mathrm{~cm}$ is the highest recorded value across all sites in both transects. Paired samples at $254 \mathrm{~cm}$ and $256 \mathrm{~cm}$ have a large difference in OM concentration as evidenced by the drop in TOC and TN to $1.4 \%$ and $0.1 \%$ and then an increase to $6.6 \%$ and $0.35 \%$ (a relative difference of $78.8 \%$ and $97.1 \%$ respectively). At $265 \mathrm{~cm}$ and $275 \mathrm{~cm}$ TOC and TN decline.

\section{C:N}

The C:N ratio (mol TOC:TN) for each site on T2 shows uniformity to a shallower depth (than T1) of $5 \mathrm{~cm}$ to $15 \mathrm{~cm}$ at a mean value of $10.73 \pm 0.6$. Sites 1,3 and 4 continue this linear trend down to $35 \mathrm{~cm}$ depth ( $\mathrm{S} 1$ has a slight reduction trend of 9.1 at $35 \mathrm{~cm}$ ), while $S 2$ shows a large increase in C:N ratio from $10-45 \mathrm{~cm}$ depth of 18.4. Sites 3 and S4 then follow a similar trend to that of S2 but with more subdued peaks in $\mathrm{C}: \mathrm{N}$ at $35 \mathrm{~cm}$ and $45 \mathrm{~cm}$ depth of 13.9 and 14.4 respectively. Variability from $\sim 45 \mathrm{~cm}$ depth rapidly increases although $\mathrm{S} 2$ and S3 have some trend similarities to a depth of $125 \mathrm{~cm}$. Site 4 may follow a similar pattern but sample resolution was insufficient through this section to show this below $55 \mathrm{~cm}$. Site 3 displays a negative shift to 8 at $115 \mathrm{~cm}$ depth and is strikingly uniform with increasing depth to $395 \mathrm{~cm}$ (S3 $115 \mathrm{~cm}-395 \mathrm{~cm} \bar{x}=7.3 \pm$ $0.9 \mathrm{~mol})$. Site 4 has low resolution sampling through the mid range of the core $(55-195 \mathrm{~cm})$. Below $195 \mathrm{~cm}(18.8)$ there is a shift from high C:N ratio to mid range $(205 \mathrm{~cm}, 215 \mathrm{~cm}$ and $225 \mathrm{~cm} \bar{x}=11.4 \pm 1.9)$, to a low C:N for the $234 \mathrm{~cm}$ and $236 \mathrm{~cm}$ lamination paired samples of 4.4 and 3.5 respectively, corresponding to the transition between the bottom of the grain size laminations with the top of the OM laminations. There is a large increase to the next grouping of C:N values at $244 \mathrm{~cm}$ and $246 \mathrm{~cm}, 254 \mathrm{~cm}$ and $256 \mathrm{~cm}, 265 \mathrm{~cm}$ and $275 \mathrm{~cm}(\bar{x}=19.4 \pm 2.1)$. The OM rich sample of each pair has a higher C:N than the other even though they are close together in $\mathrm{C}: \mathrm{N}$ value for both low and high pairs.

\section{$\delta^{13} \mathrm{C}$}

As with $\mathrm{T} 1$ topsoil $\delta^{13} \mathrm{C}$ values, $\mathrm{T} 2$ has the expected $\delta^{13} \mathrm{C}$ enrichment curve with increasing depth from a mean $(\bar{x})$ of $-28.5 \pm 0.1 \%$ at $5 \mathrm{~cm}$ depth to $25 \mathrm{~cm}(-$ $25.8 \%$ ) for $\mathrm{S} 1$ and $35 \mathrm{~cm}$ for S2, 3 and $4(\bar{x}=-25.7 \pm 0.6 \%$ ). Site 1 data end at $35 \mathrm{~cm}$ depth on a slight depletion trend $(-26 \% 0)$. S2 and S3 maintain the approximate values they have at $55 \mathrm{~cm}$ depth $(-25.3 \%$ and $-26 \%$ respectively) to $95 \mathrm{~cm}$. S2 below $95 \mathrm{~cm}$ initially enriches again to $125 \mathrm{~cm}$, and then sharply 
depletes at $135 \mathrm{~cm}$. Sites 3 and 4 show trends of depletion below $115 \mathrm{~cm}$, but the resolution of data for S4 is poor from $55-195 \mathrm{~cm}$ depth. In S3 the shift is gradual depletion over the range $85-250 \mathrm{~cm}$ depth $(-25.8 \%$ o to $-27.3 \%$ o before enriching again at $350 \mathrm{~cm}(-25 \%)$. Site 4 has an erratic profile at depth (195$275 \mathrm{~cm}$ ) with $\delta^{13} \mathrm{C}$ values equivalent to or more depleted than those of the contemporary topsoil to $35 \mathrm{~cm}$ depth. The mean value for $195-275 \mathrm{~cm}$ is $-28 \pm$ $1 \%$ including one outlier at $244 \mathrm{~cm}(-30.4 \%)$. There is no apparent trend relating to the paired samples in enrichment or depletion.

$\delta^{15} \mathrm{~N}$

For T2 the $\delta^{15} \mathrm{~N}$ values of the $5 \mathrm{~cm}$ topsoil show little variation ranging from $4.8 \%$ at S2 to $5.2 \%$ at S4 and fall within the $\delta^{15} \mathrm{~N}$ expected range for C3 terrestrial plants (+3 to $+7 \%$ ) and SOM (+2 - +5\%o) (Kendall et al. 2001). The shallow core at Site 1 displays a small enrichment trend to $15 \mathrm{~cm}$ depth where it stabilises at $\sim 6 \%$ to $35 \mathrm{~cm}$ depth. With increasing depth S2, S3 and S4 all follow a similar pattern of depletion with slightly different values, from an average value of $4.9 \pm 0.2 \%$ at $5 \mathrm{~cm}$ to an average of $3.5 \pm 0.4 \%$ at $45 \mathrm{~cm}$ depth. From $45 \mathrm{~cm}-125 \mathrm{~cm} \mathrm{~S} 2$ switches to an enrichment trend increasing from $3.1 \%$ o to $6.3 \%$. Site 3 from $45 \mathrm{~cm}-395 \mathrm{~cm}$ displays uniform values with little variation about a mean of $4.2 \pm 0.5 \%$ o. Site 4 below $55 \mathrm{~cm}$ displays a large shift in trend towards very low depleted values at $195 \mathrm{~cm}-275 \mathrm{~cm}$ with some variation around a mean of $1.7 \pm 0.7 \%$.

\section{Transect 2 Summary}

Sites 2, 3 and 4 display similar trend characteristics across all variables analysed, particularly in the contemporary topsoil to $\sim 50 \mathrm{~cm}$ depth where a common paleosol exists. S1 was only analysed to a shallow depth $(35 \mathrm{~cm})$, as it is relatively uniform and contains no buried $\mathrm{OM}$ below this depth. $\delta^{13} \mathrm{C}$ profiles all show the characteristic enrichment curve with increasing depth in the contemporary topsoil. There is a large deviation in S4 at $195 \mathrm{~cm}-275 \mathrm{~cm}$ in all variables analysed. The values observed at depth fall outside the range of all other measurements at similar depths. Sample pair $234 \mathrm{~cm}$ and $236 \mathrm{~cm}$ has almost exactly the same values across all categories; the other pairs differentiate in values reflecting the presence of $\mathrm{OM}$ rich and $\mathrm{OM}$ poor sediments.

\section{Bivariate Plots}

Samples from different environments often exhibit characteristic patterns and ranges in values of various geochemical properties, and these can be displayed simply using bivariate plots. Figures 5.8 and 5.9 show bivariate plots $\left(\delta^{13} \mathrm{C}\right.$ plotted against C:N) for Tutira sample data compared to known ranges of these variables for weathered rock, C3 SOM and C3 plant material.

The intersection of weathered mineral material with SOM forms the necessary components for the classical soil definition and, as a result, the samples for most sites and depths in T1 are centred near or in this intersection. The outliers which lie in the C3 terrestrial plant range for S1 and S3 correspond to the appearance of paleosols within the cores e.g. S3 $=205 \mathrm{~cm}, 215 \mathrm{~cm}$ and $225 \mathrm{~cm}$ 
and $\mathrm{S} 1=90 \mathrm{~cm}$ (Figure 5.1). When T2 is plotted in the same manner (Figure 5.9) the differences in OM preservation characteristics are shown with S2, S3 and S4 all containing evidence of C3 plant material.

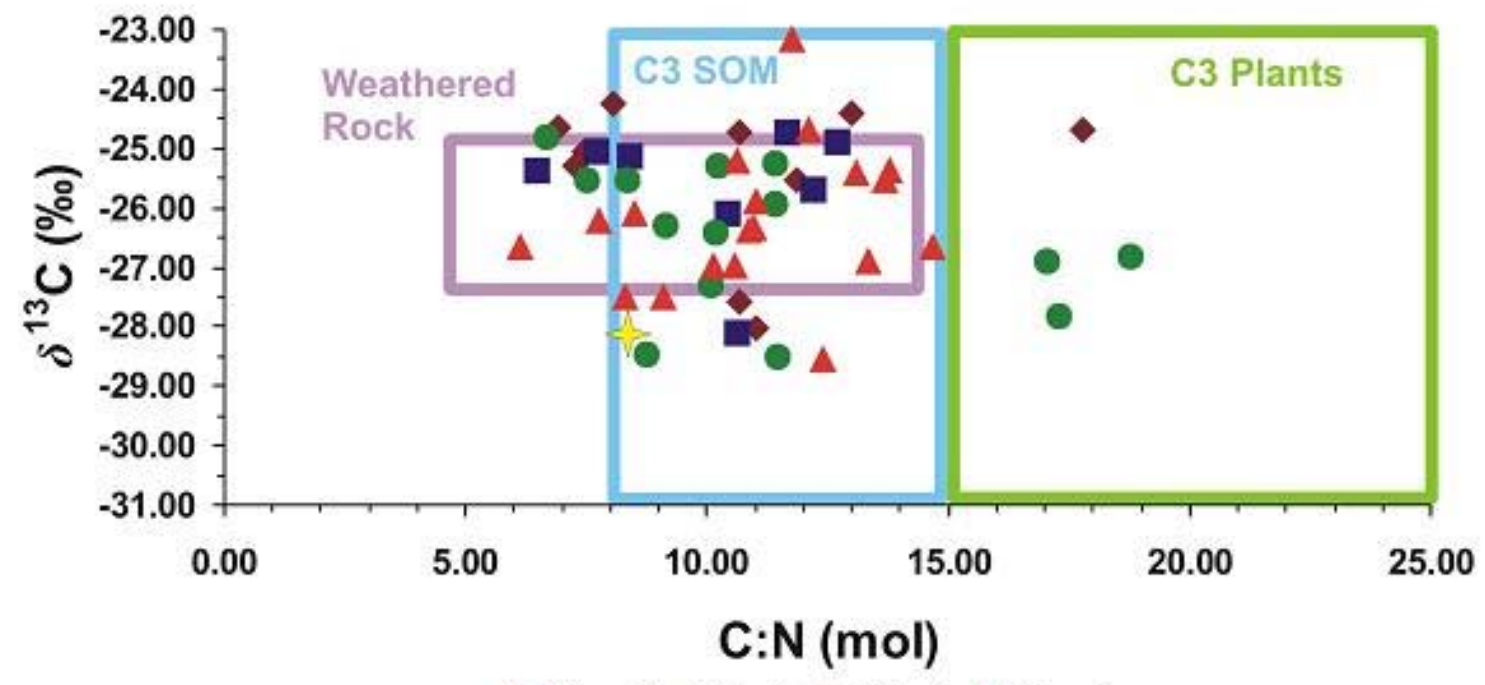

- Site 1 \& Site $2 \bullet$ Site $3 \Delta$ Site 4

Figure 5.8: shows the $\mathrm{T} 1 \delta^{13} \mathrm{C}$ and $\mathrm{C}: \mathrm{N}$ values for weathered rock, $\mathrm{C} 3$ SOM and C3 terrestrial plants from Table 4.3. The yellow star is from a gully site (Gomez et al. 2004, $n=2$ ) in the geologically similar Waipaoa catchment which has a $\delta^{13} \mathrm{C}$ range of $-24.8 \%$ to $-27.2 \%$ and $\mathrm{C}: \mathrm{N}$ of $4.8-14.4 \mathrm{~mol}$ from weathered bedrock (sandstone, siltstone and argillite).

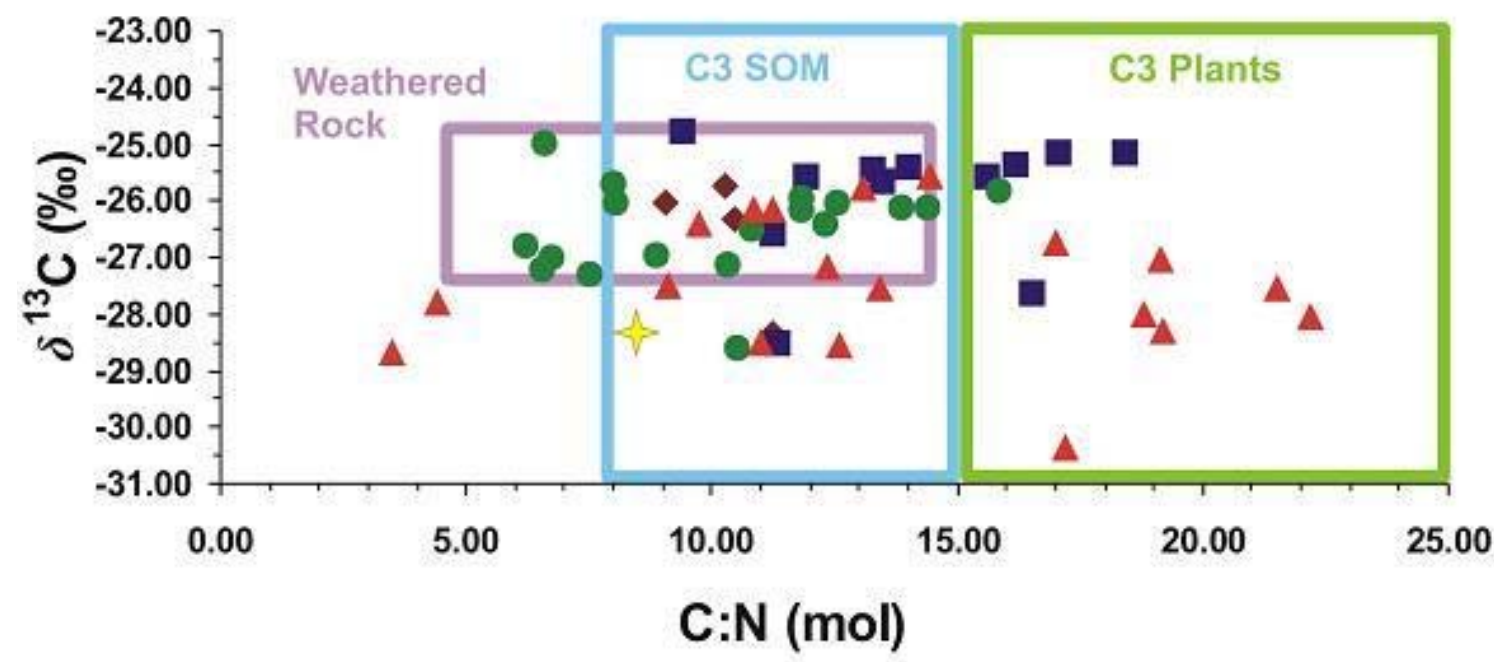

Site 1 Site $2 \bullet$ Site $3 \Delta$ Site 4

Figure 5.9: Transect $2 \delta^{13} \mathrm{C}$ and $\mathrm{C}: \mathrm{N}$ values for weathered rock, $\mathrm{C} 3$ SOM and $\mathrm{C3}$ terrestrial plants from Table 4.3. The yellow star is from a gully site (Gomez et al. $2004, n=2$ ) in the geologically similar Waipaoa catchment which has a $\delta^{13} \mathrm{C}$ range of $-24.8 \%$ to $-27.2 \%$ and $\mathrm{C}: \mathrm{N}$ of $4.8-14.4 \mathrm{~mol}$ from weathered bedrock, sandstone, siltstone and argillite lithologies.

The increase in C3 plant material in T2 occurs both at depth (S4: $195 \mathrm{~cm}, 246$ $\mathrm{cm}, 254 \mathrm{~cm}, 256 \mathrm{~cm}, 265$ and $275 \mathrm{~cm})$ and in shallower paleosols (S2: $25 \mathrm{~cm}$, $35 \mathrm{~cm}, 45 \mathrm{~cm}, 55 \mathrm{~cm}$ and $135 \mathrm{~cm}$; S3: $85 \mathrm{~cm}$ ), (Figure 5.2). This indicates that the paleosol characteristics of T2 are more conducive to C3 plant material 
preservation than that of T1. Despite the increase in C3 plant material, all T2 site samples are also centred near or in the intersection of weathered parent material and C3 SOM.

High C:N values can be the result of differential rates of nutrient decay i.e. $\mathrm{N}$ being consumed faster than $C$ in which case a high $\mathrm{C}: \mathrm{N}$ value implies active nutrient decomposition. Alternatively, the relatively high $C$ levels could imply that the present source of rapidly buried OM, i.e. preserved C3 plant material, is removed from active microbial decomposition through rapid accumulation of sediment.

\section{Mixing Models}

A concentration-weighted linear mixing model developed by Phillips and Koch (2002; available from www.epa.gov/wed/pages/models.htm) using three common input variables such as two isotopes and the organic carbon content (e.g. ${ }^{13} \mathrm{C},{ }^{15} \mathrm{~N}, \mathrm{TOC}$ and TN) can be used to determine the relative contributions of the components to a mixture. In a geomorphological application this model allows for the comparison of the relative contributions to depositional sediments of three different source materials. Gomez et al. (2004) applied this model to floodplain sediments from McPhail's Bend in the Waipaoa catchment using gullies, weathered bedrock and Bw horizon soil as three different sediment source types. For a concentration-weighted linear mixing model to work the isotopic composition of the different sources must vary substantially, and the overall distribution should have a low variance (Phillips and Koch 2002). Reference data from the Oporae Valley were not collected, but the characteristics of the Waipaoa catchment described by (Brackley 2005) and that of the Oporae Valley are comparable in terms of tectonic setting, rainfall,

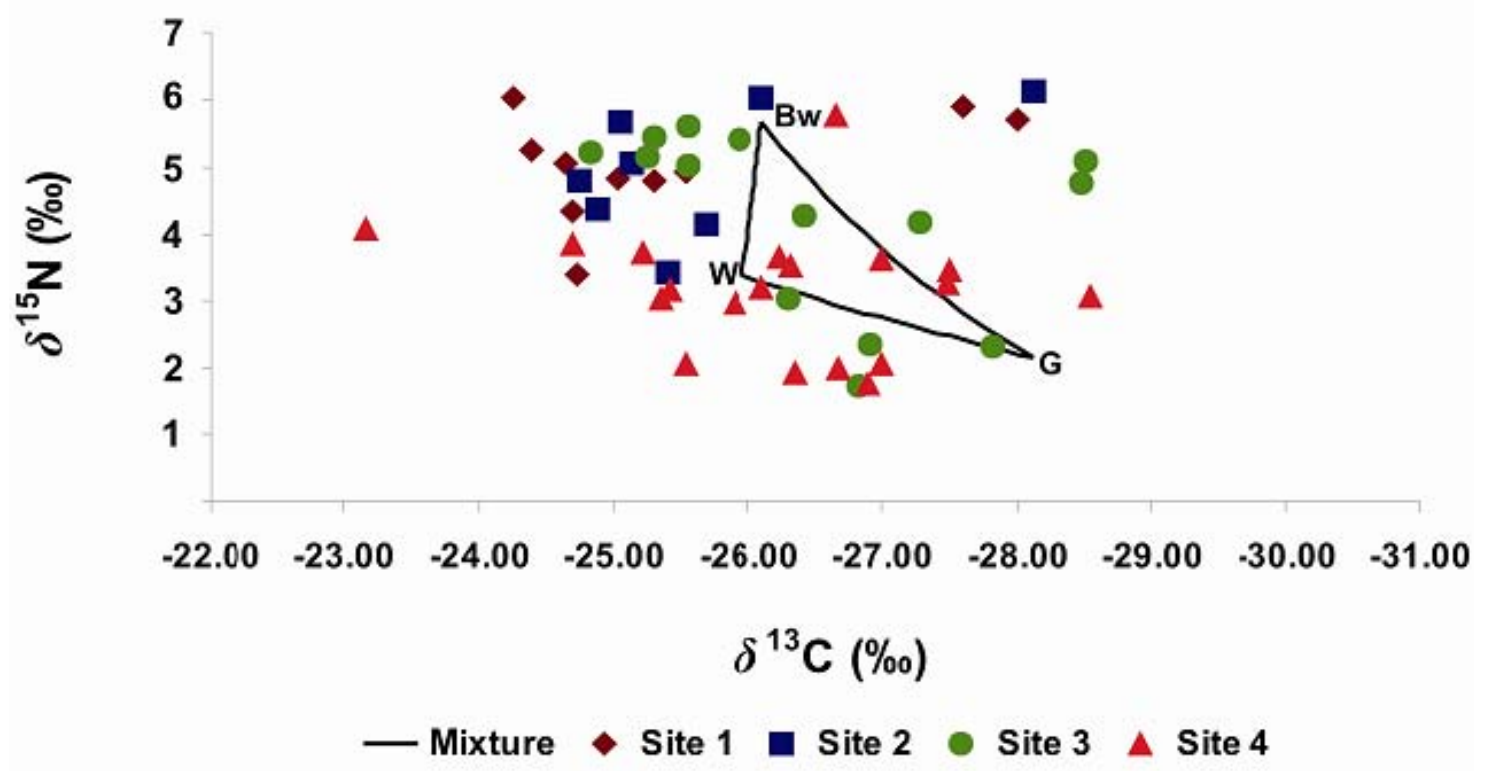

Figure 5.10: T1 $\delta^{13} \mathrm{C}$ and $\delta^{15} \mathrm{~N}$ overlain by the source type mixing triangle. $\mathrm{S} 1$ and S2 are similar to each other in distribution, whereas S3 and S4 have a more widespread distribution. $\mathbf{S} 4$ shows a significant depletion in $\delta^{15} \mathrm{~N}$ values. 
erosion history, tephra and lithology. Based on values of $\delta^{13} \mathrm{C}$ and $\delta^{15} \mathrm{~N}$, mixing triangles from Gomez et al. (2004) are shown in Figures 5.10 and 5.11, with Oporae data superimposed.

Based on the assumption that the values used by Gomez et al. (2004) are similar to those in the Oporae Valley, T1 displays only a general trend towards the contributing source materials having predominantly come from weathered rock and Bw soil horizons. Site 3 and 4 appear to have more contributing source material from gullies. However as shown in Figure 5.11, T2 reveals a more distinct pattern relating to the relative contribution of gully sediments.

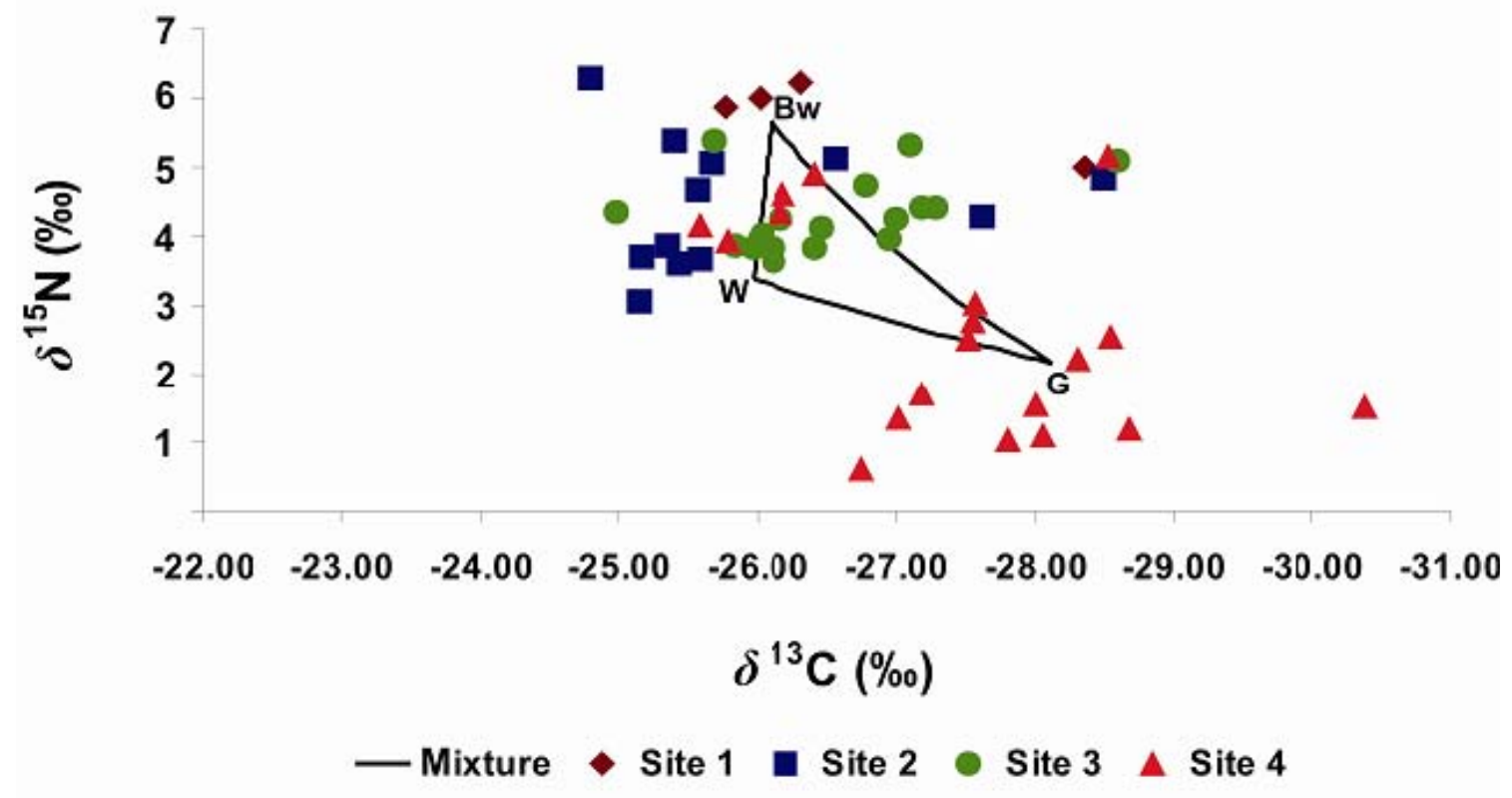

Figure 5.11: shows the grouping of $S 1, S 2, S 3$ and the top $55 \mathrm{~cm}$ of $S 4$. S4 below $135 \mathrm{~cm}$ depth shows a small depletion shift in $\delta^{13} \mathrm{C}$ and a large depletion shift in $\delta^{15} \mathrm{~N}$.

The separation of weathered rock and Bw soil from gully source material into two distinct clusters happens along a broadly similar axis to that of T1 but is more well defined in T2. Notably the depositional environment in the lower section of T2 S4, which has been identified as unique within the cores, displays a strong shift towards gully sediment source material from the rest of the T2 data set. The lower section of T2 S4 is heavily laminated with what appears to be erosion pulses deposited over an organic rich possibly swampy forest soil. Despite the OM rich horizons there appears to be a definite shift in sediment source material that is less evident in all the other cores. This supports the conclusion that lower section of T2 S4 may have been part of a swampy drainage network in the central valley where sediments were deposited frequently as fine laminations sourced from gully networks in the Oporae Valley headwaters.

\section{Carbon Loss through Land Use Change}

Using undisturbed and regenerating forest soil \%TOC from two nearby locations as proxy values, the \%TOC is compared to that of the Oporae Valley topsoil to 


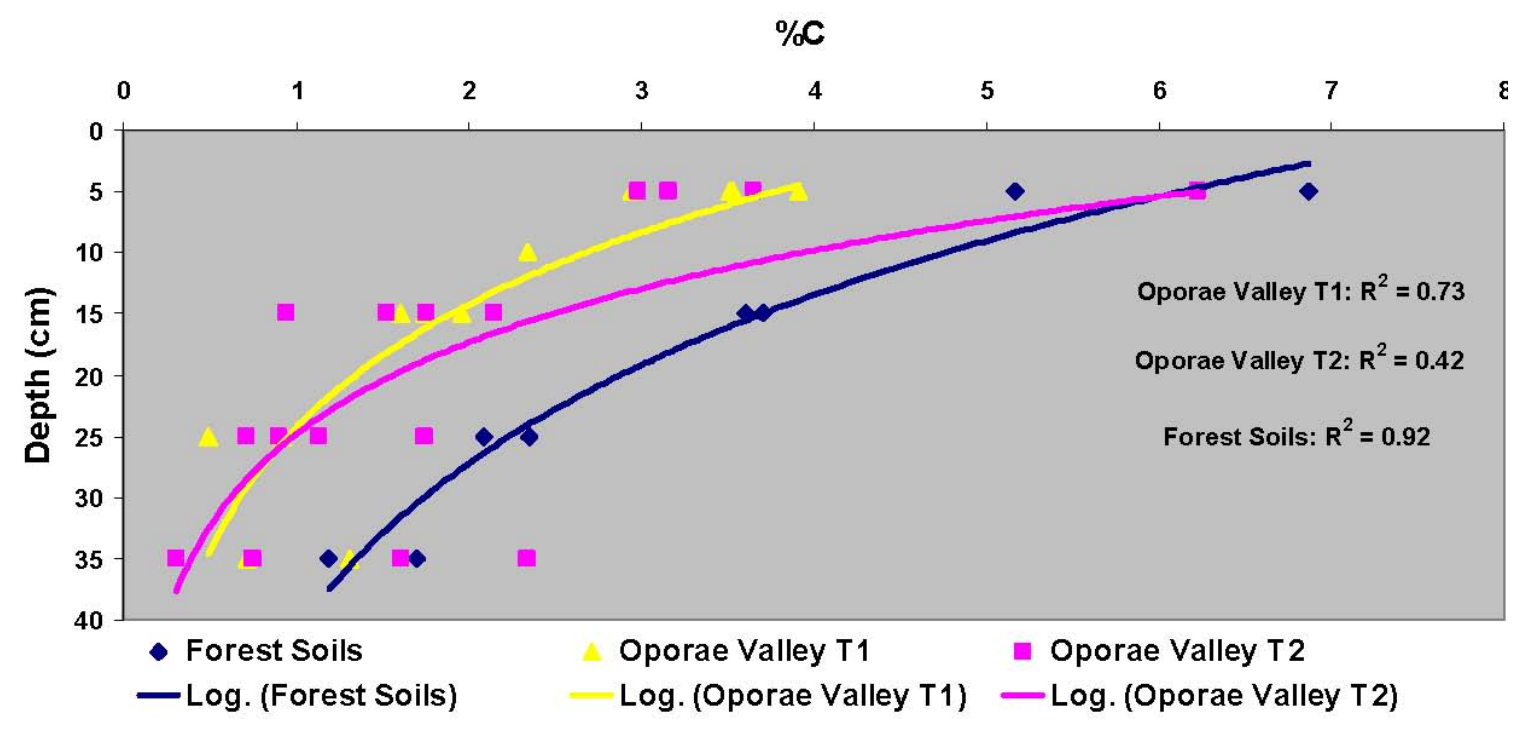

Figure 5.12: \%TOC from forest soils and pasture soils to $35 \mathrm{~cm}$ depth. White Pine Bush and Hanger data are combined and have a high $R^{2}$ value of 0.92 . Oporae Valley $\mathrm{T} 1$ has an $R^{2}$ of 0.73 and $\mathrm{T} 2$ a low $\mathbf{R}^{2}$ of 0.42 .

$35 \mathrm{~cm}$ depth. Figure 5.12 shows the distribution and trend lines for the two forest soil sites (combined) and T1 and T2.

The poor $\mathrm{R}^{2}$ value in $\mathrm{T} 2$ is due to the incorporation of a paleosol at $\sim 35 \mathrm{~cm}$ depth at $S 2$ and $S 4$, also the single high value at $5 \mathrm{~cm}$ depth is from $S 1$ which is under pasture but immediately adjacent to regenerating native forest up-slope. Based on the broad assumption that T1 (pasture) and the native forest soil sample sets are representative of topsoils of similar characteristics from the wider catchment (with no paleosol SOM), the strong $\mathrm{R}^{2}$ value in the proxy forest soils and that of T1 can be used as a basis for calculating the approximate loss of \%TOC due to land use change. The mean \%TOC to $35 \mathrm{~cm}$ depth for the proxy forest soils is $3.34 \%$, and for $\mathrm{T} 1$ is $2.08 \%$. This equates to a difference of $1.34 \%$ TOC, or a soil that has lost $(\Delta) 39.36 \%$ of the total TOC that it would have under native forest to $35 \mathrm{~cm}$ depth.

\section{$5.4{ }^{14} \mathrm{C}$ Analysis}

Prior to this study four unpublished ${ }^{14} \mathrm{C}$ ages were obtained for the Oporae Valley as supporting evidence for establishing the age of the pre-human forest soils. Of these samples three were taken from buried in situ tree stumps in the forest paleosol along the Oporae Valley stream channel, accompanied by one corroborating soil sample taken from the paleosol immediately adjacent to the buried tree stump in the upper valley (Page, M., unpublished data). Also, one wood fragment taken from a core situated on the contemporary colluvial footslope (northern side of the valley in close proximity to T2 S2) was obtained during field work in the area (Crozier, M., unpublished data). Additional to these ages, a further three samples from the Oporae Valley cores were processed and analysed for their ${ }^{14} \mathrm{C}$ isotope ratios. Figure 5.13 displays the infrared image of the Oporae Valley Cyclone Bola erosion scars and colluvial/alluvial deposition; superimposed upon this image are the position, depths and ages (yr $\mathrm{BP}$ ) from both the pre-existing ${ }^{14} \mathrm{C}$ ages and those obtained during this study. 


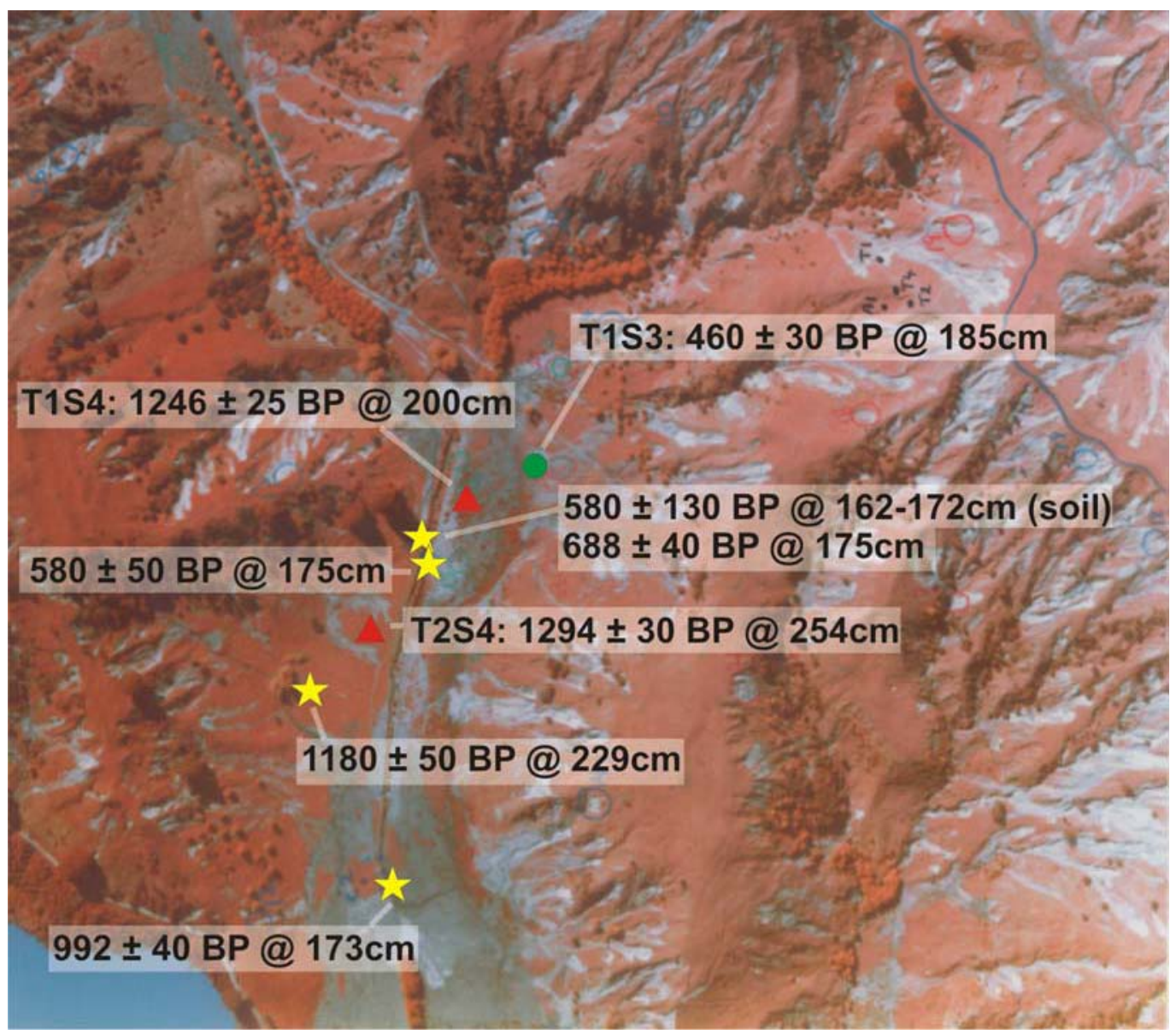

Figure 5.13 shows the eight ${ }^{14} \mathrm{C}$ ages from the Oporae Valley on the infrared image of the Cyclone Bola erosion scars and colluvial/alluvial deposition. Yellow stars denote the pre-existing ages: three were taken from in situ tree stumps along the contemporary drainage channel which can be clearly seen as a dark line down the centre of the valley. A paleosol adjacent to one of the upper valley stumps was also analysed. A further ${ }^{14} \mathrm{C}$ age was taken from a joint VUW/GNS drilling expedition in 1999 near to T2 from this study. The two red triangles denote the T1 S4 and T2 S4 wood fragment samples. The green circle denotes the T1 S3 wood fragment taken from colluvial sediments.

The observable trends from the ${ }^{14} \mathrm{C}$ data set show that based on depth alone there are two broad groupings from the seven upper valley samples. Four ages ranging from $460 \pm 30$ to $688 \pm 40 \mathrm{yr} \mathrm{BP}$ and $162 \mathrm{~cm}$ to $185 \mathrm{~cm}$ deep form the first grouping, and three ages ranging from 1,180 \pm 50 to 1,294 $\pm 30 \mathrm{yr}$ BP and $200 \mathrm{~cm}$ to $254 \mathrm{~cm}$ deep make up the second grouping. The age from the lower valley which falls between these two groups at $992 \pm 40 \mathrm{yr}$ BP at $173 \mathrm{~cm}$ deep fits the theory of standard geomorphological development of a valley in-filling at a slower rate as the depositional environment is further from the source area. Using ${ }^{14} \mathrm{C}$ ages from Figure 5.13 and supporting palynological evidence, an approximate sedimentation rate for the upper Oporae Valley can be determined. Table 5.4 shows all of the known ${ }^{14} \mathrm{C}$ ages from the Oporae Valley and the deposition rate for each.

\subsection{Palynology}

The samples taken for pollen analysis were selected to locate the transition from pre-human paleosol to anthropogenic sedimentation in Unit 6, the colluvial 
footslope, and Unit 7, the alluvial toeslope. Dependent upon the species, a grain count of $50-150$ is necessary for statistical significance in palynological studies (Moore et al. 1978). The highest grain count recorded from the Oporae Valley core samples was 26 grains across all species. Due to the lack of preservation and the variable rates of degradation between pollen spores from different species, the grain count results that were obtained are potentially biased for species of 'more resistant' (to degradation) grain types. Table 5.5 displays the summary of results for the eight samples analysed from Unit 6 and Unit 7 on T1.

The abundance of the relatively corrosion resistant Cyathea and Asplenium pollen grains over that of all other species is evidence of biogeochemical degradation, with little evidence remaining of the pollen record in these cores (McLea 2007). The ubiquity of very fine charcoal across almost all of the samples suggests that this very fine material has been either washed in and/or transported down through the profile via hydrological processes or that is in situ within the sediment. Based on this small sample size it is difficult to determine which is the more likely, but $\mathrm{S} 4$ exhibits finer particles with increasing depth consistent with the preferential downward movement of finer particles, whereas S3 exhibits increasing coarseness of particles with depth. The only site that contained no charcoal (S4 $225 \mathrm{~cm}$ ) did contain some evidence of heat transformation on the remaining corroded plant debris, but the fragments would have required more heat before being classified as charcoal (McLea 2007). The presence of undecomposed plant fragments suggests either preservation or a lack of current microbial activity. Supporting this notion, Dr. McLea (2007) noted the absence of fungal spores whose presence would indicate contemporary biological activity. The visual appearance of the two cores can be directly attributed to their position on the transect and the associated geomorphic process dominance (or land surface model unit). T1 S4 is predominantly alluvial and T1 S3 is interpreted as alluvial in the base (laminations/paleosol) and colluvial toward the top (uniform block of sediments). In T1 S4 the upper core is absent of almost any spores (samples taken at $45 \mathrm{~cm}$ and $95 \mathrm{~cm}$ ), and this is where the visual presence of iron oxides indicates an aerobic environment. The mode of deposition and the associated sediment characteristics in the lower core appear to have created an environment in S4 more conducive (wetter) to a wider variety of pollen spore preservation at similar depth range in S3, yet S3 has a higher grain count for fewer taxa. These findings show that some decomposition has taken place at some point. However, the abundant fine charcoal contamination relates to the initial pre-European forest fires set by the Maori. Such fires may have destroyed much of the pollen evidence.

\subsection{Organic Matter Species Identification}

In T2 S4 $(185-285 \mathrm{~cm})$ there is high frequency alternation between clayey silts with some organic material with sharp $(<0.5 \mathrm{~cm})$ transitions to laminated alluvial deposits with sharp transitions of fine to medium sands, clayey silts and pumice contain charcoal and well preserved organic material. The organic material included root and leaf structures (possibly Matai and Rimu), hollow reed stems, grasses, seeds and several large pieces of wood (some evidence of charring). 
Table 5.4. Distribution and depth range of known ${ }^{14} \mathrm{C}$ ages from the Oporae Valley.

\begin{tabular}{|c|c|c|c|c|c|c|c|}
\hline \multirow[t]{2}{*}{ Source } & \multirow[t]{2}{*}{ Location } & \multirow{2}{*}{$\begin{array}{l}\text { Specimen } \\
\text { Type }\end{array}$} & \multirow{2}{*}{$\begin{array}{l}\text { Depth } \\
(\mathrm{cm})\end{array}$} & \multirow{2}{*}{$\begin{array}{c}\text { Age } \\
\text { (Years BP) }\end{array}$} & \multirow{2}{*}{$\begin{array}{c}\begin{array}{c}\text { Deposition } \\
\text { Rate }\end{array} \\
\text { (mm/year) }\end{array}$} & \multicolumn{2}{|c|}{ Relative Position } \\
\hline & & & & & & Slope & Valley \\
\hline This study & T1 S4 & Wood fragment & 200 & $1246 \pm 25$ & 1.6 & Unit 7 & Upper \\
\hline This study & T2 S4 & Wood fragment & 254 & $1294 \pm 30$ & 2 & Unit 7 & Upper \\
\hline $\begin{array}{c}\text { VUW } \\
\text { (unpublished) }\end{array}$ & Crozier core & Wood & 229 & $1180 \pm 50$ & 1.9 & Unit 6 & Upper \\
\hline \multicolumn{3}{|c|}{$\begin{array}{l}\text { Average for the Pre-Human + Anthropogenic } \\
\text { Grouping }\end{array}$} & 227.7 & 1240 & 1.8 & - & Upper \\
\hline $\begin{array}{c}\text { GNS } \\
\text { (unpublished) }\end{array}$ & Stream Bank & Soil & $\begin{array}{l}162-172 \\
(167)\end{array}$ & $580 \pm 50$ & 2.9 & Unit 7 & Upper \\
\hline $\begin{array}{c}\text { GNS } \\
\text { (unpublished) }\end{array}$ & Stream Bank & $\begin{array}{l}\text { Wood (buried } \\
\text { stump) }\end{array}$ & 175 & $688 \pm 40$ & 2.5 & Unit 7 & Upper \\
\hline $\begin{array}{c}\text { GNS } \\
\text { (unpublished) }\end{array}$ & Stream Bank & $\begin{array}{l}\text { Wood (buried } \\
\text { stump) }\end{array}$ & 175 & $580 \pm 40$ & 3 & Unit 7 & Upper \\
\hline \multicolumn{3}{|c|}{ Average for the Anthropogenic Grouping } & 172.3 & 616 & 2.8 & - & Upper \\
\hline \multicolumn{3}{|c|}{$\begin{array}{c}\text { Difference between averages (Pre-human - } \\
\text { Anthropogenic) }\end{array}$} & 53.3 & 624 & 0.9 & - & Upper \\
\hline This study & T1 S3 & Wood fragment & 185 & $460 \pm 30$ & 4 & Unit 6 & Upper \\
\hline $\begin{array}{c}\text { GNS } \\
\text { (unpublished) }\end{array}$ & Stream bank & $\begin{array}{l}\text { Wood (buried } \\
\text { stump) }\end{array}$ & 173 & $992 \pm 40$ & 1.7 & Unit 7 & Lower \\
\hline
\end{tabular}


Table 5.5. Pollen Grain Count for the Oporae Valley Terrestrial Cores.

\begin{tabular}{|c|c|c|c|c|c|c|c|c|c|c|c|c|}
\hline Sample & Asplenium & Cyathea & $\begin{array}{l}\text { Pteridium } \\
\text { aquilinum }\end{array}$ & $\begin{array}{c}\text { Dacrydium } \\
\text { cupressinum }\end{array}$ & $\begin{array}{c}\text { Prumnopitys } \\
\text { taxifolia }\end{array}$ & $\begin{array}{l}\text { Nothofagus } \\
\text { fusca }\end{array}$ & Apiaceae & Asteraceae & Poaceae & Cyperaceae & Charcoal & $\begin{array}{l}\text { Plant } \\
\text { debris }\end{array}$ \\
\hline & $\begin{array}{l}\text { Ground } \\
\text { Fern }\end{array}$ & $\begin{array}{l}\text { Tree } \\
\text { Fern } \\
\end{array}$ & Bracken & Rimu & Matai & Red Beech & $\begin{array}{c}\text { Aromatic } \\
\text { plants }\end{array}$ & Daisy & Grasses & $\begin{array}{c}\text { Rushes \& } \\
\text { sedges }\end{array}$ & & \\
\hline & $\begin{array}{l}\text { Tropical } \\
\text { climate }\end{array}$ & $\begin{array}{l}\text { Tropical } \\
\text { climate } \\
\text { (colonis } \\
\text { er) }\end{array}$ & Coloniser & $\begin{array}{l}\text { Podocarp/ } \\
\text { broadleaf } \\
\text { forest } \\
\text { emergent }\end{array}$ & $\begin{array}{c}\text { Podocarp/ } \\
\text { broadleaf } \\
\text { forest } \\
\text { emergent }\end{array}$ & $\begin{array}{l}\text { Mild } \\
\text { oceanic } \\
\text { climate }\end{array}$ & & & $\begin{array}{c}\text { Introduced } \\
\text { and } \\
\text { naturally } \\
\text { occurring }\end{array}$ & $\begin{array}{l}\text { Grows all } \\
\text { over but } \\
\text { prefers } \\
\text { wetlands }\end{array}$ & & \\
\hline $\begin{array}{c}\mathrm{S} 3 \\
125 \mathrm{~cm}\end{array}$ & 6 & 20 & & & & & & & & & Yes * ${ }^{\dagger}$ & \\
\hline $205 \mathrm{~cm}$ & 1 & 6 & & & & & & & & & Yes $^{*^{\dagger}}$ & \\
\hline $225 \mathrm{~cm}$ & 1 & 14 & & 1 & $1^{c}(26 / 4)$ & & & & & & Yes $^{\dagger}$ & \\
\hline $\mathrm{S} 445 \mathrm{~cm}$ & & & & & & & & 3 & & & Yes & Yes * \\
\hline $95 \mathrm{~cm}$ & & & & & & & & & & & Yes * ${ }^{\dagger}$ & \\
\hline $125 \mathrm{~cm}$ & & & 3 & & & 3 & & & 4 & 1 & Yes * & Yes * \\
\hline $175 \mathrm{~cm}$ & & & & & & & & & & & $\begin{array}{l}\text { Yes * } \\
\text { (small } \\
\text { qty) }\end{array}$ & \\
\hline $225 \mathrm{~cm}$ & & 9 & 1 & & & & 3 & & 3 & 8 & more heat & Yes * ${ }^{c}$ \\
\hline
\end{tabular}

* denotes very fine

${ }^{\dagger}$ denotes limited count (sometimes absent from count)

c denotes corroded 
The two large well preserved seeds were identified as Prumnopitys taxifolia (matai, black pine; Figure 5.14) (Webb and Simpson 2001).

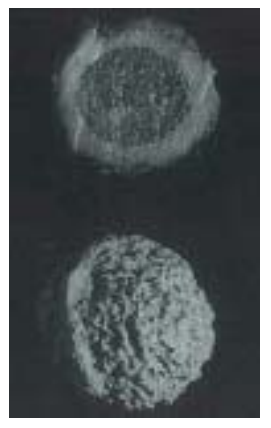

Figure 5.14: Matai seed Source: Webb and Simpson (2001).

Matai occurs throughout New Zealand in lowland forests favouring alluvial soils and volcanic ash. It is most commonly found in the remaining forests of the pumice country in the centre of the North Island (Poole 2006; Dawson and Lucas 2000). This species is often found with other tall podocarps (rimu, totara, miro, and kahikatea) forming a canopy over smaller broadleaf plants and ferns. They usually indicate the presence of a good soil, and this can be seen to correspond with the high carbon content of the untouched Urewera National Park vegetation and soils (Tate et al. 1997). 


\section{Chapter 6: Discussion}

\subsection{Discussion Overview}

The discussion is arranged in an order which addresses the main objectives in a logical progression. Beginning with some general observations that supplement subsequent interpretations, the focus then shifts to what impacts on the contemporary soils anthropogenic land-use change has had. Then having quantified the impacts of land-use change on topsoils the focus shifts to paleosols and the geomorphology of paleosols. Finally the sediment accumulation rates in the Oporae Valley are discussed. The main objectives all lead to conclusions that have implications for the accurate carbon accounting of terrestrial carbon from an area which is potentially representative of $10,000 \mathrm{~km}^{2}$ of North Island dry eastern hill country.

\subsection{General Observations}

All sites cored beyond $1 \mathrm{~m}$ in depth contain paleosols as indicated by the $\% \mathrm{TOC}$ and \%TN inflections. Transects 1 and 2 have physical differences in spatial scale, aspect, slope, lithology and mode of deposition, and between them are representative of the predominant depositional slopes within the valley. These physical differences are evidenced within the core logs, grain size analyses and geochemical analyses $\left(\mathrm{C} \%, \mathrm{~N} \%, \mathrm{C}: \mathrm{N},{ }^{13} \mathrm{C}\right.$ and $\left.{ }^{15} \mathrm{~N}\right)$. By analysing the variables and their relationships to each other, a determination of process dominance and its impacts on SOM can be made.

\section{Water Table Fluctuation}

The water table height throughout both transects varies primarily as a function of slope. There is a visual indication of this in the cores, as the effect of oxidation and reduction processes produces a rust coloured mottling (oxidation) and a distinctly blue hue which increases in brightness with increasing depth (reduction). The range of overlap (indicated by the arrows in Figure 5.1 and 5.2) can be used as a proxy for the fluctuation height of the water table. There are two distinct and observable trends that can be seen in Figure 5.1 that indicate that slope is the dominant control on water table height. Firstly the depth of the visible reducing conditions becomes shallower moving down slope, indicating that there is more soil water on the alluvial toeslope. Secondly, the range of overlap between reducing and oxidising conditions is larger up slope, indicating the greater range over which the water table height fluctuates dependant upon the precipitation input and evaporation potential of any given time of year. Therefore, OM buried on the alluvial toeslope is more likely to experience anaerobic conditions, thus dramatically slowing the rate of decomposition by soil micro-organisms which largely require oxygen for respiration. The greater range of overlap up-slope indicates increased wetting and drying cycles which has been shown to impact on the formation of soil aggregates thereby decreasing the amount of SOM protected from decomposition. Increased gradient up-slope also increases the rate of groundwater throughflow, increasing the amount of nutrient depletion through translocation and removal of organic compounds in solution. 
The deforestation and subsequent rapid accumulation of sediment in the Oporae Valley will have impacted significantly on the hydrology of the soils. Where the gradient is low, increased deposition will have increased the height of the water table proportionate to the increased rate of hydrological throughput created by the removal of the native forest vegetation. Where the gradient is steeper, the lack of vegetation will increase the overland flow, thereby removing any accumulating OM from the soil surface, also increasing the rate and range over which the water table height fluctuates creating temporary perched water tables. Under these circumstances and with little in the way of root strength cohesion, further erosion in the catchment is inevitable. This will then result in the increased transport of SOM through overland flow and mass movement events.

\section{Pumice Inclusions}

Volcanic glass typically found in fine silts and clays implies either in-situ deposits within undisturbed profiles, or reworked sediments as a part of the natural or anthropogenically enhanced erosion regime. Ryholitic (silica rich) tephra can also be found. Given that the age of the oldest ${ }^{14} \mathrm{C}$ age is $1,294 \pm 30$ yr BP (which is deeper than many of the pumice inclusions), and based on the frequency/magnitude of recent eruptions from likely source areas, the volcanic materials are most likely to have been reworked and deposited in their current locations subsequent to eruption events. Many of the cores contain large concentrations of matrix supported pumice clasts without orientation or sorting, suggesting that the sediments are allochthonous and that colluvial deposition is the dominant mode of transport where these concentrations arise. ${ }^{14} \mathrm{C}$ ages indicate that it is reasonable to assume all of the Oporae Valley cores contain sediments accumulated post the 1,850yr BP Taupo event even though evidence of pumice from this and other events is ubiquitous throughout the cores. And that therefore these are indeed depositional sites rather than in situ soils. Furthermore, in T1 the presence of poorly sorted pumice clasts is largely confined to distinct zones within the cores, in T2 they are more widespread throughout. This suggests that either the pumice content in the source material of $\mathrm{T} 1$ is more variable than that of $\mathrm{T} 2$, and/or that the mode of deposition is more variable on T1.

\subsection{Contemporary Pasture and Forest Soils}

The \%TOC of the contemporary topsoil from all sites has been compared with proxy pre-human native forest soils from the surrounding area. The proxy soils are representative of soil nutrient levels in undisturbed (White Pine Bush) and regenerating native forest (The Hangar). While the sample size is low ( $n=8$ for the proxy forest soils), the values from two different forested sites at the same depths are very similar, showing a strong correlation between depth and \%TOC $\left(R^{2}=0.92\right.$ : Figure 5.12). This high correlation indicates the relative stability of SOC in forest soils after recovering from disturbance. The data show (Figure 5.12 ) that to $35 \mathrm{~cm}$ depth there is a loss of $1.34 \%$ TOC, or that the pasture soil has lost $(\Delta) 39.4 \%$ of the TOC it would have contained under native forest. The $\%$ TOC for topsoils has been shown to respond differently to land-use change scenarios depending on local factors (Cerri et al. 1998). As with other published 
findings it is likely that the differences between the two transects such as aspect and vegetation type in the source area have influenced the nutrient content of the soil. In T2 (Figure 5.12) the presence of outliers due to paleosols at $35 \mathrm{~cm}$ (S2 and S4) and a single high $5 \mathrm{~cm}$ value (S1) have caused a low correlation between depth and \%TOC ( $R^{2}$ of 0.42$)$. This is indicative of the SOM incorporating effects that slope stability revegetation measures can provide.

On the very broad assumption that this sample set is representative of the wider east coast soft rock hill country covering over $10,000 \mathrm{~km}^{2}$ (now largely deforested), it is possible to make the broad approximation of the extent to which this land use change may have affected SOC storage in topsoils. Based on the \%TOC values used in this research and assuming a constant dry density of $1.204 \mathrm{~T} / \mathrm{m}^{3}$, a forest soil to $35 \mathrm{~cm}$ depth covering this area would contain 0.14 $\mathrm{Gt}$ of SOC $\left(14,150 \mathrm{~T} / \mathrm{km}^{2}\right)$. Under pasture the same area would contain $0.09 \mathrm{Gt}$ of $\operatorname{SOC}\left(8,812 \mathrm{~T} / \mathrm{km}^{2}\right)$, equating to an approximate loss of $0.05 \mathrm{Gt}$ of SOC $\left(5,338 \mathrm{~T} / \mathrm{km}^{2}\right)$ due to anthropogenic land use change. However, if it can be shown that SOC has been buried as paleosols then there is a medium to long term sink beneath the contemporary topsoil that somewhat offsets this loss to the atmosphere and to distribution through the hydrological cycle.

The elevated levels of \%TOC and \%TN in T2 relative to those of T1 suggest that regeneration of native forest up-slope and a different slope and aspect may have contributed to an increase in SOC under pasture down-slope. These important characteristics play a significant role in controlling the drying and wetting (DW) cycles down-slope. Extreme DW cycles can negatively impact upon the formation of aggregates, whereas for stable microaggregates frequent low magnitude DW cycles are thought to aid in the efflux of soluble organic carbon into aggregate micropores, thereby removing the SOC from active respiration (Smucker et al. 2007). T1 has a northerly aspect, predominantly grass vegetation, and a currently active erosion regime; seasonal extremes in DW cycles may lead to a topsoil environment less conducive to the formation of soil aggregates, and therefore potential SOC storage. Transect 2 has a southerly facing aspect with regenerating forest up-slope, a reduced disturbance regime and a less extreme DW cycle, thereby creating an up-slope soil environment more conducive to the retention and incorporation of SOC into aggregates which are then available for transport down-slope.

\section{Geochemical Analyses}

Most of T1's contemporary topsoils exhibit similar characteristics across both the geochemical $\left(\delta^{13} \mathrm{C}, \delta^{15} \mathrm{~N}, \% \mathrm{TOC}\right.$ and $\left.\% \mathrm{TN}\right)$ and physical variables analysed. The exception is more negative $\delta^{15} \mathrm{~N}$ values at $\mathrm{S} 4$ which is likely to have a higher accumulation of stock inputs and possibly fertiliser residues due to the drainage characteristics of the shallow valley floor gradient. The C:N ratio is the same for all sites at $\sim 11$ in the contemporary topsoil except for the depletion shift in $\delta^{15} \mathrm{~N}$ at $\mathrm{S} 4$, further supporting the stock/fertiliser input hypothesis. The strong vegetation input and the Suess effect produce the depleted $\delta^{13} \mathrm{C}$ values that rapidly enrich from $5 \mathrm{~cm}$ to a maximum of $45 \mathrm{~cm}$ depth, where they stabilise producing the characteristic enrichment curve 
expected with increasing depth across sites 1,2 and 3; the only exception is the S4 outlier of $-23.2 \%$ at $45 \mathrm{~cm}$. Initially thought to be the result of incomplete sample demineralisation, this sample was re-processed producing the same result and remains a speculative anomaly within the data set. Transect $2 \%$ TOC and \% TN display trends of nutrient depletion with increasing depth similar to T1, but this transect has wider ranging nutrient values in the contemporary topsoil across sites 1 to 4 at the same depth, indicating a naturally higher or recovered SOM content. Site 1 has a high \%TOC $(6.23 \%)$ and $\%$ TN $(0.65 \%)$ at $5 \mathrm{~cm}$ depth which declines rapidly to very low values at $35 \mathrm{~cm}$ of $0.31 \%(\Delta 95 \%)$ and $0.04 \%(\Delta 94 \%)$ respectively. This rapid reduction in nutrient content of S1 topsoil is the largest decline across all sites on both T1 and T2 to $35 \mathrm{~cm}$ depth. The very high \%TOC in the S1 topsoil under pasture can be attributed to the almost immediately adjacent regenerating native forest up-slope. It is likely that the downward movement and overland flow characteristics of the steep slope above have contributed to elevating the topsoil SOM content down-slope. Furthermore the rapid decline in nutrient content combined with the physical core analysis indicates that $\mathrm{S} 1$ is the toe lobe of a large colluvial deposit. The overall geochemical similarity of the topsoils from T1 is also noteworthy, as it indicates that under pasture and in the absence of natural vegetation up-slope, the topsoil \%TOC has remained in equilibrium across the transect despite hydrological throughput or any other topographically related variable. As discussed below, there is evidence to suggest that this scenario is not the case for paleosols.

\subsection{Paleosols}

Below the contemporary topsoil all sites except T2 S1 exhibit some buried/accumulated SOM which is manifest as inflections against the depletion trend in \%TOC normally observed with increasing depth. A single short core at T2 S1 was not cored past $1 \mathrm{~m}$ as the underlying regolith density would not allow it. In all other instances below the topsoil a \%TOC inflection against the depletion trend is correlated to a change in grain size either above and/or below the SOM. Both T1 and T2 have inflections of \%TOC and \%TN that correspond to a SOM concentration in a fine matrix (clay/silt) which is overlain with abrupt transitions to sand e.g. T1 S4 $175 \mathrm{~cm}$ and T2 S4 $225 \mathrm{~cm}$. Occurring most often on the alluvial toeslope, this abrupt change in grain size, correlated with a significant decrease in SOM content, supports the hypothesis of a large geomorphic event burying topsoil with accumulated SOM as a paleosol horizon.

Alternatively, there are examples in both T1 and T2 where inflections of \%TOC and \%TN correspond to a SOM concentration in fine matrix (clay/silt) which is overlain with sediments of similar grain size (often only one textural classification difference) e.g. T1 S1 $95 \mathrm{~cm}$ and T2 S2 $45 \mathrm{~cm}$. The evidence for the burial of paleosols in this instance is less compelling, but based on the depth of the SOM and the often more subtle yet still abrupt transitions between grain size classes, SOM accumulation due to the movement of particles downward through the profile is less likely to be the dominant cause of SOM at depth. A number of small inflections may indicate that the length of time SOM accumulated in the topsoil before burial was brief, or that the OM was 
consumed by aerobic respiration after the burial event, as the event magnitude was insufficient to effectively remove the SOM from the active decomposition zone within the soil profile.

Between $250 \mathrm{~cm}$ and $175 \mathrm{~cm}$ in the upper valley sites there are three peak $\%$ TOC inflections with a mean of $2.37 \%$. The deepest and highest \%TOC paleosol is found at T2 S4 with an average value of 3.99\% TOC. Carbon dating, palynology and fossil plant material provide the supporting evidence to suggest that T1 S3, T1 S4 and T2 S4 are a pre-human forest paleosol (known as the $200 \mathrm{~cm}$ paleosol). There is also evidence for paleosols of lesser \%TOC magnitudes commonly found at $\sim 45 \mathrm{~cm}$ and $\sim 95 \mathrm{~cm}$ depth (referred to subsequently as the 50 and $100 \mathrm{~cm}$ paleosols). Across eight cores there are four \%TOC inflections peaking between 35-45 cm depth with a mean value of $1.76 \%$ TOC, and from $85 \mathrm{~cm}$ to $95 \mathrm{~cm}$ there are six peak inflections at a mean value of $1.06 \%$ TOC. Table 6.1 shows the actual carbon content of the pasture and proxy forest covered topsoils and the $200 \mathrm{~cm}$ paleosol. The $200 \mathrm{~cm}$ paleosol is broken down further by site as T2 S4 which has characteristics of a different depositional environment is significantly different from T1 S4 and S3.

Table 6.1. Actual SOC for Pasture/Proxy Forest Soils and $200 \mathrm{~cm}$ Paleosol.

\begin{tabular}{|l|c|c|c|c|c|}
\hline \multicolumn{1}{|c|}{ Layer } & $\begin{array}{c}\text { Average } \\
\text { Thickness }\end{array}$ & Volume & $\begin{array}{c}\text { Average } \\
\text { Carbon } \\
\text { Value } \\
(\mathrm{m})\end{array}$ & $\begin{array}{c}\text { Carbon } \\
\text { weight } \\
\left(\mathrm{m}^{3}\right)\end{array}$ & $\begin{array}{c}\text { Carbon weight } \\
\text { per } \mathrm{km}^{2} \\
\left(\mathrm{~T} / \mathrm{km}^{2}\right)\end{array}$ \\
\hline Pasture Surface Soil & 0.30 & 41625 & 2.17 & 903 & 7880 \\
\hline $\begin{array}{l}\text { Pre human (contemporary } \\
\text { forest) }\end{array}$ & 0.35 & 48563 & 3.34 & 1622 & 14150 \\
\hline $\begin{array}{l}\text { 200cm Paleosol (average } \\
\text { T1 S4, S3 and T2 S4) }\end{array}$ & 0.32 & 44400 & 2.37 & 1052 & 9180 \\
\hline $\begin{array}{l}\text { 200cm Paleosol (T2 S4 } \\
\text { only) }\end{array}$ & 0.31 & 43013 & 3.99 & 1716 & 14971 \\
\hline $\begin{array}{l}\text { 200cm Paleosol (T1 S4 } \\
\text { only) }\end{array}$ & 0.4 & 55500 & 1.44 & 799 & 6972 \\
\hline $\begin{array}{l}\text { 200cm Paleosol (T1 S3 } \\
\text { only) }\end{array}$ & 0.25 & 34688 & 1.68 & 583 & 5084 \\
\hline
\end{tabular}

Note: for the actual SOC calculations in Table 6.1 the soil density and area were held constant at $138,750 \mathrm{~m}^{2}$ (valley floor area) and $1.2 \mathrm{~T} / \mathrm{m}^{3}$. To eliminate unrepresentative skewing of the data, the pasture surface soil calculation does not include paleosols, where these did not occur a $0.5 \%$ SOC value was used to determine the depth at which SOM input was negligible and therefore designated background sediment.

Based on the Oporae Valley surface area of $138,750 \mathrm{~m}^{2}$ (13.9 ha), the contemporary topsoil with an average depth of $30 \mathrm{~cm}$ contains $903 \mathrm{~T}$ of SOC $\left(7,880 \mathrm{~T} / \mathrm{km}^{2}\right)$. The average depth of $30 \mathrm{~cm}$ excludes all paleosols and therefore represents a truer quantification of the contemporary topsoil carbon characteristics than the calculation using $35 \mathrm{~cm}$ from section 6.2 . This figure can serve as a basis for comparison with the pre-human paleosol averaging 32 $\mathrm{cm}$ thick and ranging in depth from $175 \mathrm{~cm}$ to $265 \mathrm{~cm}$ under the contemporary alluvial toeslope. If this paleosol surface were to extend across the entire valley floor as is indicated by its presence in the contemporary stream channel, then the buried soil would contain $1052.28 \mathrm{~T}$ of $\operatorname{SOC}\left(9,179.67 \mathrm{~T} / \mathrm{km}^{2}\right)$. This value 
represents the average \%TOC content of the $200 \mathrm{~cm}$ paleosol. As shown in Table 6.1, the average \%TOC in T2 S4 is more than that of T1 S4 and S3. The type of depositional processes and soil environments responsible for this large variation in OM preservation are discussed further in Section 6.4. While the cores taken do not in themselves reveal the full lateral extent of the $200 \mathrm{~cm}$ paleosol, the fact that a higher proportion of SOC exists within part of this paleosol after burial than what currently exists in the pasture covered topsoil is a significant finding. If the area over which the paleosol still exists can be established, and these surfaces are common within the tributary valleys, then it could be incorporated into the catchment carbon budget as a long term sink just as surely as the lake sediments. The implications also extend into the geomorphic interpretation. Calculating carbon losses due to landsliding based on the C content exported through the fluvial system (e.g. Scott et al. 2006; Page et al. 2004) is only telling part of the story. Soil carbon lost due to erosion exacerbated by land-use change can be transported to a number of different sinks. The duration, state of flux and capacity of these sinks varies greatly. As demonstrated, the magnitude of the pre-human and anthropogenic paleosols as a long term $\mathrm{C}$ sink derived from land-use change represents an important component of the larger terrestrial carbon cycle.

\subsection{Geomorphology of Paleosols}

Due to the proximity of the cores to each other and the documented evidence of rapid long shallow runout deposition events, it is likely that some of the paleosols from separate cores belong to a common surface. SOM inflections that are common to each other in depth and magnitude further support this hypothesis. Once identified, the paleosol can be tied back to geomorphic processes through the physical and circumstantial evidence. This then allows for an interpretation of the impact geomorphic processes have had on SOC preservation. Table 6.2 shows the relative carbon content of the aforementioned paleosols, surface soil and background soils which have been normalised for thickness.

The main findings in Table 6.2 are shown in bold; the following sections discuss these findings and the possible interpretations from a geomorphological standpoint for each of the different paleosols.

\section{$50 \mathrm{~cm}$ Paleosol}

T1 S2 and S4 contain \%TOC and \%TN nutrient inflections at $\sim 50 \mathrm{~cm}$, but the distance between the two sites $(\sim 140 \mathrm{~m})$ and the change in slope from Unit 6 to Unit 7 reduces the likelihood of the OM belonging to a common paleosol. In contrast T2 S2, S3 and S4 inflect strongly at $35-45 \mathrm{~cm}$ and extend through 50 $\mathrm{cm}$. The inflections correspond to the appearance of $\mathrm{OM}$ concentrations overlain with a unit (or units) of a different grain size classification. The most pronounced \%TOC inflection of these is in S2, where \%TOC drops from 3.65\% at $5 \mathrm{~cm}$ to $1.62 \%$ at $15 \mathrm{~cm}$, then returns to $2.63 \%$ at $45 \mathrm{~cm}(72 \%$ of the surface $\% \mathrm{TOC}$ ). A relatively short distance of $50 \mathrm{~m}$ encompasses all three cores (S2S4) and the south-easterly facing slope has less extreme DW cycles with regenerating forest up-slope, leading to conditions more conducive to a stable 
Table 6.2. Relative SOC content of surface soils, paleosols and background sediments.

\begin{tabular}{|c|c|c|c|c|c|}
\hline Transect & Site & Layer & $\begin{array}{c}\text { Average Carbon } \\
\text { Value } \\
\text { (\%/Site) }\end{array}$ & $\begin{array}{c}\text { Carbon } \\
\text { weight } \\
\left(\mathrm{T} / 13875 \mathrm{~m}^{3}\right)\end{array}$ & $\begin{array}{l}\text { Carbon weight } \\
\left.\text { per } \mathrm{km}^{2}\right) \\
\left(\mathrm{T} / \mathrm{km}^{2}\right)\end{array}$ \\
\hline 1 & 1 & Surface Soil & 2.64 & 443.9 & 3199.1 \\
\hline 1 & 2 & Surface Soil & 2.14 & 360.2 & 2595.9 \\
\hline 1 & 3 & Surface Soil & 2.19 & 368.5 & 2655.6 \\
\hline 1 & 4 & Surface Soil & 2.74 & 460.8 & 3321.3 \\
\hline 2 & 1 & Surface Soil & 3.03 & 508.5 & 3665 \\
\hline 2 & 2 & Surface Soil & 2.31 & 387.4 & 2792.4 \\
\hline 2 & 3 & Surface Soil & 2.46 & 412.7 & 2974.6 \\
\hline 2 & 4 & Surface Soil & 1.96 & 329.6 & 2375.5 \\
\hline \multicolumn{3}{|c|}{ Average of T1 Surface soil } & 2.43 & & 2943 \\
\hline \multicolumn{3}{|c|}{ Average of T2 Surface soil } & 2.44 & & 2951.9 \\
\hline \multicolumn{3}{|c|}{ Average of T1 and T2 Surface soil } & 2.44 & & 2947.4 \\
\hline 2 & 2 & $50 \mathrm{~cm}$ Paleosol & 2.49 & 417.7 & 3010.3 \\
\hline 2 & 3 & $50 \mathrm{~cm}$ Paleosol & 1.57 & 263.3 & 1897.9 \\
\hline 2 & 4 & $50 \mathrm{~cm}$ Paleosol & 1.37 & 230.4 & 1660.7 \\
\hline \multicolumn{3}{|c|}{ Average of T2 $50 \mathrm{~cm}$ Paleosol } & 1.81 & & 2189.6 \\
\hline 1 & 1 & $\begin{array}{c}100 \mathrm{~cm} \\
\text { Paleosol }\end{array}$ & 0.93 & 155.9 & 1123.3 \\
\hline 1 & 2 & $\begin{array}{c}100 \mathrm{~cm} \\
\text { Paleosol }\end{array}$ & 0.57 & 96 & 691.7 \\
\hline \multicolumn{3}{|c|}{ Average of T1 $100 \mathrm{~cm}$ Paleosol } & 0.75 & & 907.5 \\
\hline 1 & 3 & $\begin{array}{l}200 \mathrm{~cm} \\
\text { Paleosol }\end{array}$ & 1.68 & 282.2 & 2033.9 \\
\hline 1 & 4 & $\begin{array}{l}200 \mathrm{~cm} \\
\text { Paleosol }\end{array}$ & 1.44 & 242.2 & 1745.4 \\
\hline 2 & 4 & $\begin{array}{c}200 \mathrm{~cm} \\
\text { Paleosol }\end{array}$ & 3.99 & 669.7 & 4826.9 \\
\hline \multicolumn{3}{|c|}{$\begin{array}{r}\text { Average of T1 and T2 } 200 \mathrm{~cm} \\
\text { Paleosol }\end{array}$} & 2.37 & & 2868.7 \\
\hline 1 & 1 & Background & 0.35 & 59.2 & 426.5 \\
\hline 1 & 2 & Background & 0.26 & 42.8 & 308.7 \\
\hline 1 & 3 & Background & 0.27 & 46.1 & 332.6 \\
\hline 1 & 4 & Background & 0.43 & 73 & 526 \\
\hline 2 & 1 & Background & 0.31 & 51.7 & 372.6 \\
\hline 2 & 2 & Background & 0.64 & 107.7 & 776 \\
\hline 2 & 3 & Background & 0.39 & 64.7 & 466.2 \\
\hline 2 & 4 & Background & 0.57 & 95.8 & 690.1 \\
\hline \multicolumn{3}{|c|}{$\begin{array}{r}\text { Average of T1 Background } \\
\text { Average of T2 Background } \\
\text { Average of T1 and T2 Background }\end{array}$} & $\begin{array}{l}0.33 \\
0.48 \\
0.40\end{array}$ & & $\begin{array}{l}398.4 \\
576.2 \\
487.3\end{array}$ \\
\hline
\end{tabular}

Note: for comparative purposes during the volume and weight calculations all thicknesses, areas and densities were held constant at $10 \mathrm{~cm}, 138750 \mathrm{~m}^{2}$ (valley floor area) and $1.2 \mathrm{~T} / \mathrm{m}^{3}$. This is due to the uncertainty surrounding the lateral extent and depth of the paleosols beyond what was cored within the valley. These figures do not represent how much carbon is actually stored within the landscape (for these values see Table 6.1), but serve to show the relative differences between topsoils, paleosols and background SOC content. This then allows for the interpretation of the impacts that geomorphic processes and position within the landscape has on SOC. 
landform surface and the accumulation of SOM. The C:N ratio for the $\mathrm{T} 250 \mathrm{~cm}$ paleosol also correlates well across S2, S3 and S4 with a large increase in C:N ratio peaking in $\mathrm{S} 2$ at $18.4(45 \mathrm{~cm})$. This suggests that this surface has existed for some time in an aerobic environment as a paleosol due to the preferential consumption of $\mathrm{N}$ over that of $\mathrm{C}$ by aerobic micro-organisms. This relatively short transect lies within the depositional zone of a large historically landslide prone hillside (now forested to enhance slope stability). Due to the abrupt change in slope and the uniformly compacted clay/silt, which contained little evidence of textural or lithological variation and no buried OM, S1 is interpreted as being a large block of regolith most probably rafted during a landslide event. An event of this magnitude would have had a substantial runout, possibly the same event that buried the $50 \mathrm{~cm}$ paleosol.

Despite remaining in an aerobic environment the $T 250 \mathrm{~cm}$ paleosol has retained an average of $74 \%$ of the surface $\%$ TOC. Based on the relatively short distance to the contemporary drainage channel and the evidence of a large colluvial deposit at $\mathrm{S} 1$, the evidence for colluvial runout over this paleosol surface is compelling. Furthermore Figure 3.3 shows the runout path of a medium sized landslide after the Cyclone Bola event in 1988 which covers much of $\mathrm{T} 2$ in the manner described. This thick layer of material is relatively poor in OM and blankets the alluvial toeslope during large events isolating the $\mathrm{OM}$ from the readily oxygenated topsoil and thereby creating a quantifiable medium to long-term C sink. The $50 \mathrm{~cm}$ paleosol is approximately $10 \mathrm{~cm}$ thick across T2 S2, S3 and S4, it contains an average TOC content of $1.81 \%$ or 2190 $\mathrm{T} / \mathrm{km}^{2} \mathrm{OC}$. This is relative to an average T2 background of $576 \mathrm{~T} / \mathrm{km}^{2} \mathrm{OC}$. However, as some of this paleosol resides within the contemporary topsoil $\mathrm{SOM}$, the actual background $(5 \mathrm{~cm}$ either side) contains an average of 1,277 $\mathrm{T} / \mathrm{km}^{2} \mathrm{OC}$.

\section{$100 \mathrm{~cm}$ Paleosol}

In T1S1, S2, S4 and T2 S2, S3 \%TOC and \%TN inflections peaking over the 75 $\mathrm{cm}$ to $95 \mathrm{~cm}$ range indicate the possibility of another common buried surface. T1 S1 and S2 are in close proximity to each other on the colluvial footslope increasing the likelihood of this scenario. T1 S4 is more distant and therefore potentially has a different accumulation rate due to the change from a colluvial to an alluvial dominant regime (Unit 6 to Unit 7). Field observations suggest that T1 S1 and S2 are a part of a large landslide (or series of landslides) depositional lobe. This is supported by the infrared photo of Cyclone Bola erosion scars and runout paths (Figure 3.3) and the lobes position down hill from a large steep gully network. Despite some variation in physical appearance (Figure 5.1) which can be put down to photography and coring method (window sampler versus closed barrel), T1 S1 and S2 mirror each other in all of the other geochemical analyses for the first $100 \mathrm{~cm}$. The relative uniformity of the sediments in S1 and S2 in T1 and S1 in T2 is indicative of colluvial deposition. The preservation of OM at depth below $110 \mathrm{~cm}$ does not occur in any of these sites. This suggests a number of possible scenarios: the paleosol at $100 \mathrm{~cm}$ is not the pre-human forest soil; it was only briefly the contemporary topsoil before another event buried it; other paleosols lay beyond what was cored on the 
colluvial footslopes; erosion and leaching have removed OM from the paleosol. Because no ${ }^{14} \mathrm{C}$ ages, palynology or OM species identification are available for the colluvial footslope cores, the residence time and surface duration of the 10 $\mathrm{cm}$ paleosol depth remains unknown. It is hypothesised that based on their similar range of depth $(10 \mathrm{~cm})$, the $50 \mathrm{~cm}$ and $100 \mathrm{~cm}$ paleosols spent a similar amount of time as the contemporary topsoil. Whether this scenario is an accurate interpretation remains open to further investigation. However, based on the core and field observations alone it was noted that the T1 S1 and S2 colluvial deposit lies directly below the source area and that the sediments below are relatively uniform. Thus the hypothesis that the $100 \mathrm{~cm}$ paleosol is a relatively recent (European) paleosol of similar period to the $50 \mathrm{~cm}$ paleosol is put forward.

The proximity of T1 S1 and S2 increases the likelihood of them being a shared common surface at the $100 \mathrm{~cm}$ depth. Therefore the values in Table 6.2 are based on T1 S1 and S2 only. Assuming an average $10 \mathrm{~cm}$ thick paleosol across S1 and S2 (window sampler barrel obscured definitive measurements), the paleosol averaged $907.50 \mathrm{~T} / \mathrm{km} 2 \mathrm{OC}$ and $398.43 \mathrm{~T} / \mathrm{km}^{2} \mathrm{OC}$ for the surrounding sediments. (Note that the sampling interval at depth was lower than that of the surface and so while the sediments are representative, those background sediments immediately adjacent to the paleosol were not sampled). The $100 \mathrm{~cm}$ paleosol is significantly 'lighter' in SOC, holding less than half the OC of the 50 $\mathrm{cm}$ paleosol $(41.4 \%)$. This difference in paleosol OC stored up-slope highlights the impact geomorphic processes can have on SOC preservation in that the alluvial toeslope is the preferred location for the development and preservation of a SOC pool.

\section{$200 \mathrm{~cm}$ Paleosol}

The $200 \mathrm{~cm}$ paleosol ranges in depth from $175 \mathrm{~cm}$ to $265 \mathrm{~cm}$ across three separate cores and averages $32 \mathrm{~cm}$ in thickness. T1 S3 $(225 \mathrm{~cm})$ and S4 $(175$ $\mathrm{cm}$ ) are the first and second sites to exhibit large inflections equivalent in \%TOC and \%TN content to the contemporary $10 \mathrm{~cm}$ to $25 \mathrm{~cm}$ topsoil. Transect $2 \mathrm{~S} 4$ is the third site and is on the other side of the contemporary drainage channel, therefore this paleosol is common to both transects. This site exhibits levels of $\%$ TOC that exceed even the contemporary topsoil. For such high levels of OM to be preserved either the OM must be physically protected by incorporation into clay minerals or removed from the aerobic environment i.e. rapid burial or in an anaerobic depositional environment (Stevenson and Cole 1999). The T1 S3, S4 and T2 S4 (below $236 \mathrm{~cm}$ ) inflections have depleted $\mathrm{N}$ contents increasing the $\mathrm{C}: \mathrm{N}$ value significantly. This indicates that the OM concentrations have most likely been in an aerobic environment unlike the one in which they currently reside. Based on the T1 S3 position in the unit 6/7 margin of overlap, it is possible that the burial process was more abrupt than that of T2 S4. The sediments above the $\mathrm{S} 3$ paleosol $(225 \mathrm{~cm})$ are relatively uniform and exhibit pumice inclusions throughout suggesting the reworked nature of the deposit. Bearing in mind that the bottom of the T1 S3 core at $300 \mathrm{~cm}$ depth is vertically aligned with the first metre of T1 S4, it becomes more intuitive that the top of S3 could be a large colluvial fan toe lobe. T1 S2 and S3 both contain a large 
common section ( $100 \mathrm{~cm}$ thickness) of clay/silt that has inclusions of pumice further supporting this interpretation.

The third ' $200 \mathrm{~cm}$ ' paleosol in T2 S4 is significantly different in that it contains high levels of well preserved OM in what appears to have been a swampy or poorly drained soil. This paleosol provided two pristine specimens of Prumnopitys taxifolia seed, along with grasses, root and leaf structures (possibly Dacrydium cupressinum), which are all considered indicative of a swampy forest soil matching the pre-human vegetation described by Wilmshurst (1997). In Table 6.1 this paleosol, averaging $32 \mathrm{~cm}$ in thickness across three cores was calculated to contain $9,180 \mathrm{~T} / \mathrm{km}^{2} \mathrm{OC}$, or $2,869 \mathrm{~T} / \mathrm{km}^{2}$ for every 10 $\mathrm{cm}$ (Table 6.2) compared to $2,190 \mathrm{~T} / \mathrm{km}^{2}$ (50 cm paleosol) and $908 \mathrm{~T} / \mathrm{km}^{2}(100$ $\mathrm{cm}$ paleosol). Notably the data are skewed by the T2 S4 paleosol which exhibits the characteristics of a swampy or wet environment. The early descriptions of the tributary valleys to Lake Tutira indicate the relative lake level may have been higher, and that before drainage channels were dug, swamp like conditions existed on the valley floors (Guthrie-Smith 1953). Within this core there are distinctly laminated alluvial deposits of fine to medium sands, clayey silts, pumice, charcoal and very well preserved $\mathrm{OM}$. These fine laminations with abrupt transitions from OM rich to OM poor sediments indicate that even in this (then) relatively stable forested environment the alluvial toeslope was vulnerable to frequent storm generated pulses of sediment derived from the underlying lithology up-slope.

In summary, the three most likely connected paleosol surfaces across seven different sites represent three different depositional environments. The T1 100 $\mathrm{cm}$ paleosol is found within a large landslide lobe and contains the least OM; the T2 $50 \mathrm{~cm}$ paleosol contains double the amount of OC when compared to the T1 $100 \mathrm{~cm}$ paleosol, and appears to span the transition from colluvial footslope to alluvial toeslope. Despite the T2 $50 \mathrm{~cm}$ paleosol having the topographic appearance of an alluvial toeslope, the circumstantial and photographic evidence from Cyclone Bola indicates that this relatively young paleosol could have been formed as a result of colluvial deposition some time before the event. Finally the $200 \mathrm{~cm}$ pre-human paleosol contains, at an average of $32 \mathrm{~cm}$, approximately four times the $\mathrm{OC}$ of the $50 \mathrm{~cm}$ paleosol and ten times that of the $100 \mathrm{~cm}$ paleosol. This surface is found in numerous places along the contemporary drainage channel in the valley indicating its widespread extent. The laminations of sands at depth in T2 S4 indicate an alluvial deposition regime was in operation and that during this time very high levels of OM were incorporated and then preserved within the soil structure. Immediately above these laminations the sediment suggests a regime change that is correlated to the changing land use and the rapidly escalating sedimentation rate mirrored by that found within the lake cores for the same period. Both T1 S4 and S3 also contain a few fine laminations of sands but are clearly dominated by colluvial deposition as indicated by the often abrupt changes in grain size classification on the blocks of sediments containing reworked pumice clasts. 


\section{Bivariate plots}

Transect 2 has a short colluvial run out distance to the contemporary drainage channel increasing the likely hood of colluvial deposition being the dominant process over the entire depositional slope. The $\delta^{13} \mathrm{C} \mathrm{C:N}$ bivariate plot for $\mathrm{T} 2$ shows a higher proportion of C3 plant material in the $50 \mathrm{~cm}$ and $200 \mathrm{~cm}$ paleosols. These findings are consistent with the interpretation that the shallow $50 \mathrm{~cm}$ paleosol has recently and abruptly been buried by colluvial deposition and the $200 \mathrm{~cm}$ pre-human paleosol shows evidence of an alluvial environment less likely to accommodate aerobic respiration also abruptly transitioning to colluvial deposition.

\section{Mixing Model}

Transect 1 showed only a broad distribution of all three different lithology source types (gullies, weathered bedrock and Bw horizon soil), suggesting that the composition of depositional sediments comes from a mixture of all three sediment source types with S4 and S3 containing a greater proportion of gully sediments than S2 and S1. Transect 2 has a more distinct grouping associated with anomalous lower section of T2 S4. The lower section of T2 S4 is heavily laminated with what appears to be erosion pulses deposited over an organic rich sediment of the same or similar grain size (Figure 5.2). Despite the OM rich horizons there appears to be a definite shift towards gullies (and/or tunnel gullies) as the dominant sediment source. This supports the conclusion that lower section of T2 S4 may have been part of a swampy drainage network in the central valley where sediments were deposited frequently as fine laminations sourced from gully networks in the Oporae Valley headwaters. Questions that arise from this interpretation relate to the relative input of \%TOC as a determinant of $\delta^{13} \mathrm{C}$ and $\delta^{15} \mathrm{~N}$, and the type of environment in which preservation/decomposition is taking place. The \%TOC as a confounding variable on its own is easily eliminated, as the gully cluster from T2 S4 includes laminated sediments with paleosol \%TOC and with low \%TOC from adjacent units. This then leaves the type of preserving environment as the other possible confounding variable. Transect 2 S4 contains very high levels of OM relative to the other paleosols within the Oporae Valley cores. It has been identified as a possible anaerobic alluvial depositional environment. The other $200 \mathrm{~cm}$ paleosols (T1 S4 and S3) also currently reside within anaerobic environments (as indicated by the reducing conditions in which they were found). While it is not as pronounced in T1 (Figure 5.10), the shift in terms $\delta^{13} \mathrm{C}$ and $\delta^{15} \mathrm{~N}$ towards gully sediments associated with these paleosols is still evident. Whether this shift is a true reflection of gully sediment input or rather the type of environment in which \%TOC is preserved is open to further investigation.

\section{Grain Size}

The increasing complexity within the cores down slope corresponds to larger and more frequent $\mathrm{OM}$ concentrations at depth. All sites display a change in grain size class near or immediately adjacent to an inflection against the downward nutrient depletion trend. In the sediments containing and surrounding buried OM concentrations, T1 S1 and S2 show little variation in clay content and a small amount of variation in silt and sand content, T1 S3 and especially 
S4 show some variation in clay content and a large amount of variation in silt and sand content (Figure 5.3). These findings indicate that the complex colluvial/alluvial deposition zone (S3 and S4) on the valley floor alternates between short periods of stability (OM accumulation) and relatively high frequency but low magnitude deposition events, whereas the up slope colluvial deposition zone is characterised by lower frequency higher magnitude events and a higher degree of conformity within the deposited sediments i.e. a landslide toe lobe or rafted block. The different environments in which the preservation of $\mathrm{OM}$ occurs are dictated by the dominance of these processes over time.

\section{The Colluvial Footslope}

Transect $1 \mathrm{~S} 1$ and S2 paleosols on the colluvial foot slope are loamy silts and sandy loams with a relatively narrow grain size classification distribution. Transect 1 S3 and S4 on the alluvial toeslope have higher proportions of OM in the paleosols which are characterised by loamy silts, silt loams and sandy loams, surrounded by sediments with a significantly greater proportion of sand. This indicates that while in the same run out path for mass movements, S1 and S2 are sufficiently up-slope from the valley floor to be operating under a different set of boundary conditions for deposition processes than the valley floor sites 3 and 4 . Transect 2 has a shorter runout path creating a depositional environment that is predominantly colluvial in origin. Overall fewer paleosols and one common $50 \mathrm{~cm}$ paleosol found in relatively homogenised sediments (Loamy-Silts) support this interpretation.

\section{The Alluvial Toeslope}

During the period antecedent to a large colluvial transport/deposition event, fine grain sediments and $\mathrm{OM}$ build up during the normal floodplain sequence of plant growth/decomposition (OM flux) and occasional fine grain alluvial deposition. The capacity of clay minerals to protect and preserve the OM fraction through the formation of aggregates under these circumstances is well documented (Jones and Donnelly 2004). The clay content ranges from $6.1 \%$ to $24.4 \%$ across the samples analysed. This variation holds significant implications for the potential for OM protection by the formation of organo-mineral complexes. T1 S4 shows an OM rich horizon of clay/silt and silt from $55 \mathrm{~cm}$ to $125 \mathrm{~cm}$, below this lies a large unit of sand from $130 \mathrm{~cm}$ to $155 \mathrm{~cm}$, and below this is another OM rich clay unit. The unit of sand is almost completely devoid of any OM, indicating two things: that the sand arrived after the OM was already incorporated with the clay minerals below (a paleosol), and also that the OM above has so far also been protected from downward translocation by the formation of clay organo-mineral complexes. This sequence of OM accumulation in a paleosol, burial by an event and accumulation in a new topsoil (now paleosols as well) is characteristic of valley floor accumulation being interrupted by a low frequency high magnitude event. During this event coarse grain sediments eroded from landsliding or gullying have been carried in a flow some distance from the contemporary colluvial deposition zone onto the alluvial toeslope. Therefore the dominant process that buries OC creating a medium to long term sink is colluvial deposition even on the alluvial toeslope. 
But it is the process of alluvial deposition provides fine grain sediments which aid in the formation organo-mineral complexes and thereby protection of OM from decomposition, thus making the valley floor the ideal location for OM accumulation and incorporation into medium to long term storage.

\subsection{Accumulation Rates}

\section{Lake Tutira}

The sedimentation rates calculated for Lake Tutira (Page et al. 1997; Wilmshurst 1997) give an excellent indication of the effect of land use change on the erosion regime within the catchment. A combination of sedimentology, tephrochronology, palynology and ${ }^{14} \mathrm{C}$ ages, combined with the lake's naturally low circulation characteristics give accurate and reliable rates for the prehuman, Maori and European land use regimes. Discerning the same rates on land is more difficult as the key markers have been either removed or reworked by subsequent geomorphic activity or are less distinct if preserved. Paleosols indicate where the pre-human forest soils might have lain, but as indicated by the lake core (LT16) there was a two phase regime change resulting in an increase from $1.7 \mathrm{~mm} \mathrm{yr}^{-1}$ (pre-human forested) to $2.7 \mathrm{~mm} \mathrm{yr}^{-1}$ (bracken) and then rapidly increasing to $13.8 \mathrm{~mm} \mathrm{yr}^{-1}$ (pasture) (Wilmshurst 1997).

\section{Oporae Valley}

The ${ }^{14} \mathrm{C}$ ages in Table 5.4 bracket the critical period before and after the initial period of anthropogenic land use change. Two groupings of ${ }^{14} \mathrm{C}$ ages provide evidence to support the hypothesis of the upper valley pre-human paleosol at $\sim 200 \mathrm{~cm}$ depth. Those older and deeper ages come from wood samples found within and below sediments thought to represent the pre-human paleosol, and the younger grouping from soil, tree stumps and wood fragments in or above the pre-human paleosol representing the initial onset of land use change. As there are no terrestrial ages from depths shallower than $173 \mathrm{~cm}$, and no definitive visual indication of where the European regime change from bracken to pasture occurred, the estimation of sedimentation rates calculated must encompass both these phases of land-use change in the valley. Similarly, in comparing terrestrial and lacustrine sedimentation rates, using the LT16 lake core (Wilmshurst 1997), the lake sedimentation rates from the European period spanning 123 years period $(170 \mathrm{~cm})$ and the pre-European period spanning 518 years $(140 \mathrm{~cm})$ must be added together. The sum anthropogenic sedimentation rate for the lake is $4.8 \mathrm{~mm} \mathrm{yr}^{-1}$. Immediately below this accumulated depth of anthropogenic sedimentation, defined by palynology, from $310 \mathrm{~cm}$ to $350 \mathrm{~cm}$ tephrostratigraphy indicates two Ruapehu events at $\sim 600$ and $\sim 750$ years BP respectively (Wilmshurst 1997). Of the five ages that exist for the alluvial (Unit 7) upper Oporae Valley floor, the two stream bank ages support an inference of initial onset of land use change 688-580 yr BP. On this basis, the average terrestrial sedimentation rate using an average value of $616 \mathrm{yr}$ BP from the three alluvial upper valley stream bank sites is $2.8 \mathrm{~mm} \mathrm{yr}^{-1}$. The terrestrial rate therefore is $58 \%$ of the lake sedimentation rate.

This balance between lacustrine and terrestrial sedimentation rates correlates closely to the long-term landslide sediment delivery ratio (SDR) calculated for 
Lake Tutira at 0.43 (Page et al. 2004). This latter calculation was based on aerial photographs and evacuated landslide scar volumes and covered the 114 year period from 1887-2001. Page et al. (2004) calculated that $\sim 75 \%$ of the sediment volume delivered to the lake during the European period was primarily derived from storm generated erosion pulses. Despite the differences in time periods over which these ratios are calculated, if the sedimentation rates for the European period on land could be estimated, it is likely that they would be proportional to those for the lake over the same period. This is due to the role of storm generated erosion pulses as the dominant geomorphic agent for terrestrial and aquatic sediment deposition during both phases of land use. The lake cores used by Eden et al. (1993) demonstrated this with two distinct zones over the last $\sim 6,500$ years, these zones were interpreted as representing different modes of deposition. Zone $A$ sediments are predominantly sands and pumice sands to $5.77 \mathrm{~m}, \sim 1,250 \pm 60 \mathrm{yr}$ BP. Then zone B which is alternating fine sands and silt, laminated clay and silt with some organic matter and organic clays and silt from 5.77 to $16.7 \mathrm{~m}$ at $\sim 6,500 \mathrm{yr}$ BP. These two distinct zones were interpreted as a possible delta front (coarse grain sediments deposited by storm generated erosion pulses) filling up the swamp. The grouping of three older ${ }^{14} \mathrm{C}$ ages from the upper valley (Table 5.4) range from 1,294 \pm 30 to 1180 $\pm 50 \mathrm{yr}$ BP. This pre-human grouping of ages from 254 to $200 \mathrm{~cm}$ corresponds closely with the age given for the Zone $A$ to Zone $B$ transition found within the lake cores. With an average depth of $227.7 \mathrm{~cm}$ between these cores the average total accumulation rate is $1.8 \mathrm{~mm} \mathrm{yr}^{-1}$. The difference between the two age cluster averages is $55.3 \mathrm{~cm}$ and 624 years. This produces a pre-human terrestrial sedimentation rate of $0.9 \mathrm{~mm} \mathrm{yr}^{-1}$. Recall that for the anthropocene the terrestrial accumulation rate for the upper valley was 0.58 of the lake's accumulation rate. Based on these calculations the terrestrial accumulation rate of $0.9 \mathrm{~mm} \mathrm{yr}^{-1}$ for the pre-human period was 0.53 of the corresponding prehuman lake accumulation rate $\left(1.7 \mathrm{~mm} \mathrm{yr}^{-1}\right)$. This indicates that while land-use change and vegetation loss played a large role in destabilising the landscape and increasing sedimentation rates, for the upper valley, it did not significantly alter the efficiency of the fluvial systems capacity to transport sediment.

Due to the lack of defining palynological evidence in the terrestrial cores that would allow for distinction between the Maori and European sedimentation rates, sedimentation rates in this study are based on the entire anthropocene. The values presented by Wilmshurst (1997) and Page and Trustrum (1997) for the Maori and European lacustrine sedimentation rates are based on the assumption of constant sedimentation rates over these periods. However, it has been shown that $54 \%$ of the European sedimentation was derived from just two storm induced erosion pulses (Page et al. 1994). Furthermore, that there are six 'clusters' of storm intensity resulting in high sedimentation rates in the prehuman period to $2250 \mathrm{yr} \mathrm{BP}$, these have been related to natural climate cycles e.g. ENSO (Eden et al. 1998). When calculating sedimentation rates by dividing over short periods of time, such as is the case with the European period compared with that of the Maori, the data may be skewed by the occurrence of relatively infrequent large magnitude events that may or may not fall within each time period. Thus the advantage of taking the longer term view is that it allows 
for the comparison of the terrestrial sedimentation rate with that of the lake, and that variability in triggering events is reduced by the averaging effect of a longer time span.

\section{Palynology}

The pollen analysis was inconclusive. Corrosion and biodegradation had occurred to such an extent that there were few recognisable grains remaining. However, what was preserved still provided some insight into the impacts of geomorphic process and slope on the water table. The anaerobic environment indicated by the blue green colour in the cores can be correlated with the increased abundance of pollen spores.

Despite the lack of podocarp pollen spores in T1 S4 the palynological evidence fits the ${ }^{14} \mathrm{C}$ age of $1,246 \pm 25 \mathrm{yr} \mathrm{BP}$ at $200 \mathrm{~cm}$ above which lies a pre-human paleosol. In T1 S3 the relative abundance of tree fern spores (above and below ${ }^{14} \mathrm{C}$ age of $460 \pm 30 \mathrm{yr} \mathrm{BP}$ at $185 \mathrm{~cm}$ ) and podocarp pollen spores at $225 \mathrm{~cm}$ indicates that this is another pre-human paleosol. From T2 S4 there is no palynological data but there are preserved and identifiable OM specimens indicating a paleosol with vegetation typical of a swampy undisturbed lowland forest site.

\section{Summary}

Land-use change in the Oporae Valley has destabilised the landscape, negatively impacting on the contemporary terrestrial carbon pool through severe erosion. The process of erosion has created a terrestrial carbon sink in the buried soils (paleosols) as the valley rapidly infilled after conversion to pasture. Having broadly quantified both the topsoil carbon loss and the paleosol carbon storage, both can now be added to the net balance of carbon flux within the catchment for the anthropocene. The nature of the paleosols can be correlated to their relative position on the transect. The topography and grain size analysis allow for the geomorphological interpretation of the dominant processes at each site. Colluvial deposition has been identified as the dominant sediment accumulation process. On the alluvial toeslope the inter-fingering of colluvial and alluvial deposition has created an environment conducive to a higher density of paleosols and SOC preservation. Using ${ }^{14} \mathrm{C}$ ages and the pre-human $200 \mathrm{~cm}$ paleosol, terrestrial sedimentation rates for the anthropocene were calculated and can be compared with the lake sedimentation rates for the same period. The connectivity (SDR) between the terrestrial and lacustrine depositional environments appears not have been overly influenced by land-use change even if the actual sedimentation rate has gone up significantly. 


\section{Chapter 7: Conclusion}

\subsection{Aim}

The stated aim of this thesis is to qualitatively and quantitatively describe the impact land-use change has had on carbon storage in contemporary soils and paleosols from the late Holocene in the Oporae Valley, Lake Tutira, New Zealand. To achieve this aim a number of objectives were established. The results and supporting evidence were presented in Chapter 5, then in Chapter 6 this information was used to develop the current understanding of what has happened to the terrestrial carbon pool under land-use change in the Oporae Valley.

\subsection{Land Use Change and Soil Organic Carbon}

Objective 1: Quantify the SOC content of topsoil that has undergone anthropogenic land-use change. Compare these values with topsoil values of local proxy native forest soils to establish whether the net balance of SOC has increased or decreased post land use change.

Soil organic carbon can either increase or decrease under different land use change scenarios. In the Oporae Valley SOC in the contemporary topsoil is significantly less than what would have existed prior to anthropogenic land-use change $\sim 600$ years BP. Proxy undisturbed forest soils to $35 \mathrm{~cm}$ depth indicate that the contemporary topsoil contains $\sim 40 \%$ less SOC (note: $35 \mathrm{~cm}$ includes some paleosol SOC from the Oporae Valley pasture soils). This equates to an approximate loss of $5,338 \mathrm{~T} / \mathrm{km}^{2}$ of SOC for topsoil. If the Oporae Valley is representative of the $10,000 \mathrm{~km}^{2}$ of the North Island's dry eastern hill country (much of which has undergone deforestation and pasture conversion), this then demonstrates the potential for the currently unsustainable land use of erosion prone hill country as an economically valuable long term carbon sink through revegetation. Additionally, there is some evidence to suggest revegetated hillslopes may provide an increase in SOM input on the pasture covered slope below, possibly through overland flow and by providing an environment conducive to soil aggregate formation and SOC protection.

\subsection{Paleosols and Soil Organic Carbon}

Objective 2: To identify and quantify the SOC content of paleosols, thereby determining the significance of paleosols as a $C$ sink.

The contemporary soil to an average depth of $30 \mathrm{~cm}$ (thereby excluding paleosols) contains $7,880 \mathrm{~T} / \mathrm{km}^{2} \mathrm{OC}$, and the pre-human $200 \mathrm{~cm}$ paleosol averaging $32 \mathrm{~cm}$ contains $9,180 \mathrm{~T} / \mathrm{km}^{2}$. The fact there is more OC buried at depth than what currently exists in the contemporary topsoil indicates the relative importance of paleosols as $\mathrm{C}$ stores and the geomorphic processes associated with land-use change. The inclusion of paleosols as a significant and ongoing addition to the terrestrial carbon sink has been shown through the identification and quantification of numerous discontinuous surfaces and three larger common surfaces between the two transects. The incorporation of this significant proportion into the catchment carbon budget is the next step in 
understanding the complex terrestrial carbon pool and its response to ongoing land use change first locally and ultimately globally. For example the incorporation of this mechanism into carbon budgets and models could help offset the contemporary reduction in SOC from the topsoil identified in section 7.2. The previously unknown 'missing carbon sink' has recently been linked to tropical forests up-taking more atmospheric $\mathrm{CO}_{2}$ than previously thought; however it is likely that anthropogenic paleosols derived from large scale land use change also form a part of the equation where they occur on a large scale.

\subsection{Geomorphology of Paleosols}

Objective 3: To correlate the physical sediment characteristics and the geochemical signatures across the core sites, using the relationships and stratigraphy to ascertain the impact of slope and fluvial process dominance on SOC preservation.

The landscape evolution of this catchment post deforestation has been punctuated with frequent landsliding events and low angle colluvial fan development which have created paleosols that laterally are both continuous and discontinuous between the cores. The evidence for this lies in the relationship between paleosol frequency and slope angle as shown in figures 5.1 and 5.2. Where the slope is steeper, gravity has deposited large blocks or rafts of sediment from up-slope, whereas rapid long shallow runout and overland flow carries less sediment (and more often) out onto the alluvial toeslope. This helps to create a higher density of paleosols and therefore SOC on the alluvial toeslope.

Notwithstanding the change in paleosol frequency between alluvial and colluvial deposition zones, there are still paleosols found within every core (except the T2 S1 shallow core) creating a series of $C$ sinks that vary in magnitude and longevity. While from a holistic view point they all form one sink derived as a result of land-use change, greater understanding of the relationship between process and sink formation can be derived by treating these $\mathrm{C}$ sinks as discrete entities.

There are considered to be three common paleosol surfaces at $\sim 50 \mathrm{~cm}, \sim 100$ $\mathrm{cm}$ and $\sim 200 \mathrm{~cm}$. When normalised for thickness (Table 6.2) the $50 \mathrm{~cm}$ paleosol contains over double the amount of OC than the $100 \mathrm{~cm}$, and the $200 \mathrm{~cm}$ prehuman paleosol contains $25 \%$ more SOC than the $50 \mathrm{~cm}$ paleosol. These differences can be put down to the vegetation and soil characteristics which dictated their formation and the type of geomorphic activity which subsequently resulted in their burial.

\section{Vegetation}

The T1 pasture-covered contemporary topsoil contains an almost identical nutrient profile irrespective of its position on the slope i.e. across all sites. This suggests that this type of vegetation does not impact on the nutrient content of the topsoil for depositional slopes. T2, however, has an up-slope revegetated source area which impacts on the slope erosion characteristics and therefore on 
SOM accumulation down-slope. This is seen as greater variability in the topsoil SOC content down-slope with the additional OM input through overland flow and increased slope stability.

\section{Geomorphic activity}

The preservation characteristics of a paleosol are determined by slope angle and the relative position they hold in relation to the inter-fingering of the alluvial toeslope with the colluvial footslope. The alluvial toeslope is dominated by high frequency low magnitude deposition events, whereas the colluvial footslope is dominated by lower frequency higher magnitude events. The grain size analysis, photographic evidence and geochemical analyses show that the valley floor is a preferred site for OM preservation compared to the colluvial footslope. Furthermore, the geomorphic processes of low energy fine grain alluvial deposition providing fine sediments conducive to OM preservation and more frequent low energy long shallow colluvial runout deposition combine to create conditions conducive to creating a long term $\mathrm{C}$ sink.

\subsection{Accumulation Rates}

Objective 4: Define the residence time and sedimentation rate of carbon in the soil profile, based on the stratigraphy established using elemental analysis and sediment characterisation, corroborated with pollen analysis and ${ }^{14} \mathrm{C}$ dating.

Comparing pre-human and anthropogenic sedimentation rates between Lake Tutira and the tributary Oporae Valley has shown significant differences between the two depositional environments. At $0.9 \mathrm{~mm} \mathrm{yr}^{-1}$ the terrestrial prehuman sedimentation rate averaged over the valley floor is approximately half (0.53) of the corresponding pre-human lake rate of $1.7 \mathrm{~mm} \mathrm{yr}^{-1}$. As a proportion

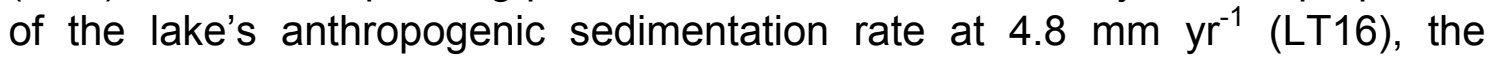
terrestrial anthropogenic sedimentation rate has slightly increased to $2.8 \mathrm{~mm} \mathrm{yr}^{-}$

1 (alluvial upper valley) or 0.58 of the lake sedimentation rate. This finding demonstrates that with the loss of landscape stabilising vegetation, the associated approximately three-fold increase from pre-human to anthropogenic sedimentation has occurred both on land and in the lake. Other than supporting the pre-existing findings that land-use change has significantly increased the catchment erosion regime, this finding lends insight into the terrestrial and hydrological sediment transport and storage processes. Despite landsliding as a dominant geomorphic agent, the fluvial transport system is only slightly less efficient at re-working colluvial and alluvial terrestrial deposits on a pasture covered landscape as it is in a forested one. Remembering that the anthropogenic terrestrial sedimentation rate calculated here does not distinguish between the pre-European (bracken) phase and the post-European (pasture) phase, which on its own has an 8-fold increase over that of the prehuman sedimentation rate, this finding has significant implications for land management practices. The cost of Cyclone Bola as a single event exceeded $\$ 12$ million dollars in damage to the Hawke's Bay District, and over \$120 million for the North Island (Trustrum and Page 1992). Severe erosion and the associated soil carbon redistribution/loss are problems that can be managed 
more effectively. Directing resources efficiently based on greater understanding of the fluvial and terrestrial transport/storage mechanisms will not only reduce the potential environmental and financial impacts of future events, but also help to preserve a non-renewable resource, soil.

\subsection{Hypothesis Evaluation}

During the anthropocene land-use change has exacerbated erosion of the SOC rich topsoil in the Oporae Valley. As well as reducing the SOC content of the contemporary topsoil, the large scale redistribution of sediment has created a long term SOC sink at depth in buried soils or paleosols.

The confirmed existence and quantification of a significant carbon sink derived from land-use change in the Oporae Valley has confirmed the hypothesis. Furthermore, using a small data set it has been shown that the contemporary topsoil under pasture contains less $\mathrm{OC}$ than under contemporary native forest vegetation. These forest soils can be used as a proxy for the loss of SOC in the contemporary topsoil. The change in vegetation type and accelerated erosion regime has also created a medium to long term carbon sink that offsets this loss for the area of the alluvial valley floor. However the frequency of paleosols and SOC density on the colluvial footslope is lower, and further up-slope into the source areas it is reasonable to expect that the paleosols will disappear entirely. In this heavily dissected landscape where a large proportion of the terrain is potential source area, the SOC loss from the topsoil post land use change is expected to outweigh SOC sink formation in paleosols. These initial findings demonstrate the potential for further research in this area, so that ultimately ongoing land-use change can be properly incorporated into terrestrial carbon accounting.

\subsection{Future Directions}

\section{Carbon Accumulation Rates}

If the aforementioned assumptions for both the carbon calculations and the sediment accumulation rates are held, then the theoretical calculation of a carbon accumulation rate for the last $\sim 600$ years is possible. This step would allow for the closure of the terrestrial carbon budget. However, as with the terrestrial accumulation rate, distinguishing between the European and Maori periods in the terrestrial sediments would further augment this type of analysis.

\section{Linking C Pools}

Based on the preliminary comparative analyses between the Oporae Valley terrestrial accumulation rate and the pre-existing accumulation rates established for Lake Tutira, the potential now exists to further refinement and linking the terrestrial and lake sedimentary regimes. Ultimately improved understanding of the connectivity between the two OC pools could be transferred into modelling applications.

\section{Wetlands}

The regeneration of the Lake Tutira wetland environment at the bottom of the Oporae Valley provides an opportunity to study the soil nutrient characteristics 
as they would have been before anthropogenic land use change. Based on the observation of the wetland paleosol in T2 S4, SOC capture and preservation in this environment may prove to be an interesting case study in the argument for riparian carbon capture initiatives. 


\section{Reference List}

Allen, T. 1975. Particle Size Measurement. 2nd ed. London: Chapman and Hall.

Anderson, A. 1991. The chronology of colonization in New Zealand. Antiquity 65:767795.

Andersson, J.O. and L. Nyberg. 2008. Spatial variation of wetlands and flux of dissolved organic carbon in boreal headwater streams. Hydrological Processes 22 (12):1965-1975.

Andreux, F., C. Cerri, P.B. Vose and V.A. Vitorello. 1990. Potential of Stable Isotope ${ }^{15} \mathrm{~N}$ and ${ }^{13} \mathrm{C}$ Methods for Determining Input and Turnover in Soils. In Nutrient Cycling in Terrestrial Ecosystems: Field Methods, Application and Interpretation, edited by A.F. Harrison and P. Ineson. New York: Elsevier Science Publishers Ltd.

Ågren, G.I., D.O. Hessen, T.R. Anderson, J.J. Elser and P. DeReuter. 2003. Element Interactions: Theoretical Considerations. In Interactions of the Major Biogeochemical Cycles, edited by J. M. Melillo, C.B. Field and B. Moldan. Washington DC: Island Press.

Barrett, P.J., M.R. Brooker and J.J. Anderson. 2000. Grain size analysis at VUW. Wellington: Research School of Earth Sciences, Victoria University of Wellington.

Berryman, K. 1988. Tectonic geomorphology at a plate boundary: a transect across Hawke Bay, New Zealand. Zeitschrift fur Geomorphologie, Supplementband 69:69-86.

Beuselinck, L., G. Govers, J. Poesen, G. Degraer and L. Froyen. 1998. Grain-size analysis by laser diffractometry: comparison with the sieve-pipette method. Catena 32:193-208.

Blott, S.J. and K. Pye. 2006. Particle size distribution analysis of sand-sized particles by laser diffraction: an experimental investigation of instrument sensitivity and the effects of particle shape. Sedimentology 53 (3):671-685.

Brackley, H.L. 2005. Land to ocean transfer of erosion-related organic carbon, Waipaoa Sedimentary System, East Coast, New Zealand. Unpublished PhD thesis, Victoria University of Wellington, Wellington.

Carter, L., L. Northcote, M.J. Page, H. Brackley, N.A. Trustrum, B. Gomez and A. Palmer. 2004. Paleo-climate research: drilling Lake Tutira for evidence of climate change. Water \& Atmosphere 12 (2):12-13.

Cerri, N.C., J.M. Melillo, B.J. Feigl, P.A. Steudler, J.F.L. Moraes and M.C. Piccolo. 1998. Stocks and Dynamics of Soil Carbon following Deforestation for Pasture in Rondonia. In Soil Processes and the Carbon Cycle, edited by R. Lal, J.M. Kimble, R.F. Follett and B.A. Stewart. Boston: CRC Press.

Cole, J.W. and K.B. Lewis. 1981. Evolution of the Taupo-Hikurangi subduction system. Tectonophysics 72 (1-2):1-21.

Conacher, A.J. and J.B. Dalrymple. 1977. Contemporary landsurface process responses. Geoderma 18 (1-2):36 - 63.

Courtney, FM. and S.T. Trudgill. 1984. The Soil: An Introduction to Soil Study. London: Edward Arnold.

Dawson, J. and R. Lucas. 2000. Nature guide to the New Zealand Forest. Auckland: Godwit.

Denman, K.L., G. Brasseur, A. Chidthaisong, P. Ciais, P.M. Cox, R.E. Dickinson, D. Hauglustaine, C. Heinze, E. Holland, D. Jacob, U. Lohmann, S. Ramachandran, P.L. da Silva Dias, S.C. Wofsy and X. Zhang. 2007. Couplings between Changes in the Climate System and Biogeochemistry. In Climate Change 2007: The Physical Science Basis. Contribution of Working Group I to the Fourth Assessment Report of the Intergovernmental Panel on Climate Change, edited by S. Solomon, D. Qin, M. Manning, Z. Chen, M. Marquis, K.B. Averyt, M. Tignor and H.L. Miller. Cambridge University Press, Cambridge, United Kingdom and New York, NY, USA.

Eden, D. and P.C. Froggatt. 1996. A 6,500-year-old history of tephra deposition recorded in the sediments of Lake Tutira, eastern North Island, New Zealand. Quaternary International 34-6:55-64. 
Eden, D.N., P.C. Froggatt, N.A. Trustrum and M.J. Page. 1993. A multiple source Holocene tephra sequence from Lake Tutira, Hawke's Bay, New Zealand. New Zealand Journal of Geology and Geophysics 36 (2):233-242.

Eden, D.N. and M.J. Page. 1998. Palaeoclimatic implications of a storm erosion record from late Holocene lake sediments, North Island, New Zealand. Palaeogeography Palaeoclimatology Palaeoecology 139 (1-2):37-58.

Ehleringer, J.R., N. Buchmann and L.B. Flanagan. 2000. Carbon isotope ratios in belowground carbon cycle processes. Ecological Applications 10 (2):412-422.

Eleki, K., R.M. Cruse and K.A. Albrecht. 2005. Root segregation of C3 and C4 species using carbon isotope composition. Crop Science 45 (3):879-882.

Faure, K. 2007. Stable Isotope Geochemistry: definitions, terminology, measurement and some applications. Paper read at Quaternary Techniques Short Course, at GNS Science, Gracefield.

Flanagan, L.B. 2005. Introduction: Stable Isotopes and Earth System Science. In Stable Isotopes and Biosphere-Atmosphere Interactions: Processes and Biological Controls, edited by L.B. Flanagan, J.R. Ehleringer and D.E. Pataki. London: Elsevier Academic Press.

Froggatt, P.C. 2007. New Zealand's volcanoes: The Taupo volcanic centre, Victoria Link Ltd \& Research School of Earth Sciences, Victoria University of Wellington

GNS. 2007. Geological and Nuclear Sciences Natural Hazards Resource Web Page.

Gomez, B., H.L. Brackley, D.M. Hicks, H. Neff and K.M. Rogers. 2004. Organic carbon in floodplain alluvium: Signature of historic variations in erosion processes associated with deforestation, Waipaoa River basin, New Zealand. Journal of Geophysical Research - Earth Surface. 109. F04011.

Goudie, A., M. Anderson, T. Burt, J. Lewin, K. Richards, B. Whalley and P. Worsley. 1998. Physical Properties. In Geomorphological Techniques. London: Routledge.

Guthrie-Smith, H. Tutira: the story of a New Zealand sheep station. 4th ed. London: Godwit.

Hawke, R.M. and J.A. McConchie. 2003. Variability of in situ moisture measurements and implications for modeling hill-slope processes. Environmental Engineering and Geoscience IX (No.3):213-223.

Haywick, D.W., R.M. Carter and R.A. Henderson. 1992. Sedimentology of 40000 year Milankovitch-controlled cyclothems from central Hawke's Bay, New Zealand. Sedimentology 39 (4):675-696.

Högberg, P., A. Ekblad, A. Nordgren, A.H. Plamboeck, A. Ohlsson, B. Singh and M.N. Högberg. 2005. Factors Determining the ${ }^{13} \mathrm{C}$ Abundance of Soil-Respired $\mathrm{CO}_{2}$ in Boreal Forests. In Stable Isotopes and Biosphere-Atmosphere Interactions:

Processes and Biological Controls, edited by L.B. Flanagan, J. Ehleringer and D.E. Pataki. London: Elsevier Academic Press.

Huggett, R.J. 2007. Fundamentals of Geomorphology. 2nd ed. London: Routledge. Ingram, R.L. 1971. Sieve Analysis. In Procedures in Sedimentary Geology, edited by R.E. Carver. London: Wiley-Interscience.

IPCC. 2007. Climate Change 2007: The Physical Science Basis. Contribution of Working Group I to the Fourth Assessment Report of the Intergovernmental Panel on Climate Change [Solomon, S., D. Qin, M. Manning, Z. Chen, M. Marquis, K.B. Averyt, M. Tignor and H.L. Miller (eds.)]. Cambridge University Press, Cambridge.

Jeffery, P.G. and D. Hutchison. 1981. Chemical Methods of Rock Analysis. Edited by R. Belcher, D. Betteridge and L. Meites. 3rd ed. Oxford: Pergamon Press.

Johnstone, J. 2007. Professor of Chemistry and Head of Department, School of Chemical and Physical Sciences, Victoria University of Wellington.

Jones, M.B. and A. Donnelly. 2004. Carbon sequestration in temperate grassland ecosystems and the influence of management, climate and elevated $\mathrm{CO}_{2}$. New Phytologist 164 (3):423-439.

Kamp, P.J.J. 1992. Landforms of the Hawke's Bay and their Origin: A Plate Tectonic Interpretation. Edited by J.M. Soons and M.J. Selby. 2nd ed, Landforms of New Zealand. Auckland: Longman Paul. 
Kendall, C., S.R. Silva and V.J. Kelly. 2001. Carbon and nitrogen isotopic compositions of particulate organic matter in four large river systems across the United States. Hydrological Processes 15 (7):1301-1346.

Konert, M. and J. Vandenberghe. 1997. Comparison of laser grain size analysis with pipette and sieve analysis: A solution for the underestimation of the clay fraction. Sedimentology 44 (3):523-535.

Krull, E.S., J.A. Baldock and J.O. Skjemstad. 2003. Importance of mechanisms and processes of the stabilisation of soil organic matter for modelling carbon turnover. Functional Plant Biology 30 (2):207-222.

Krull, E.S. and J.O. Skjemstad. 2003. $\delta^{13} \mathrm{C}$ and $\delta^{15} \mathrm{~N}$ profiles in ${ }^{14} \mathrm{C}$-dated Oxisol and Vertisols as a function of soil chemistry and mineralogy. Geoderma 112 (1-2):1-29.

Lal, R., J.M. Kimble and R.F. Follett. 1998. Pedospheric Processes and the Carbon Cycle. In Soil Processes and the Carbon Cycle, edited by R. Lal, J.M. Kimble, R.F. Follett and B.A. Stewart. Boston: CRC Press.

Lawton, J.R. 1988. Ultrastructure of chloroplast membranes in leaves of maize and ryegrass as revealed by selective staining methods. New Phytologist 108 (3):277283.

Lowe, D.A. 1987. The Geology and Landslides of the Lake Tutira-Waikoau area, Northern Central Hawke's Bay. Unpublished MSc thesis, School of Earth Sciences, Victoria University of Wellington, Wellington.

Malvern Instruments Ltd. 2007. Mastersizer application note MRK561-01: Wet method development for laser diffraction measurements 2007 [cited 18 September 2007]. Available from http://www.malvern.co.uk/malvern/kbase.nsf/allbyno/KB000597/\$file/MRK56102\%20Wet\%20Method\%20Development $\% 20$ for\%20laser\%20diffraction\%20meas urements.pdf.

Malvern Instruments Ltd. 2007. Understanding how laser diffraction works. Malvern Instruments Ltd. 2007 [cited 18 September 2007]. Available from http://www.malvern.co.uk/LabEng/technology/laser_diffraction/laser_diffraction.htm

McConchie, J.A. 1992. Water and Slope Stability In Waters of New Zealand, edited by M.P. Mosley: New Zealand Hydrological Society.

McGlone, M.S., A. Anderson and R.N. Holdaway. 1994. An Ecological Approach to the Polynesian Settlement of New Zealand. . In The Origins of the First New Zealanders, edited by D.G. Sutton. Auckland: Auckland University Press.

McLaren, R.G. and K.C. Cameron. 1990. Soil Science - An Introduction to the Properties and Management of New Zealand Soils. Auckland: Oxford University Press.

McLea, W. 2007. Personal communication on the pollen analysis conducted by Dr. William McLea on the Oporae Valley cores. Victoria University of Wellington, School of Geography, Environment and Earth Sciences.

Moore, P.D. and J.A. Webb. 1978. An Illustrated Guide to Pollen Analysis. 1st ed. London: Hodder and Stoughton.

Müller, G. 1967. in Goudie, A. (1998) Geomorphological Techniques - Chapter 3.2: Physical Properties. Edited by A. Goudie. 2nd ed. London: Routledge.

Neill, C., C. Cerri, J.M. Melillo, B.J. Feigl, P.A. Steudler, J.F.L. Moraes and M.C. Piccolo. 1998. Stocks and Dynamics of Soil Carbon Following Deforestation for Pasture in Rondonia. In Soil Processes and the Carbon Cycle, edited by R. Lal, J.M. Kimble, R.F. Follett and B.A. Stewart. Boston: CRC Press.

Nelson, D. and L. Sommers. 1996. Total Carbon, Organic Carbon, and Organic Matter. In Methods of Soil Analysis: Chemical Methods, edited by D.L. Sparks, A. Page, P. Helmke, R. Loeppert, P. Soltanpour, M. Tabatabai, C. Johnston and M. Summer. Madison: American Society of Agronomy.

Page, M.J. and N.A. Trustrum. 1997. A late Holocene lake sediment record of the erosion response to land use change in a steepland catchment, New Zealand. Zeitschrift für Geomorphologie 41 (3):369-392. 
Page, M.J., N.A. Trustrum and J.R. Dymond. 1994. Sediment budget to assess the geomorphic effect of a cyclonic storm, New Zealand. Geomorphology 9 (3):169188.

Page, M., N. Trustrum, H. Brackley and T. Baisden. 2004. Erosion-related soil carbon fluxes in a pastoral steepland catchment, New Zealand. Agriculture Ecosystems \& Environment 103 (3):561-579.

Page, M.J., N.A. Trustrum and R.C. DeRose. 1994. A high resolution record of storminduced erosion from lake sediments, New Zealand. Journal of Paleolimnology: 333-348.

Pettinga, J. 2001. Rock Formation and Earth Building Processes. Edited by A. Sturman and R. Spronken-Smith, The Physical Environment: A New Zealand Perspective. New York: Oxford University Press.

Phillips, D.L. and P.L. Koch. 2002. Incorporating concentration dependence in stable isotope mixing models. Oecologia 130 (1):114-125.

Ponge, J.-F. 2003. Humus forms in terrestrial ecosystems: a framework to biodiversity. Soil Biology and Biochemistry 35 (7):935-945.

Poole, A.L. 2006. 'Matai, Black Pine', from An Encyclopaedia of New Zealand, edited by A.H. McLintock, originally published in 1966.

Post, W.M. and K.C. Kwon. 2000. Soil carbon sequestration and land-use change: processes and potential. Global Change Biology 6 (3):317-327.

Raymond, P.A. 2005. The age of the Amazon's breath. Nature 436:469-470.

Robertson, G.P. and A.P. Eldor. 2000. Decomposition and Soil Organic Matter Dynamics. In Methods in Ecosystem Science, edited by O.E. Sala, R.B. Jackson, H.A. Mooney and R.W. Howarth. New York: Springer.

Rogers, K. 2007. Personal communication on the maximum grain size necessary for reproducibility of replicates from soil samples processed by Gas Chromatography Mass Spectrometry. Geological and Nuclear Sciences National Stable Isotope Laboratory, Seaview, Wellington.

Roose, E.J., R. Lal, C. Feller, B.G. Barthes and B.A. Stewart. 2006. Soil Erosion and Carbon Dynamics. Edited by B.A. Stewart, Advances in Soil Science. London: Taylor and Francis.

Scott, D.T., W.T. Baisden, R.J. Davies-Colley, B. Gomez, D.M. Hicks, M.J. Page, N.J. Preston, N.A. Trustrum, K.R. Tate and R. Woods. 2006. Localized erosion affects national carbon budget. Geophysical Research Letters 33(1). L01402.

Schwartz, E., S. Blazewicz, R. Doucett, B.A. Hungate, S.C. Hart and P. Dijkstra. 2007. Natural abundance $\delta^{15} \mathrm{~N}$ and $\delta^{13} \mathrm{C}$ of DNA extracted from soil. Soil Biology and Biochemistry 39 (12):3101-3107.

Sharp, Z. 2007. Principles of Stable Isotope Geochemistry. New Jersey: Pearson Prentice Hall.

Shillabeer, N., B. Hart and A.M. Riddle. 1992. The use of a mathematical model to compare particle size data derived by dry-sieving and laser analysis. Estuarine, Coastal and Shelf Science 35 (1):105-111.

Smith, P. and D. Martino. 2007. Agriculture. In: IPCC Fourth Assessment Report, Working Group III (Final Draft).

Smucker, A.J.M., E.J. Park, J. Dorner and R. Horn. 2007. Soil micropore development and contributions to soluble carbon transport within macroaggregates. Vadose Zone Journal 6 (2):282-290.

Sollins, P., C. Glassman, E.A. Paul, C. Swanston, K. Lajtha, J. Heli and T.E. Elliott. 1999. Soil Carbon and Nitrogen Pools and Fractions. In Standard Soil Methods for Long-Term Ecological Research, edited by G.P. Robertson, D.C. Coleman, C.S. Bledsoe and P. Sollins. New York: Oxford University Press.

Sperazza, M., J.N. Moore and M.S. Hendrix. 2004. High-resolution particle size analysis of naturally occurring very fine-grained sediment through laser diffractometry. Journal of Sedimentary Research 74 (5):736-743.

Sperazza, M., J.N. Moore and M.S. Hendrix. 2002. Methodology for sediment grain size analysis by laser diffraction: a high resolution application. In Sediments, Clastic: Processes, Petrology, and Provenance. Denver, Colorado. 
Stevenson, F.J. and M.A. Cole. 1999. Cycles of Soil - Carbon, Nitrogen, Phosphorus, Sulfur and Micronutrients. New York: John Wiley and Sons.

Tate, K.R., D.J. Giltrap, J.J. Claydon, P.F. Newsome, I.A.E. Atkinson, M.D. Taylor and R. Lee. 1997. Organic carbon stocks in New Zealand's terrestrial ecosystems. Journal of the Royal Society of New Zealand 27 (3):315-335.

Thompson, C.S. 1987. The Climate and Weather of Hawke's Bay. Miscellaneous Publication 115(5), 2nd ed. Wellington: New Zealand Meteorological Service

Trustrum, N.A. and M.J. Page. 1992. The long term erosion history of Lake Tutira watershed: implications for sustainable land-use management. In: Proc. Int. Conf. on Sustainable Land Management. Napier, New Zealand.

Turner, G.M. 1997. Environmental magnetism and magnetic correlation of high resolution lake sediment records from Northern Hawke's Bay, New Zealand. New Zealand Journal of Geology and Geophysics 40:287 - 298.

Wardle, P. 1991. Vegetation of New Zealand Plants. Cambridge: Cambridge University Press.

Webb, C.J. and J.A. Simpson. 2001. Seed of New Zealand: Gymnosperms and Dicotyledons. Christchurch: Manuka Press.

Whittow, J. 1984. The Penguin Dictionary of Physical Geography. Middlesex: Penguin Books.

Wilmshurst, J.M. 1997. The impact of human settlement on vegetation and soil stability in Hawke's Bay, New Zealand. New Zealand Journal of Botany 35 (1):97-111.

Worrall, F. and T.P. Burt. 2007. Flux of dissolved organic carbon from UK rivers. Global Biogeochemical Cycles 21 (1). 


\section{APPENDIX I: Isotope Geochemistry Definitions, Terminology and Notation}

As Faure points out "the accepted terminology of stable isotope geochemistry is not straightforward" (pers. comm. Faure 2007). To avoid the misinterpretation of isotopic data, the following section contains some basic definitions and explanations of the relevant subject material to this thesis:

1. Isotope: the same element whose atoms nucleus that has the same number of protons but a different numbers of neutrons, thus it carries the same charge, but has a different mass.

2. Isotope atomic mass: because of the different number of neutrons, atoms of the same element can have different mass. The mass number is superscript to the left of the element symbol e.g. ${ }^{12} \mathrm{C}$ represents one carbon atom with six protons and six neutrons, ${ }^{13} \mathrm{C}$ represents one carbon atom with six protons and seven neutrons.

3. Stable isotopes are atoms which are nuclides that are inactive and do not change composition over geological time scales. Alternatively 'Radioactive' nuclides are 'unstable' and therefore do decay and change to different isotopes through time e.g. ${ }^{14} \mathrm{C}$ represents one carbon atom with six protons and 8 neutrons. Through time the ${ }^{13} \mathrm{C}:{ }^{14} \mathrm{C}$ ratio within dead organic material will decrease, as the ${ }^{14} \mathrm{C}$ component 'decays' to ${ }^{13} \mathrm{C}$, this decay rate which is relatively constant when calibrated to known natural and anthropogenic perturbations in ${ }^{14} \mathrm{C}$, can be used to quantify the age of organic materials through radiogenic isotope geochemistry.

4. Table 1 summarises the basic characteristics of some commonly analysed stable isotopes.

Table 1. Characteristics of some common isotopes, adapted from (Faure 2007).

\begin{tabular}{|c|c|c|c|c|}
\hline Element & Isotope & $\begin{array}{c}\text { Natural } \\
\text { Abundance (\%) }\end{array}$ & $\begin{array}{c}\text { Mass } \\
\text { Difference (\%) }\end{array}$ & $\begin{array}{c}\text { Reference } \\
\text { Standard }\end{array}$ \\
\hline Carbon & $\begin{array}{l}{ }^{12} \mathrm{C} \text { (light, common) } \\
{ }^{13} \mathrm{C} \text { (heavy, rare) }\end{array}$ & $\begin{array}{c}98.89 \\
1.11\end{array}$ & 8.36 & VPDB \\
\hline Nitrogen & $\begin{array}{l}{ }^{14} \mathrm{~N} \text { (light, common) } \\
{ }^{15} \mathrm{~N} \text { (heavy, rare) }\end{array}$ & $\begin{array}{c}99.64 \\
0.36\end{array}$ & 7.12 & Air $\mathrm{N}_{2}$ \\
\hline Oxygen & $\begin{array}{l}{ }^{16} \mathrm{O} \text { (light, common) } \\
{ }_{17} \mathrm{O} \text { (heavy, rare) } \\
{ }^{18} \mathrm{O} \text { (heavy, rare) }\end{array}$ & $\begin{array}{l}99.76 \\
0.037 \\
0.20\end{array}$ & 12.5 & $\begin{array}{l}\text { VSMOW } \\
\text { VPDB }\end{array}$ \\
\hline
\end{tabular}

5. Stable isotope measurement is carried out using an isotope ratio mass spectrometer (IRMS). IRMS splits the element into the masses of the different isotopologues (in this case $\mathrm{CO}_{2}$ is derived from sample combustion in an inert gas stream). Table 2 shows the isotopologues for carbon and nitrogen.

Table 2. Carbon and Nitrogen isotopologues, adapted from Sharp (2007).

\begin{tabular}{|c|c|c|}
\hline Element & Gas & Mass of isotopologues (measured by IRMS) \\
\hline Carbon & $\mathrm{CO}_{2}$ & 44,45 and 46 \\
\hline Nitrogen & $\mathrm{N}_{2}$ & 28,29 and 30 \\
\hline
\end{tabular}


The isotopologues are derived by simply adding the different possible combinations of isotopes that form the compound derived from combustion together e.g. the nine isotopologues for $\mathrm{CO}_{2}$ are:

mass $44={ }^{16} \mathrm{O}+{ }^{12} \mathrm{C}+{ }^{16} \mathrm{O}$;

mass $45={ }^{16} \mathrm{O}+{ }^{13} \mathrm{C}+{ }^{16} \mathrm{O}$, or ${ }^{16} \mathrm{O}+{ }^{12} \mathrm{C}+{ }^{17} \mathrm{O}$, or ${ }^{17} \mathrm{O}+{ }^{12} \mathrm{C}+{ }^{16} \mathrm{O}$;

mass $46={ }^{16} \mathrm{O}+{ }^{12} \mathrm{C}+{ }^{18} \mathrm{O}$, or ${ }^{18} \mathrm{O}+{ }^{12} \mathrm{C}+{ }^{16} \mathrm{O}$, or ${ }^{17} \mathrm{O}+{ }^{12} \mathrm{C}+{ }^{17} \mathrm{O}$, or ${ }^{16} \mathrm{O}$ $+{ }^{13} \mathrm{C}+{ }^{17} \mathrm{O}$, or ${ }^{17} \mathrm{O}+{ }^{13} \mathrm{C}+{ }^{16} \mathrm{O}$ (Sharp 2007).

Isotopologues containing two rare isotopes $\left({ }^{13} \mathrm{C}\right.$ and $\left.{ }^{17} \mathrm{O}\right)$ are negligible in IRMS.

6. Simultaneous analyses of different gases are possible by the addition of a gas chromatograph system on the front end of the IRMS unit (GCIRMS). GC-IRMS combusts the sample at high temperature, the resultant gases are introduced to a helium gas stream where the $\mathrm{CO}_{2}$ and $\mathrm{N}_{2}$ components are separated by a chromatographic column. The temporally separated gases are then passed onto the IRMS where the isotopologues for a given compound are measured simultaneously (Sharp 2007).

7. The output data from GC-IRMS is converted to $\%$ element and a delta $(\delta)$ value e.g. for $\mathrm{C}$ and $\mathrm{N}$ analysis, $\delta^{13} \mathrm{C}$ or $\delta^{15} \mathrm{~N}$. The delta value calculation step is automatically carried out by the accompanying analysis software, but is critical to understanding the correct meaning of the values and notation. The actual abundance of an isotope is difficult to determine, however the ratio of relative concentrations can be determined very precisely (Sharp 2007). This done by comparing the isotopologue ratio of a sample against that of a known standard. The following equation is used to derive the delta value that represents this comparison.

$$
\delta=1000 \times \frac{\mathrm{R}_{\text {unknown }}-\mathrm{R}_{\text {standard }}}{\mathrm{R}_{\text {standard }}}
$$

Where $\quad \mathrm{R}={ }^{13} \mathrm{C} /{ }^{12} \mathrm{C}$ of either the 'unknown' sample or 'standard.'

Delta values are reported using the per mil (\%o) notation (parts per thousand) e.g. the $\delta^{15} \mathrm{~N}$ value of the topsoil was $5.16 \%$; the $\delta^{13} \mathrm{C}$ value for the same sample was $-28.52 \%$. Negative $\delta$ values mean that the ratio of heavy to light isotope is lower in the sample than in the standard, and the opposite is true for positive values (Sharp 2007). Often the literature refers to $\delta^{13} \mathrm{C}$ enrichment or depletion via one of a number of possible processes, if a delta value were enriched from $-28.52 \%$ by $3 \%$, it would become $-25.52 \%$.

The purpose of this notation is to accurately express the very small differences in isotopic ratios between known standards and the unknown sample (Sharp 2007). When all measurements are calculated against standards, the importance of calibration and uniformity is vital for ensuring accuracy across different laboratories globally.

The following section covers the possible variables that will impact upon the delta values derived from the Oporae Valley for the elements of $\mathrm{C}$ and $\mathrm{N}$. 


\section{Factors impacting upon geochemistry (fractionation)}

In Section 2.2 a list of nine factors was given for the stability of any given SOC pool. These factors correspond to three different mechanisms that impact upon delta values for $\mathrm{C}$ and $\mathrm{N}$, they are:

1. Biological processes: transformation of $\mathrm{C}$ or $\mathrm{N}$ from one form to another

2. Physical processes: displacement, burial and the protection of SOM from biological transformation through interaction with soil particles

3. Chemical processes and properties: the structure of the molecule dictates its availability for biogeochemical processes.

Quantifying the degree to which these different processes or properties impact on stable isotope delta values is a rapidly developing field of science. The characteristic range of delta values for $\delta^{13} \mathrm{C}$ and $\delta^{15} \mathrm{~N}$ across a range of variables is summarised in Table 4.5. Also summarised in Table 4.5 is the C:N ratio, this diagnostic information is derived from the result out put of the elemental analyser and is often used for aiding data interpretation. It is calculated using the $\% \mathrm{C}$ and $\% \mathrm{~N}$ values:

$$
\mathrm{C}: \mathrm{N}=\frac{\% \mathrm{C}}{\% \mathrm{~N}} \times \frac{14}{12}
$$

The values in Table 4.5 have been taken from a number of different sources with differing applications, however due to the natural complexity of soils it is necessary to consider all of the variables that can impact upon the data set when attempting to provide the basis for interpretation e.g. Kendall et al. (2001) find that in general the $\delta^{13} \mathrm{C}$ value typically increases by $1-4 \%$ and occasionally up to $6 \%$ with increasing depth in a soil profile ${ }^{4}$. This is due to one of the following processes which are summarised by Högberg et al. (2005) and Krull and Skjemstad (2003):

1. The Suess effect; since industrialisation the atmosphere has been undergoing ${ }^{13} \mathrm{C}$ dilution due to burning of ${ }^{13} \mathrm{C}$ depleted fossil fuels, which originally underwent fractionation when plants removed $\mathrm{CO}_{2}$ from the atmosphere and converted the carbon to stored energy via photosynthesis. As fossil fuels have been stored below ground for a long time they are also devoid of the radio active isotopes ${ }^{14} \mathrm{C}$ and ${ }^{14} \mathrm{~N}$ (Högberg et al. 2005).

2. ${ }^{13} \mathrm{C}$ fractionation occurring during SOM decomposition by microorganisms can be split into several categories;

a) Microbial fractionation during litter decomposition has been shown to occur through analysing the enrichment of DNA in ${ }^{13} \mathrm{C}$ and ${ }^{15} \mathrm{~N}$ in soil microbes. Despite the enrichment the isotopic composition of microbes is still strongly influenced by that of the SOM (Schwartz et al. 2007). This effect then is relatively small; however, this small amount of fractionation could still play a significant role if the TOC content is very low, thereby increasing the proportion of fractionation.

b) Microbes will selectively decompose certain components of the SOM pool. As discussed in Section 2.2 (Figure 2.3) lignin chemical

\footnotetext{
${ }^{4}$ Values for this range can be more specific in different environments e.g. for a boreal forest the range is $3-4 \%$ (Högberg et al. 2005).
} 
compounds are more complex and less readily available for microbial decomposition than proteins or cellulose and thus persist longer in the SOM pool, potentially causing fractionation as they do so.

c) Figure 1 shows the plant biogeochemical fractions compiled from the literature and summarised by Krull and Skjemstad (2003).

d) The enrichment of ${ }^{13} \mathrm{C}$ in microbes also has a number of possible explanations that are summarised in Högberg et al. (2005). But whatever the cause Högberg et al. (2005) conclude that this could explain the $\delta^{13} \mathrm{C}$ enrichment trend that occurs with increasing depth, if microbial $\mathrm{C}$ is a pre-curser to stable SOM.

3. Long term changes in environmental boundary conditions (e.g. light and water) which limit plant fractionation (Krull and Skjemstad 2003)

4. Downward movement of ${ }^{13} \mathrm{C}$ enriched fractions that are soluble (Krull and Skjemstad 2003)

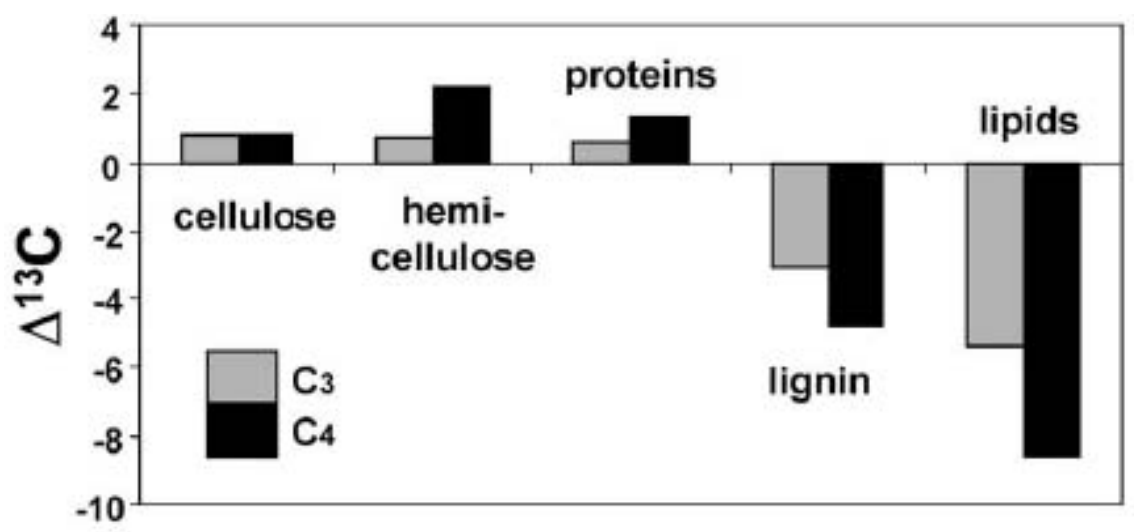

Figure 1 shows the relative change in $\delta^{13} \mathrm{C}$ (enrichment or depletion) of the biogeochemical fractions relative to the whole for C3 and C4 plants. Source: Krull and Skjemstad (2003).

Of these possibilities 1 and $2 \mathrm{c}$ are considered to be the most likely by Högberg et al. (2005) and Ehleringer et al. (2000), whose approach comes from the ecological perspective, yet Krull and Skjemstad (2003) have also shown that geochemical and mineralogical input can also greatly impact on the rate of decomposition and isotopic fractionation, which has implications for the modelling based on the former assumptions; yet all agree that the need for the further research in this area to help clarify the complexity of the processes responsible for isotope fractionation in soils is necessary (Ehleringer et al. 2000; Krull and Skjemstad 2003; Högberg et al. 2005). 


\section{APPENDIX II: Isotope Geochemistry Sample Preparation}

Preparing samples for $\mathrm{C}$ and $\mathrm{N}$ isotopic analysis was carried out with several precautions governing all procedures:

- Properly cleaning equipment between sample processing using, lint free wipes, compressed air and ethanol, to reduce the risk of cross contamination.

- Processing the samples of low carbon content first through to high, that way if contamination does occur, the impact will be negligible.

- Wearing disposable gloves when handling the sample, as contact with human skin can cause contamination of the sample.

\section{Drying and Splitting}

Excess heat can alter the $\mathrm{C}$ content of soils, so the recommended drying procedure is to air dry, or oven dry at $30-40^{\circ} \mathrm{C}$ for a minimum of $24 \mathrm{hrs}$ or until dry. Both methods were employed over the complete sample set, depending on the availability of apparatus. Once dry, to obtain a representative sub sample the splits must be carried out either using a splitter, riffle box or cone and quartering method. While ideally cone and quartering is to be avoided due to the potential of particle size biasing the distribution during handling, once dry the samples were small enough to simply separate into two replicates for processing.

\section{Grinding}

Inadequate grinding (insufficient homogenisation) and poor sub sampling (representation) are the primary causes of variability in soils analyses for EA IRMS (Sollins et al. 1999; Brackley 2005). To achieve sufficient homogenisation, samples must be ground and sieved using either mortar and pestle or ball mill to reduce the sample to the desired particle size. Initial grinding using mortar and pestle and sieving using $500 \mu \mathrm{m}$ and $250 \mu \mathrm{m}$ mesh sieves allows for the easy identification and removal of coarse organic matter (roots and leaves), while breaking up any clasts within the sample. It is necessary to grind the sub-sample to $\leq 125 \mu \mathrm{m}$ ensuring sufficient homogenisation of the soil sample for combustion and IRMS analysis (pers. comm. Rogers 2007). When grinding to this level, the volcanic glass component of the soil was revealed and required firm pressure to break up using a quartz mortar and pestle.

\section{Demineralisation (carbonate dissolution)}

This empirically based procedure contains variables which must be controlled across replicates, these variables include; the weight of the sample, type, volume, concentration, temperature of solvent, duration and frequency of application, and the particle grain size that the sample has been ground to (Jeffery et al. 1981). To remove carbonate from the soil sample without also altering the organic carbon or nitrogen isotopic composition, careful consideration of the ratio of acid application to strength must be given e.g. one high strength dose may also dissolve the component that is being sought for measurement, but repetitive low strength washes may also result in the loss of organic carbon through repetitive washes. Once again the experience of the 
EA-IRMS instrument operator is vital when dealing with soil samples, and repetition of the carbonate pre-treatment process has shown that for samples of low carbonate content a one application of $0.5 \mathrm{~mol} \mathrm{HCl}$ is sufficient to remove any carbonates if present (pers. comm Rogers 2007).

\section{Procedure for carbonate dissolution}

In a fume cupboard add $5 \mathrm{ml}$ of $0.5 \mathrm{~mol} \mathrm{HCl}$ to $\sim \mathrm{g}$ of ground sample in a $50 \mathrm{ml}$ centrifuge tube, the sample was gently agitated to achieve uniform dissolution, if a reaction occurred bubbles were noted. After $24 \mathrm{hrs}$ the samples were rinsed and vortexed using $\sim 50 \mathrm{ml}$ of deionised water $\left(\mathrm{dH}_{2} \mathrm{O}\right)$ to dilute the $\mathrm{HCl}$ in preparation for settling by centrifuge and decanting. The amount of $\mathrm{dH}_{2} \mathrm{O}$ varies slightly depending on the amount required to balance the centrifuge canisters when full. Centrifuge of the samples at 2,400rpm $(r 26 \mathrm{~cm})$ for 24 mins settles out the clays to $0.2 \mu \mathrm{m}$. The demineralised samples were then rinsed and centrifuged again to fully neutralise the acid. A very small amount of organic matter was floated off during this exercise on the upper organic horizon (0$10 \mathrm{~cm}$ ) of all the cores, and some organic rich buried soils. All contaminated waste was treated with a bicarbonate neutralising agent before disposal. The demineralised samples were then oven dried for a minimum of $24 \mathrm{hrs}$ at $35^{\circ} \mathrm{C}$.

\section{Weighing for IRMS}

Before the soil samples can be combusted in the IRMS furnace they must be measured out to a target weight within $\pm 0.1 \mathrm{mg}$. The target weight will vary with each sample depending on the proportion of $\mathrm{C}$ and $\mathrm{N}$ contained within the sample, the Spec number/name mass spectrometer used for this research is calibrated for $600-800 \mathrm{mg}$ of $\mathrm{CO}_{2}$ and $50-150 \mathrm{mg}$ of $\mathrm{N}_{2}$ (optimal values of $700 \mathrm{mg}$ and $100 \mathrm{mg}$ respectively). Typically for a topsoil of organic $\mathrm{C}$ content of around $7 \%, 15 \mathrm{mg}$ samples were prepared, or up to $100 \mathrm{mg}$ for low carbon content samples $(<1 \%)$. Dependent upon sample density $\sim 100 \mathrm{mg}$ is the maximum size sample that can be placed in a $5 \times 8 \mathrm{~mm}$ combustion capsule and in some cases carbon content was still at the minimum end of the IRMS detectability range. It is vital for calculation of the \% element that the weighing and sample preparation be conducted with close attention to detail. The combustion capsule must not be punctured or loose any sample through incorrectly sealing the opening.

\section{Equipment and Materials:}

Scales accurate to $0.00001 \mathrm{~g}$

Micro spoon

Combustion capsules $5 \times 8 \mathrm{~mm}$

Tweezers

Ethanol

Gloves

Lint free cloth

Sample Tray 


\section{Procedure:}

Typically $30 \mathrm{mg}$ samples are prepared for low carbon content soils. The following steps are carried out using tweezers and gloves, with thorough cleaning between samples. It is vital for calculation of the percent element that the weighing and sample preparation be conducted with close attention to detail. The combustion capsule must not be punctured or loose any sample through incorrect sealing of the opening.

Zero the combustion capsule on the scale. It is important that the scale is in a draught free environment, as errors in accurate weight measurement will effect the subsequent percent element calculation.

Off scales, spoon the sample into the combustion capsule and re-weigh until the desired weight is achieved. When spillage occurs, it is important not to get sample on the outside of the combustion capsule, as it may fall off prior to combustion, thereby impacting upon the accuracy of the weight measurement.
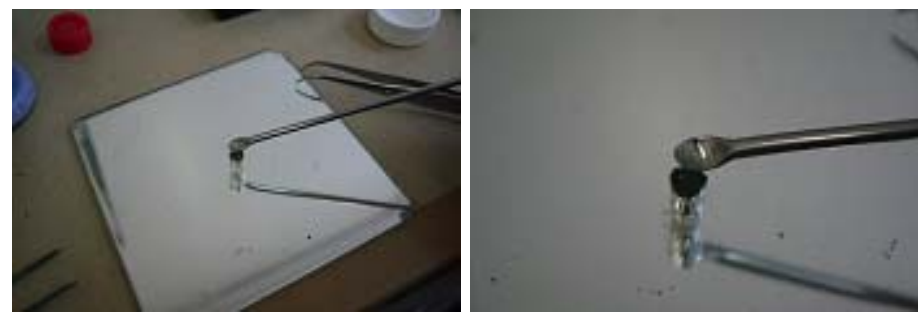

Once the desired weight is achieved (within $0.1 \mathrm{mg}$ ), the combustion capsule must be sealed. Use long nose tweezers to roll over the top. Then fold the corners in to make the beginnings of a ball shape. Use a wide blunt pair of tweezers to hold the combustion capsule in place; this decreases the risk of puncturing the capsule with the long-nose tweezers. Finally, use the wide tweezers to carefully form the combustion capsule into a ball. This is the ideal shape for uniform combustion in the analyser furnace.
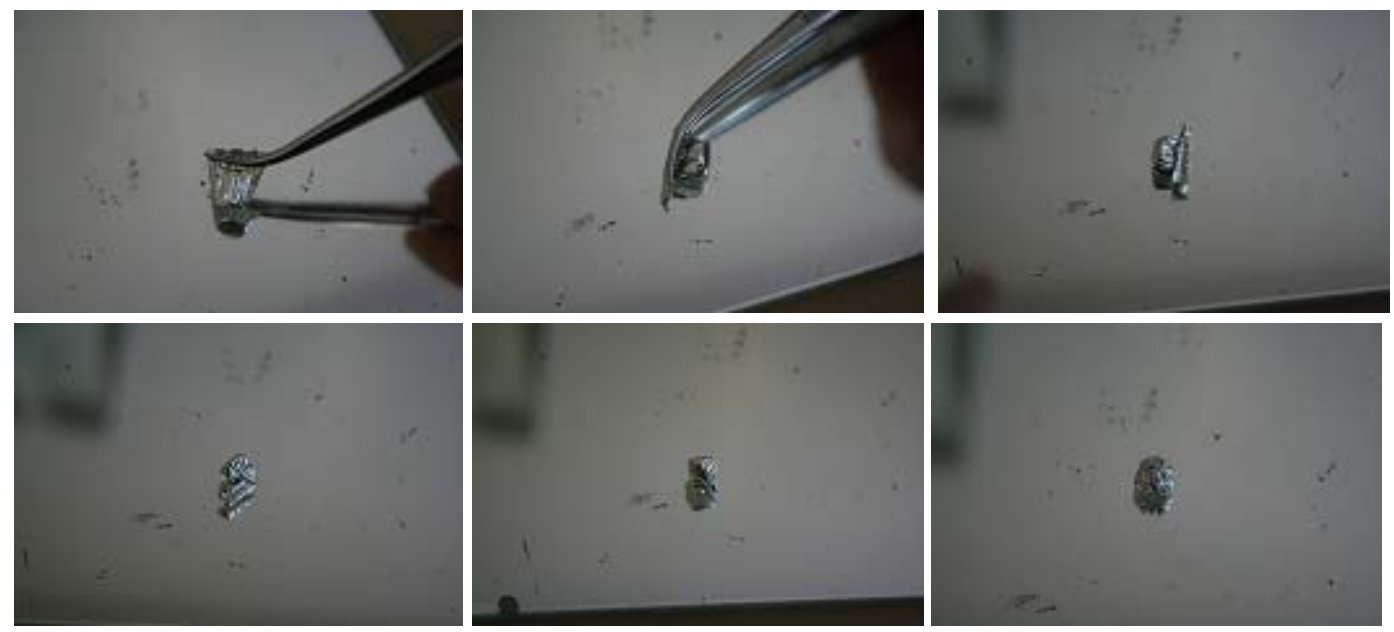

Record the final weight of the formed combustion capsule and place in an appropriately labelled sample tray ready for processing in the IRMS. If necessary, re-weigh the capsule to ensure the final weight measurement is accurate. 


\section{${ }^{14} \mathrm{C}$ preparation and procedure}

The procedure is carried out in clean room conditions.

Acid wash $\left(50 \mathrm{ml} / 500 \mathrm{mg} 0.5 \mathrm{M} \mathrm{HCl}\right.$ at $80^{\circ} \mathrm{C}$ for $\left.30 \mathrm{~min}\right)$. Filter the residue and rinse with $\mathrm{dH}_{2} \mathrm{O}$ to neutral $\mathrm{pH}$. As shown below the filtration of the sample post acid wash, the humic material removed from the sample can clearly be seen in the colour of the waste acid/ $\mathrm{dH}_{2} \mathrm{O}$ wash.
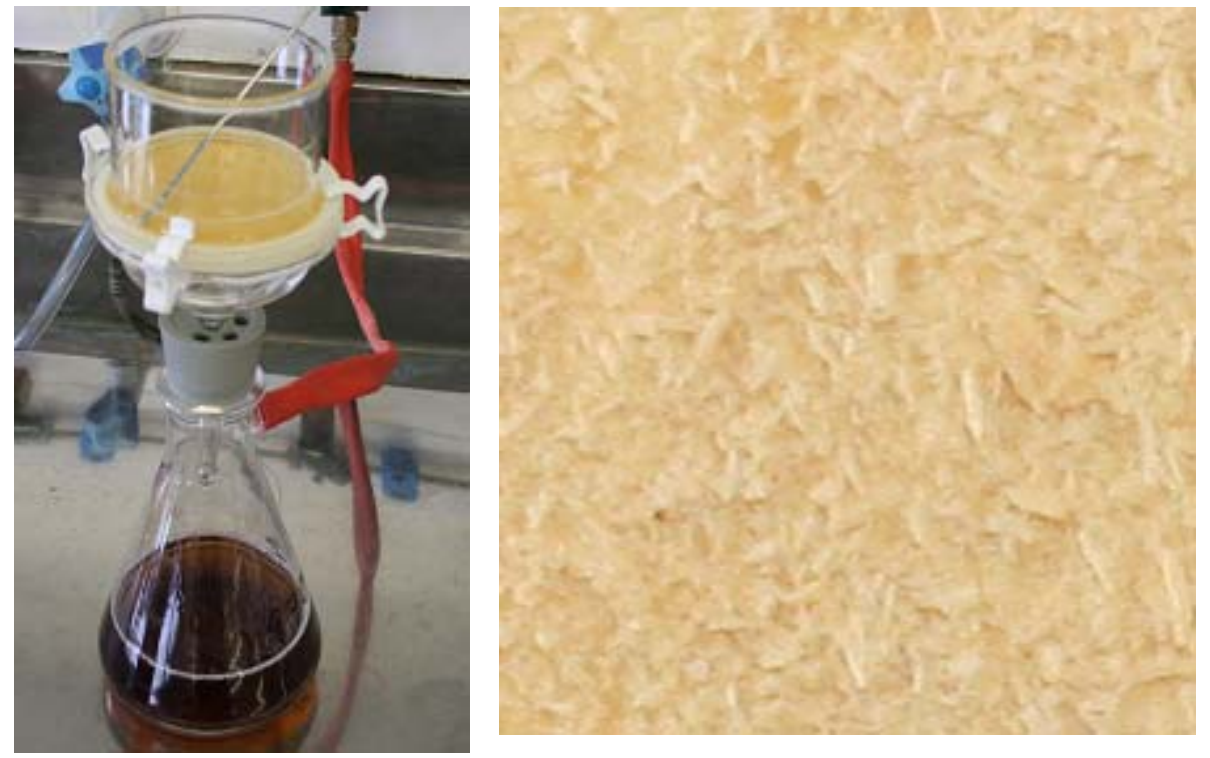

Pulping with Sodium Hydroxide $\left(50 \mathrm{ml} / 500 \mathrm{mg} 0.1 \mathrm{M} \mathrm{NaOH}\right.$ at $80^{\circ} \mathrm{C}$ for 1 hour). Filter the residue and rinse with $\mathrm{dH}_{2} \mathrm{O}$. Repeat $\mathrm{NaOH}$ treatment if necessary. Filter the residue and rinse with $\mathrm{dH}_{2} \mathrm{O}$ to neutral $\mathrm{pH}$. Only one pulping treatment was necessary for all ${ }^{14} \mathrm{C}$.

Oxidation with Hydrogen Peroxide $\left(50 \mathrm{ml} / 500 \mathrm{mg} 4 \% \mathrm{H}_{2} \mathrm{O}_{2}-\mathrm{pH} 11\right.$ at $55^{\circ} \mathrm{C}$ for $1 \mathrm{hr}$, or until residue is bleached. Filter and repeat if residue is not bleached. Filter the residue and rinse with $\mathrm{dH}_{2} \mathrm{O}$ to neutral $\mathrm{pH}$.

Acid wash $\left(50 \mathrm{ml} / 500 \mathrm{mg} 0.5 \mathrm{M} \mathrm{HCl}\right.$ at $80^{\circ} \mathrm{C}$ for $\left.30 \mathrm{~min}\right)$, Filter the residue and rinse with $\mathrm{dH}_{2} \mathrm{O}$ to neutral $\mathrm{pH}$.

Dry in a vacuum oven at $30^{\circ} \mathrm{C}$

Re-weigh the sample and store until ready for pre-treatment conversion to graphite.

\section{Sieving procedure}

In preparation for the two methods, splits of $\sim 1$ gram were taken from the ovendried $\left(40^{\circ} \mathrm{C}\right)$ gently ground (mortar and pestle), carbonates removed (negligible) core material, also used for the isotopic analysis. This was carried out with due care to avoid non-representative sub-samples i.e. sample that has been handled and undergone grain segregation of fines to the centre must be split and quartered carefully to avoid bias (Goudie et al. 1998). While $1 \mathrm{gram}$ is less than that which is recommended for typical bulk sample analysis of sands $(\geq 0.063 \mathrm{~mm})$, the preliminary field textural classification placed most of the sediment as very fine sands, silts and clays, thus biasing the sample toward preparation for the laser diffractometry which requires a small but representative quantity for fine sediments (100-200 mg) (Konert and Vandenberghe 1997). 
The $\sim 1$ gram splits were processed for organic content removal using hydrogen peroxide $\left(\mathrm{H}_{2} \mathrm{O}_{2}\right)$ and re-weighed to obtain a mass value for the organic component. This procedure was based on the method outlined by Barrett et al. (2000). To remove the organic component $5 \mathrm{ml} \mathrm{H}_{2} \mathrm{O}_{2}(-27 \%)$ was added to a $50 \mathrm{ml}$ test tube containing the sample; agitated gently to ensure complete emersion, and then placed in a hot water bath for 4 hours at $80^{\circ} \mathrm{C}$ to accelerate the reaction (where necessary further $\mathrm{H}_{2} \mathrm{O}_{2}$ was used to top up the test tube if a vigorous reaction had induced evaporation to the point where fluid no longer covered the sample). After 4 hours the sample was removed from the hot water bath and set to stand for 24 hours in a fume cupboard. The sample was then rinsed in $50 \mathrm{ml}$ of demineralised water $\left(\mathrm{dH}_{2} \mathrm{O}\right)$, vortexed, and centrifuged at 5000 rpm for $30 \mathrm{mins}(\mathrm{r} 15 \mathrm{~cm})$ settling to $0.001 \mathrm{~mm}(10 \Phi)$, decanted and repeated for three cycles. The sample was then dried in the oven at $40^{\circ} \mathrm{C}$, cooled in a desiccator and reweighed for organic carbon content calculation (Barrett et al. 2000). 


\section{APPENDIX III: Transect 1 and 2 Core Log Descriptions}

\section{Transect 1 core log descriptions}

Beginning with the contemporary top soil there is a recognisable trend of fine silts grading into silt/fine sand with organic material present across all four sites from $0-25 \mathrm{~cm}$. Beyond the initial $25 \mathrm{~cm}$ of coarsening grain size to $\sim 100 \mathrm{~cm}$ depth there is a general trend towards grain size uniformity across all cores (silts) but with some major perturbations. Site specific details are given below.

Site 1 is relatively uniform sandy silt to $270 \mathrm{~cm}$ with a $2 \mathrm{~cm}$ band of fine sand at $75 \mathrm{~cm}$ depth (upper contact is distinct/convolute, lower is sharp/smooth) and a fining of grain size to silt where buried organic material was found from $90 \mathrm{~cm}$ coarsening back to sandy silt at $120 \mathrm{~cm}$. There are clay inclusions from $50-$ $110 \mathrm{~cm}$. Pumice clasts are present throughout most of the core but are increasingly concentrated, and include lapilli, at depth.

Site 2 has an abrupt/convolute transition from sandy silt to fine sand at $40 \mathrm{~cm}$. From this depth the fine sand unit is homogenous before a sharp/smooth transition to sandy silt at $60 \mathrm{~cm}$. The sandy silt unit gradually fines towards 90 $\mathrm{cm}$ and is peppered with pumice clasts, but due to the closed end and irretrievable core in the window sampler, the transition to clayey silt seen in the second core at S2 cannot be logged or described. From $110-190 \mathrm{~cm}$ there is a homogenous clayey silt unit which is peppered by the presence of pumice and lapilli clasts.

Site 3 fines from sandy slit to clayey silt at $50 \mathrm{~cm}$ which continues to $135 \mathrm{~cm}$ and then coarsens to sandy silt. Then moving into a laminated sequence of silt and sandy silt where organics are present including a large well preserved wood fragment surrounded by roots, twigs and other OM. Below the OM and laminations the sediments coarsen from silt to fine sand until a single $2 \mathrm{~cm}$ wide sharp/smooth sand lamination at $260 \mathrm{~cm}$. Below the lamination sediments fine towards silt with a single large $(\sim 20 \mathrm{~mm})$ clay inclusion at $285 \mathrm{~cm}$.

Site 4 is more complex and was cored to greater depth than Sites 1-3. After an initial coarsening of sediments from silt to sandy silt, S4 has three distinct laminations of sand 2-4 cm wide at 30,35 and $60 \mathrm{~cm}$, all with distinct/convolute boundaries surrounded by sandy silt or silts with pumice inclusions. Below 60 $\mathrm{cm}$ uniform silts continue until $80 \mathrm{~cm}$ depth where sand inclusions appear (boundary diffuse/occluded). Below the sand inclusions from $85-110 \mathrm{~cm}$ the sediments fine to clayey silt with some root and other OM present. From 110 $125 \mathrm{~cm}$ grain size coarsens to silt with OM still present and pumice inclusions where there is a distinct/wavy transition to sand. There is an abrupt (sharp/smooth) change to silt at $157 \mathrm{~cm}$ and then fining to clayey silt at $170 \mathrm{~cm}$. From $180 \mathrm{~cm}$ to $235 \mathrm{~cm}$ the grain size gradually coarsens from silt through to fine sand with one large piece of wood at $200 \mathrm{~cm}$, roots and OM from $190-225$ $\mathrm{cm}$, and pumice from $225-250 \mathrm{~cm}$. From $235-295 \mathrm{~cm}$ is fine sand. At $295 \mathrm{~cm}$ there is a distinct/smooth transition to silty clay, immediately below which there is a lapilli inclusion with a narrow $(<1 \mathrm{~cm})$ lamination of pumice at $302 \mathrm{~cm}$. From 
$322-355 \mathrm{~cm}$ there is a distinct/smooth transition (upper and lower contacts) to sand. From $355-400 \mathrm{~cm}$ the sediments gradually fine to sandy silt with some pumice clasts $(360 \mathrm{~cm})$ and $\mathrm{OM}(375 \mathrm{~cm})$.

\section{Transect 2 core log descriptions}

The contemporary top soil in S1, S3 and S4 has a trend of silts coarsening with increasing depth with varying amounts of OM present. Progressing down slope the depth of this initial contemporary silty topsoil increases from $15 \mathrm{~cm}$ at $S 1,20$ $\mathrm{cm}$ at S2, $33 \mathrm{~cm}$ at S3 to $45 \mathrm{~cm}$ at S4. Site 2 stands alone as the only site from both $\mathrm{T} 1$ and $\mathrm{T} 2$ where the contemporary topsoil fines in grain size from silts to clayey silt with increasing depth. Beyond the contemporary topsoil profile of each site in T2, there are some general observable trends in coarsening and fining of grain size across all cores but with major variations that are more frequent with increasing depth on the lower slope of T2. Site specific details are given below.

Site 1 has shallow topsoil $(15 \mathrm{~cm})$ with OM, pumice and lapilli present. Below the contemporary topsoil is a block of uniform compacted silty clay resistant to the coring apparatus that has little evidence of textural or lithological variation and no buried $\mathrm{OM}$ to a depth of $90 \mathrm{~cm}$.

Site 2 exhibits a trend of fining contemporary topsoil from silt to clayey silt with decreasing $\mathrm{OM}$ and increasing frequency of pumice clasts to $20 \mathrm{~cm}$ depth. Below $20 \mathrm{~cm}$ there is a sharp/smooth transition to silt with a few pumice clasts and some organic material. At $27 \mathrm{~cm}$ there is an abrupt/occluded transition to clayey silt with few pumice clasts. This abrupt transition is then followed by another abrupt/occluded transition at $30 \mathrm{~cm}$ back to silt gradually coarsening with increasing depth to a distinct/occluded transition to sandy silt at $90 \mathrm{~cm}$. From $30-58 \mathrm{~cm}$ there is a concentration of $\mathrm{OM}$ and few pumice clasts increasing in frequency with depth. There are some lapilli at $60 \mathrm{~cm}$. From $90-$ $115 \mathrm{~cm}$ sandy silt coarsens to sand with a distinct/smooth transition. This sandy silt unit begins with an OM concentration $(90-102 \mathrm{~cm})$ which quickly transitions (sharp/smooth) to loosely packed silty sand sediment containing a large quantity of pumice clasts. From $115 \mathrm{~cm}-125 \mathrm{~cm}$ sand containing many pumice clasts is distinctly different from the unit below it. From $125-135 \mathrm{~cm}$ there is an indistinct/smooth transition from sand to clayey silt which continues to $162 \mathrm{~cm}$. From $162-187 \mathrm{~cm}$ there is a distinct/smooth transition from silty clay to silt.

Site 3 has the typical contemporary topsoil of coarsening silts with roots, OM and pumice clasts to $33 \mathrm{~cm}$ depth. At $33 \mathrm{~cm}$ there is a sharp/smooth transition to silty clay. The silty clay unit contains $\mathrm{OM}$, sand inclusions and a few pumice clasts to $50 \mathrm{~cm}$. At $50 \mathrm{~cm}$ there is an abrupt/wavy transition from clayey silt to silt. The silt unit from $50-80 \mathrm{~cm}$ contains some mottles of $\mathrm{OM}$ and a few pumice clasts. There are sharp/smooth transitions from silt to sand at $80 \mathrm{~cm}$, from sand to clayey silt at $85 \mathrm{~cm}$ and from clayey silt to sandy silt at $95 \mathrm{~cm}$. From $95-120 \mathrm{~cm}$ the sandy silt remains uniform before a sharp/smooth transition to a lamination of sand with abundant pumice clasts and lapilli before returning through a sharp/smooth transition at $128 \mathrm{~cm}$ to sandy silt. At $142 \mathrm{~cm}$ 
there is a sharp/smooth transition to silt with fewer pumice clasts, and then another sharp/smooth transition from silt to sandy silt at $160 \mathrm{~cm}$ with an increase in pumice clasts and lapilli. From $160-235 \mathrm{~cm}$ sandy silt is peppered with varying quantities of pumice and lapilli forming a relatively uniform profile. At $235 \mathrm{~cm}$ there is a distinct/smooth transition to fine sand and an increase in pumice and lapilli. At $245-248 \mathrm{~cm}$ there is a sharp/smooth transition to a lamination of pumice clasts, below which a distinct/smooth transition to clayey silt and frequent pumice clasts occurs. Pumice clasts become less frequent until a distinct/smooth transition to silt in which pumice increases in frequency again while silts continue to coarsen to silty sand at $304 \mathrm{~cm}$, before fining out to clayey silt with abundant pumice clasts at $325 \mathrm{~cm}$. From $355-388 \mathrm{~cm}$ sediments coarsen from clayey silt to sandy silts through a diffuse/smooth transition.

Site 4 has a deeper contemporary topsoil of coarsening silts to $45 \mathrm{~cm}$, with roots and $\mathrm{OM}$ present in the very top of the profile $(<5 \mathrm{~cm})$ and reappearing in abundance at $25-45 \mathrm{~cm}$. Pumice clasts are present in the top $0-25 \mathrm{~cm}$ only. At $45 \mathrm{~cm}$ there is a sharp/smooth transition to clayey silt with a decrease in OM and a large increase in pumice clast frequency. After the transition the unit begins coarsening to silt again through an indistinct/smooth transition at $55 \mathrm{~cm}$. The pumice clast frequency starts to decline with increasing depth from $55 \mathrm{~cm}$. Then there is an indistinct/smooth transition to a clay/silt unit at $65 \mathrm{~cm}$, continuing through $90 \mathrm{~cm}$ with a rise in pumice clast frequency again. Due to the closed end and irretrievable core in the window sampler, the location of the transition to silt and many pumice clasts in the second core of S4 at $110 \mathrm{~cm}$ cannot be described. From $110 \mathrm{~cm}-170 \mathrm{~cm}$ there is a uniform unit of silt with varying quantities of pumice. At $170 \mathrm{~cm}$ there is an sharp/smooth transition to a series of laminations that makes the bottom of S4 appear significantly different to all previously described cores. The initial series of laminations from $170-$ $185 \mathrm{~cm}$ are less obvious and contain no visible OM. From $185-202 \mathrm{~cm}$ there is a diffuse/smooth transition from silt through to fine sand which contains large amounts of OM, roots and twigs. At $202 \mathrm{~cm}$ the distinct lamination sequence continues, beginning with a lamination of pure pumice, followed by laminations of sand (with some pumice), silty sand and pure pumice. At $230 \mathrm{~cm}$ there is an abrupt change in appearance of the core, with a continued lamination sequence of OM but in a more uniform matrix of silty sand or silt. The laminations of $\mathrm{OM}$ are present from $230-260 \mathrm{~cm}$ with well preserved wood fragments (evidence of charring on some specimens), charcoal, root complexes, blades of grasses, Podocarp leaves and seeds. Below $260 \mathrm{~cm}$ there is the inclusion of pumice clasts and a sandy silt matrix of blotchy appearance possibly indicating OM concentrations. 


\section{APPENDIX IV: Mechanical Sieving Results}

Distributions for the sand fraction were also obtained using a mechanical sieve set, but due to the complexities and potential compounding errors in conversion of laser diffractometry to discrete phi intervals or vice-versa without calibrating IA, the two distributions were not combined. Despite this there are observable trends in the sand fraction grain size analysis that add to the combined tri-plot results. Table 5.3 shows the percent sand fractions of the total sample weight in phi divisions of $0 \Phi$ (coarse sand) $-4 \Phi$ (very fine sand) for T1.

Table 3: Sand fraction (\%) distributions for Transect 1

\begin{tabular}{|c|c|c|c|c|c|c|}
\hline $\begin{array}{l}\text { Depth } \\
\text { (cm) }\end{array}$ & $\begin{array}{c}\text { Very Coarse } \\
\text { Sand } \\
>0 \Phi\end{array}$ & $\begin{array}{c}\text { Coarse } \\
\text { Sand } \\
0-1 \Phi\end{array}$ & $\begin{array}{l}\text { Medium } \\
\text { Sand } \\
1-2 \Phi\end{array}$ & $\begin{array}{l}\text { Fine } \\
\text { Sand } \\
2-3 \Phi\end{array}$ & $\begin{array}{l}\text { Very Fine } \\
\text { Sand } \\
3-4 \Phi\end{array}$ & $\begin{array}{c}\text { Sand sum \% } \\
\text { of total } \\
\text { (mass) }\end{array}$ \\
\hline \multicolumn{7}{|c|}{ Site 1} \\
\hline 60 & 0.13 & 1.53 & 4.61 & 13.65 & 36.37 & 56.29 \\
\hline 70 & 0.00 & 1.82 & 3.59 & 12.61 & 40.29 & 58.30 \\
\hline 80 & 0.16 & 0.52 & 1.61 & 12.14 & 40.14 & 54.57 \\
\hline 90 & 0.00 & 0.37 & 2.57 & 10.18 & 34.15 & 47.27 \\
\hline 110 & 0.00 & 0.67 & 0.85 & 9.03 & 31.75 & 42.30 \\
\hline 120 & 0.00 & 0.28 & 5.38 & 9.61 & 32.34 & 47.61 \\
\hline \multicolumn{7}{|c|}{ Site 2} \\
\hline 5 & 0.00 & 0.66 & 2.12 & 12.21 & 27.49 & 42.48 \\
\hline 15 & 0.97 & 3.23 & 1.98 & 12.43 & 29.67 & 48.28 \\
\hline 35 & 0.00 & 0.67 & 0.78 & 6.93 & 30.71 & 39.09 \\
\hline 45 & 0.00 & 0.00 & 0.65 & 2.97 & 43.11 & 46.73 \\
\hline 55 & 0.00 & 0.00 & 0.26 & 3.51 & 44.87 & 48.64 \\
\hline \multicolumn{7}{|c|}{ Site 3} \\
\hline 165 & 0.35 & 0.96 & 1.87 & 12.77 & 34.23 & 50.17 \\
\hline 185 & 0.41 & 1.67 & 2.04 & 11.85 & 33.06 & 49.03 \\
\hline 205 & 0.07 & 0.53 & 1.02 & 9.03 & 26.77 & 37.42 \\
\hline 215 & 0.27 & 0.63 & 1.31 & 12.77 & 32.83 & 47.81 \\
\hline 225 & 0.17 & 0.71 & 0.86 & 11.87 & 28.87 & 42.50 \\
\hline 235 & 0.00 & 0.50 & 0.91 & 13.53 & 31.19 & 46.13 \\
\hline 245 & 0.71 & 1.07 & 30.13 & 1.41 & 25.98 & 59.30 \\
\hline 255 & 0.19 & 1.04 & 1.34 & 14.11 & 51.64 & 68.33 \\
\hline \multicolumn{7}{|c|}{ Site 4} \\
\hline 125 & 0.04 & 0.00 & 0.10 & 6.72 & 18.58 & 25.43 \\
\hline 135 & 0.00 & 0.24 & 0.52 & 18.63 & 55.26 & 74.65 \\
\hline 145 & 0.00 & 0.00 & 0.33 & 13.23 & 61.64 & 75.20 \\
\hline 155 & 0.00 & 0.22 & 0.22 & 1.12 & 63.40 & 64.97 \\
\hline 165 & 0.00 & 0.00 & 1.86 & 0.68 & 16.33 & 18.87 \\
\hline 175 & 0.00 & 0.00 & 0.00 & 0.42 & 8.52 & 8.94 \\
\hline 185 & 0.00 & 0.24 & 0.66 & 6.81 & 29.33 & 37.04 \\
\hline 195 & 0.00 & 0.00 & 0.23 & 1.90 & 29.55 & 31.69 \\
\hline 207 & 0.00 & 0.00 & 0.20 & 9.40 & 38.66 & 48.26 \\
\hline 225 & 0.63 & 0.27 & 0.39 & 11.60 & 38.08 & 50.96 \\
\hline 235 & 0.00 & 0.00 & 0.66 & 16.32 & 42.14 & 59.12 \\
\hline
\end{tabular}


Table 4: Sand fraction (\%) distributions for Transect 2

\begin{tabular}{|c|c|c|c|c|c|c|}
\hline $\begin{array}{l}\text { Depth } \\
\text { (cm) }\end{array}$ & $\begin{array}{c}\text { Very Coarse } \\
\text { Sand } \\
>0 \Phi\end{array}$ & $\begin{array}{l}\text { Coarse } \\
\text { Sand } \\
0-1 \Phi\end{array}$ & $\begin{array}{l}\text { Medium } \\
\text { Sand } \\
1-2 \Phi\end{array}$ & $\begin{array}{l}\text { Fine } \\
\text { Sand } \\
2-3 \Phi\end{array}$ & $\begin{array}{l}\text { Very fine } \\
\text { Sand } \\
3-4 \Phi\end{array}$ & $\begin{array}{c}\text { Sand sum \% } \\
\text { of total } \\
\text { (mass) }\end{array}$ \\
\hline \multicolumn{7}{|c|}{ Site 1} \\
\hline 5 & 0.58 & 9.54 & 11.63 & 9.23 & 11.41 & 42.39 \\
\hline 15 & 4.09 & 11.12 & 13.90 & 12.21 & 13.30 & 54.62 \\
\hline 25 & 3.08 & 4.57 & 7.01 & 8.09 & 7.52 & 30.26 \\
\hline 35 & 0.09 & 1.92 & 2.93 & 5.54 & 8.72 & 19.19 \\
\hline \multicolumn{7}{|c|}{ Site 2} \\
\hline 5 & 0.00 & 0.86 & 2.59 & 9.16 & 24.88 & 37.50 \\
\hline 25 & 0.61 & 1.04 & 1.60 & 8.50 & 32.02 & 43.77 \\
\hline 45 & 0.22 & 1.70 & 1.20 & 8.48 & 25.74 & 37.34 \\
\hline 55 & 0.21 & 0.00 & 0.61 & 8.78 & 28.60 & 38.20 \\
\hline 95 & 1.15 & 4.44 & 6.74 & 15.78 & 29.61 & 57.72 \\
\hline 125 & 20.41 & 20.13 & 7.30 & 4.73 & 7.34 & 59.91 \\
\hline 135 & 1.61 & 4.49 & 3.94 & 13.00 & 5.87 & 28.91 \\
\hline \multicolumn{7}{|c|}{ Site 3} \\
\hline 35 & 0.00 & 0.14 & 0.52 & 7.27 & 39.90 & 47.83 \\
\hline 45 & 0.00 & 0.10 & 0.40 & 7.59 & 26.24 & 34.33 \\
\hline 55 & 0.00 & 0.07 & 0.27 & 7.84 & 28.82 & 37.00 \\
\hline \multicolumn{7}{|c|}{ Site 4} \\
\hline 25 & 0.00 & 0.00 & 0.53 & 4.49 & 18.08 & 23.10 \\
\hline 35 & 0.00 & 0.46 & 0.50 & 5.98 & 27.97 & 34.90 \\
\hline 45 & 0.12 & 0.12 & 0.14 & 6.44 & 30.59 & 37.40 \\
\hline 55 & 0.27 & 0.74 & 0.71 & 7.37 & 18.41 & 27.50 \\
\hline 65 & 3.17 & 0.82 & 1.59 & 11.59 & 23.24 & 40.40 \\
\hline 75 & 1.82 & 1.16 & 1.01 & 5.06 & 21.96 & 31.00 \\
\hline
\end{tabular}


APPENDIX V: EA-IRMS Result Tables

Table 5. Transect 1 EA-IRMS Result Table

\begin{tabular}{|c|c|c|c|c|c|c|}
\hline Site & $\begin{array}{l}\text { Depth } \\
\text { (cm) }\end{array}$ & $\begin{array}{c}\mathrm{TN} \\
\text { (\% element) }\end{array}$ & $\begin{array}{c}{ }^{15} \mathrm{~N} \\
\text { Delta Air }\end{array}$ & $\begin{array}{c}\text { TOC } \\
\text { (\% element) }\end{array}$ & $\begin{array}{c}{ }^{13} \mathrm{C} \\
\text { Delta PDB }\end{array}$ & $\mathrm{C} / \mathrm{N}$ \\
\hline 1 & 5 & 0.31 & 5.71 & 2.95 & -28.01 & 11.04 \\
\hline 1 & 10 & 0.26 & 5.91 & 2.34 & -27.60 & 10.66 \\
\hline 1 & 45 & 0.06 & 3.39 & 0.57 & -24.73 & 10.69 \\
\hline 1 & 70 & 0.04 & 4.82 & 0.25 & -25.04 & 7.47 \\
\hline 1 & 90 & 0.07 & 4.35 & 1.13 & -24.68 & 17.80 \\
\hline 1 & 110 & 0.07 & 5.26 & 0.73 & -24.39 & 12.98 \\
\hline 1 & 150 & 0.04 & 6.02 & 0.31 & -24.25 & 8.03 \\
\hline 1 & 190 & 0.03 & 5.06 & 0.20 & -24.65 & 6.92 \\
\hline 1 & 215 & 0.03 & 4.79 & 0.19 & -25.30 & 7.28 \\
\hline 1 & 245 & 0.06 & 4.94 & 0.60 & -25.54 & 11.86 \\
\hline 2 & 5 & 0.39 & 6.13 & 3.52 & -28.12 & 10.62 \\
\hline 2 & 15 & 0.18 & 6.03 & 1.61 & -26.10 & 10.43 \\
\hline 2 & 35 & 0.12 & 4.39 & 1.31 & -24.88 & 12.68 \\
\hline 2 & 55 & 0.02 & 3.43 & 0.13 & -25.39 & 6.49 \\
\hline 2 & 85 & 0.07 & 4.78 & 0.66 & -24.74 & 11.66 \\
\hline 2 & 125 & 0.05 & 4.16 & 0.49 & -25.68 & 12.22 \\
\hline 2 & 145 & 0.05 & 5.06 & 0.34 & -25.13 & 8.40 \\
\hline 2 & 175 & 0.05 & 5.68 & 0.30 & -25.05 & 7.69 \\
\hline 3 & 5 & 0.40 & 5.08 & 3.92 & -28.50 & 11.44 \\
\hline 3 & 15 & 0.18 & 5.41 & 1.75 & -25.94 & 11.42 \\
\hline 3 & 25 & 0.09 & 5.15 & 0.92 & -25.25 & 11.39 \\
\hline 3 & 35 & 0.08 & 5.45 & 0.71 & -25.29 & 10.23 \\
\hline 3 & 65 & 0.05 & 5.62 & 0.32 & -25.55 & 8.37 \\
\hline 3 & 95 & 0.03 & 5.23 & 0.18 & -24.82 & 6.66 \\
\hline 3 & 125 & 0.04 & 5.03 & 0.25 & -25.55 & 7.50 \\
\hline 3 & 165 & 0.03 & 4.77 & 0.25 & -28.48 & 8.74 \\
\hline 3 & 185 & 0.03 & 4.17 & 0.30 & -27.29 & 10.07 \\
\hline 3 & 205 & 0.08 & 2.33 & 1.19 & -27.81 & 17.29 \\
\hline 3 & 215 & 0.11 & 1.76 & 1.79 & -26.83 & 18.75 \\
\hline 3 & 225 & 0.14 & 2.38 & 2.06 & -26.90 & 17.05 \\
\hline 3 & 255 & 0.03 & 3.04 & 0.22 & -26.30 & 9.12 \\
\hline 3 & 285 & 0.05 & 4.29 & 0.41 & -26.42 & 10.18 \\
\hline 4 & 5 & 0.33 & 3.08 & 3.53 & -28.54 & 12.39 \\
\hline 4 & 15 & 0.22 & 3.63 & 1.96 & -26.99 & 10.59 \\
\hline 4 & 25 & 0.05 & 3.74 & 0.49 & -25.21 & 10.61 \\
\hline 4 & 45 & 0.12 & 4.07 & 1.22 & -23.16 & 11.78 \\
\hline 4 & 55 & 0.08 & 3.84 & 0.80 & -24.70 & 12.12 \\
\hline 4 & 75 & 0.08 & 3.18 & 0.95 & -25.41 & 13.10 \\
\hline 4 & 95 & 0.11 & 3.06 & 1.34 & -25.35 & 13.78 \\
\hline 4 & 110 & 0.06 & 2.08 & 0.75 & -25.54 & 13.67 \\
\hline 4 & 125 & 0.07 & 2.97 & 0.63 & -25.91 & 11.04 \\
\hline 4 & 145 & 0.03 & 1.96 & 0.24 & -26.36 & 10.87 \\
\hline 4 & 165 & 0.03 & 2.08 & 0.30 & -26.99 & 10.12 \\
\hline 4 & 175 & 0.14 & 1.77 & 1.60 & -26.89 & 13.34 \\
\hline 4 & 207 & 0.10 & 2.01 & 1.29 & -26.67 & 14.67 \\
\hline 4 & 235 & 0.07 & 3.54 & 0.67 & -26.33 & 10.95 \\
\hline 4 & 275 & 0.04 & 3.22 & 0.26 & -26.11 & 8.50 \\
\hline 4 & 315 & 0.02 & 3.65 & 0.16 & -26.23 & 7.75 \\
\hline 4 & 325 & 0.01 & 5.77 & 0.07 & -26.67 & 6.14 \\
\hline 4 & 365 & 0.02 & 3.26 & 0.14 & -27.49 & 9.10 \\
\hline 4 & 385 & 0.03 & 3.46 & 0.21 & -27.49 & 8.30 \\
\hline
\end{tabular}


Table 6. Transect 2 EA-IRMS Result Table

\begin{tabular}{|c|c|c|c|c|c|c|}
\hline Site & $\begin{array}{l}\text { Depth } \\
\text { (cm) }\end{array}$ & $\begin{array}{c}\text { TN } \\
\text { (\% element) }\end{array}$ & $\begin{array}{c}15 \mathrm{~N} \\
\text { Delta Air }\end{array}$ & $\begin{array}{c}\text { TOC } \\
\text { (\% element) }\end{array}$ & $\begin{array}{c}13 C \\
\text { Delta PDB }\end{array}$ & $\mathrm{C} / \mathrm{N}$ \\
\hline 1 & 5 & 0.65 & 4.98 & 6.23 & -28.35 & 11.23 \\
\hline 1 & 15 & 0.24 & 6.23 & 2.14 & -26.31 & 10.45 \\
\hline 1 & 25 & 0.08 & 5.86 & 0.72 & -25.76 & 10.27 \\
\hline 1 & 35 & 0.04 & 5.99 & 0.31 & -26.01 & 9.08 \\
\hline 2 & 5 & 0.37 & 4.83 & 3.65 & -28.50 & 11.36 \\
\hline 2 & 15 & 0.16 & 5.14 & 1.52 & -26.56 & 11.26 \\
\hline 2 & 25 & 0.13 & 3.67 & 1.75 & -25.58 & 15.62 \\
\hline 2 & 35 & 0.16 & 3.70 & 2.34 & -25.16 & 17.05 \\
\hline 2 & 45 & 0.17 & 3.05 & 2.63 & -25.14 & 18.41 \\
\hline 2 & 55 & 0.10 & 3.87 & 1.40 & -25.34 & 16.20 \\
\hline 2 & 65 & 0.05 & 3.61 & 0.59 & -25.42 & 13.28 \\
\hline 2 & 75 & 0.04 & 4.67 & 0.46 & -25.56 & 11.90 \\
\hline 2 & 85 & 0.06 & 5.07 & 0.64 & -25.67 & 13.46 \\
\hline 2 & 95 & 0.11 & 5.39 & 1.34 & -25.40 & 14.02 \\
\hline 2 & 125 & 0.06 & 6.30 & 0.47 & -24.79 & 9.38 \\
\hline 2 & 135 & 0.02 & 4.30 & 0.29 & -27.62 & 16.54 \\
\hline 3 & 5 & 0.35 & 5.09 & 3.16 & -28.59 & 10.54 \\
\hline 3 & 15 & 0.20 & 5.33 & 1.75 & -27.11 & 10.31 \\
\hline 3 & 25 & 0.10 & 4.14 & 0.90 & -26.47 & 10.80 \\
\hline 3 & 35 & 0.07 & 3.83 & 0.75 & -26.41 & 12.29 \\
\hline 3 & 45 & 0.13 & 3.63 & 1.57 & -26.12 & 13.86 \\
\hline 3 & 55 & 0.06 & 3.85 & 0.56 & -25.96 & 11.82 \\
\hline 3 & 65 & 0.05 & 4.24 & 0.54 & -26.16 & 11.81 \\
\hline 3 & 75 & 0.05 & 3.95 & 0.59 & -26.02 & 12.53 \\
\hline 3 & 85 & 0.05 & 3.87 & 0.65 & -25.83 & 15.84 \\
\hline 3 & 95 & 0.07 & 3.85 & 0.83 & -26.11 & 14.39 \\
\hline 3 & 115 & 0.03 & 4.04 & 0.22 & -26.04 & 8.03 \\
\hline 3 & 135 & 0.02 & 3.96 & 0.18 & -26.95 & 8.86 \\
\hline 3 & 195 & 0.03 & 4.75 & 0.15 & -26.79 & 6.21 \\
\hline 3 & 245 & 0.02 & 4.26 & 0.14 & -27.00 & 6.72 \\
\hline 3 & 250 & 0.02 & 4.42 & 0.14 & -27.28 & 7.51 \\
\hline 3 & 265 & 0.03 & 4.42 & 0.16 & -27.19 & 6.56 \\
\hline 3 & 350 & 0.04 & 4.36 & 0.20 & -24.98 & 6.57 \\
\hline 3 & 395 & 0.03 & 5.39 & 0.23 & -25.67 & 8.01 \\
\hline 4 & 5 & 0.32 & 5.16 & 2.98 & -28.52 & 11.00 \\
\hline 4 & 15 & 0.11 & 4.91 & 0.94 & -26.41 & 9.73 \\
\hline 4 & 25 & 0.12 & 4.60 & 1.14 & -26.17 & 10.85 \\
\hline 4 & 35 & 0.13 & 4.17 & 1.61 & -25.58 & 14.42 \\
\hline 4 & 45 & 0.08 & 3.94 & 0.93 & -25.77 & 13.06 \\
\hline 4 & 55 & 0.06 & 4.34 & 0.54 & -26.17 & 11.25 \\
\hline 4 & 135 & 0.06 & 3.05 & 0.72 & -27.56 & 13.40 \\
\hline 4 & 195 & 0.09 & 1.54 & 1.40 & -28.01 & 18.82 \\
\hline 4 & 205 & 0.02 & 1.70 & 0.24 & -27.18 & 12.33 \\
\hline 4 & 215 & 0.02 & 2.53 & 0.12 & -27.52 & 9.13 \\
\hline 4 & 225 & 0.04 & 2.55 & 0.38 & -28.54 & 12.58 \\
\hline 4 & 234 & 0.13 & 1.04 & 2.77 & -27.80 & 4.38 \\
\hline 4 & 236 & 0.15 & 1.21 & 2.70 & -28.67 & 3.48 \\
\hline 4 & 244 & 0.29 & 1.53 & 4.29 & -30.37 & 17.20 \\
\hline 4 & 246 & 0.47 & 2.23 & 7.71 & -28.31 & 19.18 \\
\hline 4 & 254 & 0.10 & 0.61 & 1.40 & -26.76 & 17.01 \\
\hline 4 & 256 & 0.35 & 1.11 & 6.60 & -28.06 & 22.18 \\
\hline 4 & 265 & 0.13 & 2.77 & 2.44 & -27.56 & 21.49 \\
\hline 4 & 275 & 0.06 & 1.37 & 1.05 & -27.02 & 19.13 \\
\hline
\end{tabular}


